$$
\text { Juan C. Elizaga }
$$

\title{
MIGRACIONES A LAS AREAS METROPOLITANAS DE AMERICA LATINA
}



CENTRO LATINOAMERICANO DE DEMOGRAFIA SANTIAGO DE CHILE - 1970






\section{Centro latinoamericano de Demografía}

$$
\text { CELADE }
$$

Sede: J. M. Infante 9. Casilla 91. Teléfono 257806 Santiago (Chile)

Subsede: Ciudad Universitaria Rodrigo Facio

Apartado Postal 5249

San José (Costa Rica)

Para la edición de este estudio se contó

con el apoyo financiero de la Fundación Ford.

(C) Centró Latinoamemicano de Demografía, 1970

Serie $E, N^{\circ} 6$ 
MIGRACIONES A LAS AREAS METROPOLITANAS DE AMERICA LATINA 


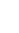




\section{PREFACIO}

Durante las tres últimas décadas las condiciones demográficas de América Latina han experimentado cambios sin precedentes en su historia por su magnitud y sus implicaciones. A la par del continuo aumento de la tasa de crecimiento de la población en la mayoría de los paises de la zona, como consecuencia inmediata de los progresos alcanzados en la prolongación de la vida humana, se da un rápido proceso de redistribución geográfica de sus habitantes al influjo de un mayor nivel educativo, de transformaciones en las economías de estos paises $y$ de una serie de innovaciones iecnológicas que, al elevar las aspiraciones $y$ crear nuevas expectativas en la población, estimularon y posibilitaron su mayor movilidad.

Como en otras regiones, este último fenómeno, inherente, por otra parte, al proceso de desarrollo económico y de cambio social, se produce a través de movimientos migratorios, principalmente de aquellos que implican desplazamientos desde zonas rurales, pueblos y pequeñas ciudades hacia centros urbanos más importantes $y$, en particular, hacia la metrópoli. Corolario de esia tendencia es que muchos paises latinoamericanos exhiban en la actualidad altas concentraciones de su población en su principal área metropolitana, lo cual generalmente significa el crecimiento de ésta a una tasa anual que excede del 5 ó 6 por ciento.

Razones diversas confieren prioridad a los estudios dc las migraciones que llegan a las grandes ciudades, en relación con otras corrientes demográficas interiores, cuya importancia tampoco podría desconocerse. Sin embargo, tratándose la primera de ellas de la mayor masa migratoria orientada hacia un solo centro geográfico, sus efectos demo. gráficos y sociales sobre la sociedad recipiente son profundos y generadores de múltiples problemas, en particular aquéllos relacionados con el empleo productivo de la mano de obra, la habilitación de escuelns $y$ de viviendas adecuadas, la prestación de servicios médicos y de seguridad social, y un sinnúmero de aspectos que atañen a las obras $y$ servicios propios de las áreas urbanizadas. Por otro lado, al habitar en éstas el segmento geográfico de la sociedad con mayor nivel de desa- 
rrollo económico, social y político, sus propios y privativos problemas influyen notoriamente en la marcha de todo el país.

Por estas y otras razones que parece innecesario mencionar en este Prefacio, CELADE inició en el año 1962 un programa de investigación sobre las migraciones en áreas metropolitanas de América Latina, comenzando con la encuesta realizada entonces en el Gran Santiago, y cuyos principales resultados se presentan en este estudio, primero de una serie de trabajos similares al que seguirán los correspondientes a Lima y Caracas.

En la introducción al estudio propiamente dicho se pasa revista a las principales características demográficas de la urbanización y de los movimientos migratorios de América Latina y se discuten aspectos teóricos y metodológicos de la investigación. En los capítulos I y II se analiza la corriente migratoria hacia el Gran Santiago, considerando la estructura por edad en la época del movimiento, sexo, periodo de migración, lugar de origen, y las etapas migratorias previas y su relación con algunas características demográficas y culturales de los inmigrantes. Los factores vinculados al movimiento migratorio son estudiados en el capítulo III a través de los motivos de emigración declarados y del grado y clase de ocupación antes de emigrar. Varios aspectos de la asimilación, relacionados con la movilidad profesional y con la ubicación de la vivienda en los distintos barrios de la ciudad, entre otros, son objeto de análisis en el capítulo IV. A su vez, en el capítulo $V$ se consideran los efectos demográficos de la población inmigrante sobre la nativa, mediante el estudio comparado de sus dijerenciales demográficos y sociales. Finalmente, en dos apéndices, se incluye la descripción de la muestra utilizada y las definiciones de los conceptos, y otros aspectos de la organización del trabajo.

Carmen A. Miró

Directora del Centro Latinoamericano de Demografía 


\section{INTRODUCCION}

\section{EL PROCESO DE REDISTRIBUCIÓN DE LA POBLACIÓN}

en AMÉRICa Latina

En el últimc medio siglo, en todas las regiones del mundo, el descenso gradual de la morialidad ha venido provocando el crecimiento cada vez más rápido de la población. La tasa de aumento es elevada, sobre todo, en los países en vías de desarrollo a causa, como es bien conocido, de que en ellos se mantienen casi sin cambios los niveles de la fecundidad, correspondiéndole a la América Latina ocupar el primer lugar con un crecimiento anual del orden del 3 por ciento o superior.

Al mismo tiempo, el proceso de redistribución interior de la población adquirió nuevas y más amplias dimensiones. Aunque las características $\mathrm{y}$, ial vez, las motivaciones de los desplazamientos geográficos que conducen a cambios de la distribución son diferentes según el grado de industrialización y nivel de vida de cada región, en todas partes aumentó la movilidad espacial. Sin olvidar las influencias recíprocas entre movilidad y tasa de crecimiento, en particular de esta última sobre la primera, para explicar la mayor movilidad habría que tomar en consideración los efectos producidos por los adelantos tecnológicos sobre la estructura de la producción, las comunicaciones y la difusión de noticias, como también la elevación progresiva de los niveles de vida -incluyendo mejor educación- y, en muchos aspectos, la política social del Estado en defensa de las clases con bajos ingresos, en materia de empleo, vivienda y asistencia social.

La redistribución es parte del proceso económico-social, del cual es a su vez consecuencia y factor determinante. Dl mecanismo y la intensidad del proceso variarán, por consiguiente, de un país a otro, según sus propias condiciones. Quizá la expresión más caxacterística y de mayores implicaciones en los cambios sociales de los países en vías de desarrollo la consitituya la urbanización. En los países altamente indusirializados ese proceso ya fue superado, siendo sustituido por movimientos inter-urbanos de población o entre regiones económicosociales (como son las zonas metropolitanas). 
La urbanización no es el único aspecto de la redistribución de la población en América Latina, aunque sí el principal. Hay que añadir que este proceso se produce acompañado por una fuerte tendencia hacia la concentración en una o unas pocas grandes ciudades. En verdad, la mayoría de los problemas que se achacan a la urbanización acelerada, probablemente sólo encontrarían justificación en relación con el crecimiento experimentado por las principales ciudades. Los desplazamientos interiores, incluyendo los que conducen a una rápida urbanización, desempeñan importante papel en la transformación de la estructura económica (industrialización), uno de cuyos aspectos más importantes son los cambios en la composición ocupacional de la mano de obra. A diferencia de lo acontecido en el pasado en los países de Europa Occidental y en los Estados Unidos de Norte América, se podria señalar que en América Latina, al igual que en otras regiones en vías de desarrollo, la industrialización marcha a paso más lento que la urbanización, lo cual ha dado pie a variadas explicaciones acerca del carácter artificial y patológico del crecimiento urbano.

Bogue y Hauser ${ }^{1}$ señalan una serie de diferencias entre las condiciones de la urbanización de los países en vías de desarrollo, con aquéllas prevalecientes en lo pasado en los países más desarrollados. Señalan, por una parte, la influencia de los factores tecnológicos, en el sentido de que la tecnología avanzada del siglo xx ahora está disponible para los países en vías de desarrollo, creando condiciones a las que no estuvieron sometidos, en su época, los países que contribuyeron a crear. la, señalándose, por ejemplo, que el estado presente de la tecnología agrícola predominante en los países en vías de desarrollo constituye, entre otros, un obstáculo al desarrollo urbano. Una segunda diferencia, que importa destacar aquí, se encuentra en la tasa de crecimiento natural de la población: cuanto más alta sea ésta, en igualdad de otras condiciones, mayores serán los excedentes de la población dependiente de la agricultura y de otras formas económicas preindustriales. La tasa de aumento natural del crecimiento de la población de los paises industrializados fluctuaba, probablemente, entre 1,5 y 2,0 por ciento anual, en la última parte del siglo xIx y en las primeras décadas del presente siglo, esto es el 50 ó el 60 por ciento de la tasa promedio actual de América Latina. Como lógica consecuencia, la urbanización siguió en aquellos países una evolución más lenta que la experimentada en América Latina durante las tres últimas décadas.

En 1960 la población urbana constituía aproximadamente el cin-

1 Bogue, D. J. y Hauser, P. M., "Population Distribution, Urbanism and Internal Migration", documento presentado a la Conferencia Mundial de Población, 1965. 
cuenta por ciento, en promedio, de la población total de la América Latina. ${ }^{2}$ Tan sólo 20 años antes, la proporción urbana probablemente no alcanzaba al tercio de la población. El nivel de la urbanización varía de un país a otro de la región, sin guardar relación con la densidad geográfica ni con el volumen de la población; pero la tendencia general ha sido bastante uniforme en cuanto a crecimiento. Como la población urbana está aumentando en la mayoría de los casos con una tasa por lo menos dos veces superior que la rural, hay que pensar que Ia urbanización continúa en la presente década y habrá de continuar en las próximas, a un ritmo similar al registrado en el pasado inmediato, con sus lógicas implicaciones. (Véase el cuadro 1.)

La elevada tasa de urbanización que de manera generalizada se ha venido registrando en los países de América Latina, en particular el rápido crecimiento de las ciudades más grandes, debe atribuirse principalmente a los movimientos migratorios interiores, mientras que el crecimiento vegetativo diferencial desempeña sólo un papel secundario. Debería esperarse una relación inversa entre el grado de urbanización y el nivel de fecundidad, como parece confirmarlo, en algunos países latinoamericanos, el mayor número medio de bijos de las mujeres de la zona rural, de acuerdo con datos censales ${ }^{3}$ y, por otra parte, una relación también inversa en lo que respecta al nivel de la mortalidad. Si se considera que esta última ya ha descendido a un nivel relativamente bajo y que, por consiguiente, las diferencias regionales dentro de un mismo país tienden a reducirse, podría considerarse que este factor tuvo poco efecto sobre el crecimiento vegetativo diferencial de los últimos años, al menos en algunos países. En consecuencia, si el crecimiento natural disminuye con la urbanización, como resultado de la fecundidad urbana, entonces el efecto de los movimientos migratorios es todavía un poco mayor de lo que se deduce de la simple comparación entre las tasas de crecimiento de la zona rural y de los núcleos urbanos de diversos tamaños. (Véase el cuadro 1.)

Las ciudades de más de un millón de habitantes (con la excepción del Gran Buenos Aires) crecieron con una tasa superior a 4, por ciento durante el decenio 1950-1960. Fsto sirnifica, según los casos, un incremento de origen migratorio de 1,5 a 2,5 por ciento anual. En los países en cuyas capitales la población no llega al millón de habitantes (la mayoría de las cuales tienen en realidad de 200 a 500 mil habitantes)

2 De acuerdo con las definiciones censales de los diferentes paises. Estas definiciones generalmente consideran urbana a la población que vive en localidades cabeceras de divisiones administrativas menores $y$, otras veces, la que vive en núcleos con un número mínimo de $1000,1500,2000$ ó 2500 habitantes, según los paises.

3 Miró, Carmen A., The Population of Latin America, Social Science Rescarch Council Conference, Nueva York, 1963. 
Cuadro 1

URBANIZACION Y TASAS DE CRECIMIENTO DE LA POBLACION TOTAL $Y$ DE NUCLEOS DE POBLACION DE DISTINTOS TAMAÑOS, DE PAISES DE AMERICA LATINA, EN LA DECADA 1950-1960

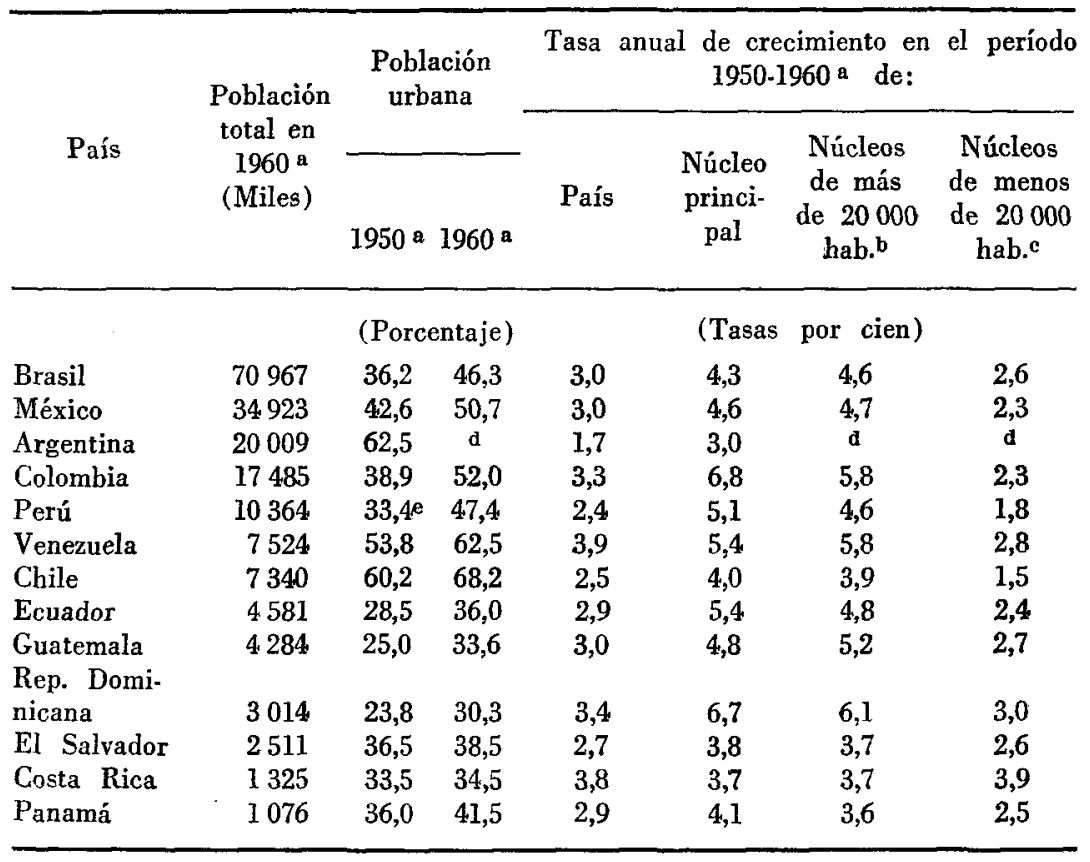

a Alrededor de 1950 y de 1960.

b Tamaño de la población al momento del primer censo.

c Incluye población rural.

d Sin información disponible.

e Censo de 1940.

éstas alcanzaron tasas de crecimiento similares. En general, las ciudades de más de 100 mil habitantes, de la misma manera que los núcleos de 20 a 99 mil, excluido el núcleo principal en ambos casos, registraron en promedio tasas de una magnitud comparable a las de las grandes ciudades, con las importantes excepciones de lo ocurrido en la Argentina y Chile. Estos dos últimos ófrecen la triple característica de ser los países con tasas de crecimiento inferiores al promedio latinoamericano, de ser los más urbanizados $y$, además, de presentar las mayores concentraciones de la población en el núcleo principal. En la actualidad el Uruguay se encuentra en la misma situación. (Véase el cuadro 1.) 
Las tendencias señaladas no son recientes. Hasta donde se puede establecer, se manifiestan con parecida intensidad por lo menos desde 1940. Podría generalizarse diciendo que esta tendencia caracteriza a los núcleos urbanos de más de 20 mil habitantes, sin atribuir a este limite otro alcance que el de un orden de magnitud.

La fuente que alimenta este notable crecimiento a través de los movimientos migratorios probablemente varía en cada país según las condiciones demográficas existentes (como son el volumen de la población nacional, el nivel de urbanización y el tamaño alcanzado por el núcleo principal). La encuesta de inmigración del Gran Santiago de CELADE indicó que el 66 por ciento de los inmigrantes llegados en la década inmediata anterior vinieron de núcleos de más de 5000 habitantes (tamaño en 1952) y la misma relación se encuentra considerando el período 1942-1951. A su vez ${ }_{2}$ los inmigrantes procedentes de núcleos de más de 20 mil habitantes representaron el 4.2 por ciento en la década 1952-1962 y el 37 por ciento en la década 1942-1951. Esta proporción relativamente elevada de inmigrantes de centros urbanos no debería causar sorpresa en un país donde ya en 1952 más del 60 por ciento de la población vivía en aglomeraciones urbanas (definición censal). Un hecho parecido debería esperarse en la inmigración a las ciudades más importantes de la Argentina y Venezuela y tal vez de Brasil, México y Colombia.

En las ciudades pequeñas y medianas, los inmigrantes deberían estar mejor representados por habitantes rurales. El moderado crecimiento de la población de los pequeños núcleos ya indica que los mismos son una estación en el movimiento hacia las ciudades. Por ejemplo, los núcleos de 1500 a 4.999 habitantes de Colombia crecieron a razón del 1,8 por ciento anual (la tasa del país era aproximadamente del 2,5 por ciento) en el período 1938-1951. Este crecimiento no es, sin embargo, una característica general, ya que, en Venezuela, los núcleos de 1000 a 4,999 habitantes crecieron a razón del 4,3 por ciento en el periodo 1941-1950 (la tasa de crecimiento de los núcleos de más de 20 mil habitantes fue bastante más elevada: 6,8 por ciento).

La conclusión principal que puede derivarse de los antecedentes disponibles es que los aportes inmigratorios que recogen las grandes ciudades, formados por corrientes que tienen origen en todas las regiones del país, no están compuestos necesaria y principalmente por campesinos, sino también frecuentemente por ciudadanos de otras ciudades y núcleos urbanos menores, incluyendoentre los últimos a cierto número de personas nacidas en el medio rural, pero con experiencia de vida ciudadana. Esto es aplicable con propiedad a los países donde el nivel de urbanización alcanzado originó el nacimiento de numerosas ciudades y otras aglomeraciones urbanas de menor jerarquía. En los países 
en donde predomina la población rural y en los cuales lo urbano se reduce casi exclusivamente al núcleo principal o a unos pocos centros, los inmigrantes que llegan a estos centros tienen que incluir una elevada proporción de campesinos.

Por consiguiente, no podría pensarse que el problema del desarrollo de los grandes núcleos de población se plantea por la migración rural. El bajo nivel económico-social de buena parte de la población inmigrante, más bien señala el de otros núcleos urbanos menos desarrollados en todos los sentidos.

Los factores que impulsan los movimientos migratorios son variados y poco conocidos, aunque se afirma, con fundamento, que en términos generales responden principalmente a factores económicos. En la situación actual, caracterizada por un acentuado contraste entre las condiciones de desarrollo económico y social de una o de pocas ciudades, según los casos, y las del resto del territorio de los países latinoamericanos, son decisivas las pobres oportunidades económicas que para la masa de la población suelen ofrecerse fuera de aquella zona privilegiada. Para el trabajador rural las mejores oportunidades conforme a sus conocimientos y capacidad de asimilación suelen estar en los pueblos y las pequeñas ciudades de su región de origen. Los artesanos y en general los trabajadores manuales en actividades no agrícolas encuentran comúnmente o esperan encontrar empleo más estable en las grandes ciudades. Por último, los técnicos, oficinistas y otros trabajadores de cuello blanco también ven en estas ciudades oportunidades de trabajo mejor remu. nerado.

Se estima que la población que en 1960 vivía en ciudades de más- de 500 mil habitantes, estaba creciendo a razón de más de un millón de seres por año y que, de esta cifra, no menos de la mitad era aporte migratorio. ${ }^{4} \mathrm{Si}$ se agregan las ciudades de $250 \mathrm{mil}$ a 500 mil habitantes, el crecimiento comentado llega a 1,3 millones por año, ${ }^{5}$ de los cuales el aporte migratorio era de $600 \mathrm{mil}$ a $700 \mathrm{mil}$. Tal aumento de población significó en los últimos años, y seguirá significando en un futuro inmediato, la demanda de miles de nuevas viviendas, obras de urbanismo (calles, acueductos, instalaciones eléctricas, etc.), escuelas, medios de transporte urbano, servicios médicos adicionales y toda una serie creciente de servicios de utilidad pública. Cabe preguntarse en qué medida se han satisfecho esas necesidades de modo adecuado, o si, por el contrario, el rápido crecimiento fue causa principal de la formación de barrios con viviendas precarias que carecen de los servicios urbanos más elementales y, en general, de la existencia de importantes

4 Veinte ciudades, con un total de 30 millones aproximadamente.

5 Veintiuna ciudades, con un total de 7 millones aproximadamente. 
núcleos humanos marginados de la vida económica y social de la metrópoli.

De los diversos problemas que plantea el crecimiento de las grandes ciudades, el más inmediato, o al menos el que se hace visible con caracteres más dramáticos, es la falta de viviendas y de servicios urbanos adecuados. Para poder satisfacer estas necesidades se requieren inversiones de elevado monto, las que la mayoría de los nuevos pobladores no están en condiciones de soportar en forma directa ni a través del mecanismo del crédito. No obstante que esta clase de gastos absorbe con frecuencia del 30 al 50 por ciento de las inversiones públicas y privadas en capital fijo de muchos países latinoamericanos y de la importante ayuda financiera internacional destinada a la provisión y mejoramiento de servicios urbanos esenciales (agua potable, alcantarillado, etc.), el déficit de vivienda urbana socialmente acepiable se podría estimar, en 1964, en 7 millones de unidades, déficit que se agrava cada año ya que las nuevas viviendas e instalaciones que se construyen son insuficientes para atender las necesidades adicionales que crea el mero aumento de la población. Manifestación típica de la incapacidad para alcanzar un desarrollo urbano, acorde con aquellas condiciones que son representativas de la ciudad moderna, son las poblaciones marginales, mejor conocidas por los nombres de "callampas", "favelas", "tugurios" o "villas miserias", según los países.

El segundo de los problemas fundamentales de las grandes ciudades latinoamericanas proviene de la incapacidad para crear empleo produclivo en cantidad suficiente. Soslayando cualquier tipo de explicación de este fenómeno, de sí muy complejo, cabria señalar dos hechos

- que contribuyen negativamente a la meta del pleno empleo y son: primero, la elevada tasa de crecimiento de la mano de obra nueva que se incorpora anualmente al mercado del trabajo, la cual, en una población que crece a razón del 5 por ciento, por ejemplo, puede llegar a ser del 6 ó del 7 por ciento por efecto de inmigración selectiva de adultos jóvenes; y segundo, el bajo nivel de educación y de formación profesional de la mano de obra en general, y en particular de los inmigrantes trabajadores.

\section{PRINCIPAIES CORRIENTES MIGRATORIAS}

a) Las corrientes migratorias dominantes se producen desde comunidades (ciudades, pueblos, zonas rurales, regiones) con relativamente bajos niveles de vida hacia comunidades con niveles más altos. Este concepto, que es muy amplio, podria expresarse en forma más precisa con referencia a los elementos concretos que constituyen el nivel de 
vida. Los autores que dan prioridad a los factores económicos intentan explicar los movimientos migratorios como el resultado de las oportunidades económicas comparadas de los lugares de salida y de llegada, o bien con palabras más técnicas, de las diferencias de productividad del trabajo. En estos supuestos, el papel de las migraciones interiores sería ajustar la distribución espacial de la población a las oportunidades económicas, o, por lo menos, aliviar disparidades regionales. ${ }^{6}$

Las facilidades en materia de educación, atención médica y otros servicios sociales, como también las condiciones del trabajo (otras que el ingreso), son otros tantos componentes del nivel de vida que desempeñan su papel en la redistribución de la población. En este sentido, las grandes ciudades latinoamericanas ofrecen condiciones netamente superiores a las vigentes en el resto del país, como si los frutos del desarrollo económico y social alcanzado hubieran beneficiado exclusivamente a la capital por su posición política y social privilegiada.

Esos elementos naturales, económicos y sociales, constituyen fuerzas de rechazo y de atracción. La acción combinada de ambas fuerzas determina la dirección y la intensidad de la migración efectiva, neta, entre dos poblaciones.

Pero los elementos mencionados constituyen sólo el aspecto objetivo del mecanismo de las migraciones. El efecto de los mismos sobre la movilidad de las personas depende de factores culturales (normas, instituciones) de las comunidades y de las actitudes y expectativas de los individuos. Estos últimos factores, aunque de difícil medición y al mismo tiempo sujetos a cambios imprevisibles a corto plazo, son igualmente esenciales para el mecanismo de las migraciones. Probablemente los modernos instrumentos de comunicación de masas están desempeñando un papel relevante en la aceleración de la movilidad de muchas poblaciones, sin que necesariamente hayan variado las condiciones económicas prevalecientes en las comunidades de emigración, ni crecido los incentivos reales de los centros de atracción.

La tasa de crecimiento de la población debe ser considerada como una de las variables del mecanismo migratorio, en cuanto es capaz de alterar la relación población-recursos; o sea, si ese crecimiento excede al de las oportunidades económicas (o del ingreso, si se prefiere), las fuerzas de rechazo cobran mayor impulso, o a la inversa si esas oportunidades avanzan a un paso más rápido que la población. Una de las explicaciones preferidas del éxodo rural es justamente ésta, ya que siendo la tierra un factor escaso, o existiendo regímenes de propiedad

6 El agotamiento de yacimientos minerales, los cambios de clima, la erosión de los suelos y otros fenómenos naturales adversos, son otros tantos factores determinantes del éxodo de las poblaciones. La falta de garantías sobre los bienes y la vida, por luchas intestinas, también pueden provocar movimientos masivos. 
y explotación de la tierra que traben el acceso a la misma, las nuevas generaciones de campesinos, sujetas a nuevas condiciones demográficas de crecimiento, exceden las posibilidades de sustento derivado del trabajo agrícola. ${ }^{7}$

b) En los países latinoamericanos, se estima que las principales corrientes migratorias interiores siguen la vía rural-urbana, en toda su graduación, desde las comunidades agrícolas hasta los centros metropolitanos. Hacia estos últimos fluye una corriente que se alimenta de las poblaciones de las otras ciudades, pueblos y áreas rurales propiamente dichas. Al mismo tiempo, las ciudades de provincia y los pueblos reciben contingentes que ceden otras poblaciones más ruralizadas. ${ }^{8}$

Una segunda corriente, también importante, se identifica con los movimientos inter-regionales. En menor o mayor medida, esta corriente se confunde con el movimiento vía rural-urbana, como ocurre con la gran corriente que fluyendo de todas las regiones del país se dirige hacia la metrópoli. Por otra parte, las estadísticas disponibles no per* miten establecer el volumen ni tampoco, frecuentemente, la naturaleza de dos o más corrientes que actúan sobre un área determinada. Durante el período 1940-1950, por ejemplo, el balance migratorio neto

7 Hay que añadir a esta explicación, las tendencias del consumo de productos agrícolas e industriales y de los servicios cuando se eleva el ingreso medio de la población, o sea, la mayor elasticidad-ingreso de la demanda de productos agrícolas, en el supuesto lógico de que también crece la productividad de la agricultura. En resumen, las tendencias de la productividad y del consumo se mani. fiestan en la menor cuota necesaria de trabajadores agrícolas.

Estas observaciones no significan olvidar que una parte considerable de la mano de obra agrícola de los países en vías de desarrollo se encuentra en situación de subempleo, en un sentido muy amplio, debido a la escasez de recursos productivos a su disposición (tierra, riego, equipo, semilla, etc.) y de conocimientos. Las fuerzas de rechazo latentes son enormes y basta el impulso de un cambio de actitudes $\mathrm{y}$ de expectativas para iniciar o intensificar una corriente migratoria. Cambios institucionales -como son la moderna legislación del trabajo, la formación de sindicatos fuertes con participación política, los programas públicos de asistencia social, entre otros-, son factores coadyuvantes o precipitantes de aquellos cambios de actitudes y expectativas.

La debilidad de la economía de los pequeños pueblos de muchas regiones sufre también el impacto de la modernización de las industrias, en particular de su tendencia centralizadora, por razones económicas y técnicas (amplitud del mercado, transporte, mano de obra, etcétera).

8 Las estadísticas censales, con todas sus limitaciones en lo concerniente a este fenómeno, dan evidencias y permiten realizar estimaciones de los movimientos migratorios comentados. Entre las principales fuentes disponibles de conocimiento de las corrientes migratorias, merecen citarse las tasas de crecimiento de la población, los datos sobre el lugar del nacimiento y de la residencia presente de los individuos, los cálculos sobre población "esperada" y su confrontación con la enumerada por el censo $\mathrm{y}$, por último, toda la información estadística relativa a condiciones demográficas y sociales reinantes en las distintas zonas y regiones. 
Cuadro 3

MIGRACION NETA INTER-REGIONAL OCURRIDA EN MEXICO EN EL PERIODO 1950-1960 a

(Miles)

\begin{tabular}{|c|c|c|c|c|c|c|c|c|c|}
\hline \multirow{2}{*}{$\begin{array}{c}\text { Región } \\
\text { de } \\
\text { nacimiento b }\end{array}$} & \multicolumn{8}{|c|}{ Región de empadronamiento ${ }^{b}$} & \multirow{2}{*}{$\begin{array}{c}\text { Total } \\
\text { de } \\
\text { emigrantes }\end{array}$} \\
\hline & 1 & 2 & 3 & 4 & 5 & 6 & 7 & 8 & \\
\hline 1 & - & 2,8 & 2,1 & 3,0 & 9,1 & 10,4 & 2,5 & 2,0 & 31,9 \\
\hline 2 & 9,5 & - & 20,5 & 2,1 & 3,1 & 13,4 & 1,1 & 1,0 & 50,7 \\
\hline 3 & 2,9 & 2,1 & - & 1,7 & 5,0 & 12,9 & 0,6 & 5,0 & 30,2 \\
\hline 4 & 25,1 & 32,7 & 41,8 & - & 36,2 & 26,9 & 2,8 & 5,3 & 170,8 \\
\hline 5 & 64,7 & 7,7 & 17,5 & 6,4 & - & 216,2 & 2,9 & 25,4 & 340,8 \\
\hline 6 & 8,2 & 3,0 & 4,6 & 0,0 & 19,2 & - & 1,7 & 5,7 & 42,4 \\
\hline 7 & 4,4 & 3,0 & 2,3 & 2,1 & 18,5 & 50,2 & - & 19,0 & 99,5 \\
\hline 8 & 3,3 & 1,6 & 6,6 & 2,2 & 13,4 & 33,2 & 6,2 & - & 66,5 \\
\hline $\begin{array}{c}\text { Total } \\
\text { de } \\
\text { inmigrantes }\end{array}$ & 118,1 & 52,9 & 95,4 & 17,5 & 104,5 & 363,2 & 17,8 & 63,4 & 832,8 \\
\hline
\end{tabular}

a Estimada a base de datos censales de habitantes clasificados por la región de nacimiento y la de émpadronamiento, en los censos de 1950 y 1960. (Véase el texto.)

b Esta división regional toma en cuenta la trazada por la Secretaria de Hacienda de México, con algunas reagrupaciones y separando el Distrito Federal. Las regiones comprenden los siguientes Estados:

1) Baja California, Baja California Sur, Sonora, Sinaloa y Nayarit.

2) Chihuahua y Coahuila.

3) Nuevo León y Tamaulipas.

4) Aguascalientes, Durango, San Luis de Potosí y Zacatecas.

5) Colima, Jalisco, Michoacán, Guanajuato, Hidalgo, Morelos, Puebla, Querétaro y Tlaxcala.

6) Distrito Federal.

7) Veracruz, Tabasco, Campeche, Yucatán y Quintana Roo.

8) Chiapas, Guerrero y Oaxaca.

cíficos de estudios (regiones económicas, agronómicas, grados de urbanización, etc.), y si al mismo tiempo se distinguiera la naturaleza rural y urbana del lugar de nacimiento y de destino, en vez de estar dada aquella información, como es corriente, por divisiones administrativas.

Cálculos del movimiento rural-urbano, como el que se presenta en el cuadro 4 pueden efectuarse comparando, por cohortes de edades, las poblaciones enumeradas en dos censos, una vez deducidas las muertes 
Cuadro 4

TASAS ANUALES DE MIGRACION DE LA ZONA URBANA $Y$ DEL NUCLEO PRINCIPAL, DE VARIOS PAISES DE AMERICA IATINA EN PERIODOS RECIENTES

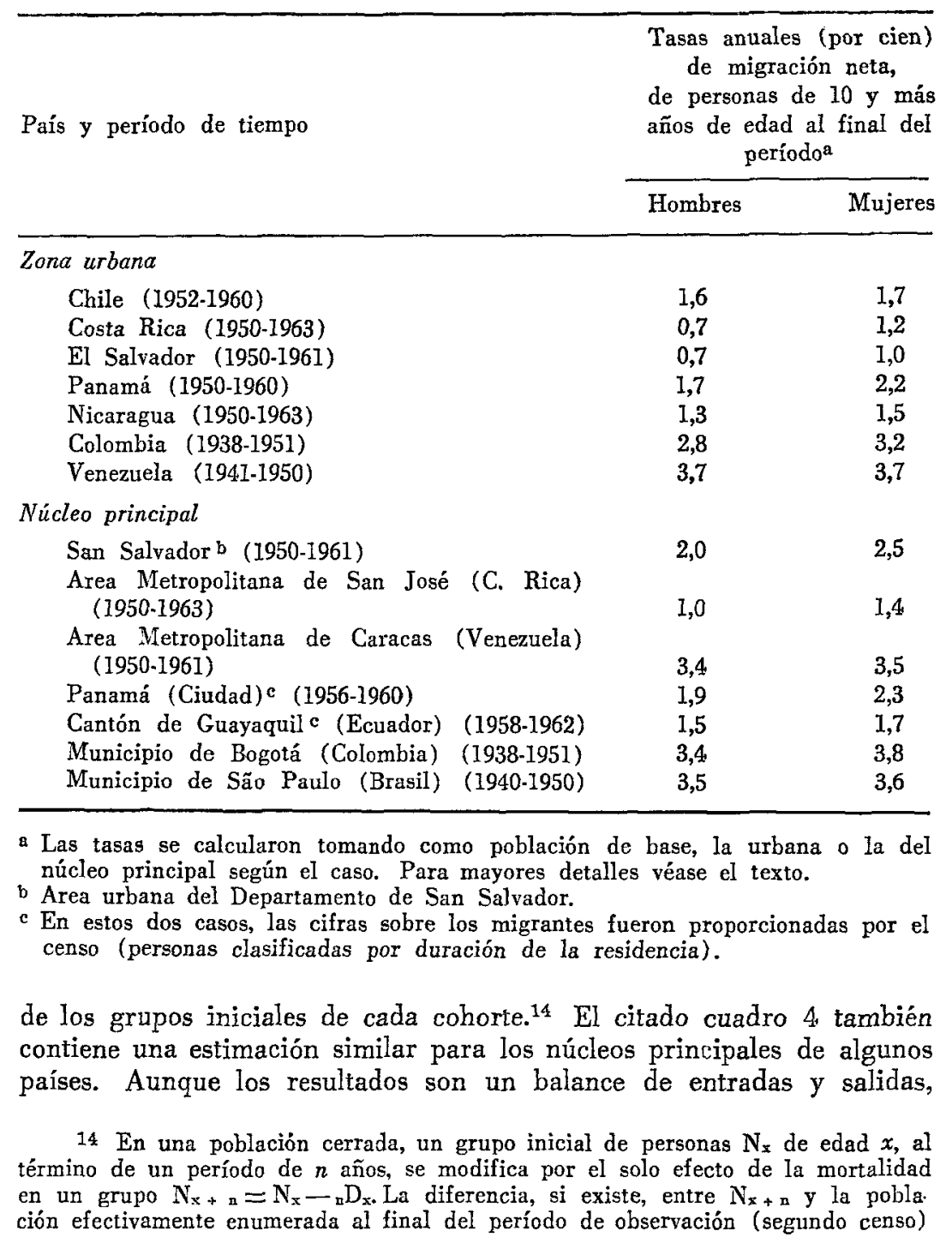


expresan bastante bien la dirección y la magnitud de las corrientes por tratarse de movimientos que en su mayoría van en un solo sentido: la zona urbana o el núcleo principal, según sea el caso.

Con las excepciones de Costa Rica y El Salvador, en los demás paises y períodos examinados, las tasas anuales de migración neta ruralurbana son del orden del 1,5 al 3,7 por ciento. ${ }^{15}$ A su vez, las tasas de migración de los núcleos principales, los cuales están incluidos en la población urbana, son ligeramente más altas que las anteriores. Estos resultados confirman el sentido y la magnitud de las corrientes ruralurbanas en América Latina.

Tanto en los movimientos inter-regionales como entre aquellos que se realizan en el interior de las regiones, se puede distinguir su carácter rural-urbano, inter-urbano o inter-rural. Debería esperarse que en la migración a larga distancia (inter-regional) predominen los movimientos inter-urbanos, en menor medida los rural-urbanos y en último lugar los inter-rurales. A falta de mejor información se puede expresar, algo burdamente, la distancia mediante la distinción de regiones limítrofes y no limítrofes. En el cuadro 5 se presentan proporciones de inmigrantes de origen urbano sobre el total de inmigrantes que llegaron a la provincia de Concepción (Chile) en el período 1952-1960, procedentes de cuatro regiones. ${ }^{16}$ Estas regiones fueron ordenadas según la "distancia" a la provincia de Concepción, y como se lee en la columna 1 del citado cuadro, la proporción de inmigrantes de origen urbano aumenta con la distancia. En la columna 2 figuran las proporciones de emigrantes urbanos sobre el total de emigrantes de la provincia de Concepción, verificándose nuevamente que dicha proporción aumenta con la distancia de la región de destino. En ambos casos -inmigrantes y emigrantes- la migración intra-regional -o sea, entre las cinco provincias que forman la región de Concepción-, marca el menor porcentaje de migrantes de origen urbano.

da una estimación del movimiento migratorio neto de supervivientes. Este método es aplicable a cualquier unidad geográfica de población (zona urbana, municipios, provincias, regiones, etc.).

15 Tasas medidas respecto de la población urbana (o del núcleo principal, según el caso). El cálculo excluye los migrantes y la población que al final del período de observación no había cumplido los 10 años de edad.

16 En 1960 la provincia de Concepción tenía 540 mil habitantes, con 82 por ciento de población urbana. 
Cuadro 5

PROPORCION DE ORIGEN URBANO DE LOS INMIGRANTES $Y$ DE LOS EMIGRANTES, HACIA Y DESDE LA PROVINCIA DE CONCEPCION (CHILE), POR REGIONES DE SALIDA Y DE DESTINO, RESPECTIVAMENTE (PERIODO 1952-1960)

\begin{tabular}{lcc}
\hline \multirow{2}{*}{ Regiones $^{\mathrm{a}}$} & $\begin{array}{c}\text { Porcentajes de migrantes } \\
\text { de lugar urbano de salida, } \\
\text { por cien migrantes: }\end{array}$ \\
\cline { 2 - 3 } & Inmigrantes $^{\mathrm{b}}$ & Emigrantes $^{\mathrm{b}}$ \\
\hline 1. Región de Concepción $\mathrm{c}$ & 63 & 82 \\
2. Región limítrofed & 70 & 85 \\
3. Región de Santiago & 98 & 91 \\
4. Otras provincias & 93 & 95 \\
Total & 73 & 89 \\
\hline
\end{tabular}

a Región de salida para los inmigrantes; de entrada para los emigrantes.

b Inmigrantes y emigrantes son los que tuvieron residencia fuera de la provincia de empadronamiento (censo de 1960) en el período 1952-1960. Por consiguiente, no están contados los movimientos producidos en el interior de la provincia de Concepción, pero sí los movimientos entre las provincias que forman la región de Concepción.

c Provincias de: Concepción, Nuble, Arauco, Bío-Bio y Malleco.

d Provincias de: Talca, Maule, Linares, Cautin y Valdivia.

e Provincia de Santiago, incluso el Gran Santiago.

\section{Objetivos de la encuesta del Gran Santiago}

La investigación fue planeada, principalmente, para poder satisfacer determinados requerimientos de información demográfica de un área metropolitana, en este caso del Gran Santiago. Ello explica por qué se basó en una muestra de hogares de toda la población de la ciudad, para obtener por este camino un marco de población completo, dentro del cual debía estudiarse a los inmigrantes; también justifica el énfasis puesto, tanto en el cuestionario como en el análisis, sobre características objetivas de la población (sexo, edad, educación, actividad económica, vivienda, lugar de origen, duración de la residencia en la ciudad, etc.), las que permiten establecer el volumen y tendencias del movimiento y los diferenciales demográfico-sociales de inmigrantes y nativos; esto es, conocer los principales aspectos cuantitativos de la corriente que recibe el Gran Santiago y los efectos de la misma sobre la composición de su población. En todo esto, la encuesta viene a suplir la información que 
podía haber proporcionado un censo de población que hubiera tomado las debidas provisiones en este campo.

Sin embargo, la investigación no se limitó a los aspectos antes descriptos. También prestó especial atención a la movilidad previa de los inmigrantes, las motivaciones para emigrar y condiciones de trabajo anteriores al movimiento, y ciertos importantes tópicos acerca de la asimilación de los inmigrantes, como son la movilidad profesional, circunstancias vinculadas a la primera ocupación en la ciudad (educación, lugar de origen, etc.) y vivienda.

Por cierto que hay lagunas, si se piensa en un estudio más amplio, comprensivo de los elementos y mecanismos de una corriente migratoria. Las motivaciones, por ejemplo, pueden ser investigadas con mayor profundidad en una encuesta, y complementadas con estudios en los lugares de origen que den información sobre las condiciones económicosociales reinantes en los mismos, en lo relacionado con las oportunidades de trabajo y otros factores que puedan operar como fuerzas de rechazo, así como indicaciones del carácter diferencial (en educación, por ejemplo) del emigrante respecto del que permanece en su tierra.

Se podrá encontrar que ha sido descuidado el problema de la asimilación de los inmigrantes. Esta encuesta nunca pretendió incluir una sección destinada al estudio psico-social de la asimilación en sus distintas expresiones y procesos (ajustamiento, participación y aculturación), y sobre tópicos tan diversos como son: vida familiar; aspectos técnicos, sociales y psicológicos del trabajo; relaciones sociales y cultura material (localización y vecindad); acceso a los medios de comunicación de masas; movilidad social intergeneracional; participación política; costumbres y hábitos (alimentación), etcétera. ${ }^{17}$ Tales investigaciones no solamente requieren un aparato metodológico altamente especializado, sino que por la orientación específica de sus objetivos y la índole de la información requerida tienen que ser realizados en pro. fundidad, lo cual generalmente conlleva un número relativamente pequeño de entrevistas, seguramente un procedimiento de selección de la muestra distinto del usado en la encuesta del CELADE y, frecuentemente, una investigación dirigida a determinados segmentos de la población (obreros de fábrica, poblaciones marginales, enfermos mentales, etc.) ${ }^{18}$

17 Germani, Gino: Assimilation of Immigrants in Urban Areas. Methodological Notes. Instituto Torcuato Di Tella, Buenos Aires, 1964.

18 Resultados de investigaciones realizadas en poblaciones seleccionadas de tres ciudades latinoamericanas, se pueden encontrar en:

Germani, Gino: "Investigación sobre los efectos sociales de la urbanización en un área obrera del Gran Buenos Aires", en La Urbanización en América Latina (Documentos del Seminario sobre Problemas de Urbanización en América Lati- 
Con diversa intensidad y con las limitaciones que se acaban de señalar, la investigación del Gran Santiago abarcó los principales campos teóricos del estudio del fenómeno migratorio, esto es: $a$ ) mecanismo del proceso, que abarca i) motivaciones y factores y ii) la corriente migratoria (volumen, características de los migrantes, etc.); $b$ ) el proceso de asimilación, y c) los efectos sobre la composición demográfico-social del Gran Santiago (crecimiento de la población, diferenciales entre inmigrantes $y$ nativos, etc.).

Autores contemporáneos (Bogue y Lee, ${ }^{19}$ entre otros) han formulado una serie de hipótesis a modo de marco teórico para el estudio de las migraciones interiores, partiendo de la aceptación del principio básico según el cual las diferencias en las condiciones económico-sociales de dos comunidades (oportunidades económicas principalmente), habida cuenta de los obstáculos intervinientes, determinan el volumen y las características de las migraciones entre ambas.

En el esquema de Lee, el volumen de la migración varía con el grado de diversidad de las áreas implicadas, y de igual modo con la diversidad de su población. Esta hipótesis es pertinente sólo de modo parcial, desde el momento que se tiene información sobre el movimiento migratorio respecto de un único punto del país. No obstante, una somera inspección de la información censal disponible mostraría que el

na, patrocinado conjuntamente por Naciones Unidas, la CEPAL y la uNesco, realizado en Santiago de Chile, en julio de 1959. Editor P. M. Hauser).

Matos Mar, José: "Las barriadas limeñas: un caso de integración a la vida urbana", en La Urbanización en América Latina, op. cit.

Brandão Lopes, Juarez Rubens: "Aspectos de la adaptación de los inmigrantes rurales a las condiciones urbano-industriales de São Paulo, Brasil", en La urbanización en América Latina, op. cit.

Las encuestas entre pacientes hospitalarios son relativamente frecuentes, en especial de enfermos mentales. Referencias de estudios y conclusiones sobre migración diferencial y enfermedades mentales, se pueden consultar en:

Lee, Everett S.: "Socio-economic differentials in mental diseases, New York State, 1949-1951", en The Milbank Memorial Fund Quarterly, julio de 1963, vol. XLI, $\mathrm{N}^{0} 3$.

Lazarus, Judith y otros: "Migration differentials in mental disease", en The Milbank Memorial Fund Quarterly, enero de I963, vol. XLI, $\mathrm{N}^{Q} \mathrm{I}$.

Un estudio con base en entrevistas a mujeres asistidas en maternidades de la ciudad de Aberdeen (Escocia) se resume en: Illsley, Raymond y otros: "The motivation and characteristics of internal migrants", en The Milbank Memorial Fund Quarterly, abril y julio de 1963, vol. XLI, Nos. 2 y 3.

19 Bogue, Donald J.: "Techniques and Hypotheses for the Study of Differential Migration: Some Notes from an Experiment with United States Data", en International Population Conference, New York 1961, tomo I, págs. 405-410, Londres, 1963.

Lee, Everett S.: “A Theory of Migration", en Demography, 1966, vol. III, No 1, págs. 47-57. 
movimiento migratorio hacia el Gran Santiago absorbe una parte considerable de la migración de larga distancia; lo cual se explicaría, en relación con aquella hipótesis, por las marcadas diferencias de desarrollo entre el área metropolitana y el resto del país $\mathrm{y}$, al mismo tiempo, por las diferencias en educación y capacitación profesional de las poblaciones de una y otra zona.

Normalmente, tanto volumen como tasa de migración tienden a aumentar con el tiempo (Lee), principalmente a causa de que se observa una tendencia a ampliarse las diferencias en el desarrollo de distintas áreas, lo cual es particularmente aplicable a los países en vías de desarrollo; otro tanto podría decirse de la diferenciación de educación y aptitudes especializadas (unido a la toma de conciencia de ello), lo cual estimula el movimiento de los mejor dotados. Por otra parte, los adelantos tecnológicos en los transportes y la difusión de noticias remueven muchos obstáculos en la decisión de migrar. Por último, podría agregarse que la migración promueve la migración, sea porque un individuo que ha tenido esa experiencia puede repetirla con más facilidad, o porque él constituye un canal para que familiares y amigos sigan su camino. En efecto, el volumen migratorio de las últimas décadas estuvo aumentando y probablemente seguirá creciendo en cifras absolutas, pero en las condiciones particulares del Gran Santiago no es probable que también aumente la tasa; en realidad, la tasa se mantuvo más bien estacionaria en los últimos veinte años. No hay que olvidar que el Gran Santiago ya representa casi un tercio de la población del país.

La migración tiende a realizarse dentro de corrientes bien definidas (Lee), como consecuencia de que las oportunidades tienden a estar fuertemente localizadas. Respecto del Gran Santiago no caben dudas de que en él están fuertemente concentradas las actividades económicas, y que existen más amplias facilidades de educación, servicios sociales, recreo y cultura que en cualquier otra área del pais. Por otra parte, los resultados permiten establecer corrientes bastante estables de distintas regiones del país y de comunidades con diverso grado de urbanización, lo cual confiere al movimiento migratorio hacia el Gran Santiago un carácter continuo y regular desde áreas bien definidas.

La eficiencia de la inmigración (esto es la migración neta, o el balance de inmigración y emigración) es alta cuando los factores de atracción actúan en sentido contrario en el lugar de origen (Lee). Conforme con esta hipótesis, debe esperarse que una elevada proporción de inmigrantes del Gran Santiago no regrese al lugar de origen, y aunque la encuesta no provee información para verificar dicha hipótesis, ella está implícita en los análisis de la composición de la población inmigrante y su comparación con la población nativa.

La migración es selectiva de personas con una combinación parti- 
cular de características (Bogue). La razón de esta selectividad es que las personas responden de modo diferente a un conjunto de factores de atracción y repulsión de los lugares de destino y de origen, en razón de una serie de elementos intervinientes como son edad, sexo, estado civil, educación, calificación profesional y otras (Lee). Tal selectividad puede mirarse respecto de la población de salida y de la de llegada. Si predominan las fuerzas de atracción, debe esperarse que la selección sea positiva; esto es, que emigren los individuos mejor dotados; si en cambio la fuerza mayor es la de rechazo, ocurre lo contrario. De aquí se deriva que, cuando la migración es estimulada por el crecimiento económico y el desarrollo tecnológico, se produce una selección positiva, siendo de esperar que los migrantes difieran quizá menos de la población recipiente que de la de origen (Bogue, Lee). Como ocurre frecuentemente en la migración rural-urbana, la migración hacia el Gran Santiago tiene que ser positivamente selectiva respecto de una importante proporción de migrantes; esto explica por qué los inmigrantes vienen en proporción relativamente mayor de núcleos urbanos de cierta importancia (66 por ciento vino de núcleos de más de 5000 habitantes). Por otra parte, no podría omitirse la importancia de los factores de rechazo y su selectividad negativa. El juego de ambas fuerzas parece deducirse del carácter bimodal (Lee) de los diferenciales entre inmigrantes y nativos de la ciudad con respecto a diversas caracteristicas sociales, lo cual es corroborado por los resultados de la encuesta (educación, ocupaciones).

El ciclo vital desempeña un importante papel en la selección de los migrantes. Los jóvenes que alcanzan la edad de trabajar y de casarse, por esta razón, tienen una alta propensión a moverse en busca de mejores horizontes (Bogue, Lee). De los inmigrantes del Gran Santiago de la última década (1952-1962), la mitad llegó entre 15 y 30 años de edad. La proporción en edades adultas jóvenes es más alta entre inmigrantes de lugares rurales. Más de los dos tercios de los inmigrantes que llegaron adultos (14 y más años) de los inmigrantes del período 1942-1962 eran no casados (solteros, principalmente). Las facilidades de educación también desempeñaron un papel importante.

La migración diferencial por sexo y la migración en etapas, hipótesis frecuentemente formuladas, también han sido objeto de análisis en este estudio (véase, por ejemplo, el capítulo II sobre movilidad de los migrantes). Según los resultados de la encuesta, la selectividad femenina es muy acentuada; la migración en etapas, al contrario, relativamente poco importante: la proporción de inmigrantes llegados en un primer movimiento (después de cumplir 14 años) supera el 66 por ciento; de los que llegaron entre 14 y 30 años, esa proporción es, aproximadamente, del 80 por ciento. 


\section{MÉTodo}

Se realizó una encuesta con base en una muestra al azar de 2309 hogares familiares, abarcando una población de aproximadamente 11700 personas. ${ }^{20}$ Solamente se investigó población residente en el Gran Santiago, razón por la cual no fueron tomadas en cuenta las personas que formaban parte de hogares colectivos; a tales personas se las consideró, según los casos, residentes en algún hogar familiar (donde sería enumerada si ese hogar cayera en la muestra), residentes fuera del Gran Santiago (en hoteles y similares), o residentes del Gran Santiago que no tenían libertad para fijar su residencia (personas cumpliendo servicio militar, en cárceles o en conventos).

La elección de una muestra de hogares se decidió por las siguientes consideraciones:

a) En una población como la del Gran Santiago, donde más de la mitad de las personas adultas son inmigrantes, una muestra de hogares proporciona información de un número relativamente grande de inmigrantes con distintas características demográficas y sociales;

b) Varios de los principales objetivos de la investigación requieren una encuesta de hogares, como son volumen, tendencias y características diferenciales de la población inmigrante;

c) Los elementos estadísticos (datos censales) para la selección de la muestra de hogares estaban disponibles. La muestra de un segmento específico de la población, como es el de los inmigrantes, habría requerido información básica relativamente segura sobre su número, distribución y características: edad, posición en el hogar (jefe, etc.), educación y quizás otros, para realizar una buena estratificación, información que, al no estar disponible, su conocimiento habría implicado realizar una costosa enumeración previa;

d) La muestra de hogares facilita el estudio de las características familiares, $y$

e) La escasa experiencia acumulada sobre encuestas demográficas para el estudio de las migraciones, hizo aconsejable comenzar esta clase de investigación, que tiene carácter experimental, con muestras de hogares, las que pueden servir mejor a propósitos múltiples. ${ }^{21}$

20 Los procedimientos de selección, la descripción del universo y otros detalles técnicos se presentan en el Apéndice I.

21 Pueden mencionarse, como antecedentes de encuestas de hogares para in. vestigar aspectos de la migración a nivel demográfico, esto es, cubriendo toda la población de una unidad geográfica (ciudad, pais), las siguientes: La encuesta del estudio socio-económico de la población del Area Metropolitana de San Salvador 
La investigación comprendió dos partes. La primera abarcó a todos los miembros del hogar, cualquiera que fuera su edad, y tuvo por objeto recoger información sobre condiciones de la vivienda, características demográficas, de instrucción y económicas, y sobre la última residencia y fecha de llegada de los inmigrantes.

La segunda parte fue dirigida a obtener, a través de una entrevista personal con el inmigrante, información sobre la historia migratoria, motivaciones, características ocupacionales antes de emigrar y relativas a su primera ocupación en el Gran Santiago, y una consulta breve sobre participación social y grado de conformidad sobre diversos aspectos de su vida en la ciudad. Esta investigación se limitó a los inmigrantes que llegaron al Gran Santiago después de cumplir 14 años, es decir, se excluyó a aquellas personas para las cuales el movimiento migratorio se da por sentado, depende de la decisión de otras personas y que, además, en razón de su poca edad, se asimilan rápidamente a las condiciones del nuevo ambiente. ${ }^{22}$

(1960); The Philippine Statistical Survey of Households (1956); las encuestas anuales de movilidad de la población de los Estados Unidos que realiza la Oficina del Censo en el mes de abril, en conexión con el Census Current Population Survey y la investigación del National Opinion Research Center de la Universidad de Chicago, sobre Problems of Living in the Metropolis (1959).

22 El Apéndice II contiene definiciones, descripción de los cuestionarios utilizados y un breve resumen del trabajo de terreno. 



\section{LA CORRIENTE HACIA EL GRAN SANTIAGO \\ Principales Características}

\section{Tendencia históRICA $\mathbf{Y}$ COMPOSICIÓN POR SEXo}

La población inmigrante del Gran Santiago, al momento de la encuesta, es el resultado final de un proceso de entradas y salidas (muertes y remigraciones) a lo largo del tiempo. Por consiguiente, la distribución de esa población por períodos de llegada no es representativa del flujo migratorio de tales períodos. Está distorsionada por la mortalidad y por emigraciones (re-migración), movimientos ambos que afectan a los inmigrantes en relación directa con el tiempo transcurrido desde su llegada. Puede pensarse, entonces, que los inmigrantes de períodos más lejanos están subrepresentados.

A pesar de este último hecho, aproximadamente 40 por ciento de los inmigrantes llegaron antes del año 1942, y la diferencia en los últimos veinte años. Cifras que muestran la importancia del movimiento migratorio de las décadas de los $30 \mathrm{y}$ de los 20. (Véase el cuadro 6.)

Por otra parte, parece cierto que la corriente creció de volumen en los dos últimos quinquenios. Entre el quinquenio 1947-1951 y el quinquenio 1952-1956, el aumento fue aproximadamente del 20 por ciento; de 1952-1956 a 1957-1962, del 30 por ciento. Sin embargo, en cifras relativas (tasas) no hay evidencias seguras de aumento durante los últimos veinte años, sino más bien un nivel relativamente constante, revelador de la regularidad del fenómeno.

El número de mujeres excede al de hombres, como lo expresa el índice de masculinidad de $72 .{ }^{23}$ Esta es una característica frecuentemente encontrada en los inmigrantes de las grandes ciudades de Latinoamérica. Aquella cifra podría ser ajustada teniendo en cuenta la sobremortalidad masculina, pero de cualquier modo la relación de masculinidad seguiría siendo baja. Por otra parte, el comportamiento diferencial por sexo se acentuó en los años más recientes, de tal modo que

23 Hombres por cada 100 mujeres. 
en los inmigrantes del último quinquenio es 67 , en la penúltima década 72 , y en los inmigrantes de antes de 1942, 76. Quiere decir que en años recientes se incrementó el diferencial por sexo.

La relación de masculinidad es más baja en las edades adultas jóvenes; esto es, en aquellas a que llegó por lo menos la mitad de los inmigrantes, como se puede ver en las siguientes cifras:

\begin{tabular}{lc}
\hline Edad de llegada & $\begin{array}{c}\text { Indice } \\
\text { de } \\
\text { masculinidada }^{a}\end{array}$ \\
\hline Menos de 15 & 85 \\
15 a 29 & 62 \\
30 a 49 & 75 \\
50 y más & 57 \\
\hline
\end{tabular}

a Hombres por cada 100 mujeres.

El bajo indice (57) de personas que inmigraron de 50 y más años de edad debería atribuirse al decisivo efecto de la sobremortalidad masculina, la cual es fuerte aun en personas llegadas en épocas recientes. Por lo contrario, el relativamente bajo índice no tiene inmediata explicación si se tiene en cuenta que es aun más bajo (50) en las personas que llegaron en la última década, las cuales, en el momento de la encuesta, tenían edades inferiores a 25 años. Finalmente, el índice correspondiente a inmigrantes de 15-29 años de la última década también y no mayores de 39 años en el momento de la encuesta, es 55, muy por debajo del índice general para todos los períodos. Estos resultados confirman, en general, la importancia creciente de la migración femenina. (Véase el cuadro 6.)

\section{Estructura POR EDAD DE LLEGAdA}

Es probable que la edad constituya una caracteristica diferencial universal de las poblaciones migrantes, a juzgar por el conocimiento que de este fenómeno demográfico se tiene. Las personas de 15 a 30 años, por ejemplo, tienen una movilidad más alta que los adultos de mayor edad, de cualquier sexo, y también que los niños.

Aunque las diferencias varian en intensidad, según el tipo de migración predominante —esto es, de grupos familiares o de individuos aislados-, el mayor número de casos corresponde a las edades adultas jóvenes, por lo menos en condiciones normales. Este hecho podría tener una 
Cuadro 6

DISTRIBUCION DE LOS INMIGRANTES POR PERIODOS DE LLEGADA

\begin{tabular}{lcccc}
\hline & \multicolumn{2}{c}{ Hombres } & \multicolumn{2}{c}{ Mujeres } \\
\cline { 2 - 5 } Periodos de llegada & $\begin{array}{c}\text { Número } \\
\text { de } \\
\text { inmigrantes }\end{array}$ & $\begin{array}{c}\text { Porcentaje } \\
\text { del } \\
\text { total }\end{array}$ & $\begin{array}{c}\text { Número } \\
\text { de } \\
\text { inmigrantes }\end{array}$ & $\begin{array}{c}\text { Porcentaje } \\
\text { del } \\
\text { total }\end{array}$ \\
\hline Total & 1549 & 100,0 & 2152 & 100,0 \\
$1957-1962^{2}$ & 312 & 20,1 & 466 & 21,6 \\
$1952-1956$ & 240 & 15,5 & 344 & 16,0 \\
$1947-1951$ & 199 & 12,8 & 284 & 13,2 \\
$1942-1946$ & 172 & 11,1 & 234 & 10,9 \\
1941 y años anteriores & 626 & 40,4 & 824 & 38,3 \\
\hline
\end{tabular}

a Años 1957 a 1961 completos; seis meses, en promedio, de 1962.

explicación en la circunstancia de que el proceso de incorporación y de adaptación a la vida económica es más fuerte en aquellas edades. Al mismo tiempo, los obstáculos materiales y psicológicos pesan más en las personas de edad más avanzada, en relación con los vínculos familiares y con los iniereses económicos. Finalmente, la capacidad de adaptación a los cambios en los adultos jóvenes, en general es mayor.

En esta sección se estudia la estructura por edad de llegada de los inmigrantes en relación con el sexo, el período de llegada, número de movimientos migratorios previos y lugar de emigración. Estas comparaciones permiten establecer el efecto que producen estos factores en la edad de los inmigrantes, de tal manera, por ejemplo, que los inmigrantes que proceden de los sectores rurales son, en término medio, más jóvenes que los que vienen de núcleos urbanos; o también permiten comprobar que entre los inmigrantes que llegan al Gran Santiago en un primer movimiento hay una proporción más alta de adultos jóvenes que entre aquellos que llegan en una segunda, tercera o cuarta etapa migratoria.

a) Como se desprende del cuadro 7 y se ilustra en los gráficos 1 y 2 , la estructura por edad de los inmigrantes sigue la forma frecuentemente encontrada en estadísticas do esta clase. Las frecuencias más altas ocurren en el intervalo de edades de 15 a 29 años. De los inmigranles de la última década, alrededor de la mitad llegó en estas edades (44,0 y 50,7 por ciento, respectivamente, de hombres y mujeres). Cifras análogas corresponden a los inmigrantes de la década 1942-51.

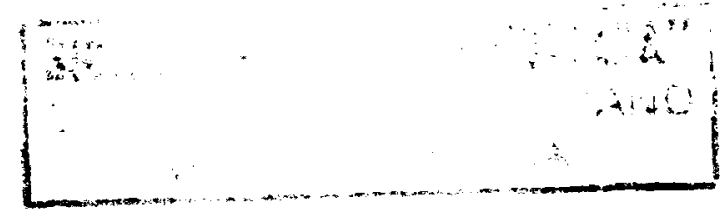


El grupo de edades con la más alta densidad es, en ambos sexos, 15-19, seguido en orden de importancia por el grupo 20-24. Los niños menores de 10 años de edad representan el 17,7 por ciento de los inmigrantes de la última década, un número mayor que el de los inmigrantes de más de 40 años (14,7 por ciento). Estas características, como se verá más adelante, están más marcadas en los inmigrantes que llegaron de pequeñas localidades y del área rural.

b) Los datos sugieren que la estructura por edad de los inmigrantes no sufrió variaciones de importancia a través del tiempo, en los tres períodos estudiados: 1952-1962, 1942-1951 y 1941 y años anteriores. (Véase el cuadro 7.)

La mayor proporción de niños observada en las épocas más lejanas, no podría considerarse un hecho real sin más análisis. Para interpretar ese resultado debe tenerse en cuenta el efecto de la mortalidad, el que distorsiona la estructura por edad; fenómeno para cuya comprensión hay que tener presente tres hechos: i) los inmigrantes de un período cualquiera son supervivientes del grupo inicial; ii) cuanto más tiempo ha transcurrido, menor número de supervivientes se encontraron en el momento de la encuesta, y iii) a igual período de tiempo, cuanto más baja la edad de llegada, mayor la supervivencia. En otras palabras, a medida que transcurre el tiempo, aumenta la sobre-representación de los más jóvenes (edad en el momento de emigrar).24 (Véanse el cuadro 7 y los gráficos 1 y 2.)

c) La estructura por edad de llegada guarda relación con el número de movimientos migratorios previos del inmigrante. En su gran mayoría, los inmigrantes jóvenes llegaron al Gran Santiago en un primer movimiento. A medida que avanza la edad, la proporción de inmigrantes de primer movimiento se reduce. Como se verá más adelante, este hecho explica, al menos en parte, la diferente estructura por edad según lugar de emigración, ya que los inmigrantes que vienen de los sectores rurales, por ejemplo, llegan, en mayor proporción que de otras zonas, en su primer movimiento.

En el cuadro 8 se presenta la estructura por edad de cuatro grupos de inmigrantes llegados con más de 14 años de edad, clasificados según el número de movimientos realizados, incluyendo el último hacia el Gran Santiago. Esta información abarca los últimos 20 años, de 1942

24 Teóricamente es posible reconstruir con cierta aproximación, a partir de los inmigrantes supervivientes, los inmigrantes iniciales. Para ello habría que apli. car apropiadas relaciones de supervivencia a las cohortes de edad presente, separadas estas últimas según la edad de llegada. Trátase, en consecuencia, de un procedimiento de "rejuvenecimiento" de la población migrante observada en el momento de la encuesta, 
LA CORRIENTE HACIA EL GRAN SANTIAGO

CUADRO 7

INMIGRANTES AL GRAN SANTIAGO, POR EDAD

Y POR PERIODOS DE LLEGADA (Porcentajes)

\begin{tabular}{|c|c|c|c|c|}
\hline \multirow{2}{*}{$\begin{array}{l}\text { Sexo y edad } \\
\text { de llegada } \\
\text { (En grupos) }\end{array}$} & \multirow{2}{*}{$\begin{array}{c}\text { Inmigrantes } \\
\text { totales } \\
\text { (Todos los } \\
\text { periodos) }\end{array}$} & \multicolumn{3}{|c|}{ Inmigrantes de los periodos } \\
\hline & & $1952-1962$ & $1942 \cdot 1951$ & $\begin{array}{c}1941 \text { y años } \\
\text { anteriores }\end{array}$ \\
\hline & (1) & (2) & (3) & (4) \\
\hline \multicolumn{5}{|l|}{ Hombres } \\
\hline $0-4$ & 12,3 & 11,3 & 13,5 & 13,6 \\
\hline $5-9$ & 12,5 & 9,6 & 9,8 & 16,8 \\
\hline $10 \cdot 24$ & 14,2 & 10,3 & 14,1 & 17,8 \\
\hline $15-19$ & 16,6 & 18,2 & 17,3 & 16,4 \\
\hline $20-24$ & 15,8 & 16,4 & 15,0 & 16,3 \\
\hline $25 \cdot 29$ & 8,7 & 9,4 & 11,0 & 6,9 \\
\hline $30-34$ & 5,9 & 5,7 & 6,9 & 4,8 \\
\hline $35-39$ & 4,2 & 4,4 & 4,0 & 3,4 \\
\hline $40-49$ & 5,7 & 8,8 & 3,8 & 3,5 \\
\hline $50 \cdot 59$ & 1,9 & 3,1 & 3,5 & 0,3 \\
\hline 60 y más & 1,4 & 2,8 & 1,1 & 0,2 \\
\hline Edad desconocida & 0,8 & & & \\
\hline Total hombres & 100,0 & 100,0 & 100,0 & 100,0 \\
\hline (Total de casos) & $(1549)^{\mathrm{a}}$ & $(523)$ & $(347)$ & $(566)$ \\
\hline \multicolumn{5}{|l|}{ Mujeres } \\
\hline $0-4$ & 10,0 & 7,3 & 9,6 & 12,7 \\
\hline $5-9$ & 9,9 & 8,2 & 7,4 & 13,5 \\
\hline $10-14$ & 13,1 & 10,4 & 12,4 & 17,1 \\
\hline $15-19$ & 21,5 & 24,0 & 21,6 & 20,5 \\
\hline $20-24$ & 14,7 & 15,7 & 14,6 & 14,2 \\
\hline $25-29$ & 11,2 & 11,0 & 12,2 & 10,8 \\
\hline $30-34$ & 5,2 & 4,7 & 6,6 & 4,7 \\
\hline $35-39$ & 4,2 & 4,1 & 4,6 & 3,9 \\
\hline $40-49$ & 5,3 & 7,4 & 5,8 & 2,4 \\
\hline $50 \cdot 59$ & 2,6 & 4,1 & 4,0 & 0,1 \\
\hline 60 y más & 1,6 & 3,1 & 1,2 & 0,1 \\
\hline Edad desconocida & 0,7 & & & \\
\hline Total mujeres & 100,0 & 100,0 & 100,0 & 100,0 \\
\hline (Total de casos) & $(2152)^{a}$ & $(782)$ & $(500)$ & $(766)$ \\
\hline
\end{tabular}

a Jas diferencias entre los totales generales y la suma de los inmigrantes de las columnas 2,3 y 4, corresponden a jersonas procedentes directamente de otros países y de procedencia desconocida, las euales están jncluidas en la columna 1. En resumen, las diferencias e! tán dadas por los siguientes casos:

Inmigrantes procedentes de otros países

Inmigrantes de procedencia desconocida

Inmigrantes de edad descono:ida (otros que

los incluidos en los dos grupos anteriores)

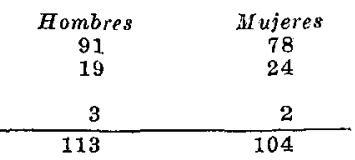




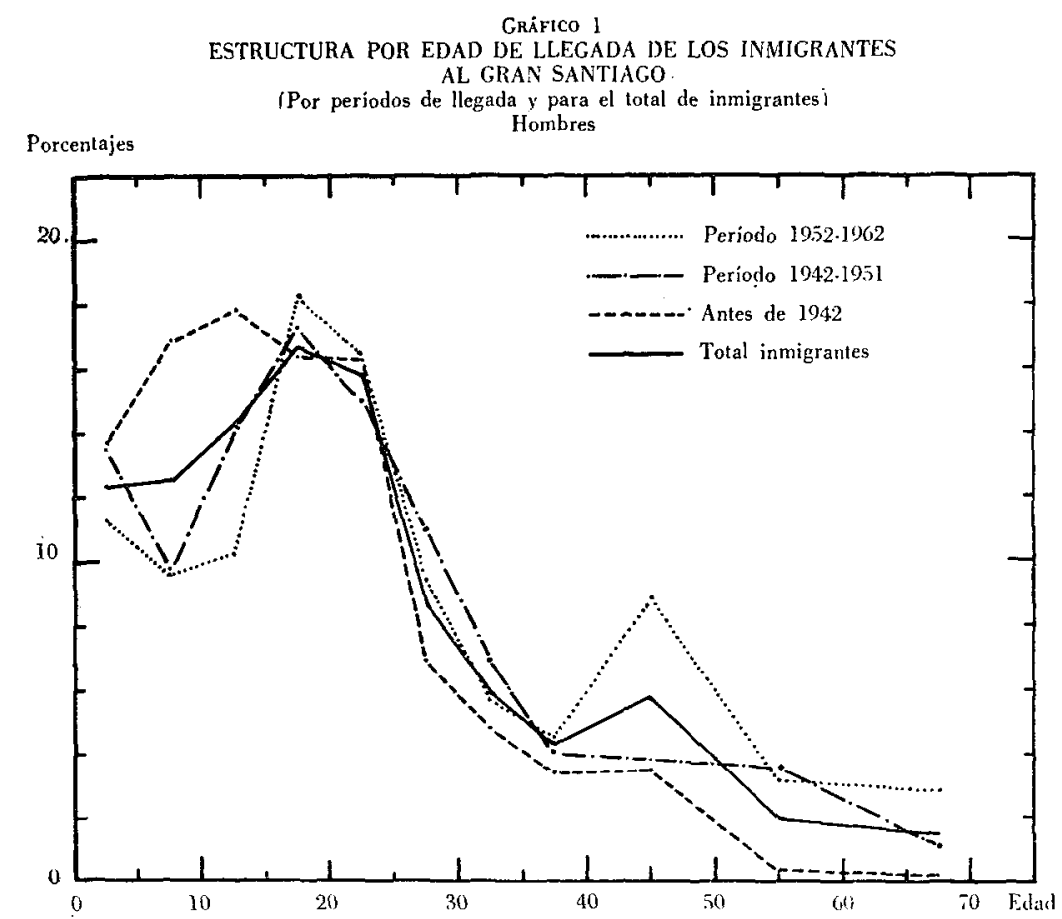

a 1962, periodo que ofrece estas dos ventajas: primero, es lo suficientemente amplio como para reunir un número grande de casos; y segundo, pone un límite hacia el pasado. Respecto de esto último es lícito pensar que la información acerca de hechos muy lejanos puede estar viciada por la falta de memoria, aparte de que correspondería a condiciones muy inactuales.

El 62,3 por ciento de los inmigrantes y el 68,8 por ciento de las inmigrantes llegados en el período 1942-1962, lo hicieron en su primer movimiento migratorio después de cumplir los 14 años. Con dos mo. vimientos hay un 15 por ciento, aproximadamente, tanto en uno como en otro sexo.

Ahora bien, como se podía prever, la estructura por edad es más joven en los inmigrantes con un solo movimiento. De éstos, el 35,6 por ciento se encontraba en el grupo de 14.19 años de edad; considerando los menores de 30 años, representaban el 78,6 por ciento. De los inmigrantes con tres o más movimientos, sólo el 28,8 por ciento correspondió a los menores de 30 años. 


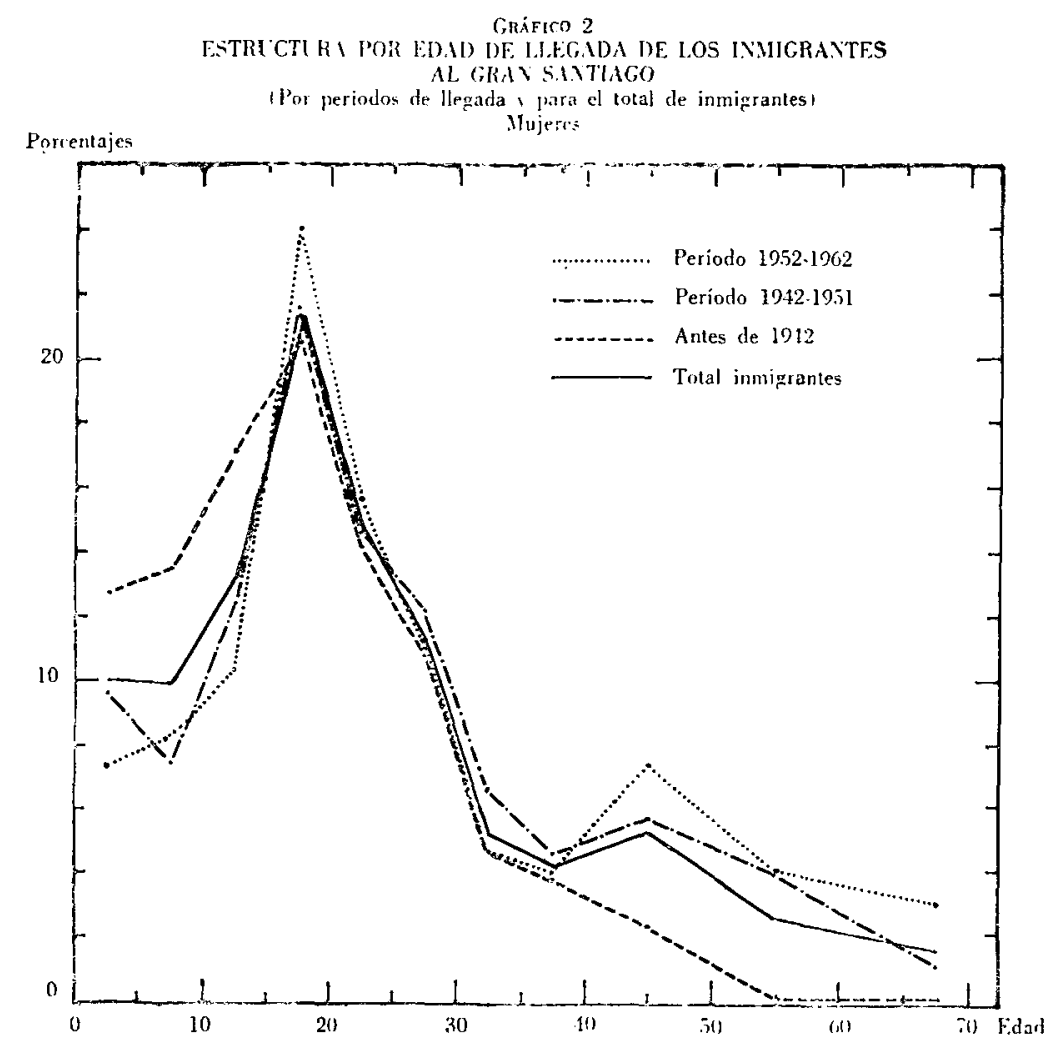

En el caso de las mujeres, las de 14, a 19 años representan el 32,8 por ciento de las inmigrantes con un solo movimiento, y las menores de 30 ar̃os, el 68,5 por ciento. De las inmigrantes con tres o más movimientos, las menores de 30 años sólo representan el 28,2 por ciento.

d) La estructura por edad también varía según los lugares de emigración, como se desprende de las cifras deì cuadro 9. El lugar de emigración ha sido clasificado para este análisis, atendiendo al tamaño de los núcleos de población, como sigue: 20000 y más habitantes, 5000 a 19999 habitantes, 900 a 4999 habitantes y zona rural. ${ }^{25}$

25 No se han tomado en consideración los inmigrantes llegados directamente desde el exterior. Estos casos, que constiiuyen un número pequeño, presentin una estructura por edad que se aparta bastante de la estructure de los inmigrantes del interior del país. 


\section{Cuadro 8}

INMIGRANTES SEGUN LA EDAD DE LLEGADA Y NUMERO

DE MOVIMIENTOS MIGRATORIOS, 1942-1962a

(Porcentajes)

\begin{tabular}{|c|c|c|c|c|c|c|}
\hline \multirow{2}{*}{$\begin{array}{c}\text { Sexo y grupos } \\
\text { de edades }\end{array}$} & \multicolumn{6}{|c|}{$\begin{array}{l}\text { Inmigrantes según el número de movimientos migratorios } \\
\text { incluyendo el último hacia el Gran Santiago }\end{array}$} \\
\hline & Total & Uno & Dos & Tres & $\begin{array}{l}\text { Cuatro } \\
\text { y más }\end{array}$ & $\begin{array}{l}\text { Descono- } \\
\text { cido }\end{array}$ \\
\hline \multicolumn{7}{|l|}{ Hombres } \\
\hline $14-19$ & 26,4 & 35,6 & 20,9 & 10,0 & 1,3 & - \\
\hline $20-29$ & 38,5 & 43,0 & 39,5 & 25,0 & 24,4 & - \\
\hline $30-39$ & 17,0 & 12,2 & 17,5 & 32,5 & 29,5 & - \\
\hline 40 y más & 18,1 & 9,2 & 22,1 & 32,5 & 44,8 & - \\
\hline 14 y más & 100,0 & 100,0 & 100,0 & 100,0 & 100,0 & $\rightarrow$ \\
\hline (Total de casos) & $(541)$ & (337) & $(86)$ & $(40)$ & $(78)$ & - \\
\hline \multicolumn{7}{|l|}{ Mujeres } \\
\hline $14-19$ & 32,8 & 43,0 & 16,2 & 3,8 & 5,6 & - \\
\hline $20-29$ & 35,7 & 37,5 & 41,6 & 26,9 & 19,7 & - \\
\hline $30-39$ & 13,4 & 9,5 & 16,9 & 23,1 & 29,6 & 一 \\
\hline 40 y más & 18,1 & 10,0 & 25,3 & 46,2 & 45,1 & - \\
\hline 14 y más & 100,0 & 100,0 & 100,0 & 100,0 & 100,0 & - \\
\hline (Total de casos) & $(946)$ & $(651)$ & $(142)$ & $(78)$ & (71) & (4) \\
\hline
\end{tabular}

a Inmigrantes llegados de más de 14 años de edad.

Por la causa explicada en el párrafo $b$ ), es aconsejable sacar conclusiones sobre la base de lo ocurrido en la última década. En este período, en general, el grupo de edades de mayor densidad es 15-19 años en las distintas categorías de lugares de salida. Sin embargo, esta característica y en general la concentración de inmigrantes en edades de 15 a 24, es más acusáda en la zona rural y en los pequeños núcleos de población, que en las localidades de 20000 y más habitantes.

Las cifras comentadas indicarían que los inmigrantes de lugares rurales y de pequeñas localidades, llegan en mayor proporción solos o con pocos niños, lo que podría atribuirse, al menos en parte, a que aquellos inmigrantes se movieron hacia el Gran Santiago a una edad media menor que los inmigrantes de las localidades importantes. Contribuye a elevar la edad media de estos últimos, su mayor movilidad previa. En efecto, aproximadamente la mitad (53,5 y 45,8 por ciento, respectivamente, hombres y mujeres) de los inmigrantes de núcleos de 
CUadro 9

INMIGRANTES, POR EDAD DE LLEGADA Y ZONA DE PROCEDENCIA, PERIODOS 1952-1962 Y 1951 Y AÑOS ANTERIORES (Porcentajes)

\begin{tabular}{|c|c|c|c|c|c|c|}
\hline \multirow[b]{2}{*}{$\begin{array}{l}\text { Sexo y edad } \\
\text { de llegada } \\
\text { (En grupos) }\end{array}$} & \multicolumn{3}{|c|}{$\begin{array}{l}\text { Período de } 1951 \\
\text { y años anteriores }\end{array}$} & \multicolumn{3}{|c|}{ Período $1952-1962$} \\
\hline & $\begin{array}{l}\text { Núcleos } \\
\text { de } \\
20000 \\
\text { y más } \\
\text { habi. } \\
\text { tantes }\end{array}$ & $\begin{array}{c}\text { Núcleos } \\
\text { de } \\
900 \\
\text { a } \\
19999 \\
\text { habi- } \\
\text { tantes }\end{array}$ & $\begin{array}{l}\text { Sectores } \\
\text { rurales }\end{array}$ & $\begin{array}{l}\text { Núcleos } \\
\text { de } \\
20000 \\
\text { y más } \\
\text { habi- } \\
\text { tantes }\end{array}$ & $\begin{array}{c}\text { Núcleos } \\
\text { de } \\
900 \\
\text { a } \\
19999 \\
\text { habi- } \\
\text { tantes }\end{array}$ & $\begin{array}{l}\text { Sectores } \\
\text { rurales }\end{array}$ \\
\hline \multicolumn{7}{|l|}{ Hombres } \\
\hline $0 \cdot 4$ & 17,9 & 10,4 & 10,9 & 13,0 & 11,1 & 4,0 \\
\hline $5-9$ & 16,5 & 13,6 & 8,4 & 11,3 & 8,1 & 8,0 \\
\hline $10 \cdot 14$ & 12,9 & 18,9 & 19,3 & 10,1 & 9,4 & 16,0 \\
\hline $15-19$ & 13,7 & 17,7 & 23,5 & 15,1 & 20,1 & 24,0 \\
\hline $20-24$ & 12,6 & 18,2 & 17,7 & 13,4 & 20,5 & 12,0 \\
\hline $25-29$ & 8,4 & 8,0 & 10,1 & 7,9 & 9,8 & 14,0 \\
\hline $30-34$ & 7,3 & 4,4 & 4,2 & 5,9 & 6,8 & - \\
\hline $35-39$ & 5,2 & 2,7 & 1,7 & 4,6 & 3,5 & 8,0 \\
\hline $40 \cdot 49$ & 3,9 & 3,1 & 4,2 & 12,1 & 6,0 & 6,0 \\
\hline $50 \cdot 59$ & 1,6 & 1,9 & - & 3,3 & 3,0 & 2,0 \\
\hline 60 y más & - & 1,2 & - & 3,3 & 1,7 & 6,0 \\
\hline $\begin{array}{l}\text { Total hombres } \\
\text { (Total de casos) }\end{array}$ & $\begin{array}{l}100,0 \\
(381)\end{array}$ & $\begin{array}{l}100,0 \\
(413)\end{array}$ & $\begin{array}{l}100,0 \\
(119)\end{array}$ & $\begin{array}{l}100,0 \\
(239)\end{array}$ & $\begin{array}{l}100,0 \\
(234)\end{array}$ & $\begin{array}{r}100,0 \\
(50)\end{array}$ \\
\hline \multicolumn{7}{|l|}{ Mujeres } \\
\hline $0 \cdot 4$ & 14,4 & 10,9 & 4,9 & 8,5 & 6,8 & 4,4 \\
\hline $5 \cdot 9$ & 11,1 & 11,5 & 9,8 & 9,4 & 6,8 & 8,9 \\
\hline $10-14$ & 11,8 & 16,6 & 20,7 & 8,8 & 11,4 & 12,2 \\
\hline $15 \cdot 19$ & 16,9 & 22,1 & 28,8 & 18,8 & 26,7 & 33,3 \\
\hline $20-24$ & 15,2 & 14,1 & 13,0 & 13,8 & 17,6 & 15,6 \\
\hline $25 \cdot 29$ & 13,6 & 9,7 & 10,3 & 12,4 & 10,0 & 10,0 \\
\hline $30-34$ & 5,8 & 4,9 & 6,0 & 7,4 & 3,1 & 1,1 \\
\hline 35.39 & 4,8 & 4,6 & 1,1 & 5,9 & 2,8 & 2,2 \\
\hline $40 \cdot 49$ & 4,1 & 3,2 & 4,3 & 8,8 & 7,1 & 3,3 \\
\hline $50-59$ & 1,5 & 1,9 & 1,1 & 3,8 & 4,3 & 4,5 \\
\hline 60 y más & 0,8 & 0,5 & - & 2,4 & 3,4 & 4,5 \\
\hline $\begin{array}{l}\text { Total mujeres } \\
\text { (Total de casos) }\end{array}$ & $\begin{array}{l}100,0 \\
(515)\end{array}$ & $\begin{array}{l}100,0 \\
(567)\end{array}$ & $\begin{array}{l}100,0 \\
(184)\end{array}$ & $\begin{array}{l}100,0 \\
(340)\end{array}$ & $\begin{array}{l}100,0 \\
(352)\end{array}$ & $\begin{array}{l}100,0 \\
(90)\end{array}$ \\
\hline
\end{tabular}

a Se excluyen los inmigrantes legados al Gran Santiago directamente de otros países y aquillos cuya zona de procedencia no se conoce, y otros cuya edad se desconoce. 
20000 y más habitantes realizaron uno o más movimientos previos. Tal proporción disminuye al pasar a núcleos menores y más aún en el área rural, siendo para esta última entre 25,0 y 20,9 por ciento, respectivamente, de hombres y mujeres.

\section{LUGAR DE EMIGRACIóN (ÚLTIMA RESIDENCIA)}

a) Los datos de los censos de población levantados en los últimos 30 años permiten estimar un importante movimiento migratorio ruralurbano en todos los países de América Latina. Es probable que tal corriente se produzca por etapas, primero, desde las zonas rurales o los núcleos urbanos de tamaño pequeño y mediano, y luego desde estos últimos hacia las grandes ciudades. Poco o nada se conoce de este proceso en cifras estadísticas. Sin embargo, en varias partes se ha comprobado que las tasas de crecimiento de la población de los núcleos relativamente grandes son elevadas, mientras que las de los pequeños y medianos corresponden al crecimiento natural, o a un ritmo ligeramente superior. Esto último hace pensar que estos núcleos cumplen la función de centros de paso en el movimiento migratorio interior. El crecimiento de los sectores rurales, en cambio, generalmente es inferior a la tasa de aumento natural y muchas veces está por debajo del uno por ciento anual, lo cual no deja dudas de que se trata de zonas de salida.

En el movimiento migratorio interior de un país es necesario distinguir entre el papel de una metrópoli como el Gran Santiago y el de las demás ciudades. Nadie podría esperar que la experiencia del Gran Santiago reflejara lo que ocurre en otras ciudades de Chile. La capital ejerce atracción sobre todas las regiones del país y sobre todas las clases sociales, mientras que las demás ciudades probablemente ejercen una atracción puramente regional. Partiendo de tales supuestos, interesa conocer la magnitud de la emigración de las diversas zonas hacia el Gran Santiago o, en otras palabras, cómo se distribuyen por zonas de procedencia los inmigrantes, sin preocuparnos por el momento de si éstos son oriundos o no de tales zonas.

Se podría formular la siguiente pregunta: ¿Qué importancia relativa tiene el número de inmigrantes que procede de los sectores rurales en relación al que procede de núcleos urbanos? En seguida, ¿esa importancia está acorde con la de la población rural del país? Es interesante medir la inmigración procedente de los sectores rurales (o de pequeños núcleos) para establecer la importancia de la población migrante que llega al Gran Santiago sin haber vivido en un medio urbano, hecho que se relaciona con las características de los inmigrantes y con sus problemas de adaptación. 
b) En esta sección se estudia el lugar de emigración considerando la clasificación mencionada en $1 d$ ): núcleos de más de 20000 habitantes, de 5 OCO a 19999 habitantes, de 900 a 4999 habitantes y zona rural. En el cuadro 10 se indica la distribución porcentual de los inmigrantes, ambos sexos, según esos lugares.

El 42,4 por ciento de los inmigrantes llegó de ciudades de más de 20000 habitantes y sólo el 12,7 por ciento directamente del medio rural. $\mathrm{Si}$ se aceptara, en términos generales, que los habitantes de núcleos de más de 5000 habitantes tienen experiencia de la vida urbana, el 68,0 por ciento de los inmigranies reuniría esa característica. Este último resul:ado tiene una gran significación al poner en evidencia que sólo una pequeña parte de la población inmigrante está formada por habitantes rurales.

c) Desde otro punto de vista, interesa conocer si el movimiento migratorio guarda relación numérica con la población del lugar de procedencia, o bien, si hay diferencias ciue indiquen intensidades diferenciales. A tal efecto, en el cuadro 10 se da la distribución relativa de la población de las mismas zonas según el censo de 1952, después de excluir la población del Gran Santiago. Se advierte de inmediato que la población de los núcleos de más de 20000 habitantes representa una proporción menor $(23,5$ por ciento) que la de los inmigrantes de esa procedencia. La columna 3 indica la relación entre tales porcentajes, que en este caso es 1,8. Por el contrario, mientras que la ruxal representa el 51,5 por ciento de la población de las zonas de emigrarión, de la zona rural sólo llegó el 12,7 por ciento de los inmigrantes. La proporción de inmigrantes respecto de la población es más alta $(2.9)$ cn los núcleos de 5000 a 19999 habitantes. Por consiguiente, puede afirmarse que la importancia relativa de la inmigración procedente de núcleos de más de 5000 habitantes es aproximadamente dos veces mayor que la de su propia población.

La distribución anotada corresponde a todos los inmigrantes sin distinción de edad de llegada y, por lo tanto, podría estar influida por la proporción de niños que figuran enire los inmigrantes procedentes de las diversas zonas. A este respecto hay algunas evidencias en cl sentido de que tal proporción varía de una zona a otra, como se dirá más adelante. Es útil, en consecuencia, verificar las cifras correspondientes a los inmigrantes adultos (en este caso mayores de 15 años de edad), cuya distribución por zonas en efecto es muy similar a la que se encontró en el conjunto de todos los inmigrantes. ${ }^{26}$ (Véase el cuadro 11.)

20 Los inmigrantes de 15 y más años representaban el 62,5 por ciento del total (excluyendo los llegados del exterior y los de edad ignorada). 
Cuadro 10

INMIGRANTES AL GRAN SANTIAGO POR LUGAR DE EMIGRACION, AMBOS SEXOS

\begin{tabular}{|c|c|c|c|}
\hline Lugar de emigración & $\begin{array}{c}\text { Inmigrantes } \\
\text { (Porcenta- } \\
\text { jes) }\end{array}$ & $\begin{array}{l}\text { Importancia relativa } \\
\text { de la población de } \\
\text { cada lugar de la po- } \\
\text { blación del país, ex- } \\
\text { cluida la del Gran } \\
\text { Santiagoa }\end{array}$ & $\begin{array}{l}\text { Relación } \\
\text { (1): (2) }\end{array}$ \\
\hline & (1) & (2) & (3) \\
\hline $\begin{array}{l}\text { Núcleos de } 20000 \text { y más habi- } \\
\text { tantes }\end{array}$ & 42,4 & 23,5 & 1,8 \\
\hline $\begin{array}{l}\text { Núcleos de } 5000 \text { a } 19999 \text { habi- } \\
\text { tantes }\end{array}$ & 25,6 & 8,8 & 2,9 \\
\hline $\begin{array}{l}\text { Núcleos de } 900 \text { a } 4999 \text { habi- } \\
\text { tantes }\end{array}$ & 19,3 & 16,2 & 1,2 \\
\hline Zona rural & 12,7 & 51,5 & 0,25 \\
\hline Total & $100,0^{\mathrm{b}}$ & 100,0 & 1,0 \\
\hline
\end{tabular}

a Estos porcentajes corresponden a la población censada en 1960. Las cifras relativas al sector rural y a los núcleos de 900 a 4,999 habitantes no corresponden exactamente a la definición seguida para clasificar a los inmigrantes de esos dos grupos, pero es muy aproximada. El porcentaje de población rural corresponde a la definición del censo de 1952. La población adjudicada al grupo de 900 a 4999 habitantes se obtuvo por diferencia entre el total y los restantes grupos. Como se dice en el encabezamiento, la población total $(=100)$ excluye a la del Gran Santiago.

b El total no incluye a los inmigrantes que llegaron al Gran Santiago directamente de otros países (4,6 por ciento), ni a los de procedencia desconocida (1,2 por ciento). El total de este cuadro representa el 94,2 por ciento de los inmigrantes encuestados.

Las distribuciones por lugar de emigración de cada sexo son prácticamente iguales en ambos, como se desprende de las cifras del citado cuadro 11.

d) Otro punto que interesa establecer es la evolución que experimenta la distribución de los inmigrantes según las zonas de procedencia. Las cifras anteriores expresan en realidad un promedio de las distintas épocas. Podría haber ocurrido un cambio sistemático en el sentido de que algunas zonas ganan importancia, mientras que otras la pierden. Para apreciar con exactitud este hecho habría que considerar al mismo tiempo, como se hizo en el párrafo anterior, la distribución relativa por zonas de la población del país, excluyendo la del Gran Santiago, en cada uno de los períodos que se considere. No obs- 
CuAdro 11

DISTRIBUCION POR ZONAS DE PROCEDENCIA DE LOS INMIGRANTES MAYORES DE 15 ANTOS DE EDADa

\begin{tabular}{lcccc}
\hline \multicolumn{1}{c}{ Zonas de procedencia } & Hombres & Mujeres & Ambos sexos \\
\hline & & \multicolumn{3}{c}{ (Porcentajes) } \\
Núcleos de 20000 y más habitantes & 41,1 & 41,9 & 41,6 \\
Núcleos de 5000 a 19999 habitantes & 27,2 & 26,0 & 26,5 \\
Núcleos de 900 a 4999 habitantes & 19,1 & 18,5 & 18,7 \\
Sectores rurales & 12,5 & 13,6 & 13,2 \\
\cline { 2 - 5 } Total & 100,0 & 100,0 & 100,0 \\
\hline
\end{tabular}

a Se excluyen los inmigrantes procedentes de otros paises y los de edad desconocida.

tante, la falta de estadísticas censales adecuadas dificulta mucho esta clase de comparaciones.

En el cuadro 12 se indica la distribución de los inmigrantes, por lugares de emigración, en distintos períodos. ${ }^{27}$

En realidad, no se observan cambios sustanciales y en algunas zonas la tendencia no es bien definida. No obstante, del conjunto de las cifras podría deducirse la tendencia al aumento de la importancia relativa de los inmigrantes de los núcleos de más de 20000 habitantes, y a la disminución de la importancia de la inmigración procedente de los sectores rurales. Las zonas intermedias conservan en conjunto casi la misma importancia, con algunas variaciones en cada una de ellas. Sin embargo, por la disminución de la importancia relativa de la po* blación rural del país, la afluencia de emigrantes de los sectores campesinos hacia el Gran Santiago podría haber conservado su importancia, si es que no la ha aumentado. Pero la conclusión más general es que hubo pocos cambios con el transcurso del tiempo.

e) En el párrafo $c$ ) se vio que la distribución por zonas de los inmigrantes, independientemente de la edad de llegada, es muy similar a la de los inmigrantes de 15 o más años de edad. A pesar de esa analogía, hay notorias diferencias en la distribución por zonas cuando se consideran intervalos de edad más pequeños, por ejemplo, grupos quinquenales.

Esta última información aparece en el cuadro 13 y se la ha repre.

27 La inclusión en este cuadro de los inmigrantes llegados al Gran Santiago directamente de otros países no afecta la comparación, ya que estos casos representan un pequeño porcentaje más o menos constante. Tampoco afecta la comparación, la inclusión de los casos de procedencia ignorada, los que carecen de im. portancia numéricamente. 
Cuadro 12

INMIGRANTES POR LUGAR DE EMIGRACION, EN DISTINTOS PERIODOS DE LLEGADA ${ }^{a}$

\begin{tabular}{|c|c|c|c|c|c|}
\hline Lugar de emigración & $\begin{array}{l}\text { Todos } \\
\text { los } \\
\text { períodos }\end{array}$ & $\begin{array}{l}1957- \\
1962\end{array}$ & $\begin{array}{l}1952- \\
1962\end{array}$ & $\begin{array}{l}1942- \\
1951\end{array}$ & $\begin{array}{c}1941 \text { y } \\
\text { antes }\end{array}$ \\
\hline \multicolumn{6}{|l|}{ Hombres } \\
\hline $\begin{array}{l}\text { Núcleos de } 20000 \text { y } \\
\text { más habitantes } \\
\text { Núcleos de } 5000 \text { a }\end{array}$ & 40,2 & 45,2 & 43,3 & 35,6 & 40,1 \\
\hline $\begin{array}{l}19999 \text { habitantes } \\
\text { Núcleos de } 900 \text { a }\end{array}$ & 24,8 & 21,8 & 22,1 & 28,8 & 24,9 \\
\hline 4,999 habitantes & 17,0 & 20,5 & 20,3 & 17,0 & 14,1 \\
\hline Sectores rurales & 10,9 & 8,0 & 9,1 & 12,1 & 11,8 \\
\hline Otros paises & 5,9 & 4,5 & 5,2 & 6,2 & 6,2 \\
\hline Sin información & 1,2 & - & - & 0,3 & 2,9 \\
\hline $\begin{array}{l}\text { Todas las zonas } \\
\text { (Número de perso. } \\
\text { nas) }\end{array}$ & $\begin{array}{r}100,0 \\
(1549)\end{array}$ & $\begin{array}{l}100,0 \\
(312)\end{array}$ & $\begin{array}{l}100,0 \\
(552)\end{array}$ & $\begin{array}{l}100,0 \\
(371)\end{array}$ & $\begin{array}{l}100,0 \\
(626)\end{array}$ \\
\hline \multicolumn{6}{|l|}{ Mujeres } \\
\hline $\begin{array}{l}\text { Núcleos de } 20000 \text { y } \\
\text { más habitantes } \\
\text { Núcleos de } 5000 \text { a }\end{array}$ & 39,8 & 40,4 & 42,0 & 37,3 & 39,2 \\
\hline $\begin{array}{l}19999 \text { habitantes } \\
\text { Núcleos de } 900 \text { a }\end{array}$ & 23,7 & 28,1 & 22,2 & 27,2 & 22,8 \\
\hline 4,999 habitantes & 19,0 & 19,1 & 21,2 & 17,0 & 18,2 \\
\hline Sectores rurales & 12,8 & 9,0 & 11,1 & 15,1 & 13,0 \\
\hline Otros países & 3,6 & 2,8 & 3,0 & 3,1 & 4,6 \\
\hline Sin información & 1,1 & 0,6 & 0,5 & 0,4 & 2,2 \\
\hline $\begin{array}{l}\text { Todas las zonas } \\
\text { (Número de perso- } \\
\text { nas) }\end{array}$ & $\begin{array}{r}100,0 \\
(2152)\end{array}$ & $\begin{array}{l}100,0 \\
(466)\end{array}$ & $\begin{array}{l}100,0 \\
(810)\end{array}$ & $\begin{array}{l}100,0 \\
(518)\end{array}$ & $\begin{array}{l}100,0 \\
(824)\end{array}$ \\
\hline
\end{tabular}

a Inmigrantes llegados a cualquier edad.

sentado en el gráfico 3. En las primeras edades, especialmente en los grupos 0-4 y 5-9, es visible la más alta proporción de inmigrantes procedentes de los núcleos de más de 20000 habitantes, lo cual apoya comentarios anteriores. En el grupo de 0-4 años, dichas proporciones alcanzan a 52,1 y 48,1 por ciento en varones y mujeres, respectivamente; en los inmigrantes de 5-9 años, siguen siendo elevadas: 4,6,6 
DISTRIBLCION DE LOS INMIGRAYTES POR ZONAS DE EMIGRACION
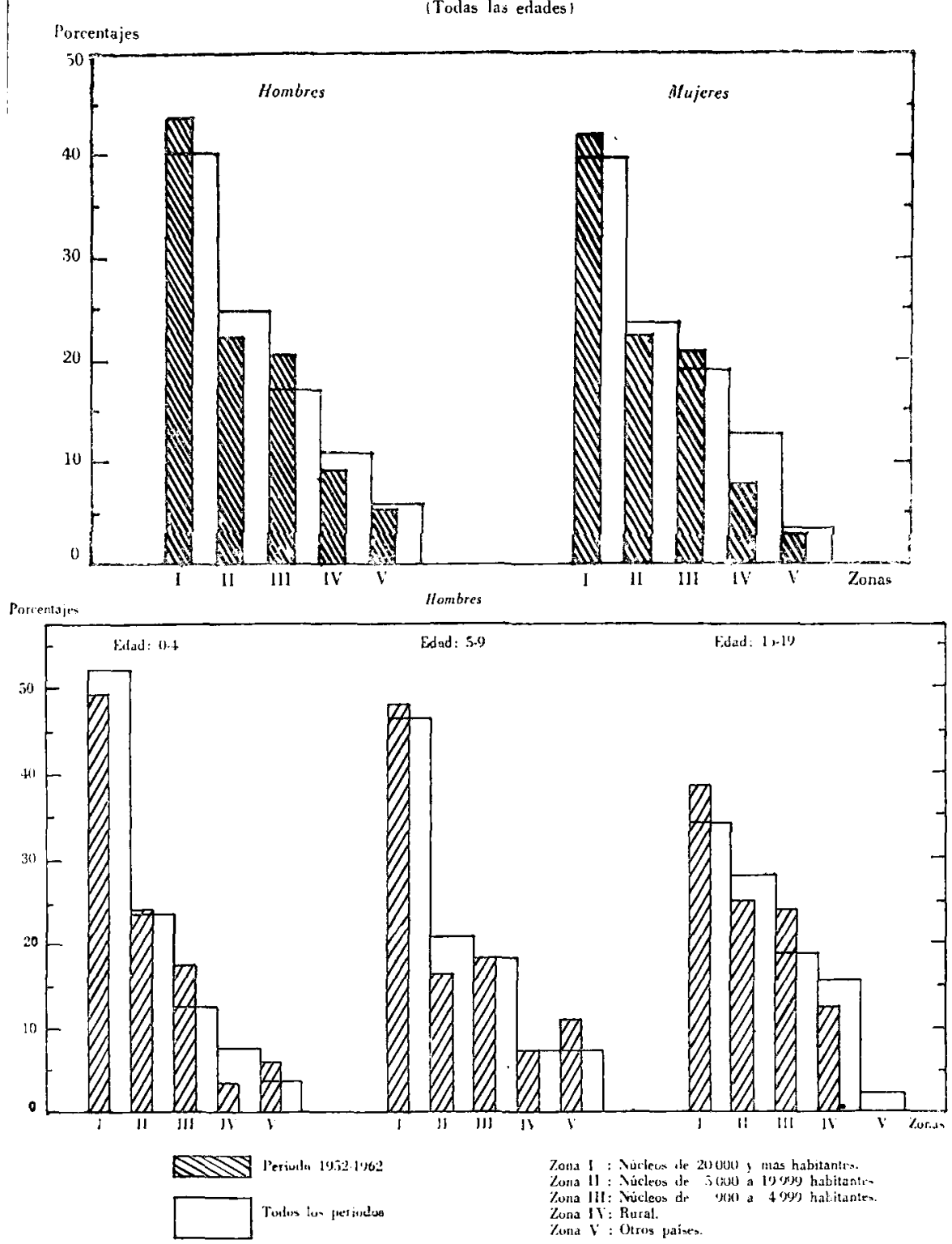
Grífico 3 (contimuación)
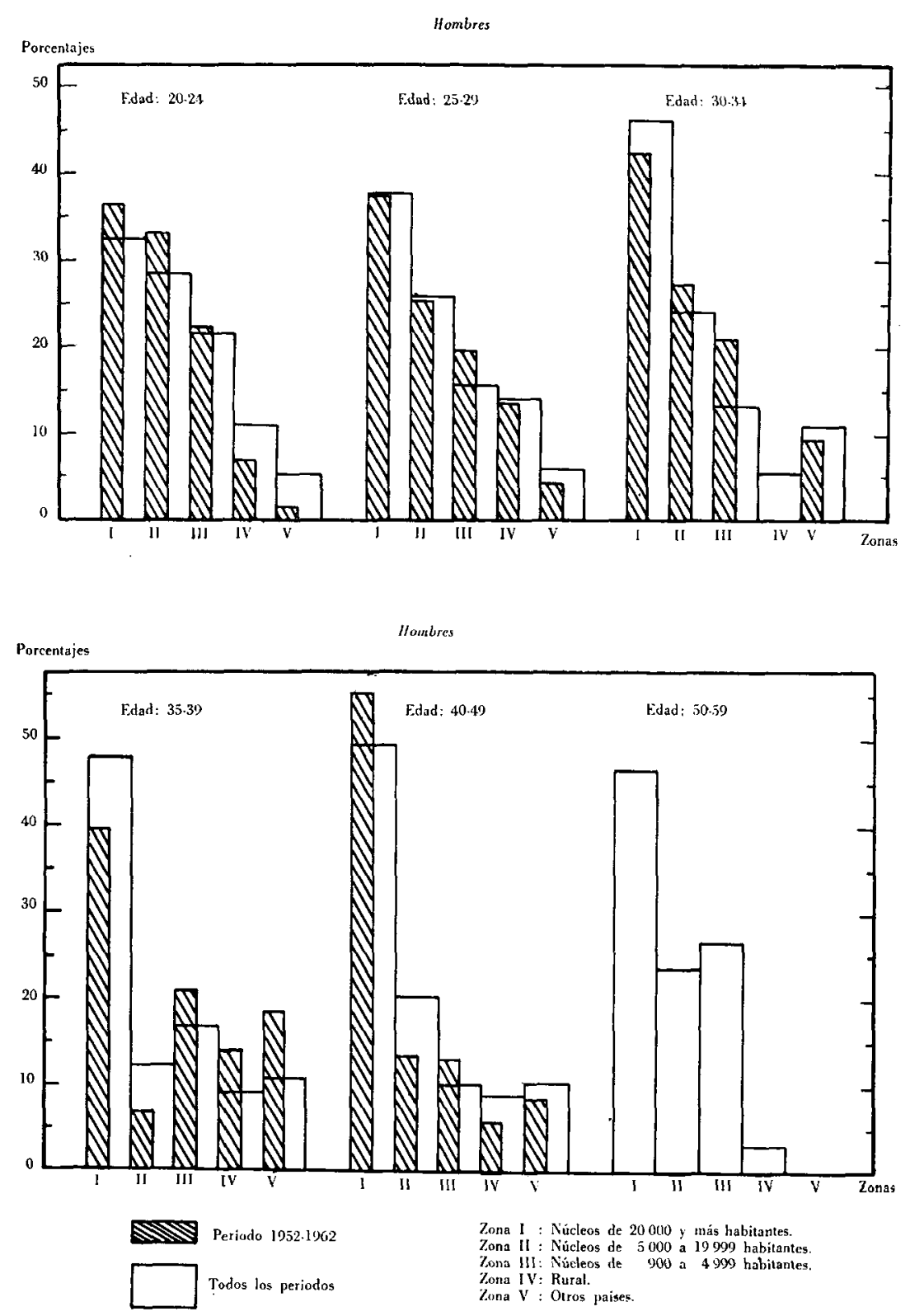
y 41,8 por ciento en uno y otro sexo. Esta situación cambia al avanzar la edad, de tal modo que, por ejemplo, en el grupo 15-19, en el caso de las mujeres, y en el grupo 20-24, en el de los hombres, la distribución por zonas es más pareja. Como la mayor proporción de inmigrantes pertenece a estas últimas edades, es oportuno presentar aquí las cifras:

\begin{tabular}{lcc}
\hline \multicolumn{1}{c}{ Zonas de procedencia } & $\begin{array}{c}\text { Hombres } \\
\text { (edad 20-24) }\end{array}$ & $\begin{array}{c}\text { Mujeres } \\
\text { (edad 15-19) }\end{array}$ \\
\hline Núcleos de 20000 y más habitantes & 32,7 & (Porcentajes) \\
Núcleos de 5000 a 19999 habitantes & 28,6 & 32,7 \\
Núcleos de 900 a 4999 habitantes & 21,6 & 27,3 \\
Sectores rurales & 11,0 & 20,1 \\
Otros países & 5,3 & 18,0 \\
Sin información & 0,8 & 1,7 \\
Total & 100,0 & 0,2 \\
(Número de personas) & $(245)$ & 100,0 \\
\end{tabular}

Al avanzar la edad, después de los 30 años y hasta por lo menos los 50, vuelve a producirse un creciente predominio de la inmigración procedente de los núcleos más grandes.

He aquí la distribución relativa de los inmigrantes del sexo masculino en algunas edades que presentan evidentes discrepancias:

\begin{tabular}{lrrrrr}
\hline \multirow{2}{*}{ Lugar de emigración } & \multicolumn{5}{c}{ Edad de llegada } \\
\cline { 2 - 6 } & $0-4$ & $5-9$ & $20-24$ & $25-29$ & $40-49$ \\
\hline & \multicolumn{5}{c}{ (Porcentajes) } \\
Núcleos de 20 000 y más habitantes & 52,1 & 46,6 & 32,7 & 37,8 & 49,5 \\
Núcleos de 5 000 a 19999 habitantes & 23,7 & 20,7 & 28,6 & 25,9 & 20,2 \\
Núcleos de 900 a 4.999 habitantes & 12,6 & 18,1 & 21,6 & 15,6 & 10,1 \\
Sector rural & 7,9 & 7,3 & 11,0 & 14,1 & 9,0 \\
Otros países & 3,7 & 7,3 & 5,3 & 5,9 & 11,2 \\
Sin información & - & - & 0,8 & 0,7 & - \\
Total & 100,0 & 100,0 & 100,0 & 100,0 & 100,0 \\
(Número de personas) & $(190)$ & $(193)$ & $(245)$ & $(135)$ & $(89)$ \\
\hline
\end{tabular}


JUAN C. ELIZAGA

Cuadro 13

INMIGRANTES POR SEXO Y EDAD, SEGUN LAS ZONAS DE EMIGRACION, LLEGADOS EN CUALQUIER TIEMPO

\begin{tabular}{|c|c|c|c|c|c|c|c|}
\hline \multirow[b]{2}{*}{$\begin{array}{c}\text { Sexo } \\
\text { y grupos } \\
\text { de } \\
\text { edades }\end{array}$} & \multirow[b]{2}{*}{$\begin{array}{l}\text { Total } \\
\text { de } \\
\text { inmigran- } \\
\text { tes } \\
\text { (número } \\
\text { de } \\
\text { personas) }\end{array}$} & \multicolumn{6}{|c|}{ Zonas de emigración } \\
\hline & & $\begin{array}{c}\text { Núcleos } \\
\text { de } \\
\text { más } \\
\text { de } \\
20000 \\
\text { habi- } \\
\text { tantes }\end{array}$ & $\begin{array}{c}\text { Núcleos } \\
\text { de } \\
5000 \\
\text { a } \\
19999 \\
\text { habi- } \\
\text { tantes }\end{array}$ & $\begin{array}{c}\text { Núcleos } \\
\text { de } \\
900 \\
\text { a } \\
4999 \\
\text { habi- } \\
\text { tantes }\end{array}$ & Rural & $\begin{array}{c}\text { Otros } \\
\text { países }\end{array}$ & $\begin{array}{l}\text { Des- } \\
\text { cono- } \\
\text { cida }\end{array}$ \\
\hline & & \multicolumn{6}{|c|}{ (Porcentajes) } \\
\hline Hombres & 1549 & 40,2 & 24,9 & 16,9 & 10,9 & 5,9 & 1,2 \\
\hline $0-4$ & 190 & 52,1 & 23,7 & 12,6 & 7,9 & 3,7 & - \\
\hline $5 \cdot 9$ & 193 & 46,6 & 20,7 & 18,1 & 7,3 & 7,3 & - \\
\hline $10-14$ & 220 & 33,2 & 28,2 & 17,3 & 14,1 & 6,8 & 0,4 \\
\hline $15-19$ & 257 & 34,2 & 28,0 & 18,7 & 15,6 & 2,3 & 1,2 \\
\hline $20-24$ & 245 & 32,7 & 28,6 & 21,6 & 11,0 & 5,3 & 0,8 \\
\hline $25-29$ & 135 & 37,8 & 25,9 & 15,6 & 14,1 & 5,9 & 0,7 \\
\hline $30-34$ & 91 & 46,1 & 24,2 & 13,2 & 5,5 & 11,0 & - \\
\hline $35-39$ & 65 & 47,7 & 12,3 & 16,9 & 9,2 & 10,8 & 3,1 \\
\hline $40 \cdot 49$ & 89 & 49,5 & 20,2 & 10,1 & 9,0 & 11,2 & - \\
\hline $50-59$ & 30 & 46,7 & 23,3 & 26,7 & 3,3 & - & - \\
\hline 60 y más & 21 & 38,1 & 23,8 & 19,0 & 14,3 & 4,8 & - \\
\hline Desconocida & 13 & 15,4 & 7,7 & - & - & 76,9 & - \\
\hline Mujeres & 2152 & 39,8 & 23,7 & 19,0 & 12,8 & 3,6 & 1,1 \\
\hline $0-4$ & 214 & 48,1 & 21,5 & 18,7 & 6,1 & 4,7 & 0,9 \\
\hline $5-9$ & 213 & 41,8 & 18,8 & 23,0 & 12,2 & 3,7 & 0,5 \\
\hline $10-14$ & 282 & 32,3 & 23,8 & 23,7 & 17,4 & 2,5 & 0,3 \\
\hline $15-19$ & 462 & 32,7 & 27,3 & 20,1 & 18,0 & 1,7 & 0,2 \\
\hline $20-24$ & 317 & 39,4 & 26,8 & 18,0 & 12,0 & 3,5 & 0,3 \\
\hline $25-29$ & 240 & 46,7 & 21,7 & 15,8 & 11,7 & 3,3 & 0,8 \\
\hline $30-34$ & 112 & 49,1 & 25,9 & 8,9 & 10,7 & 5,4 & - \\
\hline $35-39$ & 91 & 49,4 & 20,9 & 18,7 & 4,4 & 6,6 & - \\
\hline $40-49$ & 115 & 41,4 & 22,6 & 14,8 & 9,6 & 6,9 & 1,7 \\
\hline $50-59$ & 55 & 38,2 & 23,7 & 23,6 & 10,9 & 1,8 & 1,8 \\
\hline 60 y más & 35 & 34,3 & 17,2 & 25,7 & 11,4 & 11,4 & - \\
\hline Desconocida & 16 & 2,9 & 一 & - & 2,9 & 2,9 & 81,3 \\
\hline
\end{tabular}


La distribución de las inmigrantes por zonas se asemeja a la que acaba de darse para los hombres.

Estos resultados indican que del sector rural y de los pequeños pueblos llegan proporcionalmente menos niños y personas de edad adulta relativamente avanzada ( 30 a 50 años) que personas de edad adulta joven (15 a 29 años). En efecto, como se desprende del cuadro 13, el 75,8 por ciento de los inmigrantes llegados antes de cumplir 5 años de edad procede de núcleos de más de 5000 habitantes, correspondiendo por lo menos dos tercios de ellos a ciudades de más de 20000 habitantes. De los inmigrantes de 20 a 24 años, una proporción importante (21,6 por ciento) viene de núcleos de 900 a 4.999 habitantes, y otra un poco mayor (28,6 por ciento), de núcleos de 5000 a 19999 habitantes. 0 sea, ambas zonas en conjunto contribuyen con el 50 por ciento de los inmigrantes de 20 a 24 años. En otros términos, ello significa que esas dos zonas son las que soportan, relativamente, la salida más alta de emigrantes en edades adultas jóvenes. En las edades más avanzadas, como acontece en el grupo 40 a 49 años, nuevamente gana importancia la inmigración procedente de los núcleos de más de 20000 habitantes, y la pierde la que se origina en los sectores rurales y en los núcleos pequeños.

No obstante, por ser el número observado de inmigrantes de estas edades muy pequeño, no se podrían extraer conclusiones seguras.

\section{LUGar dE NACIMIENTO Y DE EMigractóN}

a) En la sección precedente se puso de manifiesto que una elevada proporción de personas llegó al Gran Santiago en su primer movimiento migratorio (de los realizados después de cumplir 14 años de edad), y que este hecho es más acentuado en los inmigrantes procedentes de los sectores rurales y de las aglomeraciones pequeñas. Ello mueve a pensar que la población que emigró al Gran Santiago tuvo en general poca movilidad geográfica previa. En esta sección se investiga la relación entre el lugar de emigración y el de nacimiento. ${ }^{28}$

b) Las regiones de emigración se clasificaron siguiendo la agrupación de provincias que da la Corporación de Fomento de la Producción (CORFO) en su Geografía Económica de Chile. La distribución relativa de los inmigranies según regiones de emigración aparece en el cuadro 14. En general, han proporcionado un aporte importante y bastante uniforme todas las regiones del país, con la excepción de las provincias del Norte Grande y del Norte Chico (regiones I y II), y sobre todo del extremo sur (regiones VIII y IX).

28 La moviilidad geográfica de los inmigrantes se analiza en detalle en el capitulo II. 
Cuadro 14

INMIGRANTES SEGUN LA REGION DE EMIGRACION

\begin{tabular}{|c|c|c|c|c|}
\hline \multirow{2}{*}{ Región de emigración } & \multicolumn{2}{|c|}{ Todos los períodos } & \multicolumn{2}{|c|}{ Período 1952-1962 } \\
\hline & Hombres & Mujeres & Hombres & Mujeres \\
\hline & \multicolumn{4}{|c|}{ (Porcentajes) } \\
\hline $\begin{array}{l}\text { Región I (Tarapacá, Antofagas- } \\
\text { ta) a }\end{array}$ & 9,0 & 6,6 & 8,4 & 6,3 \\
\hline $\begin{array}{l}\text { Región II (Atacama, Coquim- } \\
\text { bo) }\end{array}$ & 6,0 & 5,6 & 5,6 & 5,9 \\
\hline $\begin{array}{l}\text { Región III (Aconcagua, Valpa- } \\
\text { raíso) }\end{array}$ & 15,8 & 13,7 & 14,6 & 14,6 \\
\hline $\begin{array}{l}\text { Región IV (Santiago, O'Hig- } \\
\text { gins, Colchagua) }\end{array}$ & 22,1 & 24,8 & 18,0 & 18,7 \\
\hline $\begin{array}{l}\text { Región } V \text { (Curicó, Talca, Li- } \\
\text { nares, Maule) }\end{array}$ & 14,5 & 16,5 & 15,3 & 13,9 \\
\hline $\begin{array}{l}\text { Región VI (Concepción, Nuble, } \\
\text { Arauco, Bío-Bío, Malleco) }\end{array}$ & 19,2 & 19,0 & 19,0 & 21,7 \\
\hline $\begin{array}{l}\text { Región VII (Cautin, Valdivia, } \\
\text { Osorno, Llanquihue, Chiloé) } \\
\text { Regiones VIII y IX (Aysén y }\end{array}$ & 12,7 & 13,2 & 17,8 & 18,0 \\
\hline Magallanes) & 0,7 & 0,6 & 1,3 & 0,9 \\
\hline $\begin{array}{l}\text { Todas las regiones } \\
\text { (Número de personas) b }\end{array}$ & $\begin{array}{l}100,0 \\
(144.1)\end{array}$ & $\begin{array}{c}100,0 \\
(2053)\end{array}$ & $\begin{array}{l}100,0 \\
(522)\end{array}$ & $\begin{array}{l}100,0 \\
(776)\end{array}$ \\
\hline
\end{tabular}

a Entre paréntesis se indican las provincias que componen cada región.

b Excluidos los inmigrantes llegados al Gran Santiago de otros países (91 hombres y 78 mujeres) y los inmigrantes cuya región de procedencia se desconoce (17 hombres y 21 mujeres).

Quizás habría que destacar la región IV, constituida por las provincias de Santiago (con exclusión del Gran Santiago), O'Higgins y Colchagua, desde las cuales ha llegado el 22,1 por ciento de los inmigrantes y el 24,8 por ciento de las inmigrantes; y la región VI (Concepción, Arauco, Bío-Bio, Ñuble y Malleco), que ha proporcionado el 19,2 y el 19,0 por ciento de inmigrantes hombres y mujeres, respectivamente. Es interesante señalar que en el periodo 1952-1962, la situación no es muy diferente, aunque se destaca la disminución relativa de la inmigración de la región IV y el aumento de la inmigración de la VI.

c) Comparando la región de emigración con la región de nacimiento de los inmigrantes, se encuentra que el 82,0 . por ciento de los 
hombres y el 84,8 por ciento de las mujeres llegaron de su región de nacimiento. De los inmigrantes que venían de un sector rural (zona rural y núcleos de 900 a 4.999 habitanies), la proporción es más alta iodavía: 89,2 y 91,4 por ciento para hombres y mujeres respectivamente.

Si la zona de procedencia es urbana (núcleos de 5000 y más habitantes), la proporción que llega de su misma región de nacimiento es un poco más baja que el promedio general: 78,9 por ciento en el caso de los hombres y 81,5 en el caso de las mujeres. (Véase el cuadro 15.)

Cuapro 15

INMIIGRANTES PROCEDENTES DE LA REGION DE NACIMIENTO RESPECTIVA ${ }^{\mathrm{a}}$

\begin{tabular}{|c|c|c|c|c|}
\hline \multirow[b]{2}{*}{$\begin{array}{l}\text { Lugar urbano o rural } \\
\text { de emigración } \\
\text { y períodos de llegadab }\end{array}$} & \multicolumn{2}{|c|}{ Hombres } & \multicolumn{2}{|c|}{ Mujeres } \\
\hline & $\begin{array}{l}\text { Número } \\
\text { de inmi- } \\
\text { grantese }\end{array}$ & $\begin{array}{l}\text { Porcen- } \\
\text { taje } \\
\text { nacido } \\
\text { en la } \\
\text { región } \\
\text { de emi- } \\
\text { gración }\end{array}$ & $\begin{array}{l}\text { Número } \\
\text { de inmi- } \\
\text { grantesc }\end{array}$ & $\begin{array}{c}\text { Porcen- } \\
\text { taje } \\
\text { nacido } \\
\text { en la } \\
\text { región } \\
\text { de emi- } \\
\text { gración }\end{array}$ \\
\hline \multicolumn{5}{|l|}{ Total urbano-rural } \\
\hline $\begin{array}{l}\text { Todos los períodos } \\
1952-1962 \\
1951 \text { y años anteriores }\end{array}$ & $\begin{array}{l}1441^{\mathrm{d}} \\
522 \\
919\end{array}$ & $\begin{array}{l}82,0 \\
79,7 \\
83,4\end{array}$ & $\begin{array}{l}2053^{\mathrm{d}} \\
776 \\
1277\end{array}$ & $\begin{array}{l}84,8 \\
83,4 \\
85,7\end{array}$ \\
\hline \multicolumn{5}{|l|}{ Procedencia urbana } \\
\hline $\begin{array}{l}\text { Todos los períodos } \\
\text { 1952-1962 } \\
1951 \text { y años anteriores }\end{array}$ & $\begin{array}{r}1006 \\
360 \\
646\end{array}$ & $\begin{array}{l}78,9 \\
77,8 \\
79,6\end{array}$ & $\begin{array}{r}1365 \\
517 \\
848\end{array}$ & $\begin{array}{l}81,5 \\
79,5 \\
82,7\end{array}$ \\
\hline \multicolumn{5}{|l|}{ Procedencia rural } \\
\hline $\begin{array}{l}\text { Todos los períodos } \\
1952-1962 \\
1951 \text { y años anteriores }\end{array}$ & $\begin{array}{l}435 \\
162 \\
273\end{array}$ & $\begin{array}{l}89,2 \\
84,0 \\
92,3\end{array}$ & $\begin{array}{l}688 \\
259 \\
429\end{array}$ & $\begin{array}{l}91,4 \\
91,1 \\
91,6\end{array}$ \\
\hline
\end{tabular}

a Agrujación provincial de la confo. (Véase el cuadro 14.)

b A los fines de este cuadro, la zona urbana comprende los núcleos de 5000 y más habitantes, y la rural, la población restante.

: Se excluyen los inmigrantes llegados de otros paises y aquéllos cuya procedencia sc desconoce. (Véase el cuadro 14.)

1. Excluidos los inmigrantes llegados al Gran Santiago de otros paises (91 hombres y 78 mujeres) y los inmigrantes cuya región de procedencia se desconoce (17 hombres y 21 mujeres). 
Los resultados del cuadro 15 confirman el hecho ya anotado de que muchos de los inmigrantes al Gran Santiago no han tenido una movilidad inter-regional previa. Esto es aun más cierto en los inmigrantes procedentes de sectores rurales, como podría haberse esperado. De cualquier modo, aun entre los inmigrantes procedentes de una zona urbana, la proporción aludida se eleva a casi el 80 por ciento de los casos. El comportamiento de los inmigrantes por sexo es muy similar.

Analizando este aspecto según la época de inmigración (antes de 1952 y en la última década), tampoco se advierten cambios importantes. La tendencia parece ser más bien un descenso del porcentaje de los inmigrantes que llegan de la misma región de nacimiento. (Véase el cua. dro 15.) En el cuadro 16 se dan en detalle estas mismas cifras siguiendo la agrupación provincial de la coRfo. Por lo menos en las regiones de donde llegó la mayor parte de los inmigrantes, existe una marcada regularidad en cuanto al comportamiento señalado.

d) Teniendo como antecedente los resultados encontrados en la sección 2, puede esperarse una correspondencia más estrecha entre la zona de procedencia y la zona de nacimiento en los inmigrantes llegados en edades adultas jóvenes que en los de edad más avanzada. (Véase el cuadro 17.) Los datos de este cuadro, que se refieren al período 19521962, presentan algunas limitaciones. Una de ellas es el número relativamente pequeño de casos que corresponde a algunas zonas; ${ }^{29}$ pero la más seria reside en el hecho de que las clasificaciones por zona de nacimiento y zona de procedencia no son cruzadas, pues los datos provienen de dos cuadros independientes.

Como podrá apreciarse en el citado cuadro, el número de inmigrantes procedentes de los núcleos de más de 20000 habitantes excede al número de inmigrantes nacidos en esta zona. La relación entre estos últimos y los primeros es de 86,6 por ciento en los hombres de 15 a 29 años (edad de llegada) y de 79,1 por ciento en las mujeres de la misma edad. Tomando todas las edades, las proporciones como era de suponer, son más bajas: 86,6 y 76,3 por ciento, respectivamente.

Respecto de los núcleos de 5000 a 19999 y de 900 a 4999 habitantes, las cifras, cercanas al 100 por ciento, indican una igualdad en el número de nacidos y procedentes de cada uno de ellos, en el caso de los hombres. En cuanto a los sectores rurales, el número de nacidos en ellos excede en 20,30 ó más por ciento a los inmigrantes que llegan de los mismos; comportamiento que también se advierte entre las mujeres procedentes de núcleos pequeños (900 a 4999 habitantes).

29 Véanse las notas $d$ y $e$ del cuadro 17. 
LA CORRIENTE HAGIA EL GRAN SANTIAGO

CuAnro 16

INMIGRANTES PROCEDENTES DE SU REGION DE NACIMIENTO

\begin{tabular}{|c|c|c|c|c|}
\hline \multirow[b]{2}{*}{$\begin{array}{l}\text { Región de emigración } \\
\text { y período de llegada }\end{array}$} & \multicolumn{2}{|c|}{ Hombres } & \multicolumn{2}{|c|}{ Mujeres } \\
\hline & $\begin{array}{l}\text { Número } \\
\text { de inmi- } \\
\text { grantes }^{b}\end{array}$ & $\begin{array}{l}\text { Porcentaje } \\
\text { nacido en } \\
\text { la region } \\
\text { de emi- } \\
\text { gración }\end{array}$ & $\begin{array}{l}\text { Número } \\
\text { de inmi- } \\
\text { grantes }\end{array}$ & $\begin{array}{l}\text { Porcentaje } \\
\text { nacido en } \\
\text { la región } \\
\text { de emi- } \\
\text { gración }\end{array}$ \\
\hline \multicolumn{5}{|l|}{ Región I } \\
\hline $\begin{array}{l}\text { Todos los períodos } \\
\text { 1952-1962 } \\
1951 \text { y años anteriores }\end{array}$ & $\begin{array}{r}130 \\
44 \\
86\end{array}$ & $\begin{array}{l}70,8 \\
77,3 \\
67,4\end{array}$ & $\begin{array}{r}136 \\
49 \\
87\end{array}$ & $\begin{array}{l}70,6 \\
75,5 \\
67,8\end{array}$ \\
\hline \multicolumn{5}{|l|}{ Región II } \\
\hline $\begin{array}{l}\text { Todos los períodos } \\
1952-1962 \\
1951 \text { y años anteriores } \\
\text { Reción III }\end{array}$ & $\begin{array}{l}87 \\
29 \\
58\end{array}$ & $\begin{array}{l}82,8 \\
82,8 \\
82,8\end{array}$ & $\begin{array}{r}114 \\
46 \\
68\end{array}$ & $\begin{array}{l}81,6 \\
82,6 \\
80,9\end{array}$ \\
\hline $\begin{array}{l}\text { Todos los periodos } \\
1952-1962 \\
1951 \text { y años anteriores }\end{array}$ & $\begin{array}{r}227 \\
76 \\
151\end{array}$ & $\begin{array}{l}75,3 \\
69,7 \\
78,1\end{array}$ & $\begin{array}{l}281 \\
113 \\
168\end{array}$ & $\begin{array}{l}73,7 \\
69,9 \\
76,2\end{array}$ \\
\hline \multicolumn{5}{|l|}{ Región IV } \\
\hline $\begin{array}{l}\text { Todos los períodos } \\
1952-1962 \\
1951 \text { y años anteriores } \\
\text { Región } V\end{array}$ & $\begin{array}{r}319 \\
94 \\
225\end{array}$ & $\begin{array}{l}87,8 \\
77,7 \\
92,0\end{array}$ & $\begin{array}{l}510 \\
145 \\
365\end{array}$ & $\begin{array}{l}89,2 \\
87,6 \\
89,9\end{array}$ \\
\hline $\begin{array}{l}\text { Todos los periodos } \\
1952.1962 \\
1951 \text { y años anteriores }\end{array}$ & $\begin{array}{r}209 \\
80 \\
129\end{array}$ & $\begin{array}{l}83,7 \\
77,5 \\
87,6\end{array}$ & $\begin{array}{l}339 \\
108 \\
231\end{array}$ & $\begin{array}{l}86,4 \\
79,6 \\
89,6\end{array}$ \\
\hline \multicolumn{5}{|l|}{ Región VI } \\
\hline $\begin{array}{l}\text { Todos los períodos } \\
1952-1962 \\
1951 \text { y años anteriores }\end{array}$ & $\begin{array}{r}276 \\
99 \\
177\end{array}$ & $\begin{array}{l}85,1 \\
86,9 \\
84,2\end{array}$ & $\begin{array}{l}391 \\
168 \\
223\end{array}$ & $\begin{array}{l}90,8 \\
90,5 \\
91,0\end{array}$ \\
\hline \multicolumn{5}{|l|}{ Región VII } \\
\hline $\begin{array}{l}\text { Todos Ios períodos } \\
1952-1962 \\
1951 \text { y años anteriores }\end{array}$ & $\begin{array}{r}183 \\
93 \\
90\end{array}$ & $\begin{array}{l}84,7 \\
88,2 \\
81,1\end{array}$ & $\begin{array}{l}270 \\
140 \\
130\end{array}$ & $\begin{array}{l}87,0 \\
88,6 \\
85,4\end{array}$ \\
\hline \multicolumn{5}{|l|}{ Regiones VIII y IX } \\
\hline $\begin{array}{l}\text { Todos los periodos } \\
1952-1962 \\
1951 \text { y años anteriores }\end{array}$ & $\begin{array}{r}10 \\
7 \\
3\end{array}$ & - & $\begin{array}{r}12 \\
7 \\
5\end{array}$ & $\begin{array}{l}- \\
-\end{array}$ \\
\hline
\end{tabular}


Cuadro 17

RAZON ENTRE EL NUMERO DE INMIGRANTES CLASIFICADOS, SEGUN LA ZONA DE NACIMIENTO Y EL NUMERO DE INMIGRANTES PROCEDENTES DE LA RESPECTIVA ZONA, 1952-1962

\begin{tabular}{|c|c|c|c|c|c|c|}
\hline \multirow[b]{2}{*}{$\begin{array}{l}\text { Sexo y grupos } \\
\text { de edades }\end{array}$} & \multirow[b]{2}{*}{$\begin{array}{l}\text { Número } \\
\text { de } \\
\text { casos }\end{array}$} & \multicolumn{5}{|c|}{$\begin{array}{l}\text { Razón (porcentual) entre el número de inmigrantes } \\
\text { nacidos en la zona indicada y el número } \\
\text { de inmigrantes procedentes de la misma }(=100)^{a}\end{array}$} \\
\hline & & $\begin{array}{c}\text { Núcleos } \\
\text { de más } \\
\text { de } \\
20000 \\
\text { habi- } \\
\text { tantes }\end{array}$ & $\begin{array}{c}\text { Núcleos } \\
\text { de } 5000 \\
\text { a } 19999 \\
\text { habi- } \\
\text { tantes }\end{array}$ & $\begin{array}{c}\text { Núcleos } \\
\text { de } 900 \\
\text { a } 4.999 \\
\text { habi- } \\
\text { tantes }\end{array}$ & $\begin{array}{c}\text { Sectores } \\
\text { rurales }\end{array}$ & $\begin{array}{l}\text { Otros } \\
\text { países }\end{array}$ \\
\hline \multicolumn{7}{|l|}{ Hombres } \\
\hline $\begin{array}{l}15 \text { y más años } \\
15 \text { a } 29 \text { años }\end{array}$ & $\begin{array}{l}377^{b} \\
233^{\mathrm{c}}\end{array}$ & $\begin{array}{l}86,6 \\
92,0\end{array}$ & $\begin{array}{r}100,0 \\
95,5\end{array}$ & $\begin{array}{l}101,3 \\
101,9\end{array}$ & $\begin{array}{l}133,3^{d} \\
136,0^{d}\end{array}$ & $\begin{array}{l}141,2^{\mathrm{e}} \\
100,0^{\mathrm{e}}\end{array}$ \\
\hline \multicolumn{7}{|l|}{ Mujeres } \\
\hline $\begin{array}{l}15 \text { y más años } \\
15 \text { a } 29 \text { años }\end{array}$ & $\begin{array}{l}600 \\
406\end{array}$ & $\begin{array}{l}76,3 \\
79,1\end{array}$ & $\begin{array}{l}103,5 \\
102,9\end{array}$ & $\begin{array}{l}120,3 \\
119,8\end{array}$ & $\begin{array}{l}131,3^{d} \\
120,8^{d}\end{array}$ & $\begin{array}{l}147,4^{e} \\
137,5^{e}\end{array}$ \\
\hline
\end{tabular}

a Por ejemplo:

$$
\frac{\text { Inmigrantes nacidos en núcleos de } 20000 \text { y más habits. }}{\text { Inmigrantes procedentes de núcleos de } 20000 \text { y más habits. }} \times 100 .
$$

b Incluye dos casos cuya zona de nacimiento es desconocida.

c Incluye un caso cuya zona de nacimiento es desconocida.

d Relaciones entre números de casos que varían de 8 a 48 .

e Relaciones entre números de casos que varían de 1 a 24 .

\section{LUGAR DE ORIGEN DE LOS INMIGRANTES Y NIVEL DE INSTRUCCIÓN}

El nivel medio de instrucción de los inmigrantes nacidos en lugares rurales y pequeños pueblos es menor que el correspondiente a aquéllos nacidos en lugares urbanos.

Las diferencias son más marcadas en los niveles de instrucción extremos de la escala utilizada. En efecto, una décima parte de los hombres de origen rural y una quinta parte de las mujeres del mismo origen, no recibieron instrucción. Las proporciones respectivas en los inmigrantes de origen urbano son 3,6 y 7,7 por ciento. Una situación inversa se presenta al considerar la proporción de inmigrantes con un 
Cuadro 18

NIVEL DE INSTRUCCION DE LOS INMIGRANTES, SEGUN LUGAR DE NACIMIENTO

\begin{tabular}{|c|c|c|c|c|c|c|}
\hline \multirow{3}{*}{$\begin{array}{l}\text { Sexo y nivel } \\
\text { de } \\
\text { instrucción }\end{array}$} & \multirow[b]{3}{*}{ Total } & \multicolumn{5}{|c|}{ Lugar de nacimiento } \\
\hline & & \multicolumn{5}{|c|}{$(\text { Núcleos de })^{b}$} \\
\hline & & $\begin{array}{l}20000 \\
\text { y más } \\
\text { hab. }\end{array}$ & $\begin{array}{c}5000 \text { a } \\
19999 \\
\text { hab. }\end{array}$ & $\begin{array}{c}900 \text { a } \\
4999 \\
\text { hab. }\end{array}$ & Rural & Otrose \\
\hline \multicolumn{7}{|l|}{ Hombres } \\
\hline Niveles 0.1 & 21,3 & 13,4 & 21,1 & 25,6 & 38,0 & 11,0 \\
\hline Niveles 2-3 & 57,6 & 56,5 & 61,8 & 65,9 & 53,5 & 39,0 \\
\hline Nivel 4 & 20,1 & 28,9 & 17,1 & 7,4 & 7,7 & 47,6 \\
\hline $\begin{array}{l}\text { Totald } \\
\text { (Número de casos) }\end{array}$ & $\begin{array}{l}100,0 \\
(844)\end{array}$ & $\begin{array}{l}100,0 \\
(253)\end{array}$ & $\begin{array}{l}100,0 \\
(204)\end{array}$ & $\begin{array}{l}100,0 \\
(176)\end{array}$ & $\begin{array}{l}100,0 \\
(129)\end{array}$ & $\begin{array}{r}100,0 \\
(82)\end{array}$ \\
\hline \multicolumn{7}{|l|}{ Mujeres } \\
\hline Niveles 0 -I & 33,5 & 21,2 & 29,4 & 47,3 & 51,8 & 12,3 \\
\hline Niveles 2-3 & 52,9 & 56,0 & 59,7 & 47,3 & 44,2 & 53,1 \\
\hline Nivel 4 & 13,1 & 22,3 & 10,9 & 4,8 & 2,7 & 34,6 \\
\hline $\begin{array}{l}\text { Totald } \\
\text { (Número de casos) }\end{array}$ & $\begin{array}{c}100,0 \\
(1398)\end{array}$ & $\begin{array}{l}100,0 \\
(430)\end{array}$ & $\begin{array}{l}100,0 \\
(350)\end{array}$ & $\begin{array}{l}100,0 \\
(315)\end{array}$ & $\begin{array}{l}100,0 \\
(222)\end{array}$ & $\begin{array}{r}100,0 \\
(81)\end{array}$ \\
\hline
\end{tabular}

a Niveles alcanzados:

$0.1=\sin$ instrucción o con uno a tres años de enseñanza primaria.

2-3 = cuatro a seis años de enseñanza primaria y uno a tres años de enseñanza secundaria.

$4 .=$ cuatro años y más de enseñanza secundaria, enseñanza superior o universitaria.

b Tamaño en 1952.

c Lugar de nacimiento desconocido y nacidos en el exterior.

d Incluye 15 casos con nivel de educación desconocido ( 8 hombres y 7 mujeres).

nivel "secundario ( 4 años y más), superior y universitario". (Véase el cuadro 18.) La relación directa entre grado de urbanización del lugar de nacimiento y nivel de instrucción, se observa clara y sistemáticamente.

Cualquiera que sea el lugar de nacimiento, el nivel medio de instrucción de los hombres sobrepasa el de las mujeres. Obsérvese que la mitad de las mujeres nacidas en lugares rurales y pequeños pueblos recibieron menos de 4 años de instrucción primaria, o no recibieron 
ninguna. Entre los hombres, esa proporción es del orden de un tercio solamente. La diferencia de nivel de instrucción por sexo también es notoria en los inmigrantes de origen urbano. (Véase el cuadro 18.)

$\mathrm{Si}$ se examina la educación diferencial según el lugar de emigración del inmigrante, en vez del lugar de nacimiento, se llega a análogos resultados. Contribuye a ello, en parte, el hecho de que una proporción relativamente grande de los inmigrantes vino directamente del lugar de nacimiento como se vio en la sección precedente.

No obstante esta observación, la información sobre el lugar de emigración sirve para mostrar algo adicional: que el nivel de instrucción de los nacidos en lugares urbanos importantes (20000 habitantes y más) es mejor que el correspondiente nivel de los emigrados de estos lugares; lo que se explica porque en estos últimos se incluyen muchos que a su vez habían emigrado a esos lugares, por ejemplo de pequeños núcleos y del área rural. En cambio, se advierte que el nivel de los nacidos en lugares semi-urbanos (5000 a 19999 habitantes) es peor que el de los emigrados desde esos lugares. ${ }^{30}$

30 Con respecto a los hombres que llegaron de núcleos de 20000 y más habitantes, el 26,2 por ciento tenía el nivel 4 (contra 28,9 del cuadro 18), y 15,3 por ciento, los niveles $0-1$ (en vez de 13,4). En las mujeres que llegaron de los mismos núcleos, correspondían a los niveles 4 y $0-1$, respectivamente, 18,2 y 26,5 por ciento (contra 22,3 y 21,2 por ciento del cuadro 18 ). 


\section{MOVILIDAD GEOGRAFICA DE LOS INMIGRANTES}

\section{Movilidad y eDad DE LLEGADA}

La historia migratoria de las personas que se movieron hacia el Gran Santiago proporciona útiles indicaciones sobre varias características de la movilidad geográfica de la población. En este capítulo se analiza el número de movimientos en relación con la edad, lugar de nacimiento y lugar de residencia inmediata anterior. Respecto de la edad, ésta se ha considerado al momento de llegar al Gran Santiago y al de iniciar la historia migratoria $\mathrm{y}$, en ambos casos, el análisis más detenido se refiere a la historia posterior a los 14 años de edad.

Esta última limitación parece legítima por varias razones. En primer lugar, y principalmente, porque la movilidad de los niños es producto de la movilidad de los adultos; en segundo término, la edad puede considerarse asociada a la movilidad sólo en las personas adultas, y de la misma manera los factores del medio (lugar de nacimiento, movimientos, etapas intermedias), $y$, en tercer lugar, porque la movilidad de los niños (en razón de su misma edad), es muy pequeña en la mayoría de los casos. Si se tiene en cuenta, por ejemplo, que una tercera parte de los inmigrantes observados llegaron al Gran Santiago antes de cumplir 14 años de edad, se comprende que su inclusión en el análisis, aparte de su escaso interés, distorsionaría los resultados. Pudo haberse adoptado otro límite como 16 ó 18 años, por ser difícil afirmar cuál es la edad ideal, al tener ésta un significado distinto, según sea el lugar de origen del inmigrante.

Algo más de la mitad de los inmigrantes así definidos, vino al Gran Santiago en un primer movimiento (51 y 55 por ciento, respectivamente, de los hombres y de las mujeres). Esa proporción se eleva a dos terceras partes de los llegados entre 14 y 29 años, y baja al crecer la edad. Por extensión, podría pensarse que de los llegados en edades infantiles, el 85 ó 90 por ciento de ellos lo hicieron en un primer movimiento.

Excluyendo ahora los movimientos realizados antes de los 14 años, la importancia relativa de los casos con un primer movimiento sube apreciablemente. La proporción de inmigrantes con un primer movi- 
miento (después de los 14 años) supera los dos tercios. Entre los llegados de 14 a 29 años llega a ser del 80 por ciento, y si sólo se consideran los llegados de 14 a 19 años, asciende al 89 por ciento.

De acuerdo con estas últimas cifras, se deduce que de cada 100 personas que emigraron al Gran Santiago entre los 14 y 29 años de edad, 80 de ellas no tenían historia migratoria después de los 14 años. Quiere decir, que sólo a un 20 por ciento podría achacársele con propiedad una experiencia migratoria previa como persona adulta. Por el contrario, de los inmigrantes que llegaron después de los 30 años, aproximadamente el 60 por ciento tenía una historia migratoria previa. En conclusión, poco menos de un tercio de los inmigrantes observados tenían experiencia migratoria previa. ${ }^{31}$

Más aún, la mitad de los inmigrantes de ese tercio tuvo una experiencia migratoria muy breve: un solo movimiento previo a su movimiento al Gran Santiago. Por lo tanto, no resta sino apenas una sexta parte, a la que podría calificarse de migrantes con relativamente alta movilidad (3 y más movimientos). (Véase el cuadro 19.)

31 Esta es la situación que se refleja en la población investigada en el mo. mento de la encuesta. Si se tratase de inmigrantes llegados el último año, o aun en los últimos cinco años, reflejaría de cerca la situación en el momento de la inmigración. Pero se trata de inmigrantes llegados durante un período de tiempo extenso y la mortalidad distorsiona los hechos. En efecto, los inmigrantes llegados en edad avanzada - que son los de más alta movilidad - están menos representados que los llegados a una edad relativamente baja, en igual época.

A continuación se comparan cifras correspondientes a inmigrantes llegados al Gran Santiago durante el período 1952-1962, con las de inmigrantes en cualquier tiempo:

\begin{tabular}{lcc}
\hline & $\begin{array}{c}\text { Porcentaje de inmigrantes con historia migratoria } \\
\text { previa al movimiento hacia el Gran Santiago }\end{array}$ \\
$\begin{array}{l}\text { Epoca de llegada } \\
\text { al Gran Santiago }\end{array}$ & $\begin{array}{c}\text { Inmigrantes llegados al Gran Santiago después } \\
\text { de cumplir 25 años de edad }\end{array}$ \\
\cline { 2 - 3 } & Hombres & Mujeres \\
\hline $\begin{array}{l}\text { Período 1952-62 } \\
\text { En cualquier tiempo }\end{array}$ & 65,4 & 57,6 \\
\hline
\end{tabular}


MOVILIEAD GEOGRÁFICA DE LOS INMIGRANTES

Cuadro 19

INMIGRANTES SEGUN LA EDAD DE LLEGADA AL GRAN SANTIAGO Y SEGUN EL NUMERO DE MOVIMIENTOS MIGRATORIOS REALIZADOS DESPUES DE CUMPLIR I4 AÑOS DE EDAD

\begin{tabular}{|c|c|c|c|c|c|c|}
\hline \multirow{2}{*}{$\begin{array}{l}\text { Sexo y edad } \\
\text { al llegar al } \\
\text { Gran } \\
\text { Santiago }\end{array}$} & \multicolumn{6}{|c|}{ Número de movimientos realizados de 14 y más años de edad } \\
\hline & Uno & Dos & Tres & $\begin{array}{l}\text { Cuatro } \\
\text { y más }\end{array}$ & $\begin{array}{l}\text { Sin } \\
\text { deter- } \\
\text { minar }\end{array}$ & Totala \\
\hline & \multicolumn{6}{|c|}{ (Porcentajes) } \\
\hline Hombres & 64,4 & 15,8 & 7,6 & 11,8 & 0,4 & $100(844)$ \\
\hline $14-19$ & 83,3 & 11,9 & 3,2 & 0,8 & 0,8 & $100(251)$ \\
\hline $20 \cdot 24$ & 72,9 & 16,5 & 5,5 & 4,6 & 0,5 & $100(218)$ \\
\hline $25-29$ & 63,6 & 15,2 & 5,1 & 16,1 & $\ldots$ & $100(118)$ \\
\hline $30 \cdot 39$ & 45,6 & 19,1 & 14,0 & 21,3 & - & $100(136)$ \\
\hline $40-49$ & 31,7 & 20,2 & 15,2 & 32,9 & $\cdots$ & $100(79)$ \\
\hline 50 y más & 33,3 & 16,7 & 16,7 & 33,3 & - & $100(42)$ \\
\hline Sin especificar & - & - & - & - & - & - \\
\hline Mujeres & 70,8 & 14,2 & 7,4 & 6,5 & 1,1 & $100(1398)$ \\
\hline $14 \cdot 19$ & 90,7 & 6,6 & 1,3 & 0,8 & 0,6 & $100(185)$ \\
\hline $20-24$ & 76,5 & 15,6 & 3,3 & 3,6 & 1,0 & $100(302)$ \\
\hline $25 \cdot 29$ & 68,2 & 18,1 & 9,7 & 4,0 & - & $100(226)$ \\
\hline $30-39$ & 45,5 & 19,4 & 15,7 & 17,3 & 2,1 & $100(191)$ \\
\hline $40-19$ & 38,2 & 22,7 & 14,6 & 22,7 & 1,8 & $100(110)$ \\
\hline 50 y más & 42,2 & 19,3 & $24, \mathrm{I}$ & 10,8 & 3,6 & $100(83)$ \\
\hline Sin cspecificar & - & - & - & $\ldots$ & - & -1 \\
\hline
\end{tabular}

a Entre paréntesis número de cusos obscrvados.

\section{MOVILIDAD Y LUGAR LE EMIGRACIÓN}

La movilidad previa de los inmigrantes que vinieron de lugares "urbanos"32 es más alia que la će los inmigrantes "rurales", lo que se explica, al menos parcialmente, porque una fracción de los primeros a su vez había emigrado al lugar "urbano" desde otro lugar "semi-urbano" o "rural". La posibilidad del proceso inverso es, seguramente, mucho menor. ${ }^{33}$

32 En adelante se llamará "urbanos" a los lugares de 20000 y más habitantes; "scmi-urbanos", a los de 5000 a 19999 habitanies, y "rurales", a los de menos de 5000 y a cualquier lugaz con población dispersa.

33 Es proballe que la mayor movilidad media que presentan los inmigrantes que vinieron de lugares "urbanos", sea conferidd por migrantes de origen rural o semi-urbano, los que llegan al Gran Santiago después de cumplir una etapa inter. media, o varias, en lugares urbanos. 
Cuadro 20

PORCENTAJES DE INMIGRANTES CON UN MOVIMIENTO MIGRATORIO

(DE LOS MOVIMIENTOS REALIZADOS DESPUES DE CUMPLIR

14 AÑOS DE EDAD), SEGUN LA EDAD DE LLEGADA

AL GRAN SANTIAGO Y SEGUN EL LUGAR DE EMIGRACION

\begin{tabular}{|c|c|c|c|c|c|c|c|}
\hline \multirow{2}{*}{$\begin{array}{c}\text { Sexo } \\
\text { y lugar de } \\
\text { emigracióna }\end{array}$} & \multicolumn{7}{|c|}{ Edad de llegada al Gran Santiago } \\
\hline & 14-19 & $20-24$ & $25-29$ & $30-39$ & $40-49$ & 50 y más & Total \\
\hline & \multicolumn{7}{|c|}{ (Porcentajes) } \\
\hline Hombres ${ }^{\mathrm{b}-\mathrm{c}}$ & $(251)$ & $(218)$ & (118) & $(136)$ & (79) & $(42)$ & (844) \\
\hline Urbano & 85,9 & 68,6 & 48,8 & 35,9 & 22,5 & 26,3 & 55,8 \\
\hline Semi-urbano & 79,7 & 64,4 & 63,3 & 32,1 & 26,7 & 22,2 & 60,5 \\
\hline Rural & 83,1 & 78,9 & 72,2 & 60,0 & 26,7 & 46,1 & 72,6 \\
\hline Mujeres ${ }^{\mathrm{b}-\mathrm{c}}$ & $(485)$ & $(302)$ & $(226)$ & $(191)$ & $(110)$ & $(83)$ & $(1398)^{d}$ \\
\hline Urbano & 87,4 & 69,7 & 66,4 & 40,8 & 28,6 & 23,3 & 63,1 \\
\hline Semi-urbano & 93,7 & 77,8 & 58,7 & 37,8 & 37,5 & 33,3 & 70,7 \\
\hline Rural & 92,0 & 82,0 & 76,6 & 53,8 & 37,0 & 56,7 & 78,5 \\
\hline
\end{tabular}

a Urbano: 20000 y más habitantes.

Semi-urbano: 5000 a 19999 habitantes.

Rural: menos de 5000 y población rural dispersa.

b Incluye casos con lugar de procedencia indeterminado.

c Entre paréntesis, número de casos respecto del cual se calcularon los porcentajes.

d Incluye un caso con edad desconocida.

Para establecer las diferencias más notables pareció suficiente analizar la importancia relativa que ocupan los inmigrantes de un movimiento, o sea de ningún movimiento previo. Como se desprende de las cifras del cuadro 20 y a pesar de ciertas irregularidades que se pueden observar en algunos grupos de edades, debidas probablemente al pequeño número de casos, es clara la mayor importancia relativa de los inmigrantes sin movimientos previos entre los que emigraron de lugares "rurales". Esta diferencia, como es lógico que sea, se acentúa al aumentar la edad de llegada.

En el cuadro 21 se presenta la importancia relativa de los inmigrantes con un determinado número de movimientos - después de los 14 años- según el lugar de emigración, del grupo más característico e importante numéricamente; esto es, los inmigrantes llegados entre $14 \mathrm{y}$ 29 años de edad.

Es significativo que de los hombres inmigrantes que llegaron al Gran Santiago desde lugares "urbanos", casi la mitad ya se había mo- 


\section{Cuadro 21}

MOVILIDAD DE LOS INMIGRANTES LLEGADOS AL GRAN SANTIAGO DE 14 A 29 ANOS, SEGUN EL LUGAR DE EMIGRACION

(Movimientos realizados después de los 14 años de edad)

\begin{tabular}{lcc}
\hline $\begin{array}{c}\text { Sexo } \\
\text { y lugar de } \\
\text { emigración }\end{array}$ & Porcentaje de inmigrantes con: \\
\cline { 2 - 3 } & Un movimiento & $\begin{array}{c}\text { Uno y dos } \\
\text { movimientos }\end{array}$ \\
\hline Hombres & & \\
Urbano & 53,5 & 74,0 \\
Semi-urbano & 60,2 & 76,0 \\
Rural & 73,0 & 83,0 \\
Mujeres & & \\
Urbano & 63,0 & 82,0 \\
Semi-urbano & 70,0 & 84,0 \\
Rural & 79,0 & 88,0 \\
\hline
\end{tabular}

a Urbano: 20000 y más habitantes.

Semi-urbano: 5000 a 19999 habitantes.

Rural: menos de 5000 y población dispersa.

vido por lo menos una vez previamente después de cumplir los 14 años (53,5 por ciento no se había movido, véase el cuadro 21). La proporción baja a sólo 27 por ciento de los llegados de lugares "rurales". La movilidad de las mujeres inmigrantes, con ser menor, sigue similar comportamiento.

Podría ser de interés agregar todavía que una cuarta parte de los inmigrantes de lugares "urbanos" (hombres), ya se habían movido previamente por lo menos dos veces después de cumplir los 14 años de edad (74 por ciento se había movido una o dos veces, incluyendo el movimiento hacia el Gran Santiago). Esa movilidad, aunque algo menor, es aún importante en las mujeres (18 por ciento).

Resumiendo: los inmigrantes que vinieron de lugares "urbanos" tuvieron una movilidad previa, a partir de los 14 años de edad, más alta que los inmigrantes de lugares "semi-urbanos", y éstos, a su vez, una más elevada que la de los inmigrantes de lugares "rurales". 


\section{Movilidad Y LUGAR DE NAGIMIENTo}

De los resultados de la sección precedente se podría inferir que, en promedio, los inmigrantes nacidos en lugares "rurales" tuvieron mayor movilidad que los nacidos en lugares "urbanos".

En el caso particular de Chile, la alternativa de un destino migratorio distinto del Gran Santiago pareciera ser menor para una persona nacida en lugar "urbano" que para la nacida en uno "rural", la cual tendría más posibilidades intermedias.

Los comentarios que anteceden tienen una confirmación en los resultados que se mostrarán aquí. La mayor movilidad de los inmigrantes nacidos en lugares "rurales" y "semi-urbanos" es más acentuada en la población femenina, hecho que estaría reflejando más bien una movilidad particularmente baja de la mujer nacida en lugares "urbanos". 34

En el cuadro 22 se resume la importancia relativa que representan los inmigrantes con un determinado número de movimientos, según el lugar de nacimiento. La proporción de inmigrantes de un movimiento después de los 14 años (esto es, sin movimientos previos) aumenta en el caso de los hombres al pasar de lugares "urbanos" a "rurales" (67,6 y 62,6 por ciento, respectivamente) y permanece relativamente constante (72 por ciento, aproximadamente) en el caso de las mujeres. (Véase la columna 2 del cuadro 22 .)

Si ahora se observa el comportamiento respecto de los movimientos a partir del nacimiento, la movilidad, juzgada a través del porcentaje que no había realizado ningún movimiento previo, es más alta, en ambos sexos, en los inmigrantes nacidos en lugares "rurales", en tanto que la más baja corresponde a los nacidos en lugares "urbanos". (Véase la columna 1 del cuadro 22 .)

De la comparación de las cifras de las columnas 1 y 2 podría concluirse que la movilidad diferencial según el lugar de nacimiento ocurre en los hombres antes y después de los 14, años de edad. En la mujer, en cambio, la mayor movilidad de las nacidas en lugares "rurales" estaría limitada al período anterior a los 14 años, ya que considerando solamente los movimientos posteriores a esa edad no se advierte aquel diferencial.

Estas observaciones son aplicables a los inmigrantes llegados al Gran Santiago después de los 14 años de edad. Las cifras de la columna

34 La expresión "baja movilidad" no debería ser fuente de confusión. Ella no tiene el significado de baja tasa de emigración desde una clase de lugar, por ejemplo, "urbano", sino la de movimientos migratorios sucesivos o de etapas migratorias. 
MOVILIDAD GEOGRÁFICA DE LOS INMIGRANTES

CUAdro 22

PORCENTAJES DE INMIGRANTES CON UN MOVIMIENTO, Y PROPORCION CON UNO Y DOS MOVIMIENTOS

\begin{tabular}{|c|c|c|c|}
\hline \multirow{3}{*}{$\begin{array}{c}\text { Sexo, número } \\
\text { de movimientos y lugar } \\
\text { de nacimiento }{ }^{\mathrm{a}}\end{array}$} & \multicolumn{3}{|c|}{ Inmigrantes Ilegados en Ia edad: } \\
\hline & \multicolumn{2}{|c|}{14 y más años } & \multirow{2}{*}{$\begin{array}{l}\text { 14 a } 29 \text { años } \\
\text { Movimientos } \\
\text { a partir de } \\
\text { los } 14 \text { años }\end{array}$} \\
\hline & $\begin{array}{l}\text { Movimientos } \\
\text { a partir del } \\
\text { nacimiento }\end{array}$ & $\begin{array}{l}\text { Movimientos } \\
\text { a partir de } \\
\text { los 14 años }\end{array}$ & \\
\hline Hombres & \multicolumn{3}{|c|}{$($ Porcentajes) } \\
\hline Un movimiento & $50,8 d$ & $64,8 d$ & $63,0 \mathrm{~d}$ \\
\hline 20000 y más habitantes & 54,7 & 67,6 & 65,4 \\
\hline 5000 a 19999 habitantes & 52,2 & 62,9 & 62,9 \\
\hline Menos de 5000 habitantes ${ }^{b}$ & 51,6 & 62,6 & 60,8 \\
\hline Hasta dos movimientos & $71,5 \mathrm{~d}$ & $80,7 \mathrm{~d}$ & $79,0 \mathrm{~d}$ \\
\hline 20000 y más habitantes & 72,1 & 81,8 & 80,1 \\
\hline 5000 a 19999 habitantes & 72,4 & 80,2 & 79,4 \\
\hline Mienos de 5000 habitantes & 72,0 & 78,8 & 77,7 \\
\hline \multicolumn{4}{|l|}{ MuJEREs } \\
\hline Un movimiento & $55,1^{\mathbf{a}}$ & $71,6^{\mathrm{d}}$ & $70,5 \mathrm{~d}$ \\
\hline 20000 y más habitantes & 62,6 & 72,5 & 71,2 \\
\hline 5000 a 19999 habitantes & 53,6 & 69,3 & 68,9 \\
\hline Menos de 5000 habitantes $b$ & 52,8 & 73,2 & 72,4 \\
\hline Hasta dos movimientos & $77,7 \mathrm{~d}$ & $86,0 \mathrm{a}$ & 85,54 \\
\hline 20000 y más habitantes & 76,0 & 83,7 & 82,1 \\
\hline 5000 a 19999 habitantes & 76,8 & 86,4 & 87,1 \\
\hline Meros de 5000 habitantes $b$ & 80,8 & 88,1 & 87,7 \\
\hline
\end{tabular}

¿ Lugares de nacimiento clasificados según el tamaño del núcleo.

b Incluye población rural.

c Se excluyeron de los totales $(=100)$, los casos de los cuales no se conoce el número de movimicntos.

(1) Estos porcentajes incluyen los cásos de los cuales no se conoce el lugar de nacimiento.

3 cicl cuadro 22, indican que ese comportamiento es válido tanio para los inmigranies adulios jóvenes (14 a 29 años) como para los de edad más avanzada: la movilidad diferencial (después de los 14 años) según el lugar de nacimiento se veritica, para los hombres, en ambos grupos 
de edades, pero no se cumple —como ocurrió en el caso general- para las mujeres.

En lugar de tomar como criterio de movilidad diferencial el que se haya realizado un movimiento previo, es útil avanzar un paso adop. tando como criterio la realización de dos o más movimientos previos. Si bien la proporción de inmigrantes con 3 y más movimientos es bastante pequeña (aproximadamente 20 por ciento en los hombres y 14 en las mujeres), es posible advertir que, probablemente, hay una movilidad diferencial, en el nivel señalado, según el lugar de nacimiento, al menos en el sexo femenino. Lo curioso es que ahora las inmigrantes que se manifestaron más móviles son las nacidas en lugares "urbanos". En efecto, ello se verifica sistemáticamente en tres columnas del cuadro 25. Podría intentarse la siguiente explicación: al nivel de uno o más movimientos previos, la mujer de origen "urbano" sería, en promedio, menos móvil que la de origen "rural", pero habría un segmento relativamente pequeño de las primeras con una movilidad más alta (esto es, al nivel de dos o más movimientos previos).

\section{LUGAR DE NACIMIENTO Y LUGAR DE PROCEDENCIA}

De 2020 inmigrantes observados y que llegaron al Gran Santiago de 14. y más años de edad, un poco más de la mitad vino directamente del lugar de nacimiento respectivo. ${ }^{35}$ La relación es levemente más elevada para el sexo femenino. (Véase el cuadro 23.)

Con la sola excepción de las mujeres nacidas en lugares "urbanos", en todos los demás casos y cualquiera que sea la clase del lugar de nacimiento, la proporción que llegó directamente del lugar de nacimiento fluctúa alrededor del 52 por ciento. Las inmigrantes nacidas en lugares "urbanos", en cambio, llegaron del lugar de nacimiento en una proporción netamente más alta: 62 por ciento. Este resultado es otro indicio de la menor movilidad de la mujer inmigrante que nació en lugares "urbanos", siempre que se computen también, como es el caso ahora, los movimientos ocurridos antes de los 14 años. (Véase la sección 6.)

Respecto de los inmigrantes que no vinieron directamente del lugar de nacimiento $\mathrm{y}$, por consiguiente, que hicieron una o más escalas migratorias, interesa saber cuántas escalas hicieron dentro de la misma

35 Es necesario aclarar que se considera que un inmigrante vino de $s u$ lugar de nacimiento cuando lo ha hecho, en sentido literal, desde el mismo y no meramente de un lugar de la misma categoría ("urbano", etc.). A los efectos de este análisis se considera que el inmigrante llegó del lugar de nacimiento cuando llegó al Gran Santiago en un primer movimiento (sin movimientos previos antes de los 14. años de edad). 
Cuadro 23

INMIGRANTES LLEGADOS AL GRAN SANTIAGO DE 14 Y MAS AÑOS DE EDAD, EN UN PRIMER MOVIMIENTO MIGRATORIO, DEL LUGAR DE NACIMIENTO

\begin{tabular}{lccc}
\hline $\begin{array}{c}\text { Sexo } \\
\text { y lugar de } \\
\text { nacimiento }\end{array}$ & $\begin{array}{c}\text { Total } \\
\text { de } \\
\text { inmigrantesa }\end{array}$ & $\begin{array}{c}\text { Inmigrantes } \\
\text { llegados del lugar } \\
\text { de nacimiento } \\
\text { (un movimiento) }\end{array}$ & $\begin{array}{c}\text { Porcentaje } \\
\text { de inmigrantes con } \\
\text { un movimiento }\end{array}$ \\
\hline Hombres & 736 & 380 & 52 \\
Urbano & 240 & 128 & 53 \\
Semi-urbano & 199 & 102 & 51 \\
Rural & 297 & 150 & 51 \\
Mujeres & 1284 & 712 & 55 \\
Urbano & 419 & 260 & 62 \\
Semi-urbano & 344 & 182 & 53 \\
Rural & 521 & 270 & 52 \\
Ambos sexos & 2020 & 1092 & 54 \\
\hline
\end{tabular}

a Se excluyeron los inmigrantes de los que no se conoce el número de movimientos: 108 hombres y 114 mujeres, de los cuales de 82 y 81 , respectivamente, se desco. noce el lugar de nacimiento. De los restantes, de 18 hombres y de 24 mujeres la información sobre número de movimientos es incoherente con la relativa a Iugar de nacimiento (con un movimienio viniendo de un lugar diferente del lugar de nacimiento). Finalmente, los demás excluidos son inmigrantes de los cuales se dcsconoce sólo el número de movimientos.

clase de lugar y entre clases distintas, y en este último caso cuántas en dirección ascendente (rural-urbana) y cuántas en la descendente (urbana-rural). En el cuadro 24 se provee información sobre el lugar de procedencia de los inmigrantes de cada tipo de lugar de nacimiento. Las diferencias entre las cifras de este cuadro y las correspondientes del cuadro 23 expresarían, aproximadamente, la proporción de inmigrantes con un movimiento previo entre lugares de diferente clase o categoría ("urbana", etc.), o "intra-clases".36 Las diferencias respecto de 100 , de las cifras del cuadro 24, expresarian la proporción de inmigrantes con un movimiento previo entre lugares de diferente clase o "inter-clases".

36 En los casos con dos o más movimientos previos, no podría asegurarse que fueron entre lugares de la misma clase. Cuando hay un movimiento previo, éste se realiza entre el "lugar de nacimiento" y el "lugar de emigración", ambos identificados en el cuadro 24. Pero si hubiera dos (tres, etc.) movimientos previos, quedaría un (dos, eic.) lugar indeterminado. 
Cuadro 24

PORCENTAJES DE INMIGRANTES LLEGADOS AL GRAN SANTIAGO

DE 14. ANOS Y MAS DE EDAD, SEGUN LUGAR DE NACIMIENTO

Y SEGUN LUGAR DE EMIGRACION

\begin{tabular}{lcccc}
\hline \multirow{2}{*}{$\begin{array}{c}\text { Sexo } \\
\text { y lugar de } \\
\text { emigración }\end{array}$} & Urbano & Semi-urbano & Rural & Totala $^{\mathbf{a}}$ \\
\cline { 2 - 5 } & \multicolumn{4}{c}{ (Porcentajes) } \\
\hline Hombres & $100(250)$ & $100(203)$ & $100(304)$ & $(790)$ \\
Urbano & 77,6 & 22,7 & 20,4 & \\
Semi-urbano & 13,2 & 65,0 & 10,9 & \\
Rural & 9,2 & 12,3 & 68,7 & \\
Mujeres & $100(4,28)$ & $100(350)$ & $100(535)$ & $(1344)$ \\
Urbano & 84,6 & 24,0 & 18,7 & \\
Semi-urbano & 8,6 & 67,2 & 11,2 & \\
Rural & 6,8 & 8,8 & 70,1 & \\
\hline
\end{tabular}

a Incluye inmigrantes cuyo lugar de nacimiento no se conoce.

b Entre paréntesis, número de casos observados.

Los resultados del cuadro 25 son aproximados por la circunstancia explicada en la nota 36 . Es verosímil, por ejemplo, que una persona nacida en un "lugar urbano" emigrara a un lugar "semi-urbano" (o "rural"), desde allí emigrara nuevamente, ahora a un lugar "urbano" (incluso al lugar de nacimiento), y desde este último lugar emigrara al Gran Santiago. Este inmigrante quedaría clasificado en el cuadro 24, como un caso de migración "intra-clase",-si bien existió también un movimiento "inter-clase" que pasa inadvertido. Es posible imaginar una serie de situaciones análogas. No obstante, es razonable pensar que, por lo menos, una parte de los inmigrantes nacidos en un lugar "urbano" y procedentes de un lugar de la misma clase, de los que tuvieron dos o más movimientos previos, volvieron al lugar de nacimiento después de uno o más movimientos, o bien se movieron entre lugares "urbanos". Similar razonamiento podría extenderse a inmigrantes nacidos en lugares "semi-urbanos" y "rurales".

Con las reservas que nacen de las observaciones anteriores, de los cuadros 23 y 24 resultarían las siguientes conclusiones provisionales: i) cerca de la cuarta parte de los inmigrantes nacidos en lugares "urbanos" y procedentes de estos lugares hicieron por lo menos una escala intermedia en un lugar de la misma clase $(24,6$ y 22,6 por ciento, hom- 
bres y mujeres respectivamente); ii) de los inmigrantes nacidos en lugares "semi-urbanos" y procedentes de éstos, la correspondiente proporción que tuvo al menos una escala intermedia, en un lugar de su misma clase, es del 14 por ciento en cifras redondas, y de los nacidos en lugares "rurales" y que procedían de ellos, los casos con una etapa intermedia, en lugar rural, fue 18 por ciento; iii) de las etapas intermedias en lugares de una clase distinta (movimientos "inter-clase"), la tendencia es la mayor frecuencia de etapas intermedias en la clase más alta; por ejemplo, el 24 por ciento de las inmigrantes nacidas en un lugar "semi-urbano" Ilegaron de un lugar "urbano", y sólo el 8,8 por ciento de uno "rural"; iv) consecuencia de lo inmediato anterior, la proporción de inmigrantes nacidos en lugares "urbanos" o "semi-urbanos" que vinieron de un lugar "rural" es baja, alrededor del 10 por ciento o menos, y la proporción de inmigrantes nacidos en lugares "rurales" y "semi-urbanos" que vinieron de lugares "urbanos" es alta (alrededor del 20 por ciento o más).

Tales resultados confirman la hipótesis corrientemente enunciada, de que los inmigrantes que llegan a las grandes ciudades realizan etapas intermedias, que la proporción que lo hace es más alta en los que salen originariamente de lugares "rurales" y, finalmente, que estas etapas se cumplen con mayor frecuencia en la dirección rural-urbana. Sin embargo, hay que insistir en el hecho de que la mitad de los inmigrantes llegaron directamente del lugar de nacimiento, y por consiguiente sin cumplir etapa alguna.

El análisis anterior acerca de los movimientos previos o etapas migratorias se puede particularizar un grado más, examinando aisladamente el comportamiento de los inmigrantes con dos movimientos, lo que equivale a decir con un movimiento previo. (Véase el cuadro 25.) Los porcentajes indican las proporciones con un movimiento "intraclase" o con un movimiento "inter-clase". De los nacidos en lugar "urbano", aproximadamente el 55 por ciento realizó una etapa en otro lugar "urbano", y sólo aproximadamente el 17 por ciento en un lugar "rural". El movimiento "intra-clase" es en cambio menos importante que el movimiento "inter-clase" en los inmigrantes originarios de lugares "semi-urbanos" y "rurales". Nuevamente se comprueba que el movimiento "inter-clase" es más fuerte hacia arriba que hacia abajo.

En el cuadro comentado también se incluyen los resultados correspondientes a inmigrantes con 3 y más movimientos, o sea con dos y más etapas previas, algunas de ellas indeterminadas de las que ya se habló anteriormente en esta sección. Como nota característica, el movimiento "intra-clase" de estos inmigrantes, cualquiera que sea su lugar de nacimiento, es relativamente más importante que el observado en los inmigrantes de una sola etapa previa. 
Cuadro 25

INMIGRANTES LLEGADOS AL GRAN SANTIAGO DE 14 Y MAS AÑOS DE EDAD, SEGUN LUGAR DE NACIMIENTO

Y SEGUN LUGAR DE EMIGRACION

(Inmigrantes con dos y más movimientos durante toda su vida)

\begin{tabular}{|c|c|c|c|c|}
\hline \multirow{2}{*}{$\begin{array}{l}\text { Sexo } \\
\text { y lugar de } \\
\text { procedencia }\end{array}$} & \multicolumn{4}{|c|}{ Lugar de nacimiento } \\
\hline & Urbano & Semi-urbano & Rural & Totala \\
\hline & \multicolumn{4}{|c|}{ (Porcentajes) } \\
\hline & \multicolumn{4}{|c|}{ a) De dos movimientos } \\
\hline Hombres & $100(43)$ & $100(41)$ & $100(62)$ & $100(163)$ \\
\hline Urbano & 55,8 & 46,3 & 37,1 & 45,4 \\
\hline Semi-urbano & 27,9 & 22,0 & 27,4 & 28,2 \\
\hline Rural & 16,3 & 31,7 & 35,5 & 26,4 \\
\hline Mujeres ${ }^{\mathrm{b}}$ & $100(57)$ & $100(81)$ & $100(149)$ & $100(302)$ \\
\hline Urbano & 54,4 & 53,1 & 34,2 & 45,4 \\
\hline Semi-urbano & 28,1 & 29,6 & 24,9 & 26,5 \\
\hline \multirow[t]{2}{*}{ Rural } & 17,5 & 17,3 & 40,9 & 28,1 \\
\hline & \multicolumn{4}{|c|}{ b) De tres y más movimientos } \\
\hline Hombres $\mathbf{b}$ & $100(69)$ & $100(56)$ & $100(85)$ & $100(224)$ \\
\hline Urbano & 58,0 & 46,5 & 40,0 & 48,7 \\
\hline Semi-urbano & 27,5 & 37,5 & 16,5 & 25,9 \\
\hline Rural & 14,5 & 16,0 & 43,5 & 25,4 \\
\hline Mujeres ${ }^{\mathrm{b}}$ & $100(102)$ & $100(81)$ & $100(101)$ & $100(298)$ \\
\hline Urbano & 67,7 & 43,2 & 42,5 & 51,7 \\
\hline Semi-urbano & 18,6 & 35,8 & 16,8 & 23,8 \\
\hline Rural & 13,7 & 21,0 & 40,6 & 24,5 \\
\hline
\end{tabular}

a Incluye inmigrantes cuyo lugar de nacimiento se desconoce.

b Entre paréntesis, número de casos observados.

\section{MOVILIDAD Y NIVEL DE INSTRUCCIÓN}

La movilidad - a partir de los 14 años de edad - aumenta con el nivel de instrucción. Dicho con mayor exactitud, los inmigrantes que al momento de la encuesta tenían más alto nivel de educación, registraban en su historia migratoria un número promedio de movimientos también más alto. Esta conclusión se desprende de las cifras del cuadro 26. 
Cuadro 26

MOVILIDAD DE LOS INMIGRANTES SEGUN EL NIVEL DE INSTRUCCION

(Movimientos realizados después de los 14 años de edad)

\begin{tabular}{|c|c|c|c|c|}
\hline \multirow{3}{*}{$\begin{array}{l}\text { Nivel de instrucción } \\
\text { en la época de la encuesta }\end{array}$} & \multicolumn{4}{|c|}{ Porcentajes de inmigrantes: } \\
\hline & \multicolumn{2}{|c|}{$\begin{array}{l}\text { Sin movimiento } \\
\text { previo }\end{array}$} & \multicolumn{2}{|c|}{$\begin{array}{c}\text { Con un movimiento } \\
\text { previo } y \sin \text { él }\end{array}$} \\
\hline & Hombres & Mujeres & Hombres & Mujeres \\
\hline Totales ${ }^{a}$ & 64,4 & 70,9 & 80,2 & 85,0 \\
\hline Sin instrucción & 66,7 & 73,7 & 84,2 & 89,4 \\
\hline Primaria: 1 a 3 años & 69,9 & 75,8 & 83,7 & 87,5 \\
\hline Primaria: 4 y más años & 65,9 & 73,1 & 80,0 & 88,2 \\
\hline Secundaria: 1 a 4 años & 65,1 & 67,2 & 80,7 & 80,1 \\
\hline $\begin{array}{l}\text { Secundaria: (5 y más años), su- } \\
\text { perior y universitaria }\end{array}$ & 55,3 & 60,1 & 76,0 & 74,9 \\
\hline
\end{tabular}

a Incluye casos con "otra" clase de instrucción (ciegos, sordomudos, etc.) y casos de los que se desconoce el nivel de educación.

Sin embargo, la diferencia en movilidad es pequeña hasta llegar a un nivel de instrucción relativamente alto. Por ejemplo, de los inmigrantes del sexo masculino "sin instrucción", el 66,7 por ciento no había realizado ningún movimiento previo (movimientos realizados después de los 14 años) antes de venir al Gran Santiago, y de los inmigrantes con nivel "secundario: 1, 2, 3, 4 años", 65,1 por ciento estaban en la misma situación. Pero al pasar al nivel de educación siguiente la proporción baja a 55,3 pơr ciento. Similar observación se podría hacer basándose en la proporción de inmigrantes con un movimiento previo o sin él, tomados juntos.

El aumento de la movilidad de los inmigrantes del sexo femenino se hace aparente a partir de un nivel de instrucción más bajo, esto es, después del nivel "primaria, 4, y más años".

En la sección 4, se vio que los inmigrantes más móviles son los nacidos en lugares rurales y pequeños pueblos. Ahora se encuentra que los más móviles son los que tienen más alto nivel de instrucción. De ambas observaciones no se podría deducir que los inmigrantes de origen rural tienen un nivel de educación más elevado; al contrario, comparativamente con los inmigrantes de origen urbano, su nivel educativo es más bajo (véase el cuadro 18). Esta aparente contradicción se po- 
dría explicar por la circunstancia de que los inmigrantes de menor movilidad, sea su origen urbano o rural, son los inmigrantes con bajo nivel de instrucción.

\section{EDAD INICIAL DE LA HISTORIA MIGRATORIA}

De los datos de la encuesta se deduce que alrededor del 35 por ciento de los inmigrantes al Gran Santiago de las últimas décadas, iniciaron su historia migratoria antes de cumplir los 15 años de edad. De aquel número, dos tercios llegaron al Gran Santiago antes de cumplir esa edad; el tercio restante después de cumplirla. ${ }^{37}$

Estas cifras demuestran que una parte importante de los inmigrantes del Gran Santiago realizó por lo menos un movimiento migratorio en edad infantil.

Los comentarios que siguen se refieren exclusivamente a inmigrantes llegados al Gran Santiago después de cumplir los 14 años de edad. De ellos se estudia: a) la edad inicial de la historia migratoria desde el momento del nacimiento, y $b$ ) la edad inicial de la historia después de cumplir los 14 años de edad.

a) La edad inicial de la historia migratoria a partir del momento del nacimiento se tabuló para el último (Gran Santiago), el penúltimo y antepenúltimo movimiento. Por consiguiente se tiene la información precisa para los inmigrantes con uno, dos y tres movimientos. ${ }^{38}$

Para orientar el análisis se plantean los siguientes supuestos provisionales: i) la mayoría de los inmigrantes comenzaron su historia migratoria antes de cumplir 20 años; ${ }^{39}$ ii) el promedio de las mujeres comienza su historia migratoria antes que los hombres; iii) la historia

37 En lo que sigue de esta sección solamente se consideran los inmigrantes llegados al Gran Santiago después de los 14 años de edad. En consecuencia, es oportuno indicar aquí cuál fue la importancia relativa de la población inmigrante que se deja de lado, esto es, la que llegó antes de cumplir los 14, años. A falta de información adecuada para ese grupo, se da, como aproximación, la información correspondiente a los que llegaron antes de cumplir los 15 años.

Los porcentajes de inmigrantes en esas edades fueron del 39 y 33 por ciento, hombres y mujeres, respectivamente. Las cifras correspondientes a inmigrantes de la ủltima década (1952-1962) fueron 31 y 26 por ciento; las del período 19421951, de 37 y 29 por ciento; y las cifras de los inmigrantes de 1941 y años anteriores, fueron 48 y 43 por ciento. Como se sabe, estas proporciones están sobreestimadas por el efecto de la mortalidad diferencial según la edad, de modo que las cifras de la última década constituyen el punto de referencia más seguro.

38 Los restantes casos, con 4 y más movimientos, constituyen sólo el 14 por ciento de los casos estudiados.

39 De acuerdo con las leyes de Chile, la mayoría de edad se alcanza a los 21 años de edad. 
Cuadro 27

INMIGRANTES LLEGADOS AL GRAN SANTIAGO DE 14 Y MAS AÑOS DE EDAD, SEGUN LA EDAD INICIAL DE LA HISTORIA MIGRATORIA (A PARTIR DEL NACIMIENTO) Y SEGUN EL NUMERO DE MOVIMIENTOS

(Inmigrantes de uno, dos y tres movimientos)

\begin{tabular}{lcccc}
\hline \multirow{2}{*}{$\begin{array}{c}\text { Sexo } \\
\text { y número de }\end{array}$} & \multicolumn{4}{c}{ Edad inicial de la historia migratoria } \\
\cline { 2 - 5 } & $\begin{array}{c}\text { Antes de } \\
14 \text { años }\end{array}$ & $\begin{array}{c}14 \text { a } 29 \\
\text { años }\end{array}$ & $\begin{array}{c}30 \text { y más } \\
\text { años }\end{array}$ & Totala \\
\hline & \multicolumn{4}{c}{ (Porcentajes) } \\
Hombres & 12,4 & 70,9 & 16,7 & $100(691)$ \\
Uno & - & 82,5 & 17,5 & $100(435)$ \\
Dos & 40,5 & 48,8 & 10,7 & $100(168)$ \\
Tres & 20,5 & 55,7 & 23,8 & $100(88)$ \\
Mujeres & 15,6 & 68,9 & 15,5 & $100(1207)$ \\
Uno & - & 82,9 & 17,1 & $100(774)$ \\
Dos & 55,3 & 37,5 & 7,2 & $100(293)$ \\
Tres & 18,6 & 57,1 & 24,3 & $100(140)$ \\
\hline
\end{tabular}

a Entre paréntesis, número de casos observados.

migratoria se inicia antes en los inmigrantes con más movimientos migratorios, y iv) la edad inicial de la historia migratoria es más baja, en promedio, en los inmigrantes de origen rural.

Respecto del punto i), las cifras dan una respuesta afirmativa. Los datos del cuadro 27 no son conclusivos por sí mismos, por falta de detalle en las edades, pero complementados con los datos del cuadro 29 se puede asumir que más del 50 por ciento de los inmigrantes llegados al Gran Santiago después de los 14 años, comenzó su historia migratoria antes de los 20. El cuadro muestra que casi 15 por ciento lo hicieron antes de los 14 años, por consiguiente se está admitiendo que entre los 14 y 19 años se movió por primera vez más del 35 por ciento de los inmigrantes considerados. Algo más de un 15 por ciento inició su historia migratoria en edad tardía, esto es después de los 30 años. ${ }^{40}$

40 Los resultados presentados se refieren, como se dijo en el texto, a inmigrantes con uno, dos y tres movimientos, los que forman el 86 por ciento de los casos. Ahora bien, los inmigrantes con 4 y más movimientos presentan en conjunto, si se consideran en ellos sólo los tres últimos movimientos, una distribución por 
Lo indicado en el punto ii) parece válido solamente para los inmigrantes de origen "rural" y "semi-urbano", ya que ocurría lo contrario entre los inmigrantes de origen "urbano". Entre los primeros, es netamente más alta la proporción de mujeres que inician su historia antes de los 14. años (véanse los cuadros 27 y 28), asi como también lo es la proporción de los que emigraron por vez primera entre los 14 y 29 años. (Véase el cuadro 28.)

El supuesto iii) sólo puede verificarse parcialmente y ello con los inmigrantes con uno o más movimientos previos. ${ }^{41}$ Comparando los datos de inmigrantes con uno y con dos movimientos previos, tal supuesto no se cumple. En efecto, la proporción que se movió antes de los 14 años entre los inmigrantes con dos movimientos previos, es aproximadamente la mitad de la proporción que correspondió a los inmigrantes con un movimiento. Por otra parte, la proporción que se movió después de los 30 años es netamente mayor en el grupo con dos movimientos. Ambos resultados, que se repiten para los dos sexos, indicarían que la edad inicial de la historia migratoria de los inmigrantes con dos movimientos previos es netamente más alta que la edad inicial de los inmigrantes con un movimiento. Podría pensarse en varias explicaciones. Una de ellas, que los inmigrantes con un movimiento comprenden una parte relativamente grande de personas que cumplieron una etapa migratoria previa al Gran Santiago acompanando a sus padres o a las personas de quienes dependían; mientras que en los inmigrantes con 2 movimientos predomina un tipo de persona de alta movilidad, no obstante que su vida migratoria comenzó relativamente tarde y quizá se movieron inicialmente solos. Examinando el comportamiento de los inmigrantes con 3 y más movimientos previos, se vuelven a encontrar los resultados similares a aquéllos obtenidos para los de 2 movimientos.

Sistemáticamente, aunque en forma relativamente leve, se cumple en las cifras de los cuadros 28 y 29 el supuesto iv), lo que está netamente definido respecto de las mujeres, cumpliéndose, cualquiera que sea el número de movimientos, que la edad inicial de la historia es más baja en los lugares "rurales" y "semi-urbanos". Las diferencias, no obstante, no merecen destacarse como una característica saliente.

b) El estudio de la edad inicial de la historia migratoria a partir de los 14 años parece justificado por algunas de las razones ya expues-

edad muy similar a los inmigrantes con 3 movimientos. Considerados así, su introducción en el cuadro 27 elevaría levemente las proporciones en las edades extremas y disminuiría proporcionalmente el grupo central.

41 Tratándose de inmigrantes sin movimientos previos, resulta obvio que la edad inicial sea mayor que la de los inmigrantes con un movimiento previo, ya que por definición el análisis se limitó a los que llegaron al Gran Santiago después de los 14 años de edad. 
Cuadro 28

PORCENTAJE DE INMIGRANTES LLEGADOS AL GRAN SANTIAGO

DE 14. Y MAS AÑOS DE EDAD, SEGUN LA EDAD INICIAL

DE LA HISTORIA MIGRATORIA, EL LUGAR DE NACIMIENTO

Y EL NUMERO DE MOVIMIENTOS

(Inmigrantes de uno, dos y tres movimientos)

\begin{tabular}{|c|c|c|c|c|}
\hline \multirow{2}{*}{$\begin{array}{c}\text { Lugar de } \\
\text { nacimiento, } \\
\text { sexo y número } \\
\text { de movimientos }\end{array}$} & \multicolumn{4}{|c|}{ Edad inicial de la historia migratoria } \\
\hline & $\begin{array}{l}\text { Antes de } \\
14 \text { años }\end{array}$ & $\begin{array}{c}14 \text { a } 29 \\
\text { años }\end{array}$ & $\begin{array}{l}30 \text { y más } \\
\text { años }\end{array}$ & Totalb \\
\hline & \multicolumn{4}{|c|}{ (Porcentajes) } \\
\hline \multicolumn{5}{|l|}{ URBANO } \\
\hline Hombres & 12,6 & 71,8 & 15,6 & $100(206)$ \\
\hline Uno & - & 81,6 & 18,4 & $100(136)$ \\
\hline Dos & 46,5 & 46,5 & 7,0 & $100(43)$ \\
\hline Tres & 22,2 & 63,0 & 14,8 & $100(27)$ \\
\hline Mujeres & 8,8 & 73,8 & 17,4 & $100(362)$ \\
\hline Uno & - & 81,3 & 18,7 & $100(267)$ \\
\hline Dos & 49,1 & 38,2 & 12,7 & $100(55)$ \\
\hline Tres & 12,5 & 72,5 & 15,0 & $100(40)$ \\
\hline \multicolumn{5}{|l|}{ Semi-urbano } \\
\hline Hombres & 10,8 & 74,7 & 14,5 & $100(166)$ \\
\hline Lno & - & 87,8 & 12,2 & $100(107)$ \\
\hline Dos & 40,0 & 45,0 & 15,0 & $100(40)$ \\
\hline Tres & 10,5 & 63,2 & 26,3 & $100(19)$ \\
\hline Mujeres & 18,3 & 70,1 & 11,6 & 100 \\
\hline Uno & - & 87,7 & 12,3 & $100(187)$ \\
\hline Dos & 57,5 & $4,0,0$ & 2,5 & $100(80)$ \\
\hline Tres & 26,5 & 44,1 & 29,4 & $100(34)$ \\
\hline \multicolumn{5}{|l|}{ RuRAL } \\
\hline Hombres & 12,0 & 73,2 & 14,8 & $100(250)$ \\
\hline Uno & - & 84,1 & 15,9 & $100(157)$ \\
\hline Dos & 36,7 & 56,7 & 6,6 & $100(60)$ \\
\hline Tres & 24,3 & 51,5 & 24,2 & $100(33)$ \\
\hline Mujeres & 38,7 & 68,2 & 13,1 & $100(475)$ \\
\hline Uno & - & 85,5 & 14,5 & $100(282)$ \\
\hline Dos & 56,5 & 36,9 & 6,6 & $100(138)$ \\
\hline Tres & 20,0 & 58,2 & 21,8 & $100(55)$ \\
\hline
\end{tabular}

a De acuerdo con el tamaño del núcleo o localidad: urbano, 20000 y núas habitantes; semiurbano, 5000 a 19999 habitantes, y rural, de menos de 5000 habitantes $\mathrm{y}$ población

b Entre paréntesis, número de casos observados. 


\section{Cuadro 29}

PORCENTAJES DE INMIGRANTES LLEGADOS AL GRAN SANTIAGO. DE 14 Y MAS ANNOS DE EDAD, SEGUN LA EDAD INICIAL DE LA HISTORIA MIGRATORIA DESPUES DE LOS 14 AÑOS Y SEGUN EL LUGAR DE NACIMIENTO

\begin{tabular}{|c|c|c|c|c|c|c|c|c|}
\hline \multirow{2}{*}{$\begin{array}{l}\text { Edad inicial } \\
\text { de la historia } \\
\text { migratoria, } \\
\text { después } \\
\text { de los 14 años } \\
\text { de edad }\end{array}$} & \multicolumn{4}{|c|}{ Hombres } & \multicolumn{4}{|c|}{ Mujeres } \\
\hline & Urbano & $\begin{array}{l}\text { Semi- } \\
\text { urbano }\end{array}$ & Rural & Total a & Urbano & $\begin{array}{l}\text { Semi- } \\
\text { urbano }\end{array}$ & Rural & Total a \\
\hline \multicolumn{9}{|c|}{ (Porcentajes) } \\
\hline $14-19$ & 45,0 & 44,1 & 45,9 & 43,4 & 40,7 & 48,6 & 50,1 & 45,1 \\
\hline $20-24$ & 28,5 & 28,9 & 29,5 & 28,0 & 25,6 & 25,4 & 23,1 & 24,7 \\
\hline $25-29$ & 9,9 & 12,8 & 11,5 & 12,2 & 17,0 & 12,9 & 13,0 & 14,2 \\
\hline $14-29$ & 83,4 & 85,8 & 86,9 & 83,6 & 83,3 & 86,9 & 86,2 & 84,0 \\
\hline $30-39$ & 11,5 & 8,3 & 8,5 & 10,6 & 10,7 & 8,6 & 6,2 & 8,9 \\
\hline 40 y más & 5,1 & 4,9 & 3,6 & 5,2 & 5,8 & 3,7 & 6,1 & 6,1 \\
\hline $\begin{array}{r}\text { Total b } \\
\mathbf{c}\end{array}$ & $\begin{array}{c}100 \\
(253)\end{array}$ & $\begin{array}{c}100 \\
(204)\end{array}$ & $\begin{array}{c}100 \\
(305)\end{array}$ & $\begin{array}{c}100 \\
(844)\end{array}$ & $\begin{array}{c}100 \\
(430)\end{array}$ & $\begin{array}{c}100 \\
(350)\end{array}$ & $\begin{array}{c}100 \\
(537)\end{array}$ & $\begin{array}{c}100 \\
(1398)\end{array}$ \\
\hline
\end{tabular}

a Incluye inmigrantes cuyo lugar de nacimiento no se conoce.

b Incluye inmigrantes cuya edad inicial migratoria no se conoce.

c Entre paréntesis, número de casos observados.

tas en la sección 1, principalmente aquella que se refiere a la dependencia en que se encuentran los niños en relación con los actos de sus padres. Es verdad que hasta una edad de 20 años y superior también, una parte de los migrantes siguen a sus padres o a personas que constituyen su sostén, pero la gran mayoría lo hace en forma independiente, principalmente solos o como jefes de familia. ${ }^{42}$

De la observación del cuadro 29 surgen algunas importantes observaciones, varias de las cuales ya fueron anticipadas en la parte $a$ ) de esta sección. Pero quizá lo más saliente es la similitud de la distribución por la edad inicial de la historia migratoria después de los 14

42 Véase la información relativa a la situación de los inmigrantes al llegar al Gran Santiago en el capítulo III, en particular el cuadro 39. Aunque muchas mujeres mayores de 14 años se encuentren en relación de dependencia del marido (o compañero), desde el punto de vista del estudio del movimiento migratorio deberían ser consideradas con igual criterio que el hombre. 
años, eso sí, reducida a dos grandes grupos ( 14 a 29 y 30 y más años), con la respectiva distribución de los inmigrantes sin movimiento previo. (Véanse los cuadros 28 y 29.) Dicha similitud se advierte en ambos sexos y en general en cada uno de los lugares de nacimiento tomados en consideración. Ambas distribuciones son estrictamente comparables, como es fácil de comprobar. La conclusión lógica sería: la distribución según la edad inicial de la historia migratoria después de los 14 años es en los inmigrantes que llegaron al Gran Santiago en un primer movimiento sensiblemente similar a la de los inmigrantes que realizaron alguna etapa previa (después de los 14 años). ${ }^{43}$ La proporción correspondiente al grupo de edad 14-29 se sitúa cerca del 84. por ciento, con una variación de 83 a 87 , yendo de origen urbano a rural. (Véase el cuadro 29.)

Examinando la distribución dentro del intervalo 14-29, se advierte, en general, Ia mayor importancia relativa de los hombres en la edad inicial 20-24 y, también, en los inmigrantes de origen urbano, en la edad 14-19; por el contrario, surge como más imporiante la importancia relativa de las mujeres de origen "semi-urbano" y "rural" en la edad inicial 14-19 de las mujeres y en la edad $25-29$ en las de origen "urbano". En resumen, hay una mayor concentración de los hombres de origen "urbano" en la edad inicial 14-24, y una mayor en esas mismas edades en las mujeres de origen "rural" y "semi-urbano".

c) Un supuesto razonable es que a menor nivel de instrucción, es más baja también la edad inicial de la historia migratoria a partir de los 14 años. Si fuera así, en los inmigrantes con edad inicial baja se encontraría una más alta proporción de personas con bajo nivel de educación, que en inmigrantes con edad inicial más avanzada.

Tal hipótesis respecto de los hombres no encuentra una confirmación en las cifras del cuadro 30 . En efecto, si se toman los inmigrantes con edad inicial 14-19, 20-24, y 25-29, donde caen la mayoría de los casos, se encuentra que la proporción con niveles 0 y 1 no disminuye con el avance de la edad, sino que más bien tiende a aumentar, variando de 16 a 22 por ciento, en cifras redondas.

Parece cumplirse, en cambio, con las mujeres. En éstas se encuentra una proporción con los niveles 0 y 1 de 36 por ciento para la edad 14-19. En las edades siguientes, 20-24 y 25-29, las proporciones se sitúan cerca del 30 por ciento.

A partir de la edad inicial 30 ó 40 años, aumenta en ambos sexos la proporción con niveles de instrucción 0 y 1 . Sin embargo, este hecho

43 Las proporciones de inmigrantes sin movimiento previo representan, aproximadamente, 52 por ciento de los hombres y 57 por ciento de las mujeres.

Por consiguiente, constituyen un poco más de la mitad de los inmigrantes del cuadro 29. 
Cuadro 30

INMIGRANTES LLEGADOS AL GRAN SANTIAGO DE 14 Y MAS ANTOS DE EDAD SEGUN LA EDAD AL LLEGAR Y EL NIVEL DE INSTRUCGION EN EL MOMENTO DE LA ENCUESTA

\begin{tabular}{|c|c|c|c|c|c|c|}
\hline \multirow{2}{*}{$\begin{array}{c}\text { Sexo } \\
\text { y edad }\end{array}$} & \multicolumn{5}{|c|}{ Nivel de instrucción ${ }^{\mathfrak{a}}$} & \multirow{2}{*}{ Totalb } \\
\hline & 0 & 1 & 2 & 3 & 4 & \\
\hline & \multicolumn{5}{|c|}{ (Porcentajes) } & \\
\hline Hombres & 6,8 & 14,6 & 37,9 & 19,7 & 20,1 & $100(844)^{\mathrm{c}}$ \\
\hline $14-19$ & 6,0 & 12,3 & 37,4 & 21,3 & 22,7 & $100(366)$ \\
\hline $20-24$ & 6,3 & 14,8 & 44,1 & 19,1 & 15,7 & $100(236)$ \\
\hline $25-29$ & 4,8 & 17,5 & 37,9 & 21,4 & 16,5 & $100(103)$ \\
\hline $30-39$ & 10,0 & 18,9 & 31,1 & 14,5 & 23,5 & $100(90)$ \\
\hline 40 y más & 13,6 & 15,9 & 20,4 & 15,9 & 27,3 & $100(44)$ \\
\hline Mujeres & 12,8 & 20,7 & 35,7 & 17,2 & 13,1 & $100(1398)^{\mathrm{c}}$ \\
\hline $14-19$ & 11,9 & 23,9 & 35,2 & 16,0 & 12,7 & $100(631)$ \\
\hline $20-24$ & 8,7 & 19,4 & 36,8 & 20,0 & 13,6 & $100(345)$ \\
\hline $25-29$ & 14,6 & 16,7 & 36,4 & 18,2 & 14,1 & $100(198)$ \\
\hline $30-39$ & 15,3 & 17,7 & 37,1 & 15,3 & 14,5 & $100(124)$ \\
\hline 40 y más & 25,9 & 17,6 & 31,8 & 15,3 & 9,4 & $100(85)$ \\
\hline
\end{tabular}

a Nivel 0: sin instrucción.

1: primaria, uno a tres años.

2: primaria, cuatro a seis años.

3: secundaria, uno a cuatro años.

4: secundaria, cinco años o más; superior y universitaria.

b Incluye casos cuyo nivel de educación no se conoce. Entre paréntesis, número de casos observados.

c Incluye casos cuya edad no se conoce.

no podría ser interpretado como factor de migración tardía antes de eliminar el efecto diferencial de la edad en relación al nivel de educación. En efecto, tales inmigrantes eran, en promedio, más viejos en el momento de la encuesta, que aquellos que comenzaron su historia migratoria a edad más temprana. Muchos de estos últimos todavía son jóvenes; los primeros, necesariamente, han superado los 30 años. Es bien sabido, por otra parte, que el nivel de instrucción es más alto en general en las personas jóvenes.

Puede aún mirarse qué ocurre con los niveles educativos más altos. Para ello es adecuado considerar el 4 , o sea el más alto que figura en el cuadro 30. Aquí nuevamente se encuentra que los hombres con edad 
inicial 14-19 son los que ostentan una proporción más alta (23 por ciento), comparada con las edades $20-24$ y $25-29$ (16 por ciento). Llama la atención que la proporción en el nivel 4 vuelve a subir después de la edad inicial 30 años, probablemente porque dentro de estos inmigrantes, de nivel de instrucción en general bajo, hay un grupo particularmente calificado (profesionales, semi-profesionales, etc.). No se advierte un comportamiento similar en las mujeres.

En resumen: tratándose de inmigrantes que iniciaron su historia migratoria en una edad relativamente temprana (14-29 años), el nivel educativo desciende con la edad en el caso de los hombres, pero aumenta en el de las mujeres; de los que la iniciaron tardíamente (30 años y más), en los hombres se encuentran dos grupos relativamente importantes en ambos extremos de la escala educativa, pero en las mujeres el nivel se deteriora aun más al avanzar la edad.

El bajo nivel de instrucción de las mujeres que iniciaron su historia migratoria en la edad más baja (14-19) merece especial atención. Una explicación podría ser la presencia de un grupo relativamente importante de baja instrucción que llega al Gran Santiago, muchas de las cuales trabajarán en el servicio doméstico. ${ }^{44}$

44 Véase el capítulo V, sección 5. 
.

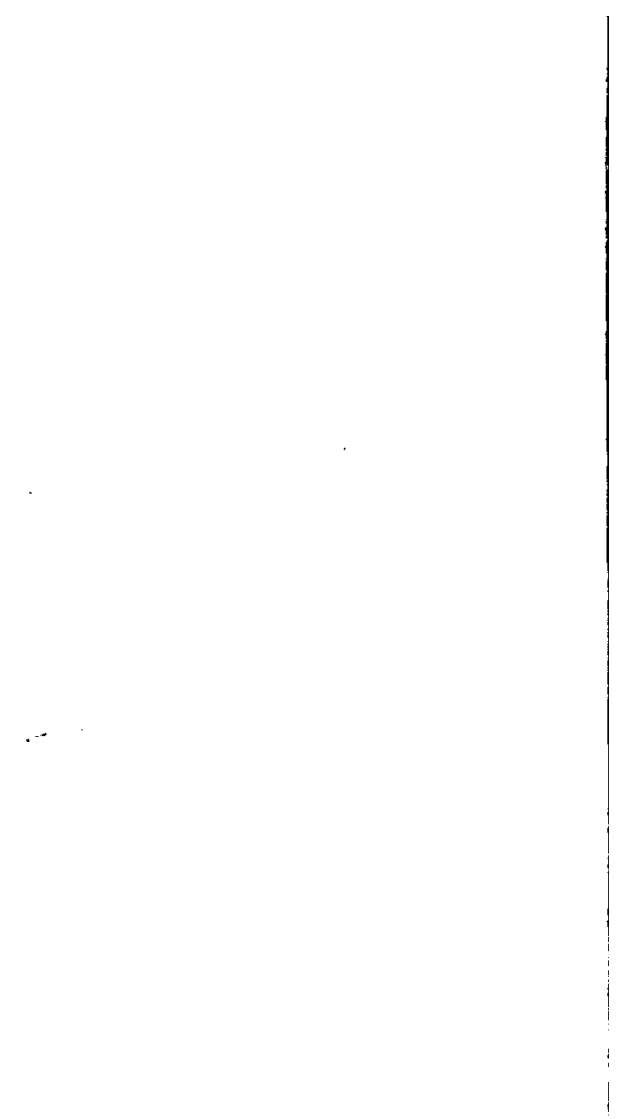




\section{FACTORES ECONOMICO-SOCIALES VINCULADOS AL MOVIMIIENTO MIGRATORIO HACIA EL GRAN SANTIAGO}

\section{INTRODUCCIÓN}

Para investigar los factores económico-sociales que influyen en los movimientos migratorios, en particular en la migración hacia un centro urbano de fuerte atracción como es el Gran Santiago, se pueden seguir dos métodos: el primero que se adopta en este estudio consiste en investigar las características individuales de los inmigrantes, y, el segundo, en averiguar las características colectivas de las poblaciones que experimenian la emigración de sus habitantes; o sea, en estudiar las condiciones demográficas y sociales de las regiones de fuerte emigración. En verdad, ambos métodos se complementan y sería deseable llevar a cabo tal investigación.

Ahora bien, la información que proporcionó la encuesta de inmigración del Gran Santiago, por su naturaleza conduce necesariamente a la primera clase de análisis, el de las características individuales de los inmigrantes. Esta clase de información tiene algunas limitaciones relativas a la representatividad de la muestra, que deberán tenerse en mente. Tales limitaciones surgen de las siguientes condiciones:

i) Aun cuando la muestra es sin duda representativa de los inmigrantes que vivían en la zona santiaguina en el momento de la encuesta, probablemente no lo es de la totalidad de los inmigrantes llegados al Gran Santiago. Quizás esté exagerada la representación de los llegados en épocas relativamente recientes por efecto de la mortalidad, y tal vez, en alguna medida, pero de poca significación, por la ulterior emigración. En razón de la mortalidad está exagerada también la representación de los inmigrantes que llegaron jóvenes y disminuida la de los que arribaron relaiivamente maduros y ancianos. La influencia de la época y la edad de llegada podría estudiarse analizando separadamente las cifras de emigrantes según estas dos características. Desafortunadamente, el tamaño de la muestra impide un análisis de esa naturaleza. Por este motivo, sólo se consideró a los inmigrantes de más de 14, años de edad llegados en los últimos 20 años (1942-1962). 
ii) Otro inconveniente reside en el hecho de que se trata de información relativa a fenómenos o situaciones que datan a veces de muchos años, lo que hace que la fragilidad de la memoria no permita reconstituirlos con fidelidad absoluta.

En la sección siguiente se define la población estudiada y se examinan su composición por sexo y edad y las zonas de procedencia. También se presenta el grado de participación en actividades económicas en la época inmediatamente anterior a la emigración al Gran Santiago y, además, una clasificación económico-social basada en la ocupación en esa misma época. Estos antecedentes tienen por objeto mostrar importantes aspectos sociales referidos a la época que precedió al movimiento.

La sección 3 contiene un estudio del tipo de inmigración (individual o familiar) que aporta elementos de juicio adicionales para la mejor comprensión de los motivos determinantes de la emigración.

En las secciones 4, 5 y 6 se analizan las causas declaradas de la emigración, en relación con el sexo, la edad y la zona de procedencia, con el grado de empleo anterior y con las clases económico-sociales.

\section{La POBLACIÓN ESTUDIADA Y SUS PRINCIPALES CARACTERÍSTICAS}

La población está formada por los inmigrantes mayores de 14, años llegados en el período 1942-1962. Todas las características (edad, ocupación, motivo para inmigrar, etc.) están referidas a la fecha de arribo a Santiago o a una época inmediata anterior.

La exclusión de los inmigrantes que llegaron antes de haber cumplido los 14 años de edad se justifica teniendo en cuenta el objetivo de este capitulo. En efecto, el movimiento de las personas excluidas es una derivación de la inmigración de personas adultas, de modo que respecto de ellas no sería lógico hablar de factores o motivos propios de emigración.

La población estudiada en esta parte está formada por 1487 inmigrantes $^{45}$ (36,4 por ciento de hombres y 63,6 por ciento de mujeres). Constituye aproximadamente el 61 por ciento de la totalidad de los inmigrantes que llegaron de más de 14, años enumerados en la encuesta, pero la composición por sexo y edad de este 61 por ciento es semejante a la del total. ${ }^{46}$

45 De los casos registrados y pertenecientes al período 1942-1962 (1620), el análisis se redujo al 91,8 por ciento (l 487). Al resto ( 133 casos, de los cuales 86 son varones) no se le pudo considerar por falta de información (no se realizó el cuestionario B; véase el Apéndice II).

46 El número total de inmigrantes llegados de más de 14 años y. sin limi- 
Cuadro 31

TASAS DE PARTICIPACION EN ACTIVIDADES ECONOMICAS DE INMIGRANTES, EN EL LUGAR DE PROCEDENCIA Y EN EL GRAN SANTIAGO EN LA EPOCA DE LA ENCUESTAa

\begin{tabular}{|c|c|c|}
\hline \multirow{2}{*}{$\begin{array}{l}\text { Clase de inmigrante, lugar y época } \\
\text { de referencia, y periodo de llegada }\end{array}$} & \multicolumn{2}{|c|}{$\begin{array}{l}\text { Tasas de participación en actividades } \\
\text { económicas (porcentajes) b, c }\end{array}$} \\
\hline & Hombres & Mujeres \\
\hline $\begin{array}{l}\text { Inmigrantes que llegaron con más } \\
\quad \text { de } 14 \text { años de edad }\end{array}$ & & \\
\hline $\begin{array}{l}\text { Actividad en el lugar de procedencia: } \\
\text { Período 1942-1962 }\end{array}$ & 78,4 & 43,6 \\
\hline $\begin{array}{l}\text { Inmigrantes que llegaron en cualquier } \\
\text { edad }\end{array}$ & & \\
\hline $\begin{array}{l}\text { Actividad en el Gran Santiago, } \\
\text { en la época de la encuesta: } \\
\text { Período 1952-1962 } \\
\text { Antes de } 1952\end{array}$ & $\begin{array}{l}81,9 \\
83,7 \\
81,1\end{array}$ & $\begin{array}{l}41,5 \\
45,3 \\
32,3\end{array}$ \\
\hline \multicolumn{3}{|c|}{$\begin{array}{l}\text { a Población de más de } 15 \text { años de edad en la época respectiva. } \\
\text { b Razón entre personas económicamente activas y el total de personas de más de } \\
15 \text { años de edad. } \\
\text { c Se excluyó de la población económicamente activa a las personas que buscaban } \\
\text { trabajo por primera vez. El número de personas en esa situación en el momento } \\
\text { de la encuesta es muy pequeño, pero probablemente no refleja la realidad. En } \\
\text { cambio, en el lugar de procedencia, la inclusión o no de las personas que } \\
\text { buscaban trabajo por primera vez tiene un efecto importante sobre la tasa de } \\
\text { actividad. Si se incluyen esas personas, las tasas de hombres y mujeres serian } \\
\text { de } 83,2 \text { y } 53,3 \text { por ciento, en lugar de } 78,4 \text { y } 43,6 \text {. }\end{array}$} \\
\hline
\end{tabular}

La información detallada por sexo, edad de llegada y zonas de procedencia se analizó en el capítulo $I$.

Los datos obtenidos (véase el cuadro 31 ) señalan que la tasa global de actividad en el lugar de procedencia de los inmigrantes es similar a la de la población inmigrante en general en el momento de la encuesta. La tasa masculina (población de más de 15 años) pasa del 80 por ciento y la femenina excede ligeramente del 40.

tación de período de llegada fue de 2440 (excluyendo unos pocos casos de edad de llegada desconocida). La proporción de hombres es 39,4 por ciento, en lugar de 36,4 por ciento. 
Cuadro 32

INMIGRANTES SEGUN "CLASES" ECONOMICO-SOCIALES EN EL LUGAR DE PROCEDENCIA, POR ZONAS DE PROCEDENCIA

\begin{tabular}{|c|c|c|c|c|}
\hline $\begin{array}{l}\text { "Clases" } \\
\text { económico-sociales }\end{array}$ & $\begin{array}{l}\text { Núcleos } \\
\text { de más } \\
\text { de } 5000 \\
\text { habitantes }\end{array}$ & $\begin{array}{l}\text { Núcleos } \\
\text { de menos } \\
\text { de } 5000 \\
\text { habitantes } \\
\text { (incluso } \\
\text { rural) }\end{array}$ & $\begin{array}{l}\text { Otras } \\
\text { proce- } \\
\text { dencias }\end{array}$ & Total \\
\hline Hombres & \multicolumn{4}{|c|}{ (Porcentajes) } \\
\hline $\begin{array}{l}\text { Trabajadores no manuales } \\
\text { Trabajadores manuales } \\
\text { Trabajadores agrícolas } \\
\text { Otros trabajadoresb }\end{array}$ & $\begin{array}{r}31,3 \\
52,0 \\
14,5 \\
2,2\end{array}$ & $\begin{array}{c}11,3 \\
27,4 \\
61,3 \\
-\end{array}$ & $\begin{array}{l}- \\
- \\
-\end{array}$ & $\begin{array}{r}27,4 \\
42,7 \\
27,9 \\
2,0\end{array}$ \\
\hline $\begin{array}{l}\text { Sub-total c } \\
\text { (Número de personas) }\end{array}$ & $\begin{array}{l}100,0 \\
(227)\end{array}$ & $\begin{array}{l}100,0 \\
(106)\end{array}$ & $\overline{(25)}$ & $\begin{array}{l}100,0 \\
(358)\end{array}$ \\
\hline $\begin{array}{l}\text { Trabajadores en todas } \\
\text { las ocupaciones (excepto } \\
\text { trabajadores familiares no } \\
\text { remunerados) } \\
\text { Trabajadores familiares }\end{array}$ & 75,4 & 70,2 & - & 74,3 \\
\hline $\begin{array}{l}\text { Personas que buscaban } \\
\text { trabajo por primera vez }\end{array}$ & 5,0 & 5,3 & - & 4,8 \\
\hline $\begin{array}{l}\text { Personas no económicamente } \\
\text { activas }\end{array}$ & 16,9 & 17,9 & -- & 16,8 \\
\hline $\begin{array}{l}\text { Sub-total } \\
\text { (Número de personas) } \\
\text { Sin información }\end{array}$ & $\begin{array}{c}100,0 \\
(301) \\
(50) \\
\end{array}$ & $\begin{array}{c}100,0 \\
(151) \\
(17)\end{array}$ & $\begin{array}{l}- \\
(30) \\
(4)\end{array}$ & $\begin{array}{c}100,0 \\
(482) \\
(71) \\
\end{array}$ \\
\hline $\begin{array}{l}\text { Total de personas } \\
\text { Mujeres }\end{array}$ & (351) & (168) & (34) & $(553)$ \\
\hline $\begin{array}{l}\text { Trabajadoras no manuales } \\
\text { Trabajadoras manuales } \\
\text { Trabajadoras agrícolas } \\
\text { Otras trabajadoras }\end{array}$ & $\begin{array}{r}27,2 \\
69,6 \\
3,2 \\
-\end{array}$ & $\begin{array}{r}13,2 \\
84,2 \\
2,6 \\
-\end{array}$ & $\begin{array}{l}- \\
- \\
-\end{array}$ & $\begin{array}{r}24,7 \\
72,3 \\
3,0 \\
-\end{array}$ \\
\hline $\begin{array}{l}\text { Sub-total e } \\
\text { (Número de personas) }\end{array}$ & $\begin{array}{l}100,0 \\
(125)\end{array}$ & $\begin{array}{l}100,0 \\
(38)\end{array}$ & $\overline{(3)}$ & $\begin{array}{l}100,0 \\
(166)\end{array}$ \\
\hline $\begin{array}{l}\text { Trabajadoras en todas las } \\
\text { ocupaciones (excepto tra. } \\
\text { bajadoras familiares no } \\
\text { remuneradas) }\end{array}$ & 49,0 & 31,4 & - & 43,3 \\
\hline
\end{tabular}


Cuadro 32 (continuación)

\begin{tabular}{|c|c|c|c|c|}
\hline $\begin{array}{l}\text { "Clases" } \\
\text { económico-sociales }\end{array}$ & $\begin{array}{c}\text { Núcleos } \\
\text { de más } \\
\text { de } 5000 \\
\text { habitantes }\end{array}$ & $\begin{array}{l}\text { Núcleos } \\
\text { de menos } \\
\text { de } 5000 \\
\text { habitantes } \\
\text { (incluso } \\
\text { rural) }\end{array}$ & $\begin{array}{l}\text { Otras } \\
\text { proce- } \\
\text { dencias }\end{array}$ & Total \\
\hline \multirow{3}{*}{$\begin{array}{l}\text { Trabajadoras familiares no } \\
\text { remuneradas } \\
\text { Personas que buscan traba- } \\
\text { jo por primera vez } \\
\text { Personas no economicamen- } \\
\text { te activas }\end{array}$} & - & 0,8 & - & 0,3 \\
\hline & 8,6 & 11,6 & - & 9,7 \\
\hline & 42,4 & 56,2 & - & 46,7 \\
\hline $\begin{array}{l}\text { Sub-total } \\
\text { (Número de personas) }\end{array}$ & $\begin{array}{l}100,0 \\
(255)\end{array}$ & $\begin{array}{l}100,0 \\
(121)\end{array}$ & $\overline{(7)}$ & $\begin{array}{l}100,0 \\
(383)\end{array}$ \\
\hline 'Total de nersonas & $(274)$ & $(129)$ & (7) & $(4,0)$ \\
\hline
\end{tabular}

a Del exterior y procedencia desconocida.

b Fuerzas armadas, personal diplomático extranjero y ocupaciones mal definidas y desconocidas.

c Excluyendo a los trabajadores familiares no remunerados.

La tasa de actividad de los inmigrantes del primer grupo (llegados de más de 14 años) es un poco más baja que la del segundo (inmigrantes llegados a cualquier edad) (véase el cuadro 31), aunque debía esperarse lo contrario. Sin embargo, la situación anotada se explica principalmenie porque la población inmigrante del primer grupo (que está considerada en el momento de la inmigración) es más joven que la del segundo. Nientras que en el primero la población masculina de 15 a 19 años representaba alrededor del 27 por ciento del total respectivo de más de 15 años, en el segundo era de sólo 9 por ciento. En la población femenina las proporciones respectivas son, aproximadamente, 32 y 9 por ciento. ${ }^{47}$ Como la tasa de actividad de personas de 15 a 19 años es más baja que la de personas de más edad, la mayor importancia relativa de la población de 15 a 19 años influye sobre el nivel de la tasa global en sentido desfavorable. ${ }^{48}$

47 Las cifras exactas son las siguientes: hombres, 27,2 y 8,7 por ciento; mujeres, 32,1 y 8,9 por ciento.

48 Otro factor que influye en el mismo sentido es la edad inicial considerada en cada caso: a partir de los 14 años, en los inmigrantes llegados de más de 
Los inmigrantes se clasificaron en "clases" económico-sociales"9 conforme a la ocupación que tenían en la época inmediata anterior a la venida al Gran Santiago. (Véase el cuadro 32.) Debió excluirse a los trabajadores familiares no remunerados por faltar la información relativa a la ocupación en el lugar de procedencia. Su inclusión aumentaría la población presentada en el cuadro en 5,6 por ciento. Aunque es probable que la mayor parte de esos trabajadores se dedicara a tareas agrícolas, no se intentó distribuirlos por ocupaciones.

El 70,6 por ciento de los inmigrantes económicamente activos corresponde a trabajadores manuales, incluyendo en éstos a los trabajadores agrícolas, que representan por sí solos el 27,9 por ciento. De

Y la mano de obra femenina, excluyendo a las trabajadoras agrícolas, las que carecen de importancia numérica ( 3 por ciento), pertenecía al sector de los oficios manuales el 72,3 por ciento.

\section{INMIGRACIÓN INDIVIDUAL E INMIGRACIÓN FAMILIAR}

Desde el doble punto de vista demográfico y sociológico, los factores determinantes y los efectos de un movimiento migratorio probablemente difieren según se trate de individuos aislados o de grupos familiares. En el movimiento migratorio hacia las grandes ciudades hay que esperar ambos tipos de migración, pero hasta ahora no se conoce casi nada acerca de la importancia numérica de las personas de uno y otro sexo que llegan solas a las capitales de América Latina. También desconocemos la importancia de la inmigración de tipo familiar según clase de familia.

El desplazamiento de individuos solos, habla generalmente de un acto de acomodación económica y social al llegar a la edad adulta. Es probable que este tipo de movimiento sea menos costoso para el inmigrante (y también para la sociedad) que el traslado de un grupo familiar. Por otra parte, parece ser verdad que contribuye con mayor frecuencia a la desorganización familiar, con sus consecuencias desfavorables en el proceso de integración del inmigrante. Además, una corriente desequilibrada de personas en cuanto al sexo (por ejemplo, mayor número de mujeres) puede crear serios problemas sociales. El efecto perturbador de tal desequilibrio sobre la estructura por sexo y edad, la nupcialidad y la fecundidad no podría desconocerse.

14 años y respecto de la ocupación en el lugar de procedencia; a partir de los 15 años, en los inmigrantes en general, respecto de la ocupación en el momento de la encuesta. Naturalmente, la tasa de participación a los 14 años es más baja que las tasas de las edades siguientes. El efecto, sin embargo, es pequeño.

49 Véanse los antecedentes de esta clasificación en el capítulo V, sección 6. 
En el presente estudio, los inmigrantes llegados después de cumplir los 14 años de edad se clasificaron en grandes grupos que permiten medir la importancia relativa de la inmigración individual y de la inmigración de familias. Los inmigrantes que estaban a cargo de otros en el momento de llegar (como esposa, hijos, hermanos, padres ancianos, inválidos, etc.) aparecen en una categoría especial (inmigrantes a cargo). Por lo tanto, con la excepción de los de esta última categoría, los restantes inmigrantes que aparecen en el cuadro 33 eran o bien personas que llegaron solas, o bien jefes virtuales de un grupo familiar de inmigrantes; se dice viriualmente porque no hay información directa sobre ello. En todo caso existe la presunción de que se trata de personas que no estaban a cargo de otras. ${ }^{50}$

Los inmigrantes que llegaron fermando parte de un grupo familiar y que, presuntivamente, no estaban a cargo de otros del grupo, se clasificaron a su vez en tres categorías: matrimonios o parejas, con hijos o sin ellos; una mujer con uno o más hijos a cargo; y un hombre (o mujer) sin compañera(o), pero con parientes. En las dos primeras categorías no se distinguió si había o no otros parientes. La tabulación básica contiene más información relativa al número de hijos, pero como un examen de los datos hizo ver que no aportaría elementos de juicio adicionales, no se consideró.

El mayor porcentaje de casos corresponde a los inmigrantes que llegaron solos: 54,3 por ciento de los hombres y 48,9 por ciento de las mujeres. En ambos sexos esa proporción es claramente mayor entre los inmigrantes procedentes de Ics sectores rurales, incluyendo los nú. cleos de menos de 5000 habitantes: 63,3 y 59,4 por ciento, respectivamente. (Véase el cuadro 33.)

En crden de importancia siguen los movimientos de parejas (con hijos o sin ellos, con otros parientes o sin ellos) : 30,1 por ciento, proporción que también varía bastante según sea la zona de procedencia. Pero esta vez, como es lógico, a la inversa de lo que ocurrió con la inmigración de personas solas, la proporción menor correspondió a los inmigrantes procedentes de núcleos de menos de 5000 habi:antes (20.5 por ciento). Ahora bien, la migración de parejas está referida casi exclusivamente a inmigrantes del sexo masculino (el marido o compa-

50 En cl cuadro 34, donde se clasifica a los inmigrantes según el motivo principal de su migración al Gran Santiago, los que estaban a cargo de otros apa. recen ea un grupo separado. Las cifras respectivas son algo inferiores a las del cuadro 33, siendo posible que la diferencia corresponda a inmirrantes que estaban a cargo, no obstante lo cual se clasificaron indebidamente atendiendo a algunos de los motivos específicos de inmigración. El motivo "estudios del entrevi:tado, o de sus parientes" -al que corresponde un número relativamente elevado de personas menores de 20 años-, puede muy bien explicar gran parte de las diferencias señaladas. 
Cuadro 33

INMIGRANTES SEGUN EL TIPO DE MIGRACION INDIVIDUAL Y DE GRUPOS FAMILIARES, POR ZONAS DE PROCEDENCIA, PERIODO 1942-1962

\begin{tabular}{|c|c|c|c|c|c|c|}
\hline \multirow[b]{3}{*}{ Tipo de migración } & \multicolumn{3}{|c|}{ Hombres } & \multicolumn{3}{|c|}{ Mujeres } \\
\hline & \multicolumn{2}{|c|}{ Núcleos } & \multirow[b]{2}{*}{ Total } & \multicolumn{2}{|c|}{ Núcleos } & \multirow[b]{2}{*}{ Totalb } \\
\hline & $\begin{array}{c}\text { Más de } \\
5000 \\
\text { habi- } \\
\text { tantes }\end{array}$ & $\begin{array}{l}\text { Menos d } \\
5000 \\
\text { habit. } \\
\text { (inclu. } \\
\text { yendo } \\
\text { sect. } \\
\text { rurales) }\end{array}$ & & $\begin{array}{c}\text { Más de } \\
5000 \\
\text { habi- } \\
\text { tantes }\end{array}$ & $\begin{array}{l}\text { Menos de } \\
5000 \\
\text { habit. } \\
\text { (inclu- } \\
\text { yendo } \\
\text { sect. } \\
\text { rurales) }\end{array}$ & \\
\hline & \multicolumn{6}{|c|}{ (Porcentajes) } \\
\hline $\begin{array}{l}\text { Parejas, con hijos o sin } \\
\text { ellos } \\
\text { Padre (madre) con }\end{array}$ & 33,1 & 20,5 & 30,1 & 0,5 & 0,7 & 0,5 \\
\hline hijosd & 0,9 & 1,8 & 1,1 & 7,8 & 6,4 & 7,1 \\
\hline Personas solas & 50,9 & 63,3 & 54,3 & 44,9 & 59,4 & 48,9 \\
\hline Con parientese & 1,2 & 4,2 & 2,4 & 1,6 & 1,7 & 1,6 \\
\hline Desconocido & 0,5 & - & 0,4 & 0,6 & 1,0 & 0,7 \\
\hline Personas a cargot & 13,4 & 10,2 & 11,7 & 44,6 & 30,8 & 41,2 \\
\hline $\begin{array}{l}\text { Total con información } \\
\text { (Número de personas) }\end{array}$ & $\begin{array}{c}100,0 \\
(344)\end{array}$ & $\begin{array}{c}100,0 \\
(166)\end{array}$ & $\begin{array}{c}100,0 \\
(5411)\end{array}$ & $\begin{array}{l}100,0 \\
(619)\end{array}$ & $\begin{array}{c}100,0 \\
(295)\end{array}$ & $\begin{array}{c}100,0 \\
(946)\end{array}$ \\
\hline $\begin{array}{l}\text { Inmigrantes con infor- } \\
\text { mación }\end{array}$ & 85,1 & 88,3 & 86,3 & 95,7 & 94,3 & 95,3 \\
\hline $\begin{array}{l}\text { Inmigrantes sin infor- } \\
\text { macióng }\end{array}$ & 14,9 & 11,7 & 13,7 & 4,3 & 5,7 & 4,7 \\
\hline $\begin{array}{l}\text { Total general } \\
\text { (Número de personas) }\end{array}$ & $\begin{array}{l}100,0 \\
(404)\end{array}$ & $\begin{array}{l}100,0 \\
(188)\end{array}$ & $\begin{array}{l}100,0 \\
(627)\end{array}$ & $\begin{array}{l}100,0 \\
(647)\end{array}$ & $\begin{array}{c}100,0 \\
(313)\end{array}$ & $\begin{array}{l}100,0 \\
(993)\end{array}$ \\
\hline
\end{tabular}

a Inmigrantes que llegaron de más de 14i años de edad, en el período 1942-1962.

b Incluye a los inmigrantes procedentes directamente del exterior y a los de procedencia desconocida.

c En esta categoría sólo deberían figurar hombres, porque tratándose de una pareja, por definición el marido o compañero es el jefe del hogar, y, por consiguiente, la mujer es "persona a cargo".

d Puede haber o no parientes, otros que esposa (o) o compañera(o).

e Sin esposa (o) ni hijos.

t Esposa o compañera, hijos y padres ancianos dependientes, $y$ en general cualquier persona que llegó a cargo de otra.

$g$ Inmigrantes de los cuales no se pudo obtener la información del cuestionario B. (Véase el Apéndice II.) 
ñero). Por consiguiente, en las inmigrantes aparece un elevado porcentaje de dependientes que incluye a esposas o compañeras de la época de inmigración.

Un tercer grupo, que también reviste importancia, lo constituyen las mujeres que llegaron con hijos (con otros parientes o sin ellos, pero sin marido o compañero) y que representan el 7,1 por ciento de las inmigrantes. El porcentaje es bastante similar en ambas zonas de procedencia.

Resumiendo, se tiene que:

a) Más del 50 por ciento de los inmigrantes, hombres o mujeres, llegaron solos. La proporción es mayor en los inmigrantes que venían de la zona rural y de los núcleos pequeños;

b) Aproximadamente un tercio de los inmigrantes hombres formaban parte de una pareja;

c) Alrededor del 7 por ciento de las inmigrantes llegó con hijos, pero sin marido o compañero;

d) El resto corresponde casi en su totalidad a "inmigrantes a cargo" de otras personas, situación en la que se encuentran principalmente las mujeres (téngase en cuenta la observación del punto $b$ ).

Para finalizar este comentario es útil señalar que, por falta de información, en estas comparaciones no se ha considerado cierta proporciỏn de inmigrantes (véase el cuadro 33 ), proporción que suma 13,7 por ciento de los hombres y 4,7 de las mujeres. ${ }^{51}$ Cabe preguntarse si estos inmigrantes, especialmente los hombres, no pertenecerán más bien a un tipo de inmigración que a otros. (Véase el cuadro 34.)

El tipo de inmigración (personas solas, parejas, etc.) está estrecha" mente correlacionado con la edad. Dado que muchos inmigrantes llegaron jóvenes, no debe sorprender que una elevada proporción de ellos lo hicieran solos. En efecto, de los inmigrantes llegados después de cumplir 14 años, el grupo de 14 a 24 años representó el 50,7 por ciento en los hombres y el 53,1 por ciento en las mujeres. Por otro lado, de los inmigrantes llegados solos, el 64,6 por ciento de los hombres y el 68,4 de las mujeres tenían de 14 a 24 años de edad (más del 80 por ciento tenía menos de 30 años). También se advierte que de esos mismos inmigrantes llegados antes de los 25 años, el mayor número procede de los núcleos de menos de 5000 habizantes: por ejemplo, el 72,0 por ciento de las mujeres que llegaron solas desde núcleos de menos de 5000 habitantes tenia menos de 25 años.

51 Inmigrantes no entrevistados con el cuestionario B por negarse a ello, o por ser imposible localizarlos para tal fin. 
Como era de esperar, en su gran mayoría los "inmigrantes masculinos a cargo" llegaron a una edad temprana: del total del grupo de más de 14 años, el 85,7 por ciento corresponde al grupo de 14, a 19 años. Entre las inmigrantes, la presencia de esposas y probablemente de otros parientes del sexo femenino a cargo del inmigrante principal, hacen que la distribución por edad de aquel grupo sea menos concentrada.

\section{Motivo PRINCiPal DeL Movimiento. ANÁlisis por SEXo, EDAD Y ZONA DE EMIGRACIÓN}

Un examen previo de la distribución de los casos clasificados según el motivo principal determinante (declarado) de la inmigración al Gran Santiago, señaló la conveniencia de resumir la información en unas pocas categorías principales, a saber:

i) Razones de trabajo.

ii) Estudios del entrevistado, de sus parientes o dependientes.

iii) Problemas familiares, incluyendo motivos de salud y muerte de un pariente.

iv) Otros motivos e información insuficientes..$^{52}$

v) Inmigrantes a cargo.

Por razones obvias, el análisis se limita a las categorías i) a iv), las cuales se refieren a inmigrantes cuya determinación de emigrar al Gran Santiago, se presume fue el producto de una decisión personal, a su propio riesgo, exceptuándose, no obstante, los casos de inmigrantes jóvenes que vinieron a estudiar por decisión paterna y a costa de la familia. ${ }^{53,54}$

52 La casi totalidad de casos que caen en este grupo corresponden a motivos vagos y muy variados, difíciles de clasificar. Los que vinieron por razones tales como "disconformidad con el medio rural" o "terremotos" son un número muy pequeño, carente de significación.

53 En efecto, casi el 50 por ciento de los casos que declararon razones de estudio tenía menos de 20 años de edad al llegar. Puede presumirse que llegaron solos (aunque a cargo de la familia), o bien que vinieron con sus padres o parientes, caso en el cual estarían mal clasificados (deberían ser, en el último supuesto, inmigrantes a cargo).

54 Antes de proseguir el análisis de los resultados es necesario hacer notar la incoherencia existente en los resultados de los cuadros 33 y 34 . En el prinero hay un número mayor de inmigrantes a cargo que el que resulta de la clasificación por motivo principal de la inmigración que aparece en el segundo, del orden de un 10 por ciento aproximadamente: 63 hombres en lugar de 57, y 390 mujeres en lugar de 350 . Es muy probable que la mayoría de los que faltan en el cuadro 34 en la categoría de los inmigrantes a cargo, esté incluida en la categoría ii), 
Por razones de trabajo llegó el 62,0 por ciento de los hombres, con escasa diferencia según las zonas de procedencia. (Véase el cuadro 34.) El segundo motivo en orden de importancia numérica, es el estudio del entrevistado o de parientes a su cargo (9,5 por ciento). En este caso la diferencia según las zonas de procedencia es importante: el 13,2 por ciento procedía de núcleos de más de 5000 habitantes, contra sólo 3,3 por ciento de núcleos de menos de 5000 habitantes y sectores rurales.

El tercer motivo imporiante son los problemas familiares (desavenencias, deseos de independizarse, salud, muerte, separación matrimonial, etc.), con un 7,6 por ciento.

Finalmente, el grupo iv), que recoge una variedad muy grande de motivos dificiles de clasificar -entre otras razones porque son respuestas ambiguas que no pueden interpretarse-, absorbe el 20,9 por ciento de los inmigrantes del sexo masculino. La amplitud de este sector demuestra que la forma de investigar el motivo de la inmigración adoleció de deficiencias. En la encuesta se formuló una pregunta abierta; es posible que una pregunta referida concretamente a ciertas situaciones particulares hubiese permitido obtener mejores resultados.

En las mujeres inmigrantes, la distribución según los motivos es bastante similar a la de los hombres. Por razones de trabajo vino el 55,9 por ciento, con exclusión de las personas a cargo, siendo la proporción ostensiblemente más alta entre las procedentes de núcleos de menos de 5000 habitantes: 67,2 por ciento. Por motivo de estudios vino un porcentaje similar al de los hombres: 10,4 por ciento, con una marcada diferencia según las zonas. Los problemas familiares constituyén un motivo más importante ( 14,9 por ciento) que en los hombres.

Resumiendo, podría decirse que las razones de trabajo gravitan fuertemente en las inmigrantes procedentes de los sectores rurales y de los núcleos pequeños, lo que no ocurre en cambio, aunque sigue teniendo importancia, en las mujeres que proceden de los núcleos más grandes. (Véase el cuadro 34.)

La información recogida permite distinguir, entre los que inmigraron por "razones de trabajo", tres grupos: uno, formado por los que vinieron a Santiago a "buscar trabajo"; otro, por los que vinieron tras una "mejor remuneración"; y el tercero, integrado por aquèllos que fueron "trasladados". Es difícil separar claramente los dos primeros grupos; es probable que muchos de los que declararon que el motivo principal fue obtener una "mejor remuneración", en realidad se encontraban sin empleo, o bien trabajaban en forma ocasional o inestable.

(estudios del entrevistado). Pensamos que la clasificación por el tipo de inmigración (cuadro 33) es más precisa respecto de la situación "a cargo" que la clasificación del motivo declarado (cuadro 34 ) que puede ser incoherente (y no advertido al codificar) con la primera situación. 
Cuadro 34

INMIGRANTES LLEGADOS EN EL PERIODO 1942-1962 SEGUN EL MOTIVO PRINCIPAL PARA VENIR AL GRAN SANTIAGO, Y ZONAS DE EMIGRACIONa

\begin{tabular}{|c|c|c|c|c|c|c|}
\hline \multirow[b]{3}{*}{$\begin{array}{c}\text { Motivo principal } \\
\text { para venir al } \\
\text { Gran Santiago }\end{array}$} & \multicolumn{3}{|c|}{ Hombres } & \multicolumn{3}{|c|}{ Mujeres } \\
\hline & \multicolumn{2}{|c|}{ Núcleos } & \multirow[b]{2}{*}{ Total $^{\mathrm{b}}$} & \multicolumn{2}{|c|}{ Núcleos } & \multirow[b]{2}{*}{ Total } \\
\hline & $\begin{array}{l}\text { Más de } \\
5 \text { oo0 ha- } \\
\text { bitantes }\end{array}$ & $\begin{array}{c}\text { Menos } \\
\text { de } 5000 \\
\text { habitan- } \\
\text { tes (in- } \\
\text { cluyendo } \\
\text { sect. } \\
\text { rurales) }\end{array}$ & & $\begin{array}{l}\text { Más de } \\
5000 \text { ha. } \\
\text { bitantes }\end{array}$ & $\begin{array}{l}\text { Menos } \\
\text { de } 5000 \\
\text { habitan- } \\
\text { tes (in- } \\
\text { cluyendo } \\
\text { sect. } \\
\text { rurales) }\end{array}$ & \\
\hline $\begin{array}{l}\text { lnmigrantes independien- } \\
\text { tes }\end{array}$ & \multicolumn{6}{|c|}{ (Porcentajes) } \\
\hline $\begin{array}{l}\text { Razones de trabajo } \\
\text { Estudios del entrevista- } \\
\text { do, o de sus parientes }\end{array}$ & 64,3 & 62,7 & 62,0 & 49,2 & 67,2 & 55,9 \\
\hline $\begin{array}{l}\text { Problemas familiares, in- } \\
\text { cluyendo motivos de } \\
\text { salud y muerte de un } \\
\text { pariente }\end{array}$ & 6.3 & 87 & 76 & 16,3 & 127 & 14.9 \\
\hline $\begin{array}{l}\text { Otros motivos e infor- } \\
\text { mación insuficiente }\end{array}$ & 16,2 & 25,3 & 20,9 & 21,9 & 13,1 & 18,8 \\
\hline $\begin{array}{l}\text { Sub-total } \\
\text { (Número de personas) }\end{array}$ & $\begin{array}{l}100,0 \\
(303)\end{array}$ & $\begin{array}{l}100,0 \\
(150)\end{array}$ & $\begin{array}{l}100,0 \\
(484)\end{array}$ & $\begin{array}{l}100,0 \\
(374)\end{array}$ & $\begin{array}{l}100,0 \\
(213)\end{array}$ & $\begin{array}{l}100,0 \\
(596)\end{array}$ \\
\hline $\begin{array}{l}\text { Inmigrantes independien- } \\
\text { tes } \\
\text { Inmigrantes a cargo }^{c}\end{array}$ & $\begin{array}{l}88,1 \\
11,9\end{array}$ & $\begin{array}{r}90,4 \\
9,6\end{array}$ & $\begin{array}{l}89,5 \\
10,5\end{array}$ & $\begin{array}{l}60,4 \\
39,6\end{array}$ & $\begin{array}{l}72,2 \\
27,8\end{array}$ & $\begin{array}{l}63,0 \\
37,0\end{array}$ \\
\hline $\begin{array}{l}\text { Total con información } \\
\text { (Número de personas) }\end{array}$ & $\begin{array}{l}100,0 \\
(344)\end{array}$ & $\begin{array}{l}100,0 \\
(166)\end{array}$ & $\begin{array}{l}100,0 \\
(541)\end{array}$ & $\begin{array}{l}100,0 \\
(619)\end{array}$ & $\begin{array}{c}100,0 \\
(295)\end{array}$ & $\begin{array}{r}100,0 \\
(946) \\
\end{array}$ \\
\hline $\begin{array}{l}\text { Inmigrantes con infor- } \\
\text { mación }\end{array}$ & 85,1 & 88,3 & 86,3 & 95,7 & 94,3 & 95,3 \\
\hline $\begin{array}{l}\text { Inmigrantes sin infor- } \\
\text { mación }^{d}\end{array}$ & 14,9 & 11,7 & 13,7 & 4,3 & 5,7 & 4,7 \\
\hline $\begin{array}{l}\text { Total general } \\
\text { (Número de personas) }\end{array}$ & $\begin{array}{l}100,0 \\
(404)\end{array}$ & $\begin{array}{l}100,0 \\
(188)\end{array}$ & $\begin{array}{c}100,0 \\
(627)\end{array}$ & $\begin{array}{l}100,0 \\
(647)\end{array}$ & $\begin{array}{l}100,0 \\
(313)\end{array}$ & $\begin{array}{l}100,0 \\
(993)\end{array}$ \\
\hline
\end{tabular}

anmigrantes con más de 14 años de edad al llegar al Gran Santiago.

b Además de las cifras parciales de las columnas, se incluye a los inmigrantes procedentes

- Eel exterior y de procedencia desconocida. los casos que faltan en el presente cuadro en la categoría "inmigrantes a cargo" figura en is categris "entu ". de la renida est ultimo entre $108 \mathrm{y}$ los 25 años, tr par 14 los 25 anos, siendo probable que nuchos de ellos vinian en realidad con inmigrantes a cargo. (V́́ase el cuadro 33.)

a inmigrantes a cargo. (Vkaso el cuadro 33.) Inmigrantes de los cuales no fue posible obtener la información del cuestionario B. (Véase
el Apéndice II.) 
Pero la inversa también es posible. En ambos tipos de declaración pudo haber influido la experiencia profesional previa, porque entre los que buscan trabajo la proporción de personas menores de 20 años (y también menores de 25 años) es más alta que entre los que buscaban mejor remuneración. En el grupo de los que buscan trabajo, tenían menos de 25 años al llegar, el 58,9 por ciento de los hombres (contra 50,7 por ciento en el conjunto de los inmigrantes comprendidos en el cuadro 34) y el 72,7 por ciento de las mujeres (contra 53,1 por ciento en el conjunto). Además, dentro de los que inmigraron por razones de trabajo, vinieron en busca de él el 58,3 por ciento de los hombres y el 73,6 por ciento de las mujeres.

Otro grupo en el que se destaca la juventud de los inmigrantes es el que forman los que vinieron por motivo de estudios: el 64,8 por ciento de los inmigrantes clasificados en esa categoría llegó entre los 14 y los 24 años de edad. (El comportamiento por sexo es semejante.) Ya se advirtió anteriormente que es posible que una parte de estos jóvenes inmigrantes haya llegado en realidad con sus padres, caso en el cual el motivo no sería los estudios y tales personas deberían estar clasificadas como "inmigrantes a cargo". ${ }^{55}$

5. Motivo PRincipal del movimiento. ANálisis SEgúN el grado DE ocupación inmediato anterior al movimiento al Gran Santiago

En la sección anterior se vio que una elevada proporción de los inmigrantes - excluyendo a las personas a cargo - tuvo como motivo principal de su traslado al Gran Santiago "razones de trabajo" y que, además, muchos de ellos vinieron a "buscar trabajo". Interesa conocer si los inmigrantes que se encontraban en esta última situación estaban realmente desocupados o en estado de subempleo visible.

Antes de entrar en el análisis de las cifras del cuadro 35, hay que señalar una incoherencia originada por el hecho de que algunos inmigrantes que llegaron por "razones de trabajo", no eran personas económicamente activas en el lugar de su procedencia. ${ }^{56}$ Tal situación, que afecta especialmente a las mujeres $(35,4$ por ciento, frente a sólo un 6,3 por ciento de los hombres), podría interpretarse en el sentido de que esas personas vinieron efectivamente a trabajar, pero que no lo habían hecho antes ni consideraban estar desocupadas o busiando trabajo (por

55 El padre, si fuera uno de los inmigrantes entrevistados, podría haber declarado correctamente que el motivo fue "estudios" de su hijo. La edad de llegada es suficiente para establecer si el entrevistado era padre o hijo.

56 La condición de no económicamente activo excluye, como se anticipó en otra parte de este informe, a los trabajadores que buscan trabajo por primera vez. 
razones de diversa índole, incluso psicológicas) en el lugar de origen. Parece razonable considerar a estos inmigrantes junto con los "desocupados". Es el criterio que se siguió en el cuadro 35.

Llama la atención en este cuadro el elevado porcentaje de "ocupados" y entre éstos, la elevada proporción de los que no buscaban trabajo. Estas cifras son más bajas, como es lógico, en los inmigrantes cuyo motivo fue "buscar trabajo", pero entre ellos son más altas que lo esperado, no obstante que al grupo de "desocupados" se sumaron aquellos casos comentados en el párrafo anterior. De los inmigrantes cuyo motivo fue "buscar trabajo", el 76,0 por ciento de los hombres estaban "ocupados", de los cuales el 60,9 por ciento no buscaba trabajo en el lugar de origen. Las cifras correspondientes a las mujeres son 34,3 y 67,9 por ciento, respectivamente.

Considerando el grupo más amplio de los que dieron como motivo "razones de trabajo" (grupo que incluye al anterior), las proporciones de "ocupados" suben notoriamente, sobre todo en las mujeres. De los inmigrantes que manifestaron otros motivos, las proporciones de "ocupados" son aun más elevadas, especialmente en el caso de las mujeres. La misma tendencia se observa entre los que no buscaban trabajo.

En resumen, se podría decir que el grado de desocupación no tuvo una importancia decisiva en la mayoría de los inmigrantes, al menos no lo consideraron así en sus respuestas. A través de una forma de subempleo visible (buscar trabajo, número de días trabajados), tampoco se vislumbra un factor decisivo. Más bien habría que pensar, si nos atenemos a las cifras, en la existencia de formas invisibles de subempleo (ingresos bajos y condiciones de trabajo no atractivas).

\section{Motivo principal Del Movimiento. ANálisis por "Clases" ECONÓMICO-SOCIALES}

El motivo para emigrar el Gran Santiago se supone vinculado a la ocupación que tenía el inmigrante en la época inmediata anterior a su movimiento. Este análisis complementa el de la sección anterior, en el que se consideró el grado de empleo. ${ }^{57}$

A tal fin, las ocupaciones se agruparon en "clases" económico-so-

57 El grado de empleo puede estar correlacionado con la ocupación, en cuyo caso un análisis satisfactorio debería abarcar simultáneamente las tres variables (motivo, ocupación y grado de empleo). Más, aparte de que un análisis simultáneo requiere una muestra más numerosa, en este informe se ha querido simplificar el estudio dejando para una ulterior oportunidad el desarrollo de aspectos particulares de la encuesta. 
Cuadro 35

INMTGRANTES LLEGADOS EN EL PERIODO 1942-1962, SEGUN EL MOTIVO PRINCIPAL PARA VENIR AL GRAN SANTIAGO Y GRADO DE EMPLEOa

\begin{tabular}{|c|c|c|c|c|c|}
\hline \multirow{2}{*}{$\begin{array}{l}\text { Grado de } \\
\text { empleo }\end{array}$} & \multicolumn{2}{|c|}{$\begin{array}{c}\text { Razones de } \\
\text { trabajo }\end{array}$} & \multirow{2}{*}{$\begin{array}{c}\text { Estudios, } \\
\text { problemas } \\
\text { familia- } \\
\text { res, etc. }\end{array}$} & \multirow{2}{*}{$\begin{array}{c}\text { Varios no } \\
\text { clasifi- } \\
\text { cados y } \\
\text { motivo } \\
\text { descono- } \\
\text { cido }\end{array}$} & \multirow{2}{*}{ Total } \\
\hline & $\begin{array}{l}\text { Buscar } \\
\text { trabajo }\end{array}$ & Total & & & \\
\hline Hombres & & & Porcentajes) & & \\
\hline $\begin{array}{l}\text { Ocupados } \\
\text { No buscaban }\end{array}$ & 76,0 & 84,7 & 86,8 & 97,7 & 87,4 \\
\hline trabajo & 60,9 & 70,1 & 81,9 & 83,3 & 74,9 \\
\hline Buscaban trabajo & 39,1 & 29,9 & 18,1 & 16,7 & 25,1 \\
\hline Desocupados ${ }^{d}$ & 22,3 & 14,0 & 9,6 & 2,3 & 11,1 \\
\hline Otras situaciones & 1,7 & 1,3 & 3,6 & - & 1,5 \\
\hline $\begin{array}{l}\text { Total hombres } \\
\text { (Número de } \\
\text { personas) }\end{array}$ & $\begin{array}{l}100,0 \\
(175)\end{array}$ & $\begin{array}{l}100,0 \\
(300)\end{array}$ & $\begin{array}{r}100,0 \\
(83)\end{array}$ & $\begin{array}{r}100,0 \\
(86)\end{array}$ & $\begin{array}{l}100,0 \\
(469)\end{array}$ \\
\hline \multicolumn{6}{|l|}{ Mujeres } \\
\hline $\begin{array}{l}\text { Ocupadasc } \\
\text { No buscaban }\end{array}$ & 34,3 & $47, I$ & 82,7 & 91,1 & 60,3 \\
\hline trabajo & 67,9 & 74,5 & 84,5 & 75,6 & 78,2 \\
\hline Buscaban trabajo & 32,1 & 25,5 & 15,5 & 24,4 & 21,8 \\
\hline Desocupadas ${ }^{\mathfrak{d}}$ & 65,3 & 52,6 & 15,0 & 8,9 & 38,9 \\
\hline Otras situaciones & 0,4 & 0,3 & 2,3 & - & 0,8 \\
\hline $\begin{array}{l}\text { Total mujeres } \\
\text { (Número de } \\
\text { personas) }\end{array}$ & $\begin{array}{l}100,0 \\
(245)\end{array}$ & 100,0 & 100,0 & $\begin{array}{r}100,0 \\
(45)\end{array}$ & $\begin{array}{l}100,0 \\
(511)\end{array}$ \\
\hline
\end{tabular}

a Inmigrantes con más de 14 años al llegar al Gran Santiago y con experiencia profesional en el lugar de procedencia.

b Estudios, problemas familiares, salud, otros motivos específicos menos frecuentes (terremotos, disconformidad con el medio rural), y casos de inmigrantes a cargo. (Véase el cuadro 34.)

c Trabajaban todos los días o solamente algunos días a la semana.

a Se incluye a las personas clasificadas como no económicamente activas en el lugar de procedencia, pero que decluraron venir al Gran Santiago por razones de trabajo. 
ciales, utilizando la misma clasificación adoptada para el estudio de las características económicas de la población inmigrante en la sección 2.

Dado el pequeño número de casos que se manejan, el examen se reduce principalmente a las grandes categorías: trabajadores manuales y trabajadores no manuales. Los agricultores constituyen una clase específica de trabajadores manuales, razón por la cual se los trata separadamente. Los "trabajadores familiares no remunerados" y las "personas que buscan trabajo por primera vez" no pudieron agruparse en las clases económico-sociales y se presentan en forma independiente; en el primer caso, porque no se pidieron datos sobre su ocupación, y en el segundo, obviamente, porque aún no habían comenzado a trabajar.

Las "razones de trabajo" constituyen, como ya se ha dicho, la causa más frecuentemente declarada en todas las clases económico-sociales. (Véase el cuadro 36.) Ello es más acentuado, como era previsible, en los hombres. La proporción que emigró por aquel motivo es más elevada en los trabajadores manuales y en los agrícolas, que en los no manuales. En la población masculina las proporciones correspondientes a dicho motivo en las tres clases económico-sociales mencionadas fueron $67,5,63,0$ y 55,5 por ciento. En la población femenina hay una diferencia aun más fuerte: 59,8 por ciento de las trabajadoras manuales contra sólo 25,0 de las no manuales. Las trabajadoras agrícolas no se consideran porque constituyen un número ínfimo (12 casos).

En los trabajadores familiares no remunerados (hombres), el porcentaje que indicó "razones de trabajo" es equiparable al de los trabajadores agrícolas. Finalmente, como parece lo más lógico, el motivo mencionado tiene un peso todavía más alto en las personas que buscaban trabajo por primera vez.

En dos columnas del cuadro 36 aparecen los demás motivos de inmigración: en una se reúnen todos los otros motivos específicos que pudieron encuadrarse en el código previsto para la clasificación (razones familiares, estudios, acompañar a la persona que era sostén económico, salud, terremoto, disconformidad con el medio rural); y en la otra, la mayoría de los casos que no respondieron a la pregunta y los que dieron motivos de dudosa interpretación. Como se lee en el citado cuadro, el grado de indeterminación es relativamente elevado: 18,3 por ciento en los hombres económicamente activos y 8,8 por ciento en las mujeres. Llama la atención que esa indeterminación sea más baja en los trabajadores manuales (especialmente trabajadoras). Es probable que ello se deba a la mayor y más clara motivación por "razones de trabajo", comparados con los trabajadores no manuales. 
Cuadro 36

INMIGRANTES LLEGADOS EN EL PERIODO 1942-1962, SEGUN EL MOTIVO PRINCIPAL PARA VENIR AL GRAN SANTIAGO Y CLASES ECONOMICO-SOCIALES ${ }^{a}$

\begin{tabular}{|c|c|c|c|c|c|c|c|c|}
\hline \multirow[b]{2}{*}{$\begin{array}{l}\text { Clases } \\
\text { econ6mico- } \\
\text { sociales }\end{array}$} & \multicolumn{4}{|c|}{ Hombres } & \multicolumn{4}{|c|}{ Mujeres } \\
\hline & $\begin{array}{c}\text { Razo- } \\
\text { nes de } \\
\text { traba- } \\
\text { jo }\end{array}$ & $\begin{array}{l}\text { Moti- } \\
\text { vos fa- } \\
\text { milia- } \\
\text { res, } \\
\text { etc. }\end{array}$ & $\begin{array}{l}\text { Varios } \\
\text { no cla- } \\
\text { sifica- } \\
\text { dos y } \\
\text { motivo } \\
\text { desco- } \\
\text { nocido }\end{array}$ & Total & $\begin{array}{c}\text { Razo- } \\
\text { nes de } \\
\text { traba- } \\
\text { jo }\end{array}$ & $\begin{array}{c}\text { Moti- } \\
\text { vos fa- } \\
\text { milia- } \\
\text { res, } \\
\text { etc. }\end{array}$ & $\begin{array}{c}\text { Varios } \\
\text { no cla- } \\
\text { sifica- } \\
\text { dos y } \\
\text { motivo } \\
\text { desco- } \\
\text { nocido }\end{array}$ & Total \\
\hline & \multicolumn{8}{|c|}{ (Porcentajes) } \\
\hline $\begin{array}{l}\text { Trabajadores } \\
\text { no manuales }\end{array}$ & 55,5 & 22,7 & 21,8 & $\begin{array}{l}100,0 \\
(110)\end{array}$ & 25,0 & 51,3 & 23,7 & $\begin{array}{r}100,0 \\
(76)\end{array}$ \\
\hline $\begin{array}{l}\text { Trabajadores } \\
\text { manuales }\end{array}$ & 67,5 & 15,7 & 16,8 & $\begin{array}{l}100,0 \\
(166)\end{array}$ & 59,8 & 30,1 & 10,1 & $\begin{array}{r}100,0 \\
(219)\end{array}$ \\
\hline $\begin{array}{l}\text { Trabajadores } \\
\text { agrícolas }\end{array}$ & 63,0 & 15,7 & 21,3 & $\begin{array}{l}100,0 \\
(108)\end{array}$ & - & - & - & $\overline{(12)}$ \\
\hline $\begin{array}{l}\text { Otros trabaja- } \\
\text { doresc }\end{array}$ & - & - & - & $\overline{(14)}$ & - & - & - & $\overline{(2)}$ \\
\hline $\begin{array}{l}\text { Personas que } \\
\text { buscaban tra- } \\
\text { bajo por pri- } \\
\text { mera vez }\end{array}$ & 77,5 & 18,4 & 4,1 & $\begin{array}{r}100,0 \\
(49)\end{array}$ & 87,8 & 10,2 & 2,0 & $\begin{array}{c}100,0 \\
(197)\end{array}$ \\
\hline $\begin{array}{l}\text { Trabajadores } \\
\text { familiares no } \\
\text { remuneradose }\end{array}$ & 63,7 & 13,6 & 22,7 & $\begin{array}{r}100,0 \\
(22)\end{array}$ & - & - & - & $\overline{(5)}$ \\
\hline $\begin{array}{l}\text { Total de per- } \\
\text { sonas econó- } \\
\text { micamente ac- } \\
\text { tivas }^{f}\end{array}$ & 64,0 & 17,7 & 18,3 & $\begin{array}{c}100,0 \\
(469)\end{array}$ & 65,2 & 26,0 & 8,8 & $\begin{array}{c}100,0 \\
(511)\end{array}$ \\
\hline $\begin{array}{l}\text { Personas } \\
\text { no económica- } \\
\text { mente activas }\end{array}$ & - & 93,1 & 6,9 & $\begin{array}{r}100,0 \\
(72)\end{array}$ & - & 86,7 & 13,3 & $\begin{array}{l}100,0 \\
(435)\end{array}$ \\
\hline
\end{tabular}

a Inmigrantes con más de 14 años de edad al llegar al Gran Santiago.

b Estudios, problemas familiares, salud, etc. (Véase el cuadro 34 .)

c Fuerzas armadas, personal diplomático extranjero $\mathrm{J}$ ocupaciones mal definidas o des-

conocidas.

- Se incluye a las personas clasificadas no económicamente activas en el Ingar de procedencia, pero que declararon venir por razones de trabajo.

- No se clasificaron por ocupaciones por faltar la información correspondiente a los tra-

bajadores de esta categorfa.
$f$ Se incluye a las personas que buscaban trabajo por primera vez y a los trabajadores familiares no remunerados. 



\section{ALGUNOS ASPECTOS DE LA ASIMILACION}

\section{Ubicación de LA VIVIENDa EN LA CIUDAD}

a) El barrio o sector de la ciudad donde se instala el inmigrante al llegar depende, principalmente, de sus recursos económicos, su nivel cultural y de la presencia en aquél de otras personas con las que tenga vínculos de parentesco o amistad.

Con frecuencia se afirma que la masa de los inmigrantes de las grandes ciudades se instala en su periferia, en barrios pobres o marginales. Este no parece ser el caso del Gran Santiago, probablemente porque una parte importante de los inmigrantes tiene características económicas y sociales similares a las de la población nativa de la ciudad.

La ubicación de la primcra vivienda proporciona una indicación útil sobre la asimilación de los inmigrantes en los primeros tiempos de su vida metropolitana. También es de interés conocer con qué frecuencia los inmigrantes trasladan su residencia a otros sectores de la ciudad. Estos cambios consituyen un indicador de movilidad social, siempre y cuando los sectores utilizados definan poblaciones con diferentes niveles económico-sociales.

Para los fines del análisis que sigue, se establecieron cuatro sectores de la ciudad. Cada sector está formado por varias comunas con continuidad geográfica y características urbanísticas y sociales bastante similares.

En el cuadro 37 se presenta la distribución porcentual de los inmigrantes en los cuatro sectores de la ciudad, según la ubicación de la primera vivienda y de la vivienda en el momento de la encuesta. ${ }^{58}$ Alrededor de la mitad de la población estudiada tuvo su primera vivienda en el Secior Central (comuna de Santiago); la mitad restante se distribuyó en los otros tres sectores en forma relativamente pareja. Esta

58 Trátase de inmigrantes llegados de más de 14 años de edad en el periodo 1942-1962. (Véase el cuadro 37.) La comparación de los datos de la primera vivienda y de la vivienda en el momento de la encuesta no es completa, debido a que el número de casos no es el mismo: del 15,5 de los hombres y del 6,0 por ciento de las mujeres no había información sobre primera vivienda. 
Cuadro 37

INMIGRANTES DISTRIBUIDOS SEGUN LOS SECTORES DONDE TENIAN SU PRIMERA VIVIENDA Y SU VIVIENDA EN LA EPOCA

DE LA ENCUESTAa

(Porcentajes)

\begin{tabular}{|c|c|c|c|c|c|c|c|c|}
\hline \multirow{3}{*}{$\begin{array}{l}\text { Sexo del } \\
\text { inmigrante } \\
\text { y sectores } \\
\text { donde estaba } \\
\text { situada la } \\
\text { vivienda }^{\mathbf{b}}\end{array}$} & \multicolumn{8}{|c|}{ Período de llegada y vivienda de los inmigrantes } \\
\hline & \multicolumn{2}{|c|}{ 1942-1962 } & \multicolumn{2}{|c|}{$1942-1951$} & \multicolumn{2}{|c|}{$1952-1956$} & \multicolumn{2}{|c|}{$1957-1962$} \\
\hline & $\begin{array}{l}\text { Pri- } \\
\text { mera }\end{array}$ & Actual & $\begin{array}{l}\text { Pri- } \\
\text { mera }\end{array}$ & Actual & $\begin{array}{l}\text { Pri- } \\
\text { mera }\end{array}$ & Actual & $\begin{array}{l}\text { Pri- } \\
\text { mera }\end{array}$ & Actual \\
\hline \multicolumn{9}{|l|}{ Hombres } \\
\hline $\begin{array}{l}\text { Centro } \\
\text { Oriente } \\
\text { Sur } \\
\text { Noroeste }\end{array}$ & $\begin{array}{l}52,6 \\
15,5 \\
15,5 \\
16,4\end{array}$ & $\begin{array}{l}34,3 \\
17,4 \\
24,4 \\
23,9\end{array}$ & $\begin{array}{l}63,8 \\
12,6 \\
10,1 \\
13,5\end{array}$ & $\begin{array}{l}33,5 \\
15,3 \\
26,4 \\
24,8\end{array}$ & $\begin{array}{l}48,1 \\
17,8 \\
16,3 \\
17,8\end{array}$ & $\begin{array}{l}30,6 \\
19,7 \\
28,0 \\
21,7\end{array}$ & $\begin{array}{l}43,7 \\
17,0 \\
20,7 \\
18,6\end{array}$ & $\begin{array}{l}37,7 \\
18,0 \\
19,7 \\
24,6\end{array}$ \\
\hline $\begin{array}{l}\text { Total c } \\
\text { (Número de } \\
\text { personas) }\end{array}$ & $\begin{array}{l}100,0 \\
(530)\end{array}$ & $\begin{array}{l}100,0 \\
(627)\end{array}$ & $\begin{array}{l}100,0 \\
(207)\end{array}$ & $\begin{array}{l}100,0 \\
(242)\end{array}$ & $\begin{array}{l}100,0 \\
(135)\end{array}$ & $\begin{array}{l}100,0 \\
(157)\end{array}$ & $\begin{array}{l}100,0 \\
(188)\end{array}$ & $\begin{array}{l}100,0 \\
(228)\end{array}$ \\
\hline \multicolumn{9}{|l|}{ Mujeres } \\
\hline $\begin{array}{l}\text { Centro } \\
\text { Oriente } \\
\text { Sur } \\
\text { Noroeste }\end{array}$ & $\begin{array}{l}48,9 \\
23,2 \\
14,8 \\
13,1\end{array}$ & $\begin{array}{l}35,2 \\
24,6 \\
22,1 \\
18,1\end{array}$ & $\begin{array}{l}57,1 \\
21,0 \\
10,1 \\
11,8\end{array}$ & $\begin{array}{l}37,8 \\
16,6 \\
23,2 \\
22,4\end{array}$ & $\begin{array}{l}46,0 \\
26,8 \\
14,9 \\
12,3\end{array}$ & $\begin{array}{l}31,0 \\
27,2 \\
27,2 \\
14,6\end{array}$ & $\begin{array}{l}42,3 \\
23,3 \\
19,5 \\
14,9\end{array}$ & $\begin{array}{l}35,4 \\
31,0 \\
17,6 \\
16,0\end{array}$ \\
\hline $\begin{array}{l}\text { Total } \text { c } \\
\text { (Número de } \\
\text { personas) }\end{array}$ & $\begin{array}{l}100,0 \\
(933)\end{array}$ & $\begin{array}{l}100,0 \\
(993)\end{array}$ & $\begin{array}{l}100,0 \\
(357)\end{array}$ & $\begin{array}{l}100,0 \\
(380)\end{array}$ & $\begin{array}{l}100,0 \\
(228)\end{array}$ & $\begin{array}{l}100,0 \\
(239)\end{array}$ & $\begin{array}{l}100,0 \\
(348)\end{array}$ & $\begin{array}{r}100,0 \\
(374)\end{array}$ \\
\hline
\end{tabular}

a Inmigrantes llegados de más de 14. años de edad en el período 1942-1962.

b Los sectores se formaron agrupando comunas contiguas que ofrecen rasgos urbanísticos similares y cuyas poblaciones tienen en promedio niveles económicosociales semejantes. La constitución de los sectores es la siguiente: Centro: comuna de Santiago; Oriente: Providencia, Las Condes, Nuñoa; Sur: Cisterna, San Miguel y La Granja; Noroeste: Conchali, Quinta Normal, Barrancas y Renca. Según orden decreciente de nivel económico-social, los sectores se pueden ordenar como sigue: Oriente, Centro, Sur y Noroeste.

e Las diferencias entre la columna de la primera vivienda y la de la vivienda actual (cifras entre paréntesis) se deben a casos de los que no fue posible obtener información de la primera vivienda. 
distribución no difiere fundamentalmente de la de la población del Gran Santiago según el censo de $1952,{ }^{59}$ esto es, a la mitad del período de inmigración que se examina en el mencionado cuadro 37.

La orientación señalada es un promedio de veinte años transcurrido entre 1942 y 1962. Sin embargo, la distribución por sectores no fue constante, variando más entre los hombres que enire las mujeres. En efecto, de los inmigrantes de la década 1942-1951, el 63,8 por ciento se estableció en el Secior Central mientras que en el quinquenio 19571962 tan sólo lo hizo el 43,7 por ciento. Esta tendencia no significa necesariamente que los inmigrantes se orientaran siguiendo otro paírón, sino que, más bien, fue resultado del proceso de expansión física y demográfica de la ciudad. ${ }^{60}$

La distribución por sectores de la vivienda en la época de la encueśa se diferencia netamente de la distribución según la primera vivienda, lo cual representa una importanie movilidad. Ahora bien, dado que los movimientos no se producen en una sola dirección, las cifras del cuadro 37 sólo pueden revelar el saldo final de los cambios y, en consecuencia, la movilidad efectiva tuvo que ser mayor.

El Sector Central evidencia en forma clara esa movilidad, al perder importancia relativa al pasarse de la primera vivienda a aquéila del momento de la encuesta. El Sector Sur resulta ser el más beneficiado con el cambio. Cuanto más tiempo ha transcurrido desde la época de llegada del inmigrante, más intenso el cambio entre sectores, de modo que, por ejemplo, la distribución según la primera y la última vivienda de los inmigranies del quinquenio previo a la encuesta, son semejantes. ${ }^{\mathrm{B}}$ (Véase el cuadro 37.)

Es explicable que a menor duración de la residencia del inmigrante corresponda menor cambio de sector entre primera y última vivienda, debido a que, en tanto que el cambio de sector de residencia signilique movilidad social, éste es un proceso que requiere tiempo. Por otro lado, si ese cambio responde principalmente al proceso de expansión física de la ciudad, sus efectos son igualmente más o menos lentos. ${ }^{62}$

59 En el censo de 1952, la comuna de Santiago contenía el 48 por ciento de la población del Gran Santiago; el Sector Noroeste el 19,3 por ciento, y los dos restantes sectores el 16 por ciento cada uno, aproximadamente. En el censo de 1960 la distribución fue: Comuna de Santiago, 33,5 por ciento; Sector Sur, 24,2 por ciento; Sector Noroeste, 22,9 por ciento y Sector Oriente, 19,4 por ciento.

60 Véase la cita 59.

61 Puede observarse que aun en el último quinquenio, el Sector Central conserva su mayor importancia como ubicación de la primera vivienda. Este sector, además de contener el centro comercial de la ciudad, comprende una extensa úrea de viviendas antiguas, donde las casas de vecindad (conventillos) y albergues (pensiones) son frecuentes. Es posible entonces que muchos inmigrantes ivan sus primeros años en dicho sector.

62 Debido a que la encresta no investigó cambios de residencia de población 
Podríanse resumir los resultados encontrados en las siguientes observaciones:

i) Casi la mitad de los inmigrantes del período 1942-1962, tuvieron su primera vivienda en el Sector Central (comuna de Santiago).

ii) En los últimos años esa tendencia fue en disminución, en beneficio de los demás sectores.

iii) La comparación entre la distribución por sectores, según la primera vivienda y la última, indica una importante movilidad, la cual, en el caso de las mujeres, favoreció al Sector Oriente de manera marcada. ${ }^{63}$

iv) La movilidad a que se refiere el punto anterior fue mayor entre los inmigrantes de más larga residencia en la ciudad.

b) El lugar de emigración puede servir para agrupar a los inmigrantes según niveles (promedios) de instrucción y calificación profesional. En efecto, en varias secciones de este libro se encontraron diferencias en el nivel de instrucción y en la composición por ocupa. ciones de los inmigrantes en relación con el grado de urbanización del lugar de emigración. ${ }^{64}$

En consecuencia parece útil analizar la ubicación de la primera vivienda respecto al lugar de emigración. En teoría debería esperarse que los inmigrantes de lugares rurales y de pequeños pueblos establecieran su primera vivienda, preferentemente, en los sectores de la ciudad de menor nivel económico-social.

En el análisis que sigue se prefirió utilizar el dato de la vivienda en el momento de la encuesta, en vez de la información sobre la primera. Por ello se limitó el estudio a la última década (1952-1962) en el su. puesto de que para una fracción importante de los inmigrantes de este período, la ubicación de la última vivienda era la misma que la de la primera. ${ }^{65}$

De las cifras del cuadro 38 se deduce que por lo menos en los dos sectores de nivel económico-social más bajo (Sur y Noroeste), los inmigrantes están igualmente representados cualquiera que sea el lugar de

nativa de la ciudad, no es posible establecer comparaciones entre la distribución por sectores y por períodos de tiempo, de las viviendas de nativos y de inmigrantes.

63 En esta situación es determinante la presencia en el Sector Oriente de mujeres que trabajan como sirvientes de hogares particulares.

64 Véase, en particular, el capítulo V.

65 Podría pensarse que sería más realista considerar la ubicación de la primera vivienda, pero esta decisión ofrece su propio riesgo: la primera vivienda podría ser, en muchos casos, muy provisional. 
Cuadro 38

DISTRIBUCION DE LOS INMIGRANTES SEGUN EL SECTOR EN QUE TENIAN SU VIVIENDA EN LA EPOCA DE LA ENCUESTA Y POR LUGAR DE EMIGRACIONa

(Hombres)

\begin{tabular}{|c|c|c|c|c|}
\hline \multirow[b]{2}{*}{$\begin{array}{l}\text { Sector en el cual } \\
\text { estaba situada } \\
\text { la viviendac }\end{array}$} & \multicolumn{4}{|c|}{ Lugar de emigración, según el tamaño del núcleo } \\
\hline & $\begin{array}{l}\text { Más de } \\
20000 \\
\text { habitantes }\end{array}$ & $\begin{array}{c}\text { De } 5000 \text { a } \\
19999 \\
\text { habitantes }\end{array}$ & $\begin{array}{c}\text { Menos } \\
\text { de } 5000 \\
\text { habitantes } \\
\text { (incluye } \\
\text { población } \\
\text { rural) }\end{array}$ & Total b \\
\hline & \multicolumn{4}{|c|}{ (Porcentajes) } \\
\hline Centro & 32,5 & 36,0 & 39,5 & 34,8 \\
\hline Oriente & 19,4 & 19,1 & 11,8 & 18,7 \\
\hline Sur & 24,4 & 22,5 & 24,4 & 23,1 \\
\hline Noroeste & 23,7 & 22,4 & 24,3 & 23,4 \\
\hline $\begin{array}{l}\text { Total } \\
\text { (Número de personas) }\end{array}$ & $\begin{array}{l}100,0 \\
(160)\end{array}$ & $\begin{array}{r}100,0 \\
(89)\end{array}$ & $\begin{array}{l}100,0 \\
(119)\end{array}$ & $\begin{array}{l}100,0 \\
(385)\end{array}$ \\
\hline
\end{tabular}

a Inmigrantes llegados de más de 14 años de edad en el período 1952-1962.

b Incluyendo, además, los inmigrantes procedentes del exterior y de procedencia desconocida.

c Véase la nota correspondiente del cuadro 37.

emigración (alrededor del 23 por ciento, en cada caso). En cambio, el Sector Oriente tenía una cuota mayor de inmigrantes de núcleos de más de 5000 habitantes, que de inmigrantes de pequeños pueblos y de la zona rural. En el Sector Central se encontró la situación inversa.

Estos resultados confirman la sospecha de que en el Sector Central se instala una población inmigrante más heterogénea que en los restantes sectores de la ciudad.

\section{TIEMPO TRANSCURRIDO DESDE LA LIEGADA HASTA COMENZAR A TRABAJAR}

Este análisis comprende solamente a los inmigrantes que en la época de la encuesta exan económicamente activos y que llegaron en el período 1942-1962, después de cumplir 14, años de edad. 
Probablemente el problema más urgente con que se enfrenta el inmigrante al llegar a la ciudad, es encontrar un empleo u otra forma de actividad remunerada. La medida en que lo logra y el tiempo que tarda en hacerlo son indicaciones de su asimilación al medio.

Muchos inmigrantes seguramente ya tenían un puesto o una actividad concreta donde trabajar. Estas situaciones deberán reflejarse en la brevedad del tiempo transcurrido hasta el comienzo de su actividad.

Además, algunos inmigrantes eran no económicamente activos a su llegada al Gran Santiago y tampoco tenían necesidad inmediata de un empleo (por lo general personas dependientes, como son los hijos, esposa, parientes a cargo, etc.). En estos casos pudo haber transcurrido un tiempo relativamente amplio hasta el momento de comenzar a trabajar, lo cual, sin embargo, no indica necesariamente que tenían obstáculos para incorporarse a la mano de obra.

Cerca del 73 por ciento de los inmigrantes estudiados, tanto de uno como de otro sexo, comenzó a trabajar dentro del primer trimestre de su residencia en el Gran Santiago. Dentro de los nueve meses siguientes lo hicieron además el 12,8 de los hombres y el 9,1 por ciento de las mujeres.

a) Los motivos tenidos para emigrar al Gran Santiago permiten hacer un análisis más específico, considerando que algunos de ellos se relacionan de manera más directa con el problema del empleo, como sería el hecho de buscar trabajo. En el cuadro 39 se resumen los datos de los inmigrantes que declararon haber venido por "razones de trabajo" (excluidos los casos de "traslados", "contratos" y similares) ${ }^{66}$ De este grupo, el 80,9 por ciento de los hombres y el 90,3 de las mujeres comenzaron a trabajar en el primer trimestre. Después del año de residencia no había encontrado aún su primera ocupación el 6,3 por ciento de los hombres y el 3,8 por ciento de las mujeres.

En una situación diametralmente opuesta se encontraban aquellos inmigrantes cuyo motivo fue el de acompañar a parientes que eran su sostén económico. Algo parecido ocurrió con aquellos que vinieron por razones de estudios, si bien es cierto que sólo una parte de éstos eran dependientes. Reuniendo ambos grupos se observa que alrededor del 40 por ciento encontró su primera ocupación en el primer trimestre $(4,5$ por ciento de los hombres y 37,5 por ciento de las mujeres) y casi un 50 por ciento lo hizo después del año. (Véase el cuadro 39.)

También se consideró un grupo de inmigrantes clasificados en la categoría "otros motivos", en la cual se incluyen motivos muy variados

66 Los inmigrantes que vinieron por "razones de trabajo" constituyen una alta proporción. Excluyendo motivos como "traslados", "contrato" y similares, esa proporción fue del 44,5 por ciento en los hombres y del 31,6 por ciento en las mujeres (véase el capítulo III, sección 4). 
CuAdro 39

INMIGRANTES CLASIFICADOS SEGUN EL TIEMPO QUE NECESITARON PARA COMENZAR A TRABAJAR EN EL GRAN SANTIAGO, EN RELACION CON ALGUNOS MOTIVOS DECLARADOS DE LA INMIGRACIONa

\begin{tabular}{|c|c|c|c|c|c|}
\hline $\begin{array}{l}\text { Sexo y motivo } \\
\text { de la migración } \\
\text { ol Gran Sentiago }\end{array}$ & Total b & $\begin{array}{l}\text { Primer } \\
\text { trimestre }\end{array}$ & $\begin{array}{l}3 \text { meses } \\
\text { a un año }\end{array}$ & $\begin{array}{c}\text { Más } \\
\text { de un año }\end{array}$ & $\begin{array}{l}\text { Sin } \\
\text { informa- } \\
\text { ción }\end{array}$ \\
\hline & \multicolumn{5}{|c|}{ (Porcentajes) } \\
\hline \multicolumn{6}{|l|}{ Hombres } \\
\hline $\begin{array}{l}\text { Razones de trabajoc } \\
\text { Estudios } \text { y acompañar }\end{array}$ & $100(235)$ & 80,9 & 12,8 & 6,3 & 一 \\
\hline a parientese & $100(82)$ & 41,5 & 9,7 & 47,6 & 1,2 \\
\hline Otros motivos & $100(75)$ & 64,0 & 20,0 & 14,7 & 1,3 \\
\hline \multicolumn{6}{|l|}{ Mujeres } \\
\hline $\begin{array}{l}\text { Razones de trabajoc } \\
\text { Estudios }^{d} \text { y acompañar }\end{array}$ & $100(289)$ & 90,3 & 5,9 & 3,8 & - \\
\hline a parientes $\mathrm{e}^{\mathrm{s}}$ & $100(14.1)$ & 37,6 & 13,5 & 46,8 & 2,1 \\
\hline Otros motivos ${ }^{f}$ & $100(58)$ & 60,4 & 17,2 & 20,7 & 1,7 \\
\hline
\end{tabular}

a Jnmigrantes llegados de más de 14. años en el período 1942-1962, cconómicamente activos en la época de la encuesta.

1) No se incluyen los casos acerca de los cuales no se conoce la información relativus a la primera ocupación en el Gran Santiago porque no se pudo completar la cricuesta.

" "Buscar trabajo" y "conseguir mejor remuneración".

"Estudios del entrevistado, de sus parientes o dependientes.

e Acompañar a parientes que eran sostén económico del inmigrante.

f No se incluyen problemas familiares, de salud, disconformidad con el medio rural ni terremotos.

y poco frecuentes y declaraciones vagas. $^{67}$ En este grupo, el 64,0 por ciento de los hombres y el 60,4 de las mujeres comenzaron a trabajar en el primer trimestre; y el 14,7 y el 20,7 por ciento, respectivamente, después del año.

La edad del inmigrante en la época de su movimiento al Gran Santiago tiene importancia en relación con el punto que se estudia. No podrían derivarse las mismas conclusiones de una determinada situación traiándose de hombres de más de 25 años de edad, por ejemplo, que de

67 No se incluyen razones de trabajo, cstudios, problemas familiares, solud, di conformidad con el medio rural ni acompañar a parientes que eran sostén del inmigrante. 
jóvenes que todavía no han alcanzado los 20. Para la gran mayoría de los primeros la necesidad de procurarse un empleo es imperiosa, en cambio, muchos de los menores de 20 años no han llegado todavia a la edad de trabajar y de hecho su participación en la mano de obra es relativa. mente más baja. Análoga reflexión podría hacerse respecto de la actividad femenina urbana, si bien los cambios en relación con la edad son menos marcados y no siguen un patrón tan definido como en el caso de los hombres.

En el cuadro 40 se muestra que efectivamente la edad desempeña un papel importante. Entre los hombres que llegaron de 14 a 19 años de edad casi la mitad se empleó en el primer trimestre; el 31,2 por ciento, después del año. Estas cifras indican que una parte importante de los menores de 20 años eran no económicamente activos en la época de su establecimiento en el Gran Santiago. No obstante, es significativo que casi el 20 por ciento se haya ocupado después del primer trimestre y antes del año, de suerte que se puede pensar que en su gran mayoría buscaban trabajo.

De los que llegaron después de los 20 años, el 80 por ciento aproximadamente comenzó a trabajar en el primer trimestre. Lo mismo sucede con los mayores de 25 años. Dado que esta población tiene una tasa de participación de casi 95 por ciento, y más todavía, habría que pensar que por lo menos un 15 por ciento tuvo dificultades para encontrar ocupación durante varios meses. Después del año, algo más del 8 por ciento aún no tenía trabajo.

Entre las mujeres, la edad no ha tenido un efecto diferencial tan claro como entre los hombres. Es probable que esto se deba a una mayor facilidad para obtener ocupación en edades muy jóvenes o también a que muchas mujeres no trabajan después de los 20 años debido, por ejemplo, a sus responsabilidades como dueñas de casa. Si se piensa que casi el 50 por ciento de las inmigrantes económicamente activas estaba formado por sirvientes de hogares particulares, parece lógico que el 71,0 por ciento de las mujeres llegadas de 15 a 19 años de edad consiguieran ocupación en el primer trimestre de su vida en el Gran Santiago, en contraste con el 49,6 por ciento de los hombres.

Una tercera variable que se vinculó con el tiempo transcurrido antes de comenzar a trabajar en el Gran Santiago, es el lugar de emigración. A tal efecto éste se clasificó en dos categorías según el tamaño del núcleo de población de salida, con el objeto de distinguir en forma más adecuada los núcleos con características urbanas relativamente bien definidas (núcleos de más de 5000 habitantes), de la población de los pequeños pueblos (núcleos de menos de 5000 habitantes) y del campo (población dispersa). Es probable que los inmigrantes procedentes de núcleos con características urbanas definidas tengan mayores facilidades para obte- 
Cuadro 40
INMIGRANTES CLASIFICADOS SEGUN EL TIEMPO QUE NECESITARON PARA COMENZAR A TRABAJAR EN EL GRAN SANTIAGO, Y EDAD AL LLEGAR ${ }^{a}$

\begin{tabular}{lcrrrr}
\hline $\begin{array}{l}\text { Sexo y edad } \\
\text { al llegar al } \\
\text { Gran Santiago }\end{array}$ & Totalb & $\begin{array}{c}\text { Primer } \\
\text { trimestre }\end{array}$ & $\begin{array}{c}3 \text { meses } \\
\text { a un año }\end{array}$ & $\begin{array}{c}\text { Más } \\
\text { un año }\end{array}$ & $\begin{array}{c}\text { Sin } \\
\text { informa- } \\
\text { ción }\end{array}$ \\
\hline Hombres & & & (Porcentajes) \\
$14-19$ & $100(125)$ & 49,6 & 19,2 & 31,2 & - \\
20.24 & $100(122)$ & 80,4 & 9,8 & 9,0 & 0,8 \\
25 y más & $100(245)$ & 80,8 & 11,0 & 7,8 & 0,4 \\
Total & $100(492)$ & 72,8 & 12,8 & 14,0 & 0,4 \\
Mujeres & & & & & \\
$14-19$ & $100(241)$ & 71,0 & 5,8 & 22,4 & 0,8 \\
20.24 & $100(137)$ & 75,2 & 8,7 & 16,1 & - \\
25 y más & $100(205)$ & 72,7 & 13,2 & 12,7 & 1,4 \\
Total & $100(583)$ & 72,6 & 9,1 & 17,5 & 0,8 \\
\hline
\end{tabular}

a Inmigrantes llegados de más de I4 años en el período 1942-1962, económicamente activos en el momento de la encuesta.

b No se incluyen los casos acerca los cuales no se conoce la información relativa a la primera ocupación en el Gran Santiago.

ner ocupación por varios motivos, como son el mejor conocimiento de las actividades urbanas, mayor instrucción y quizá mejores conocimientos del Gran Santiago.

El cuadro 41 señala, en efecto, que una mayor proporción de inmigrantes de núcleos de más de 5000 habitantes se ocupó en el primer trimestre, en uno y otro sexo. Sin embargo, este resultado puede ser mera consecuencia de la diferente edad media de los inmigrantes. En efecto, de los hombres que vinieron de núcleos de más de 5000 habitantes, el 24,4 por ciento tenía de 14 a 19 años; y de los que vinieron de núcleos de menos de 5000 habitantes, el 31,6 por ciento. Entre las mujeres las cifras respectivas son 37,9 y 49,0 por ciento. La edad media de los inmigrantes llegados de más de 14 años desde núcleos pequeños y los sectores rurales es más baja que la edad media de los que vinieron de los núcleos de más de 5000 habitantes. En párrafos anteriores, ya se había encontrado que la edad de llegada tiene un efecto diferencial importante. 
Cuadro 41

INMIGRANTES CLASIFICADOS SEGUN EL TIEMPO QUE NECESITARON PARA COMENZAR A TRABAJAR EN EL GRAN SANTIAGO, Y LUGAR DE PROCEDENCIAa

\begin{tabular}{|c|c|c|c|c|c|}
\hline $\begin{array}{l}\text { Sexo y lugar de emigración } \\
\text { según el tamaño del núcleo }\end{array}$ & Totalb & $\begin{array}{l}\text { Primer } \\
\text { trimestre }\end{array}$ & $\begin{array}{l}3 \text { meses } \\
\text { a un año }\end{array}$ & $\begin{array}{l}\text { Más de } \\
\text { un año }\end{array}$ & $\begin{array}{l}\text { Sin } \\
\text { informa- } \\
\text { ción }\end{array}$ \\
\hline & \multicolumn{5}{|c|}{ (Porcentajes) } \\
\hline \multicolumn{6}{|l|}{ Hombres } \\
\hline $\begin{array}{l}\text { Más de } 5000 \text { habitantes } \\
\text { Menos de } 5000 \text { habitan- }\end{array}$ & $100(308)$ & 76,3 & 10,1 & 13,3 & 0,3 \\
\hline tes & $100(155)$ & 67,7 & 16,8 & 15,5 & - \\
\hline Totale & $100(463)$ & 73,4 & 12,3 & 14,1 & 0,2 \\
\hline \multicolumn{6}{|l|}{ Mujeres } \\
\hline $\begin{array}{l}\text { Más de } 5000 \text { habitantes } \\
\text { Menos de } 5000 \text { habitan- }\end{array}$ & $100(375)$ & 68,0 & 10,4 & 20,3 & 1,3 \\
\hline tes & $100(200)$ & 80,0 & 7,0 & 13,0 & - \\
\hline Totale & $100(575)$ & 72,2 & 9,2 & 17,7 & 0,9 \\
\hline
\end{tabular}

a Inmigrantes llegados de más de 41 años en el período 1942-1962, económicamente activos en la época de la encuesta.

b No se incluyen los casos acerca de los cualez no se conoce la información relativa a la primera ocupación en el Gran Santjago.

c Excluye los inmigrantes del exterior y los de procedencia desconocida.

\section{Primera ocupación y nivel de instrucción}

a) La primera ocupación en el Gran Santiago guarda una definida correlación con el nivel educativo alcanzado por el inmigrante. Dado que se están considerando inmigrantes que llegaron después de 14 años de edad se puede suponer que una elevada proporción de ellos, especialmente los de bajo nivel de instrucción, tienen el mismo nivel que al llegar. Y en los casos en que ese nivel varió significativamente, se puede esperar que muchas veces la primera ocupación corresponda a una fecha posterior a aquella en que alcanzó el último nivel.

En los inmigrantes con bajos niveles de instrucción predominan las ocupaciones "manuales". De los inmigrantes con educación primaria (incluyendo los sin instrucción) más del 90 por ciento tuvo como primera ocupación una de tipo manual. Es sólo al llegar al nivel 3 (uno a tres 
años de enseñanza secundaria), cuando adquieren importancia las ocupaciones "no manuales" ( 45 por ciento de los hombres y 55 por ciento de las mujeres). Como es obvio, los inmigrantes del nivel 4 trabajan, en su gran mayoría, en esas ocupaciones. (Véase el cuadro 42.)

Si se observa lo que ocurre con algunas ocupaciones, se advierten algunos hechos de interés. Dentro de las de tipo "manual" hay variaciones con el nivel educativo, lo que se comprueba en la importancia relativa de los irabajadores no calificados ("obreros y jornaleros") que, en el caso de los hombres, pasa del 27 por ciento en el nivel 0 , al 10 por ciento en el nivel 3 (4 a 6 años de enseñanza primaria). Respecto de las mujeres, las de nivel más bajo (nivel 0 ) correspondían en el 80 por ciento de los casos al servicio doméstico. Esta proporción disminuye con el nivel educativo, aunque no tan rápidamente como se podría esperar, ya que en el nivel 3 (uno a tres años de enseñanza secundaria) una de cada cinco trabajadoras con ese nivel tuvieron como primera ocupación la de sirvientes domésticas.

b) La estabilidad en el empleo puede considerarse un indicador de la asimilación del inmigrante. Se piensa que tal estabilidad tiene que ser más dificil de conseguir en los primeros años de vida en la ciudad. Este problema debería ser más grave para los inmigrantes con bajo nivel de educación, de acuerdo a lo que se observa generalmente en relación con el grado de ocupación de los individuos.

$\mathrm{El}$ análisis que sigue se refiere a los inmigrantes asalariados y, de estes últimos, sólo a aquellos que obtuvieron una primera ocupación durante su primer año de vida en el Gran Santiago. (Véase el cuadro 43.) Esta población representa el 84 por ciento de los inmigrantes que registraron una ocupación en el Gran Santiago y el 76 por ciento de las inmigrantes con esa condición. ${ }^{68}$ La limitación a los que obtuvieron la primera ocupación durante el primer año se justifica, entre otras razones, porque muchos de los que obtuvieron su primera ocupación más adelante, no estaban buscando empleo en ese tiempo, por tratarse de estudiantes o por otros motivos.

Después de considerar el nivel de instrucción, es oportuno presentar la información sobre la distribución de los inmigrantes observados respecto de la duración del primer empleo. Los resultados indican que una proporción relativamente baja mantuvo su primer empleo por menos de un año. En los inmigrantes que llegaron de 14 a 24 años de edad, la pro. porcićn fue del 23 por ciento; en las inmigrantes de las mismas edades, del 28 por ciento. (Véase el cuadro 43.) ${ }^{69}$ De modo general, se podría

68 Compárense los cuadros 42 y 43.

69 De los que llegaron de más de 25 años, la proporción correspondiente no alcanza al 10 por ciento. 


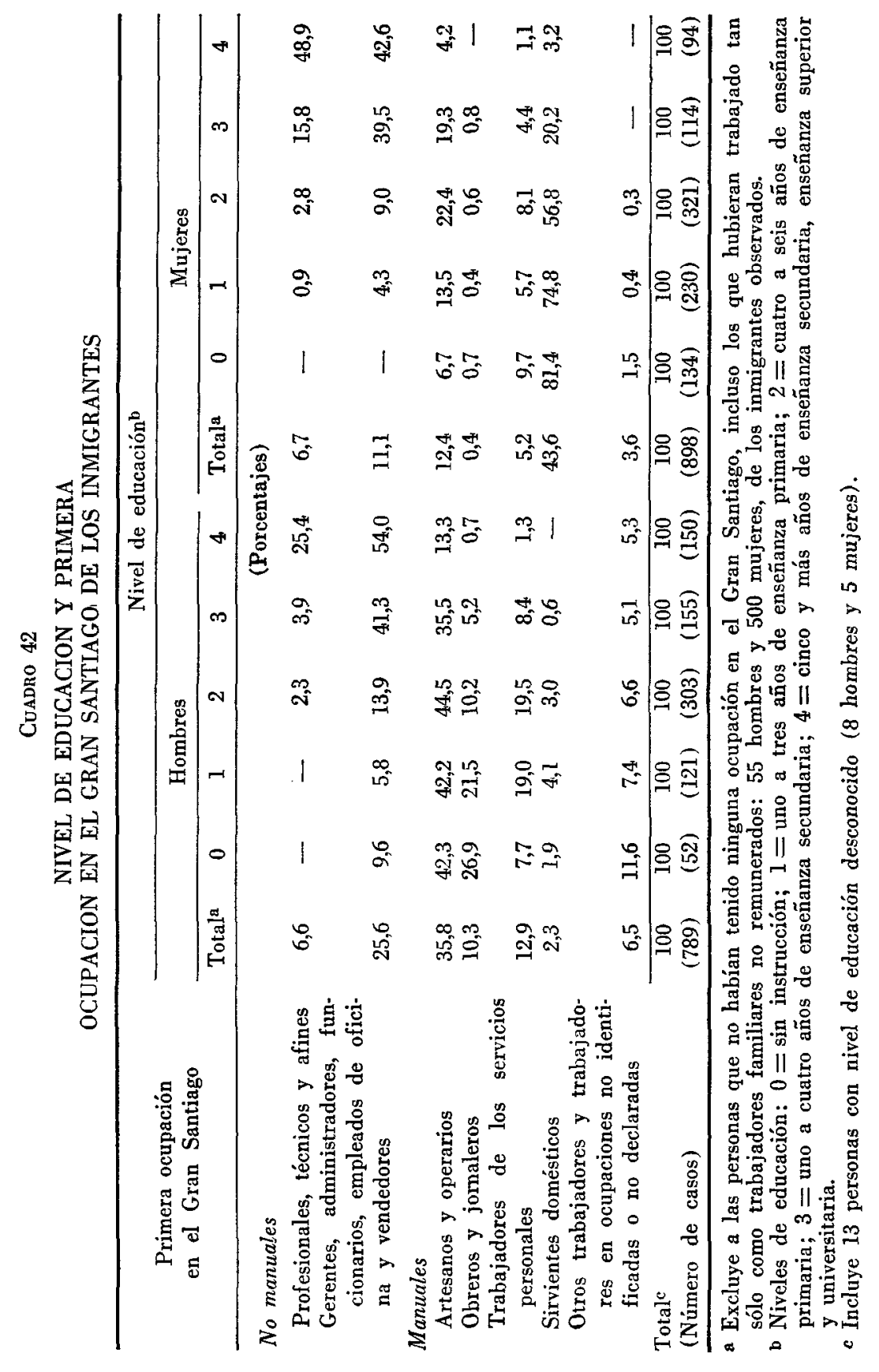


ALGUNOS ASPECTOS DE LA ASIMILACIÓN

Cuanro 43

INMIGRANTES QUE OBTUVIERON SU PRIMER EMPLEO EN EL PRIMER ANTO DE VIDA EN EL GRAN SANTIAGO, SEGUN LA DURACION EN ESE EMPLEO

\begin{tabular}{lcccc}
\hline \multirow{2}{*}{$\begin{array}{c}\text { Duración } \\
\text { en el } \\
\text { primer empleo }\end{array}$} & \multicolumn{2}{c}{ Hombres } & \multicolumn{2}{c}{ Mujeres } \\
\cline { 2 - 5 } & $\begin{array}{c}\text { (Edad al llegar al Gran Santiago) } \\
\text { Todas } \\
\text { edades }\end{array}$ & 14 a 24 & $\begin{array}{c}\text { Todas } \\
\text { edades }\end{array}$ & 14 a 24 \\
\hline & \multicolumn{4}{c}{ (Porcentajes) } \\
Menos de 3 meses & 5 & 5 & 5 & 6 \\
Tres meses a un año & 15 & 18 & 19 & 22 \\
1 a 2 años & 16 & 18 & 18 & 18 \\
2 a 5 años & 27 & 30 & 30 & 30 \\
5 años y más & 35 & 30 & 28 & 23 \\
\cline { 2 - 6 } Total & 100 & 100 & 100 & 100 \\
(Número de casos) & $(665)$ & $(347)$ & $(685)$ & $(434)$ \\
\hline
\end{tabular}

dccir que aproximadamente el 60 por cienio maniuvo su primera ocupación más de dos años. ${ }^{70}$

Una información detallada que no se presenta aģuí, muestra que el nivel de educacićn es un factor diferencial respecto de la duración del primer empleo, cuando se considera un tiempo de dos años como intervalo. Un empleo de más de dos años podría ser considerado, para los fines de este análisis, como empleo estable. En el cuadro 44 se presenta la distribución porcentual de inmigranies según que el primer empleo hubiera durado menos de dos años o más de dos años, en general y para distintos niveles de instrucción.

El comportamiento que se observa difiere según el sexo. Tratándose de hombres, la proporción de empleos "estables" aumenta con el nivel educacional. En líneas generales, de menos del 60 por ciento para los niveles $0-1-2$, la relación sube al 68 por ciento en el nivel 3 , y a 85 en el nivel 4. En el caso de las mujeres, la proporción de empleos "estables" fluctúa alrededor del 55 por ciento. Podría aun decirse que el grado de estabilidad es similar en ambos sexos en los niveles de educación bajos, pero más alto el de los hombres en los niveles superiores. Por otra parte, no parecs haber diferencias importantes en relación con la edad de los inmigranies.

T0 Es probable que la duración esté sobrestimada. Muchos inmigrantes podrían haber desestimado una ocupación, o varias, de cierta duración. 
Cuadro 44

INMIGRANTES QUE OBTUVIERON SU PRIMER EMPLEO

EN EL PRIMER AÑO DE VIDA EN EL GRAN SANTIAGO, SEGUN LA DURACION EN ESE EMPLEO Y EL NIVEL DE EDUCACION

\begin{tabular}{|c|c|c|c|c|}
\hline \multirow{3}{*}{$\begin{array}{l}\text { Sexo y nivel } \\
\text { de educación }{ }^{\mathrm{a}}\end{array}$} & \multicolumn{4}{|c|}{ Edad al llegar al Gran Santiago y duración en el primer emple } \\
\hline & \multicolumn{2}{|c|}{ Todas las edades } & \multicolumn{2}{|c|}{ De 14 a 24 años } \\
\hline & $\begin{array}{l}\text { Menos de } \\
2 \text { años }\end{array}$ & $\begin{array}{l}\text { Más de } \\
2 \text { años }\end{array}$ & $\begin{array}{c}\text { Menos de } \\
2 \text { años }\end{array}$ & $\begin{array}{l}\text { Más de } \\
2 \text { años }\end{array}$ \\
\hline & \multicolumn{4}{|c|}{ (Porcentajes) } \\
\hline Hombres $\mathbf{b}$ & 36 & 64 & 39 & 61 \\
\hline 0 & 49 & 51 & 41 & 59 \\
\hline 1 & 42 & 58 & 41 & 59 \\
\hline 2 & 43 & 57 & 45 & 55 \\
\hline 3 & 32 & 68 & 31 & 69 \\
\hline 4 & 15 & 85 & 16 & 84 \\
\hline Mujeresc & 42 & 58 & 46 & 54 \\
\hline 0 & 48 & 52 & 44 & 56 \\
\hline 1 & 40 & 60 & 42 & 58 \\
\hline 2 & 43 & 57 & 48 & 52 \\
\hline 3 & 43 & 57 & 45 & 55 \\
\hline 4 & 38 & 62 & $\ldots d$ & $-\mathrm{d}$ \\
\hline
\end{tabular}

a Niveles de educación. (Véase la nota b del cuadro 42.)

b Incluye 5 casos de nivel de educación desconocido.

c Incluye 3 casos de nivel de educación desconocido.

a Sólo hay 16 casos, por lo que se omite el porcentaje.

\section{OCUPACIÓN Y LUGAR DE EMIGRACIÓN}

La ocupación del inmigrante en el momento de la encuesta permite estudiar un aspecto de su asimilación que se relaciona con el lugar de emigración. ${ }^{71}$

71. Se analizan los datos de inmigrantes llegados en el período 1942-1962 teniendo ya más de 14 años de edad y que en el momento de la encuesta eran personas económicamente activas. 
Las conclusiones de mayor interés y que al mismo tiempo ofrecen más seguridad, se refieren a los grandes grupos de trabajadores "manuales" y "no manuales". (Véase el cuadro 45.) Mientras más definido es el carácter urbano del lugar de emigración, más baja es la proporción de trabajadores manuales. De aquellos que vinieron de núcleos de más de 20000 habitantes, el 53,2 por ciento desarrollaban actividades manuales, frente al 65,3, 75,7 y 83,6 por ciento, respectivamente, de los inmigrantes procedentes de núcleos de 5000 a 19999,900 a 4.999 habitantes y zona rural. Entre las irabajadoras la proporción varió en el mismo sentido, desde el 69,7 al 96,0 por ciento.

El número de casos con distintas ocupaciones manuales y no manuales es demasiado pequeño como para derivar conclusiones de los mismos. Por esta circunstancia sólo se hace referencia, por ser los más numerosos, al grupo de los operarios, en el caso de los hombres, y al de las sirvientes de hogares particulares, en el caso de las mujeres. ${ }^{72}$

La imporlancia que ocupa el grupo de los operarios no revela diferencias en relación con el lugar de emigración. El grupo de las sirvienies de hogares particulares si muestra diferencias según que las mujeres vinieran de núcleos de más de 5000 habitantes o de núcleos menores y del sector rural. De cualquier modo, y en ambos casos ias sirvientes de hogares particulares representaban más del 60 por ciento de las trabadoras manuales. (Véase el cuadro 45.)

\section{MOVILIDAD PROFESIONAL DE LOS INMIGRANTES}

a) Iniroducción. A menudo el cambio de lugar de residencia va acompañado por un cambio de ocupación del inmigrante. La frecuencia de este último hecho depende, entre otros factores, de la clase de ocupación que tenía aquél anies de emigrar. En su casi totalidad los trabajadores agrícolas necesariamente deben cambiar de ocupación al llegar a la ciudad. En otras ocupaciones esa disyuntiva no es tan forzosa y en algunas, como en los profesionales, técnicos y afines, la movilidad profesional originada por desplazamientos geográficos es pequeña.

Se puede suponer que un alto porcentaje de los cambios de ocupación se produce entre ocupaciones análogas en cuanto a conocimientos generales y habilidad y al medio social en que se desarrollan. Si esio es verdad, el grado de movilidad profesional depende, en buena parte, de la clásificación de ocupaciones que se use en el análisis. Cuanio mayor es la calificación requerida por un grupo de ocupaciones, menoi es el número de cambios que debería esperarse en dicho grupo, y a la inversa.

i2 Cada uno de estos grupos representaba cerca de los dos tercios de los trabajadores manuales de uno y otro sexo, respectivamente. 
Cuadro 45

ULTIMO STATUS ECONOMICO-SOCIAL Y LUGAR DE EMIGRACIONa

\begin{tabular}{|c|c|c|c|c|c|c|}
\hline \multirow[b]{2}{*}{$\begin{array}{l}\text { Sexo y clase } \\
\text { económico-social }\end{array}$} & \multicolumn{6}{|c|}{ Lugar de emigración (según el tamaño del núcleo) } \\
\hline & $\begin{array}{l}\text { Más de } \\
20000 \\
\text { habit. }\end{array}$ & $\begin{array}{c}\text { De } \\
5000 \\
a \\
19999 \\
\text { habit. }\end{array}$ & $\begin{array}{c}\text { De } \\
900 \text { a } \\
4,999 \\
\text { habit. }\end{array}$ & $\begin{array}{l}\text { Zona } \\
\text { rural }\end{array}$ & $\begin{array}{l}\text { Exte- } \\
\text { rior }\end{array}$ & Total $b$ \\
\hline & \multicolumn{6}{|c|}{ (Porcentajes) } \\
\hline \multicolumn{7}{|l|}{ Hombres } \\
\hline No manuales & 42,5 & 30,6 & 23,4 & 8,2 & 75,8 & 33,8 \\
\hline Manuales & 53,2 & 65,3 & 75,7 & 83,6 & 21,2 & 62,2 \\
\hline Otros y sin información ${ }^{c}$ & 4,3 & 4,1 & 0,9 & 8,2 & 3,0 & 4,0 \\
\hline $\begin{array}{l}\text { Total } \\
\text { (Número de personas) }\end{array}$ & $\begin{array}{l}100,0 \\
(207)\end{array}$ & $\begin{array}{l}100,0 \\
(144)\end{array}$ & $\begin{array}{l}100,0 \\
(107)\end{array}$ & $\begin{array}{c}100,0 \\
(61)\end{array}$ & $\begin{array}{r}100,0 \\
(33)\end{array}$ & $\begin{array}{l}100,0 \\
(553)\end{array}$ \\
\hline \multicolumn{7}{|l|}{ Mujeres } \\
\hline No manuales & 29,0 & 33,6 & 25,3 & 2,0 & 20,0 & 26,4 \\
\hline Manuales & 69,7 & 65,6 & 73,4 & 96,0 & 80,0 & 72,4 \\
\hline Otros y $\sin$ información ${ }^{\mathrm{e}}$ & 1,3 & 0,8 & 1,3 & 2,0 & - & 1,2 \\
\hline $\begin{array}{l}\text { Total } \\
\text { (Número de personas) }\end{array}$ & $\begin{array}{l}100,0 \\
(152)\end{array}$ & $\begin{array}{l}100,0 \\
(122)\end{array}$ & $\begin{array}{r}100,0 \\
(79)\end{array}$ & $\begin{array}{c}100,0 \\
(50)\end{array}$ & $\begin{array}{r}100,0 \\
(5)\end{array}$ & $\begin{array}{l}100,0 \\
(410)\end{array}$ \\
\hline $\begin{array}{l}\text { Porcentajes de "opera- } \\
\text { rios" en trabajadores } \\
\text { (hombres) manuales }\end{array}$ & 64,5 & 70,2 & 65,4 & 60,8 & - & 66,3 \\
\hline $\begin{array}{l}\text { Porcentajes de "sirvien- } \\
\text { tes de hogares parti- } \\
\text { culares" en trabajado- } \\
\text { res (mujeres) manua- } \\
\text { les }\end{array}$ & 62,3 & 68,8 & 74,1 & 72,9 & - & 67,7 \\
\hline
\end{tabular}

a Inmigrantes Ilegados de más de 14 años de edad en el período 1942-1962.

b Excluye los casos de inmigrantes de procedencia desconocida.

c Incluye a las fuerzas armadas y a las personas en actividades relacionadas con la agricultura.

El cambio de lugar de residencia es un factor importante de movilidad profesional, mas no el único. Esta movilidad es un proceso que afecta a una proporción elevada de trabajadores durante su vida activa en un mismo lugar, sean nativos o inmigrantes, aunque es probable que la 
movilidad sea más alta en los inmigrantes. Este comportamiento estaria vinculado al proceso de asimilación del inmigrante al nuevo ambiente. Por ejemplo, es posible que en muchos casos la primera ocupación sea forzada por la urgente necesidad que tiene el inmigrante de trabajar para ganar su sustento; o bien porque tiene menos vinculaciones, conocimientos, experiencia y, en general, menos probabilidades de obtener aquellas ocupaciones que por sus condiciones favorables son más buscadas.

El propósito del presente análisis es muy limitado. La encuesta no se propuso estudiar particularmente la movilidad profesional y, en consecuencia, tampoco se investigó la historia completa de las distintas actividades de los inmigrantes. ${ }^{73}$ Sin embargo, la información sobre la ocupación en tres momentos distintos (el de la encuesta, el de la primera ocupación desempeñada en el Gran Santiago y el de la ocupación en el lugar de procedencia inmediatamente antes de su venida), permite conocer, aunque en forma limitada, algunos hechos básicos y útiles para fu* turas investigaciones.

En lo fundamental, se compara la composición por ocupaciones en los tres momentos arriba mencionados. La población en estudio está formada por los inmigrantes llegados de más de 14 años de edad y económicamente activos en el momento de la encuesta. Como es obvio, algunas de estas personas eran no económicamente activas en la época en que emigraron al Gran Santiago.

La edad del inmigrante en la fecha de llegada y el tiempo transcurrido desde ese momento, son factores que probablemente ejercen alguna influencia sobre el cambio de ocupación. Se puede pensar que una persona joven se adapta fácilmente a una nueva actividad, e incluso que ello es parte natural de un proceso de esiabilización en los trabajadores con una corta experiencia profesional. Una selección por parte de ciertos empleadores, en particular de aquellos que absorben mano de obra en "ocupaciones modernas", quizá facilite la movilidad de las generaciones más jóvenes, al mismo tiempo que trabe la de los trabajadores de edad media.

Por otra parte, cuanto más largo es el tiempo vivido en el Gran Santiago, mayor es la probabilidad de que ocurra algún cambio como resultado del proceso de adaptación o de progreso.

Aunque se reconoce la utilidad del análisis de la influencia de estos dos factores sobre la movilidad profesional, el tamaño de la muestra limitó el estudio al examen de la edad de llegada. (Véase la sección 3 de este capítulo.)

73 El carácter limitado del estudio se pone de manifiesto si se observa que no hay una investigación comparativa de la movilidad profesional de los nativos del Gran Santiago. 
b) La composición por ocupaciones en la época de la encuesta, al comenzar a trabajar en el Gran Santiago e inmediatamente antes de emigrar al Gran Santiago. Se requieren ciertas aclaraciones. Algunos de los inmigrantes que forman la población estudiada eran no económicamente activos antes de emigrar al Gran Santiago y, por consiguiente, no aparecen clasificados por ocupaciones en ese momento. ${ }^{74}$ Otros buscaban trabajo por primera vez y se encuentran por lo tanto en la misma situación. Ambos grupos representan en conjunto el 21 y el 58 por ciento, respectivamente, de los hombres y mujeres de la población estudiada. Este hecho es explicable ya que muchos inmigrantes llegaron, por ejemplo, en edades comprendidas entre los 14 y los 20 años. Pero la notable diferencia según el sexo indica claramente que la participación de las mujeres en las actividades económicas aumentó en grado considerable al llegar al medio urbano, independientemente del factor edad.

Los mencionados porcentajes (2l y 58 por ciento) de hombres y mujeres que no están clasificados por ocupación en la época inmediatamente anterior a la emigración por las circunstancias anotadas, no invalidan la comparación con los dos momentos siguientes. De los que llegaron sin experiencia profesional (no económicamente activos y personas que buscan trabajo por primera vez), se puede suponer que de no haber emigrado se habrían ocupado en el lugar de origen en forma parecida a aquellos que al emigrar ya tenían experiencia profesional. En el caso de los hombres este supuesto parece bastante probable; en el de las mujeres, el elevado porcentaje (58 por ciento) sin experiencia profesional en el lugar de origen, hace pensar más bien que una parte importante de él no se habría incorporado a la mano de obra si no hubiera emigrado. Quizás un 20 o un 30 por ciento de las mujeres inmigrantes y económicamente activas en el momento de la encuesta, habría quedado al margen de la mano de obra en tal eventualidad..$^{75}$ Parece evidente que respecto de este último grupo es poco claro hablar de movilidad profesional, pero desafortunadamente es imposible su identificación a fin de separarlo. Este hecho debería exagerar la movilidad profesional. Sin embargo, no parece que produzca una perturbación seria en vista de los

74 La población que se considera, como se dejó establecido, está formada por los inmigrantes que llegaron al Gran Santiago después de cumplir los 14 años y eran económicamente activos en la época de la encuesta. Sin embargo, hubo que excluir a cierto número de inmigrantes en razón de que se carecía de la información relativa a las ocupaciones anteriores de tales personas por no haberse podido realizar las entrevistas respectivas, si bien se conocía su ocupación en la época de la encuesta. Esta última información permite suponer que los casos excluidos no alteran prácticamente la composición por ocupaciones, al menos de las ocupaciones correspondientes al momento de la encuesta (véase la sección 4 más adelante).

75 Suponiendo que la incorporación adicional, en razón del avance de la edad, fuera similar, en cifras relativas, a la de los hombres (21 por ciento). 
resultados obtenidos, los que señalan que la movilidad es relativamente baja. $^{78}$

En el cuadro 46 se compara la composición por ocupaciones en el momento anterior al movimiento migratorio con la composición según la primera ocupación ejercida en el Gran Santiago, para lo cual se utiliza una clasificación económico-social de las ocupaciones. ${ }^{77}$

La movilidad profesional de los inmigrantes entre esos dos momentos fue relativamente baja, sobre todo en la población femenina, si se juzga por las cifras del cuadro mencionado. A continuación se puntualizan los hechos más salientes, comenzando por la población masculina.

El 26,0 por ciento de los inmigrantes con experiencia profesional previa al movimiento migratorio tenía una ocupación no manual. Según la primera ocupación en el Gran Santiago, la proporción de trabajadores no manuales llegó a 31,9 por ciento, ${ }^{78}$ en tanto que la de trabajadores manuales (incluyendo a los trabajadores agrícolas) descendió de 71,3 a 66,0 .por ciento. Este cambio significaría que, en cifras relativas, por lo menos alrededor del 7,5 por ciento de los trabajadores manuales pasó al otro sector. Esta última cifra es un saldo (por lo tanto un mínimo), pues se supone que entre ambos sectores no hubo cambios que se compensaran mutuamente. De cualquier modo, se puede aceptar que la movilidad del sector no manual al sector manual es de poca importancia, como lo confirman algunos resultados que se presentan más adelante.

En resumen, la estabilidad de los trabajadores manuales en su sector resultaría ser elevada (9 de cada 10 casos). Probablemente, la estabilidad es todavía más alta en los trabajadores que llegaron al Gran Santiago teniendo experiencia profesional y en el sector de los trabajadores manuales. Aquellos que trabajaron por primera vez en el Gran Santiago es muy probable que se hayan orientado en menor proporción hacia el

76 Otra observación se refiere a la forma diferente con que se trató a los trabajadores familiares no remunerados. Los trabajadores que tenían esta categoría en el momento de la encuesta fueron clasificados por ocupaciones. Por falta de información no se pudo hacer lo mismo con aquellos que ingresaron a esa categoría por la primera ocupación que tuvieron en el Gran Santiago, ni con los que pertenecían a ella en el lugar de procedencia.

Para salvar este inconveniente, Ios trabajadores familiares no remunerados se distribuyeron entre varias ocupaciones en las cuales se supuso que se desempeña la mayoría de ellos; la distribución se hizo proporcionalmente al número de tra. bajadores clasificados en tales ocupaciones. Estas son: vendedores, servicios personales (excepto sirvientes domésticos), obreros y jornaleros y trabajadores agrícolas. El número de trabajadores familiares no remunerados por distribuir es relativameníe pequeño, como se apreciará en los cuadros correspondientes, y por consiguiente, su repartición no podría alterar sustancialmente los resultados.

77 Véase el capítulo V.

78 Como se señaló al comienzo de esta sección, el 21 por ciento de los trabajadores clasificados según su primera ocupación en el Gran Santiago, no tenía experiencia profesional antes de emigrar. 
Cundro 46

MOVILIDAD PROFESIONAL. COMPOSICION POR OCUPACIONES ("CLASES" ECONOMICO-SOCIALES) DE LOS INMIGRANTES

EN TRES MOMENTOS: ANTES DE EMIGRAR AL GRAN SANTIAGO, AL COMENZAR A TRABAJAR EN EL GRAN SANTIAGO Y EN LA EPOCA DE LA ENCUESTA ${ }^{a}$

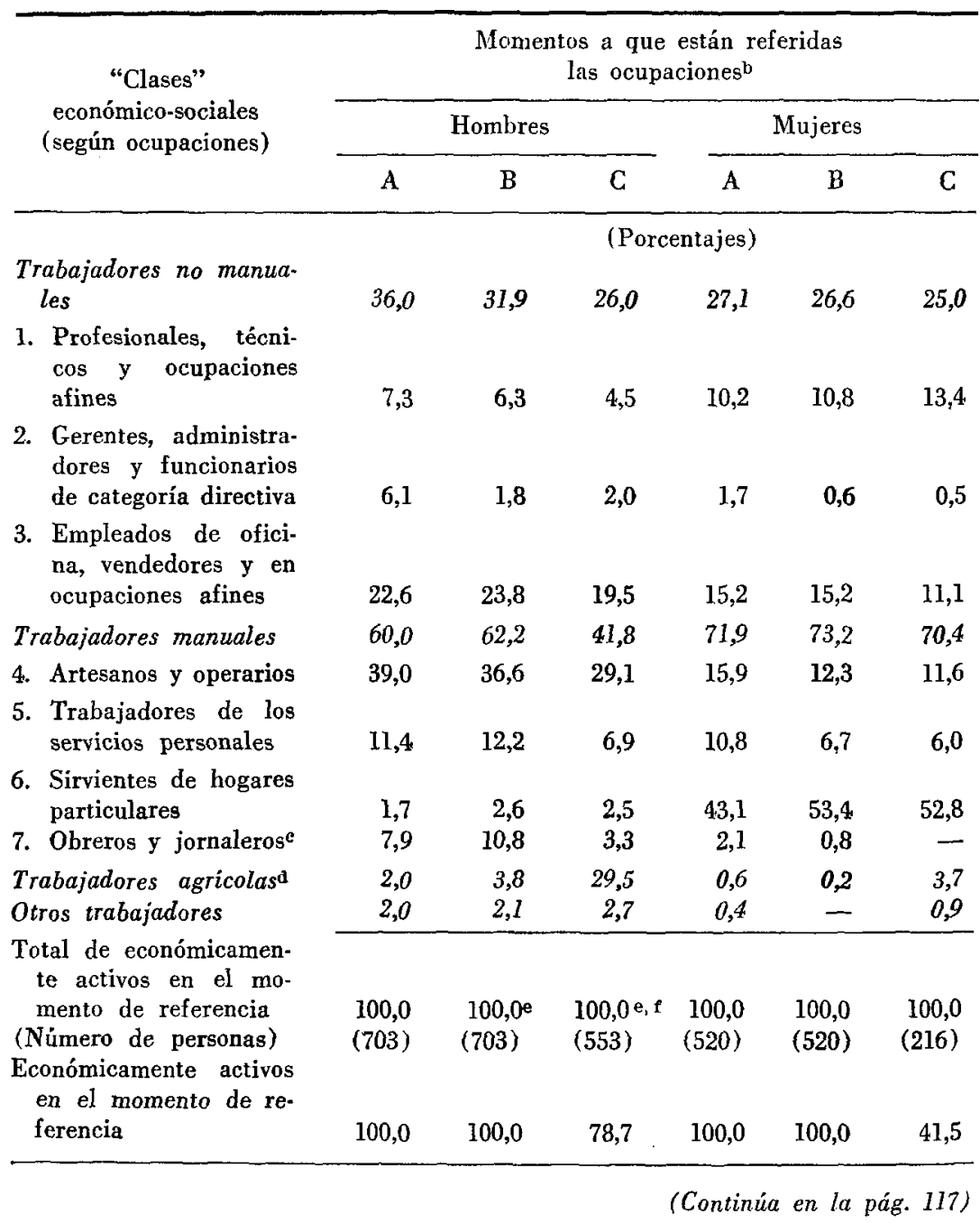


Cuadro 46 (continuación)

\begin{tabular}{|c|c|c|c|c|c|c|}
\hline \multirow{3}{*}{$\begin{array}{c}\text { "Clases" } \\
\text { económico-sociales } \\
\text { (según ocupaciones) }\end{array}$} & \multicolumn{6}{|c|}{$\begin{array}{c}\text { Momentos a que están referidas } \\
\text { las ocupaciones }{ }^{b}\end{array}$} \\
\hline & \multicolumn{3}{|c|}{ Hombres } & \multicolumn{3}{|c|}{ Mujeres } \\
\hline & A & B & $\mathrm{C}$ & A & B & $\mathrm{C}$ \\
\hline $\begin{array}{l}\text { Personas que buscaban } \\
\text { trabajo por primera } \\
\text { vez }\end{array}$ & - & - & 5,2 & - & - & 10,2 \\
\hline $\begin{array}{l}\text { No económicamente ac- } \\
\text { tivos }\end{array}$ & - & - & 16,1 & - & - & 48,3 \\
\hline $\begin{array}{l}\text { Total de económicamen- } \\
\text { te activos en la época } \\
\text { de la encuesta } \\
\text { (Número de personas) }\end{array}$ & $\begin{array}{l}100,0 \\
(703)\end{array}$ & $\begin{array}{c}100,0 \\
(703)\end{array}$ & $\begin{array}{l}100,0 \\
(703)\end{array}$ & $\begin{array}{l}100,0 \\
(520)\end{array}$ & $\begin{array}{c}100,0 \\
(520)\end{array}$ & $\begin{array}{r}100,0 \\
(520)\end{array}$ \\
\hline
\end{tabular}

a Inmigrantes con más de 14 años de edad al llegar al Gran Santiago y que eran económicamente activos en la época de la encuesta (excluidos los que en esa época buscaban trabajo por primera vez).

b A: en la época de la encuesta; B: primera ocupación en el Gran Santiago; C: cn cl lugar de procedencia y en la época inmediata anterior a la emigración hacia el Gran Santiago.

c Incluye vendedores ambulantes (excluidos del ítem 3 ).

d Agricultores, ganaderos, pescadores, etcétera.

e En las columnas B y C se ha prorrateado cierto número de "trabajadores familiares no remunerados" que en los momentos correspondientes no estaban clasificados por ocupaciones por falta de información. La distribución se hizo como sigue: Hombres ( 13 personas de la columna $B$ y 40 de la columna $C$ ), entre los siguientes grupos según su importancia numérica: vendedores (que son parte del grupo 3), trabajadores de los servicios personales (grupo 5), obreros y jornaleros (grupo 7) y trabajadores agrícolas. Mujeres (16 personas de la columna B): en partes iguales entre las vendedoras (que son parte del grupo 3) y las trabajadoras de los servicios personales (grupo 5). Dos personas de la columna $C$ fueron atribuidas a las vendedoras (grupo 3 ).

1 Excluye los que buscaban trabajo por primera vez en el lugar de procedencia.

sector manual. Pero esta distinta orientación es también una forma de movilidad profesional.

Si no se dispone de información cruzada de las ocupaciones en los dos momentos que se están comparando, es imposible establecer con suficiente seguridad la movilidad ocurrida entre las distintas ocupaciones del sector manual. La transferencia de trabajadores agrícolas (29,5 a 3,8 por ciento) ha ido a engrosar principal y necesariamente las restantes clases de trabajadores manuales ( 41,8 a 62,2 por ciento). 
En valores absolutos, la clase más beneficiada fue la de artesanos y operarios $(29,1$ a 36,6 por ciento); y en cifras absolutas y relativas, las de obreros y jornaleros $(3,3$ a 10,8 por ciento). Estos resultados muestran cuáles son las ocupaciones que entran a desempeñar los trabajadores manuales que vienen al Gran Santiago. Hay que señalar, en particular, la importancia que adquieren los obreros y jornaleros, que son trabajadores no calificados, con empleo irregular y de bajos ingresos. Además, es posible que el número de trabajadores de esta clase esté subestimado, debido a problemas de declaración y clasificación de la ocupación, y que esté sobrestimado el número de artesanos y operarios. En tal caso, la verdadera situación sería aun más grave.

La mayor ganancia relativa de los trabajadores no manuales corresponde a la clase de los "profesionales, técnicos ..." (4,5 a 6,3 por ciento). Es probable que este aumento provenga de los que llegaron al Gran Santiago sin experiencia profesional, entre los cuales hay que suponer que muchos lo hicieron en edad y condición de estudiantes.

La movilidad profesional de las mujeres es más baja que la de los hombres, no obstante que el 58,5 por ciento de la población examinada emigró sin tener experiencia profesional previa. Esto quiere decir que estas inmigrantes se orientaron en su primera ocupación en el Gran Santiago en forma muy similar a las trabajadoras con experiencia profesional en el lugar de origen. En efecto, la proporción de trabajadoras manuales prácticamente no varió: 74,1 y 73,4 por ciento.

En el caso de las mujeres, la transferencia desde el sector de las trabajadoras agrícolas, a la inversa de lo que ocurre con los hombres, no oscurece el comportamiento de las distintas clases de trabajadoras manuales. En éstas se advierte que mantienen su importancia relativa casi sin cambio.

La clase más importante la forman las "sirvientes de hogares particulares" (52,8 y 53,4 por ciento, respectivamente, en los dos momentos considerados). No cabe duda de que más del 50 por ciento de las mujeres que comenzaron a trabajar en el Gran Santiago lo hicieron en dicha calidad.

Podría llamar la atención la disminución de la importancia relativa de la clase "profesionales, técnicos...": 13,4 y 10,8 por ciento, respectivamente. Fuera de un posible error de muestreo originado por el pequeño número de personas que forman esta clase, tal disminución podría explicarse más bien por el hecho de que la elevada proporción de mujeres que carecía de experiencia profesional antes de emigrar, tuvo menos oportunidades de alcanzar ocupaciones de aquel tipo que las inmigrantes que tenían ya tal experiencia.

Corresponde ahora comparar la composición por ocupaciones considerando, por una parte, la primera ocupación desempeñada en el Gran 
Santiago y, por la otra, la ocupación en la época de la encuesta. La tendencia ya observada entre los dos momentos antes considerados se repite aquí en forma muy similar, $y$, en todo caso, denotando todavía menor movilidad. (Véase el cuadro 46.) En resumen, entre los inmigrantes examinados existe una elevada estabilidad en el curso de su vida activa en el Gran Santiago.

El cambio relativamente importante de la clase de los "gerentes, administradores y funcionarios de categoría directiva" (de 1,8 a 6,1 por ciento) en la población masculina, es producto de una evolución lógica a través de la cual se forma este núcleo dirigente. Quizá sea el ejemplo más significativo de movilidad profesional que se desprende de las cifras examinadas, junto con la gran estabilidad general.

En la población femenina hay un hecho adicional que destacar. Por lo menos 20 de cada 100 mujeres cuya primera ocupación en el Gran Santiago fue la de sirviente de hogares particulares, cambiaron de ocupación, enrolándose principalmente en otras ocupaciones manuales.

c) El factor "edad de llegada" de los inmigrantes. Se podría partir del supuesto de que las condiciones para la movilidad profesional son más favorables en los inmigrantes que llegan relativamente jóvenes, por ejemplo antes de los 25 años de edad.

El cuadro 4.7 permite hacer interesantes comprobaciones que complementan el análisis de las secciones anieriores. En él se presenta la composición por ocupaciones (grandes grupos), en los tres momentos que se vienen considerando, para los siguientes grupos de edad al llegar al Gran Saniiago: 14, a 24, 25 a 39 y más de 40 años. La población de este cuadro está definida como la de los anteriores, con la diferencia que excluye a los inmigrantes llegados antes del año 1942.

Las principales observaciones pueden resumirse como sigue:

a) En los tres rromentos considerados, la distribución de los inmigrantes en trabajadores no manuales y manuales varía apreciablemente según sea la edad de llegada al Gran Santiago. Cuanto más alta es la edad, mayor es la proporción de trabajadores no manuales. Así, por ejemplo, según la ocupación que tenían antes de emigrar al Gran Santiago, en los inmigrantes con experiencia profesional previa la proporción de no manuales fue de 12,8 por ciento en los que llegaron de 14 a 24 años de edad, de 32,5 en los que llegaron de 25 a 39 años y de 42,2 por ciento en los que lo hicieron después de los 40 años.

b) La movilidad profesional que se deduce al comparar la primera ocupación en el Gran Santiago con la que tenían en el momento de la encuesta, tiende a aumentar con la edad de llegada.

Así, mientras que en los inmigrantes de 14 a 24 años el porcentaje de no manuales prácticamente no varió (26,1 y 25,4 por ciento), en 


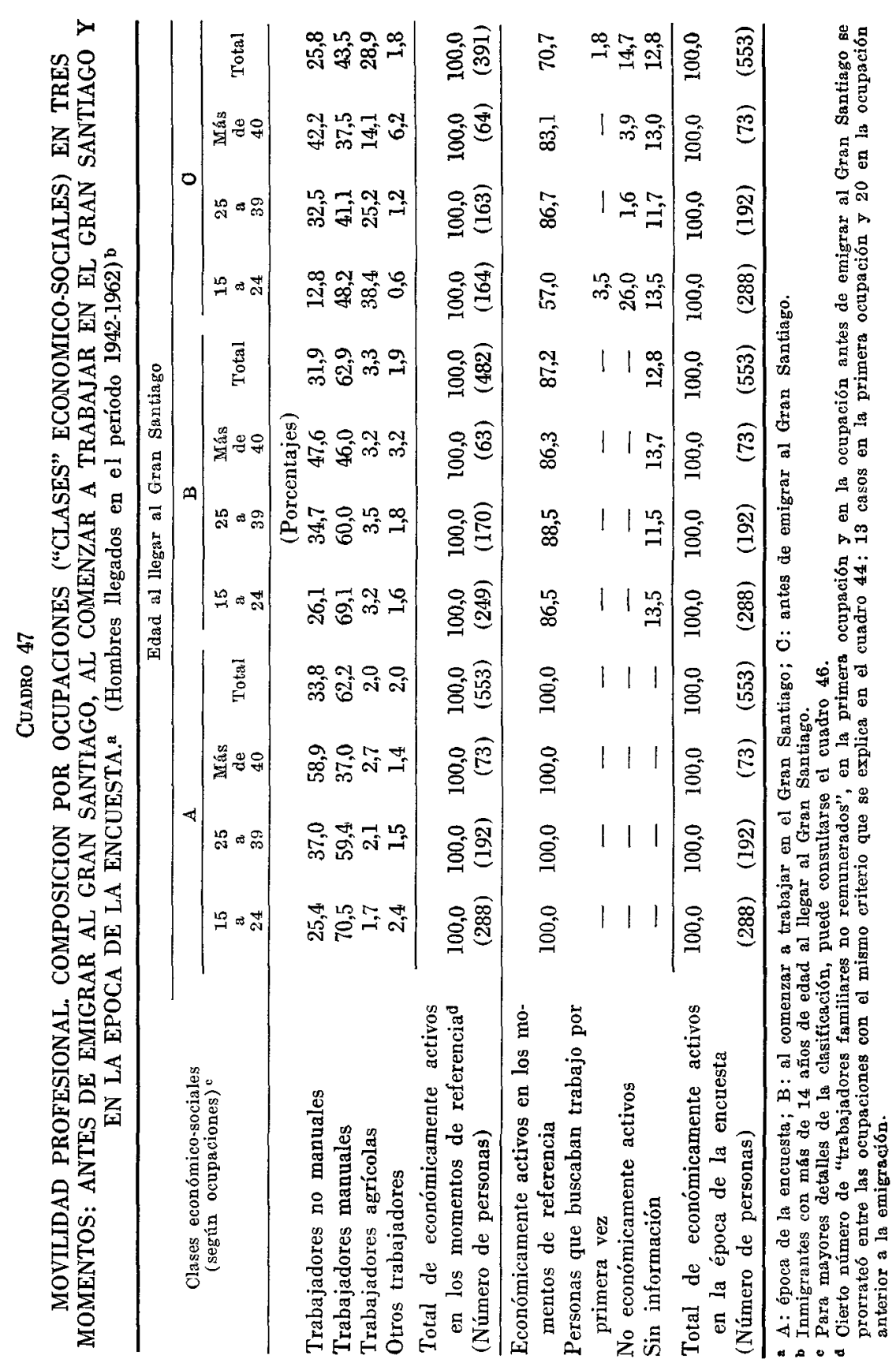


los de 25 a 39 pasó de 34,7 a 37,0 por ciento y en los de más de 40 años subió de 47,6 a 58,9 . Es posible que esta última diferencia contenga un error de muestreo grande ( $100=73$ casos), pero de cualquier modo existe una tendencia.

c) La movilidad profesional que se advierie comparando la composición según la ocupación en el lugar de origen y la primera ocupación en el Gran Santiago, es notablemente elevada en los inmigrantes de 14 a 24i años de edad, entre los cuales la proporción de trabajadores no manuales pasó de I2,8 a 26,1 por ciento. En este cambio puede haber tenido un papel importante el 29,5 por ciento de inmigrantes de esa edad que llegaron sin experiencia profesional.

Por el contrario, en los inmigrantes llegados a edades más avanzadas no se advierte movilidad profesional.

Las mujeres inmigrantes ofrecen con los hombres algunos puntos de analogía y otros de diferencia. ${ }^{79}$ Los puntos de analogía son los siguientes (véase el cuadro 48):

a) Ia proporción de trabajadoras no manuales (Ia que en general es más baja que en los hombres) aumenia con la edad.

b) La movilidad profesional que resulta comparando la composición según la ocupación antes de emigrar y la primera desempeñada en el Gran Santiago, es notablemente alta en las mujeres llegadas entre los 14. y los 24 años de edad. Como en el caso de los hombres, tiene que haber influido en esie cambio el que una elevada proporción de las mujeres Jlegadas a esa edad (57,6 por ciento) no tenía experiencia profesional previa.

La diferencia más impcrtante es la notable estabilidad que en los dos grupos de ocupaciones considerados muestran las mujeres que llegaron pasados los 25 años de edad, a pesar de que el 31,4 por ciento de las actuales trabajadoras llegó a esa edad sin previa experiencia profesional en el lugar de origen. ${ }^{80}$

79 Sólo se consideran dos grupos de edad: 14 a 24 años y más de 25 años al llegar. En el caso de las mujeres no parece ser de mayor interés subdividir este último grupo.

80 De la población considerada en los cuadros 47 y 48,71 trabajadores y 26 trabajadoras sólo fueron clasificados por ocupaciones en el momento de la encuesta, no así en los dos momentos anteriores, por falta de información (casos en que no se pudo hacer la entrevista). Este tratamiento difícilmente podría haber alterado los resultados, considerando que aquellos casos se distribuyen en forma casi proporcional en cada grupo de edades (alrededor del 12,8 y del 6,3 por ciento, rcspectivamente, de los hombres y de las mujeres). La distribución según los grandes grupos de ocupaciones (en el momento de la encuesta) también fue pareja en los hombres (alrededor del ya mencionado 12,8 por ciento). Entre las mujeres, la proporción de casos en las trabajadoras no manuales es de 9,3 por ciento y en las manuales, de 5,3 ; y si de estas úlitimas se eliminan las "sirvientes de hogares particulares" la proporción sulje a 7,9 por ciento. 


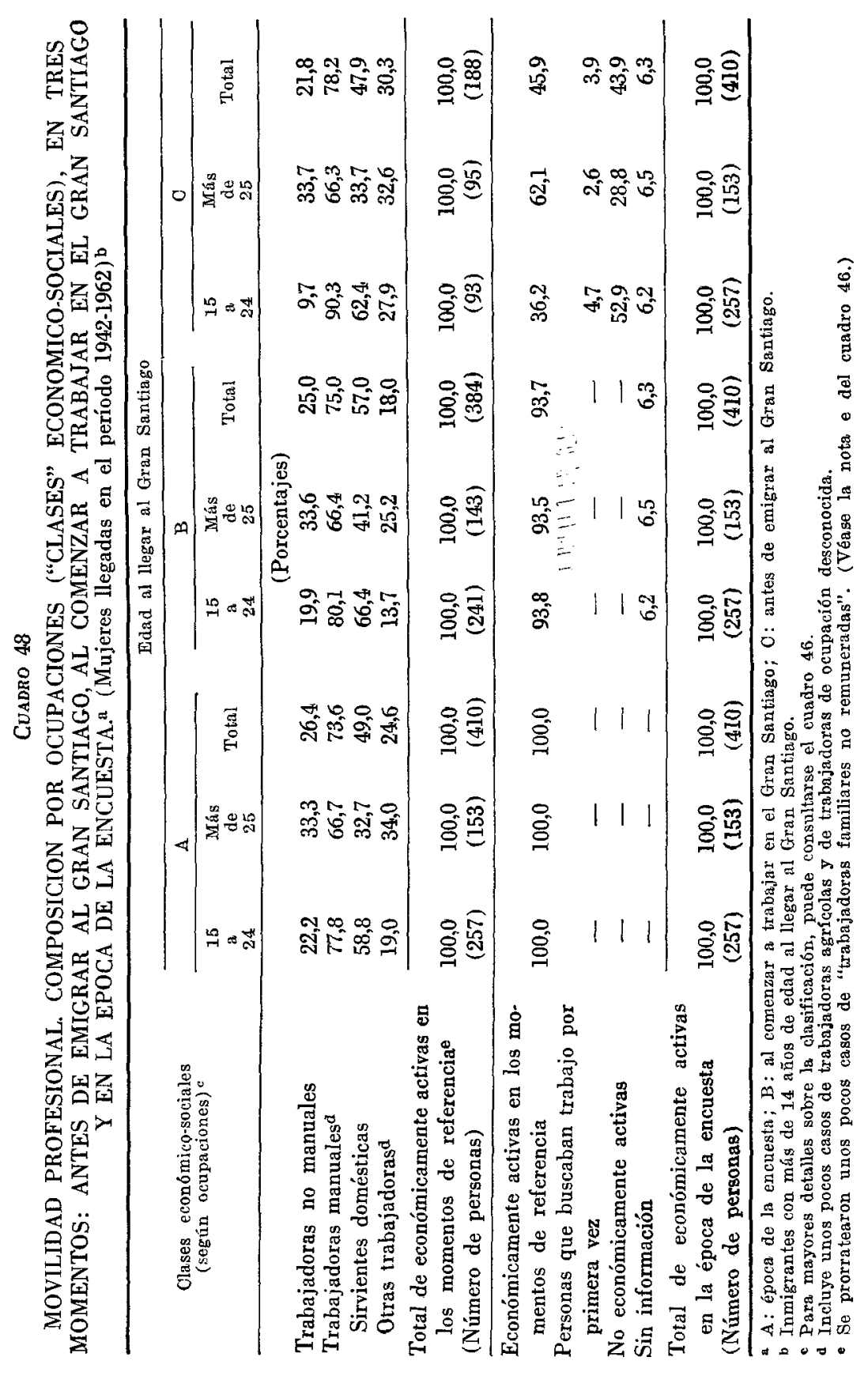


d) La movilidad profesional en un análisis directo. En esta sección se presenta una tabulación con información cruzada de la primera ocupación tenida en el Gran Santiago y de la ocupación en la época de la encuesta. Por consiguiente, la distribución de los inmigrantes que en el momento de la encuesta pertenecían a cualquiera de los grupos de ocupaciones previstos, se estableció según la primera ocupación que tuvieron en el Gran Santiago.

La población examinada es la misma de los cuadros 47 y 48 y, por consiguiente, sólo comprende trabajadores que inmigraron en los 20 años anteriores a la fecha de la encuesta. La clasificación por ocupaciones de grupos económico-sociales es la misma utilizada hasta aquí.

Los resultados obtenidos confirman en general las conclusiones avanzadas en las secciones anteriores y que están basadas en un tipo de información menos apropiado para el análisis de la movilidad profesional.

Hombres. El cuadro 49 contiene Ia información acerca de 434 inmigrantes, relativa a su primera ocupación en el Gran Santiago y a la que tenían en la época de la encuesta, distinguiendo entre trabajadores no manuales y manuales. Casi 9 de 10 trabajadores no manuales en su primera ocupación continuaban en ese mismo grupo (88,1 por ciento). La misma proporción es válida para los trabajadores manuales $(91,2$ por ciento).

Se puede pensar lógicamente que el número de trabajadores no ma* nuales que deja esta clase de ocupaciones para incorporarse a otras manuales, está condicionado por el número de trabajadores de esta categoría. Lo mismo cabe decir respecto de los trabajadores manuales que pasan al otro grupo. Teniendo presenie esta idea, se calcularon sendos índices de salida de trabajadores no manuales y manuales, siguiendo para ello el método y las mismas hipótesis de una tabla de contingencia. ${ }^{81}$

81 En una tabla de doble entrada, un criterio de independencia entre dos características A y B en el cuadro 49 sería, por ejemplo, entre las ocupaciones de los dos momentos de tiempo considerados, está dado por la igualdad:

$$
\frac{(\mathrm{AB})}{\mathrm{N}}=\frac{(\mathrm{A})}{\mathrm{N}} \cdot \frac{(\mathrm{B})}{\mathrm{N}} ; \text { también }: \frac{\mathrm{N}(\mathrm{AB})}{(\mathrm{A}) \cdot(\mathrm{B})}=1
$$

donde $(A B)$ es una frecuencia de celda; (A) y (B) son frecuencias marginales, y $N$ es la población total. Se utiliza la igualdad (I) como un índice de "asociación" entre A y B. Si la relación fuera mayor que 1, habría asociación positiva; si fuese menor, habría asociación negativa. En el cuadro 49 se utilizó el correspondiente índice de "disociación" para medir la intensidad de las salidas de cada clase o status económico. En el esquema anterior, el índice de disociación o salida de la clase $A$ es:

$$
\frac{N(A b)}{(A) \text {. (b) }} \geqslant 1 \text {; y el correspondiente a la clase } B: \frac{N(a B)}{(a) .(B)} \geqslant 1 \text {. }
$$

Esta clase de relación ha sido utilizada ampliamente en mediciones de la movilidad 
Cuadro 49

MOVILIDAD PROFESIONAL. CAMBIO DE STATUS ECONOMICO-SOCIAL: PRIMERA OCUPACION EN EL GRAN SANTIAGO Y OCUPACION

EN LA EPOCA DE LA ENCUESTA

(Hombres llegados en el período 1942-1962) a

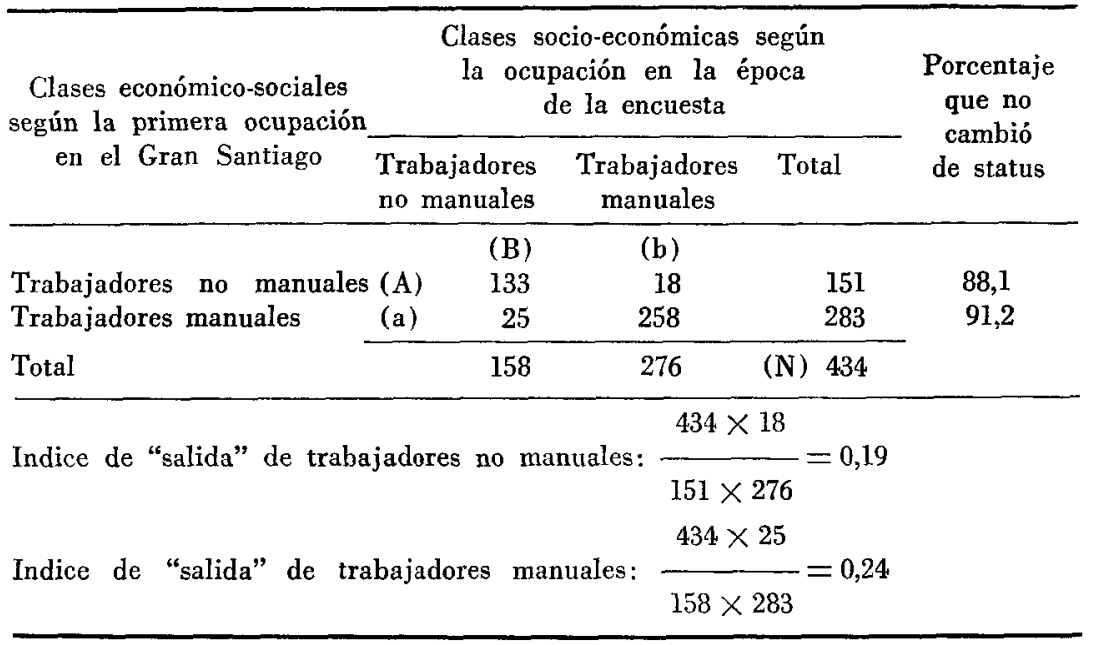

a Inmigrantes con más de 14 años de edad al llegar al Gran Santiago. Para los fines de la comparación se ha excluido a los "trabajadores agrícolas" y a "otros trabajadores", que constituyen un número pequeño de casos (véase el cuadro 47), sea en la primera ocupación o en la ocupación en la época de la encuesta. También se han excluido por falta de información sobre la ocupación 13 trabajadores que fueron "trabajadores familiares no remunerados" en su primera ocupación y las personas que buscan trabajo por primera vez.

Ambos índices, como se podría entrever, son bajos. El índice de salida en el caso de los trabajadores no manuales es de 0,19 y en el de los manuales, de 0,24. Cuanto menor es el número de salidas más pequeño es el índice y su valor tiende a cero.

El mayor índice de salida de los trabajadores manuales parecería estar en contradicción con el más alto porcentaje de permanencia de éstos

profesional por Glass y Hall (D. V. Glass y J. R. Hall: "Social Mobility in Great Britain: A study of Intergeneration Changes in Status", en Social Mobility in Great Britain, cap. VIII, págs. 177-217, Londres, 1952. La discusión estadística de los métodos utilizados se puede consultar en los apéndices 1 y 2 del citado cap. VIII, escritos por R. Mukjerjee y R. Hall, y por R. Mukjerjee, respectivamente). 
en el grupo (91,2 por ciento), pero, como se dijo en líneas anteriores, ese movimiento estaría condicionado por el número de casos en el otro grupo y, por consiguiente, mejor ref́lejado en el índice.

El cuadro 50 presenta los cambios operados en tres grupos más específicos de ocupaciones, escogidos por corresponderles un número mayor de casos y, consiguientemente, porque ofrecen más confianza los resultados que se obtienen. En los tres casos la proporción que permanece en el mismo grupo es más baja que la resultante de la clasificación dicotómica simple de no manuales y manuales. De cada 10 "empleados de oficina, vendedores...", por lo menos 7 continúan en ese sector. Lo mismo ocurre aproximadamente entre los "artesanos y operarios".

En cambio, sólo la mitad de los "trabajadores de los servicios personales ..." permanece sin salir. Si ahora se consideran los que se mantienen dentro del sector manual $\mathrm{c}$ del sector no manual, según sea el

CUAdRo 50

MOVILIDAD PROFESIONAL. CAMBIO DE OCUPACION DE TRABAJADORES DE ALGUNOS GRUPOS DE OCUPACIONES: PRIMERA OCUPACION EN EL GRAN SANTIAGO Y OCUPACION EN LA EPOCA DE LA ENCUESTA

(Hombres llegados en el período 1942-1962) $^{\mathrm{a}}$

\begin{tabular}{|c|c|c|c|c|c|c|}
\hline \multirow{2}{*}{$\begin{array}{c}\text { Primera ocupación } \\
\text { en el } \\
\text { Gran Santiagob }\end{array}$} & \multicolumn{4}{|c|}{ Ocupación en la época de la encuesta } & \multicolumn{2}{|c|}{$\begin{array}{l}\text { Porcentaje } \\
\text { que no } \\
\text { cambió de }\end{array}$} \\
\hline & $\begin{array}{l}\text { La } \\
\text { misma } \\
\text { ocupa- } \\
\text { ción }{ }^{b}\end{array}$ & $\begin{array}{c}\text { En la } \\
\text { misma clase } \\
\text { económico- } \\
\text { sociale }\end{array}$ & $\begin{array}{l}\text { En otra } \\
\text { clase } \\
\text { económico- } \\
\text { social }\end{array}$ & Total & $\begin{array}{l}\text { Grupo } \\
\text { de } \\
\text { ocupa- } \\
\text { ción }\end{array}$ & $\begin{array}{l}\text { Clase } \\
\text { econó- } \\
\text { mico- } \\
\text { social }\end{array}$ \\
\hline $\begin{array}{l}\text { Empleados de ofici- } \\
\text { na, vendedores y } \\
\text { personas en ocupa- } \\
\text { ciones afines }\end{array}$ & 77 & 91 & 17 & 108 & 71,3 & 84,3 \\
\hline $\begin{array}{l}\text { Artesanos y opera- } \\
\text { rios } \\
\text { Trabajadores de los }\end{array}$ & 132 & 161 & 16 & 177 & 74,6 & 91,0 \\
\hline servicios personales & 27 & 46 & 6 & 52 & 51,9 & 88,5 \\
\hline Total & 236 & 298 & 39 & 337 & & \\
\hline
\end{tabular}

“Inmigrantes con más de 14 años al llegar al Gran Santiago.

b Más exactamente, grupo de ocupaciones.

c Trabajadores "no manuales" y trabajadores "manuales" (no se incluye a los trabajadores agrícolas). (Véase el cuadro 46.) 
Cuadro 51

MOVILIDAD PROFESIONAL. CAMBIO DE STATUS ECONOMICO-SOCIAL: PRIMERA OCUPACION EN EL GRAN SANTIAGO Y OCUPACION EN LA EPOCA DE LA ENCUESTA

(Mujeres llegadas en el período 1942-1962)a

\begin{tabular}{|c|c|c|c|c|c|}
\hline \multirow{2}{*}{$\begin{array}{l}\text { Clases económica-sociales } \\
\text { según la primera ocupación } \\
\text { en el Gran Santiago }\end{array}$} & \multicolumn{4}{|c|}{$\begin{array}{l}\text { Clases económico-sociales según } \\
\text { la ocupación en la época } \\
\text { de la encuesta }\end{array}$} & \multirow{2}{*}{$\begin{array}{l}\text { Porcentaje } \\
\text { que no } \\
\text { cambió } \\
\text { de status }\end{array}$} \\
\hline & $\begin{array}{l}\text { Trab } \\
\text { no } \mathrm{m}\end{array}$ & $\begin{array}{l}\text { Jadoras } \\
\text { nuales }\end{array}$ & $\begin{array}{c}\text { Trabajadoras } \\
\text { manuales }\end{array}$ & Total & \\
\hline & & (a) & (b) & & \\
\hline Trabajadoras no manuales & (A) & 80 & 11 & 91 & 87,9 \\
\hline Trabajadoras manuales & (B) & 11 & 271 & 282 & 96,1 \\
\hline Total & & 91 & 282 & 373 & \\
\hline
\end{tabular}

a Inmigrantes con más de 14 años al llegar al Gran Santiago. No se incluyen las trabajadoras que eran "trabajadoras familiares no remuneradas" en su primera ocupación (Il casos), ni las personas que buscan trabajo por primera vez. (Véase el cuadro 49.)

caso, las proporciones suben aproximadamente a 9 casos de cada 10. (Véase el cuadro 50.)

En resumen, la movilidad dentro del respectivo sector, manual o no manual, parece ser más elevada, o al menos similar, a la movilidad entre ambos sectores.

Mujeres. La movilidad observada en las inmigrantes es semejante a la de los hombres en el sector no manual y menor en el manual, cuyo 96,1 por ciento no cambió de status, o sea, conserva su ocupación manual. (Véase el cuadro 5l.)

Una proporción relativamente alta de mujeres deja de ser económicamente activa en edades tempranas, en general a causa de matrimonio. Sólo el 73,4 por ciento de las mujeres cuya primera ocupación en el Gran Santiago fue no manual, continuaba trabajando en la época de la encuesta. Relacionando esa cifra con la del cuadro 48 , se puede decir que de 100 mujeres cuya primera ocupación fue no manual, 26,6 dejaron de trabajar, 64,5 seguían como trabajadoras no manuales y las 8,9 restantes lo hacian en una ocupación manual. Análogamente, de $100 \mathrm{mu}$ jeres cuya primera ocupación fue manual, 38,6 se retiraron, 59,0 continuaban en una actividad manual y el 2,4 restante estaba trabajando en 
una ocupación no manual. Este tipo de comparación acentúa todavía más la baja movilidad profesional de las inmigrantes. ${ }^{82}$

Las mujeres inmigrantes están concentradas en pocas actividades: sirvientes de hogares particulares, operarias, profesionales y técnicas, empleadas de oficina y servicios personales. Estas actividades reunían el 85,8 por cienio de los casos en la época de la encuesta. Las sirvientes de hogares particulares solas representaban el 48,8 por ciento de la población. Es interesante observar la evolución de las trabajadoras cuya primera ocupación fue la úlima nombrada. De cada 100 mujeres (34.7 casos) sirvientes en su primera ocupación, 36,9 salieron de actividad, 52,5 continuaban como sirvienies y sólo el 10,6 estaba en otras actividades, en su mayoría ocupaciones manuales. En las oiras ocupaciones donde el número de irabajadoras es comparativamente alto, la situación es parecida.

82 Un análisis similar carece de mayor interés respecto de la población masculina, dado que la proporción que salió de actividad es muy pequeña (aproximadamente el 5 por ciento) como para aportar nueva luz. 



\section{LOS EFECTOS DEMOGRAFICOS}

\section{Parte 1}

\section{El crecimiento de la población del Gran Santiago}

Entre los años 1920 y 1950, la población de las 11 comunas que forman el Gran Santiago se duplicó dos veces. ${ }^{83}$ Como ocurrió en otras ciudades capitales de países latinoamericanos, una parte importante de este incremento se debe al flujo de inmigranies.

La simple diferencia entre la tasa anual de crecimiento de la población y sa tasa de incremento natural ${ }^{84}$ es un buen indicador de la magnitud del aporie migratorio. En el período intercensal 1952-1960, la población del Gran Saniiago creció con una tasa anual de 3,9 por ciento, mientras que la tasa de incremento natural podría ser estimada en 2,3 por ciento, de lo cual se deduce que el crecimiento de origen migratorio sería del orden de 1,6 por ciento.

Este crecimiento debería considerarse relativamente mod̉erado, en comparación con los aumentos de población que experimentaron en aquella década otras grandes ciudades de la región, ${ }^{85}$ de más de 5 por ciento por año. Sin embargo, iomando en consideración el grado de urbani-

83 La población del Gran Santiago creció como se indica a continuación:

\begin{tabular}{ccc} 
Fecha del censo & $\begin{array}{c}\text { Población } \\
\text { (miles) }\end{array}$ & $\begin{array}{c}\text { Tasa anual } \\
\text { de crecimiento } \\
\text { (por cien) }\end{array}$ \\
\hline 15-XII-1920 & 541,1 & 3,4 \\
27-IX -1930 & 758,2 & 2,7 \\
28-IX -1940 & 987,3 & 3,0 \\
24-IV -1952 & 1391,0 & 3,9 \\
29-IX -1960 & 1933,5 & \\
\hline
\end{tabular}

84 La tasa de incremento natural está dada por la diferencia entre las tasas brutas de natalidad y mortalidad.

85 Ejemplos: Bogotá (1951-1964), 6,8 por ciento anual; Caracas (1950-1961), 5,4; México (1950-1960), 4,6 por ciento. 
zación alcanzado por Chile ${ }^{86}$ una tasa de crecimiento por migración del 1,6 por ciento pone de manifiesto el elevado tributo demográfico que las demás regiones del país continúan pagando al Gran Santiago.

En verdad, el fuerte movimiento migratorio hacia el Gran Santiago es un proceso de muchas décadas. Si la tasa de crecimiento de su población fue del 3,4 durante el período $1920-1930,{ }^{87}$ como en este intervalo la tasa de incremento natural debió haber sido (dado el nivel que entonces tenía la mortalidad) inferior al 2,0 por ciento anual, resulta que se llega nuevamente a una tasa de incremento migratorio de aproximadamente 1,5 por ciento.

\section{Estructura por SEXo Y EDAD}

Aparte del efecto sobre la tasa de crecimiento, la influencia más visible del movimiento migratorio es la que se opera sobre la estructura por sexo y edad de la población recipiente.

Antes de analizar la situación particular del Gran Santiago, son necesarias algunas observaciones sobre la forma como el flujo de inmigrantes modifica esa estructura. Cuanto más alta sea la tasa de incremento por migración y cuanto más diferencial sea por sexo y edad ese flujo, mayor será también el efecto modificatorio. Es fácil ver que si la población inmigrante tiene una estructura por sexo y edad (edad al llegar) similar a la de la población recipiente, no modificará la estructura de esta última aunque el movimiento sea relativamente grande. Sin embargo, como la migración a las grandes ciudades suele ser selectiva por sexo (por ejemplo, mayor número de mujeres) y por edad (por ejemplo, mayor número de personas en edades adultas jóvenes), ${ }^{88}$ las estructuras de estas ciudades difieren claramente de la que tendrían si fueran poblaciones cerradas.

Por otra parte, el impacto en los primeros años de una corriente nueva, o del incremento de una ya existente, tiene un efecto modificatorio importante en la estructura por edad. Con el transcurso del tiempo, de mantenerse esa corriente a un nivel relativo (tasas) más o menos constante, tal efecto tiende a atenuarse por varias causas: los inmigrantes tienen hijos, los que llegaron en edades adultas jóvenes envejecen, etc.

La estructura por edad de la población inmigrante de una ciudad

86 Después del Uruguay, la Argentina y probablemente Cuba, Chile es el país más urbanizado de América latina. En 1952, la población urbana representaba el 60,2 por ciento y en 1960 , el 68,2 por ciento de su población.

87 Las cifras censales en las que se basa este cálculo no han sido corregidas de probables errores de enumeración, por lo que el valor de la tasa de crecimiento sólo es aproximado.

88 En rigor, habría que decir tasas de inmigración más altas en esas edades. 
que recibe una corriente migratoria continua y sostenida, como ocurrió en el Gran Santiago, es relativamente más vieja que la correspondiente de la población nativa. ${ }^{89}$ Contribuye al "envejecimiento" de la población inmigrante, y al "rejuvenecimiento" de la nativa, el hecho de que los hijos de los primeros también son nativos; además, el número de personas inmigrantes en cualquier edad, en particular en las edades adultas y avanzadas, es producto de un proceso acumulativo, o sea de los inmigrantes llegados con esa edad en un año determinado y de los llegados con anterioridad con una edad menor y que alcanzan aquella edad en dicho año. Las cifras del cuadro 52 ilustran el efecto de este proceso, el cual se traduce en la proporción creciente, en relación con la mayor edad, de los inmigrantes respecto de toda la población.

Los comentarios que anteceden servirán para la mejor interpretación de las esiructuras por edad de la población inmigrante y la nativa, las que se presentan en el cuadro 53. El examen de la composición por edad de la población (migrantes y no migrantes) en grandes grupos (0-14, 15-59, 60 años y más) no arroja una indicación clara del efecto producido por el movimiento migratorio. En efecto, una combinación del 42 y del 53 por ciento en los grupos de edades 0-14 y $15-59$ (hombres), respectivamente, o una del 36 y 57 por ciento en las mismas edades (mujeres), iales como figuran en el cuadro 53 , podrían también darse en una población cerrada con niveles de fecundidad y de mortalidad comparables al promedio que probablemente ha tenido la población del Gran Santiago en las últimas décadas. ${ }^{90}$ Como se carece de estimaciones precisas sobre los niveles de mortalidad y fecundidad que deberían aplicarse, tampoco se podrían sacar conclusiones seguras de las cifras del cuadro 53. Sin embargo, como en una población cerrada no hay razones para que se den diferencias tan grances entre las estructuras de hombres y mujeres, la explicación inmediata que surge es el factor migración: la menor proporción de niñas $(36,1$ por ciento) revelaría la mayor importancia de la inmigración de mujeres en edades adultas jóvenes.

La información sobre la estructura por edad de inmigrantes y no migrantes, por separado, no abona la anterior afirmación. Con pequeñas

89 Relativamente vieja se llama a una población que contiene una proporción importante de individuos en edades adultas avanzadas; joven, por oposición es aquella que tiene una elevada proporción de niños, por ejemplo más del 40 por ciento de menores de 15 años.

Do Las referidas combinaciones de porcentajes de población en las edades 0-14 y 15-59, corresponden, aproximadamente, a las de una población teórica cerrada que estuviera sujeta durante un tiempo relativamente largo a niveles de mortalidad comprendidos entre 50 y 55 años de esperanza de vida al nacer, y a tasas brutas de reproducción entre 2,0 y 2,5. (Puede consultarse: United Nations, The Aging of Populations and its Economic and Social Implications, ST/SOA/Ser. A/26, Nueva York, 1956.) 
Cuadro 52

PORCENTAJES DE INMIGRANTES AL GRAN SANTIAGO POR SEXO Y GRUPOS DE EDADESa

\begin{tabular}{ccc}
\hline Edad & Hombres & Mujeres \\
\hline Todas las edades & 31,1 & 36,8 \\
Menores de 15 años & 7,0 & 7,9 \\
De 15 y más años: & 48,4 & 53,1 \\
$15-29$ & 32,7 & 40,1 \\
$30-44$ & 52,6 & 57,1 \\
$45-59$ & 63,2 & 64,4 \\
60 y más & 74,7 & 68,6 \\
\hline
\end{tabular}

a Sobre un total de 4986 hombres y 5850 mujeres, enumerados en la encuesta.

Cuadro 53

ESTRUCTURAS POR EDAD DE LAS POBLACIONES INMIGRANTE Y NATIVA DEL GRAN SANTIAGO, POR SEXO

\begin{tabular}{|c|c|c|c|c|c|c|}
\hline \multirow{2}{*}{$\begin{array}{c}\text { Grupos } \\
\text { de } \\
\text { edades }\end{array}$} & \multicolumn{3}{|c|}{ Hombres } & \multicolumn{3}{|c|}{ Mujeres } \\
\hline & $\begin{array}{l}\text { Inmigran- } \\
\text { tes }\end{array}$ & Nativos & Total & $\begin{array}{l}\text { Inmigran- } \\
\text { tes }\end{array}$ & Nativas & Total \\
\hline & \multicolumn{6}{|c|}{ (Porcentajes) } \\
\hline $0-4$ & 1,3 & 25,9 & 18,2 & 1,3 & 23,3 & 15,2 \\
\hline $5-9$ & 3,2 & 16,4 & 12,3 & 1,9 & 16,1 & 10,9 \\
\hline $10 \cdot 14$ & 5,0 & 14,1 & 11,3 & 4,5 & 13,2 & 10,0 \\
\hline $15 \cdot 19$ & 7,9 & 10,6 & 9,8 & 8,2 & 10,7 & 9,8 \\
\hline $20-24$ & 7,8 & 7,9 & 7,9 & 8,9 & 7,4 & 8,0 \\
\hline $25-34$ & 20,9 & 9,9 & 13,3 & 21,1 & 11,0 & 14,8 \\
\hline $35-44$ & 18,9 & 7,5 & 11,1 & 18,4 & 7,5 & 11,4 \\
\hline $45-59$ & 21,7 & 5,7 & 10,6 & 22,7 & 7,3 & 12,9 \\
\hline 60 y más & 13,3 & 2,0 & 5,5 & 13,0 & 3,5 & 7,0 \\
\hline \multicolumn{7}{|l|}{ Resumen } \\
\hline $0 \cdot 14$ & 9,5 & 56,4 & 41,8 & 7,7 & 52,6 & 36,1 \\
\hline $15-59$ & 77,2 & 41,6 & 52,7 & 79,3 & 43,9 & 56,9 \\
\hline 60 y más & 13,3 & 2,0 & 5,5 & 13,0 & 3,5 & 7,0 \\
\hline Total & 100,0 & 100,0 & 100,0 & 100,0 & 100,0 & 100,0 \\
\hline (Número de casos) & (1 549) & $(3437)$ & $(4,986)$ & $(2$ 152) & $(3698)$ & $(5850)$ \\
\hline
\end{tabular}


diferencias, la composición por edad de hombres y mujeres inmigrantes, son similares. La comparación podría resumirse señalando que el 77,2 por ciento de los hombres estaban en el grupo de edad 15-59 años, contra el 79,3 por ciento de las mujeres inmigrantes.

No es necesario insistir en el hecho de que la estructura de los nativos es totalmente diferente de la de los inmigrantes: más de la mitad son menores de 15 años de edad.

En resumen, puede concluirse que, no obstante la magnitud y estructura particular de la población inmigrante, la estructura por edad correspondiente a toda la población no está visiblemente afectada por el fenómeno migratorio. En apoyo de esta conclusión es oportuno mencionar que en la población de todo el país los menores de 15 años ocupan aproximadamente el 40 por ciento, y las personas de 15 a 59 años el 53 por ciento; esto es, cifras similares a las correspondientes a la población masculina del Gran Santiago. ${ }^{91,} 92$

La composición por sexo, eso sí, refleja el efecto producido por el aporte migratorio. El índice de masculinidad resultó en la encuesta de 85,2 , valor prácticamente igual al obtenido con otras fuentes. ${ }^{93}$ En la población inmigrante el índice es todavía más bajo: 72,0. Este último resultado traduce, principalmente, el carácter selectivo por sexo del movimiento migratorio hacia el Gran Santiago y, en menor medida, la sobremortalidad de los hombres así como también el movimiento de emigración de nativos de la ciudad, ambos hechos favorables a un excedente de población femenina. ${ }^{94}$ (Véase el cuadro 54. .)

La fuerza de la selectividad femenina tiene más importancia de la que surge de los datos arriba mencionados, como se pone de manifiesto en el índice de masculinidad de los inmigrantes que llegaron adultos. ${ }^{95}$

Del cuadro 54 se deduce que la población nativa está afectada por una emigración selectiva de hombres, ya que el índice de masculinidad de 92,9 es demasiado bajo como para obedecer exclusivamente al efecto de la sobremortalidad masculina. Por último, el valor de 88,0 como índice de masculinidad de la población inmigrante menor de 15 años de

91 En la población estimada a mitad de 1960, a partir de los datos del censo del mismo año corregidos en un cinco por ciento en el grupo de edad 0-4 años. (Véase: Alvarez, L., Proyección de la población de Chile por sexo y grupos de edad: 1960-2000, CELADE, C/84, página 27.)

92 El lector debe estar advertido de que los datos de la encuesta están afectados por errores de muestreo, Io que podría explicar pequcñas diferencias.

83 Según los datos del censo de 1960, el índice es de 85,8 y según la encuesta de ocupación y desocupación de junio de 1963 del Instituto de Economía de la Universidad de Chile, de 84,9.

94 En la sección 1, del capítulo I, se trata más ampliamente el efecto de la solıremortalidad masculina sobre el indice de masculinidad.

9.5 En la sección 1, del capitulo I, se vio que el indice era de 62 en los inmigrantes que llegaron entre los 15 y 30 años de edad. 
Cuadro 54,

INDICES DE MASCULINIDAD DE LOS INMIGRANTES Y LOS NATIVOS EN EL GRAN SANTIAGO

\begin{tabular}{lc}
\hline Status migratorio y edad & $\begin{array}{c}\text { Indice } \\
\text { de } \\
\text { masculinidada }^{\text {a }}\end{array}$ \\
\hline Inmigrantes (total) & 72,0 \\
Inmigrantes menores de 15 años & $\mathbf{8 8 , 0}$ \\
Inmigrantes de 15 y más años & 70,6 \\
Nativos & $\mathbf{9 2 , 9}$ \\
Población total & $\mathbf{8 5 , 2}$ \\
\hline
\end{tabular}

a Hombres por cada 100 mujeres.

edad plantea un interrogante de difícil respuesta, ya que implicaría la existencia de una migración diferencial por sexo en la población infantil de más del 10 por ciento, desmintiendo, aparentemente, el supuesto lógico de movimientos no selectivos en esas edades. ${ }^{96}$

\section{IMPORTANCIA RELATIVA DE LA POBLACIÓN MIGRANTE POR SECTORES DE LA CIUDAD}

En el cuadro 52 se indica la proporción de inmigrantes encontrada en el Gran Santiago: 31,1 y 36,8 por ciento, de hombres y mujeres, respectivamente.

Tomando grandes sectores de la ciudad con distintas características urbanísticas y sociales, podría parecer sorprendente que sean los de nivel económico-social más alto los que tengan al mismo tiempo la proporción más elevada de inmigrantes, contra lo que generalmente se espera. (Véase el cuadro 55.) En los sectores Central y Oriente, por ejemplo, el 35,0 y 32,7 por ciento, respectivamente de los hombres eran inmigrantes, contra sólo el 28,2 y 27,9 por ciento de los sectores más populares, Sur y Noroeste. ${ }^{97}$

Las cifras anteriores, sin ulterior análisis, son un tanto engañosas. Para comprender mejor qué ocurre efectivamente hay que examinar las proporciones de inmigrantes en diferentes edades, con lo cual se descu-

$96 \mathrm{El}$ error de muestreo del porcentaje, en este caso de 88,0 , estímase en menos del 2 por ciento.

97 Detalles sobre la formación de estos sectores se dan en la sección 1 del capítulo IV. 
bre que algunas de las diferencias encontradas se originan en la población infantil. En la población masculina de más de 15 años, prácticamente no habría diferencias en las proporciones de inmigrantes de los sectores Centro, Oriente y Sur; en el sector Noroeste, el de más bajo nivel, es donde viven menos inmigrantes en relación con su población, siendo más notable esta situación en el grupo de edad 15-39 años. (Véase el cuadro 55 .)

En la población femenina se advierte un comportamiento similar, aunque con una característica adicional: la elevada proporción de inmigrantes en el sector Oriente, el más residencial. No es aventurado suponer que tal situación sea debida en gran parte a las inmigrantes que trabajan en servicios domésticos y que viven en los hogares de sus em* pleadores.

En cuanto a la proporción de inmigrantes en la población infantil, probablemente es el reflejo de dos hechos que pueden considerarse independientes del volumen migratorio de los adultos: el número promedio de hijos menores que vinieron con sus padres en los últimos años, y el número promedio de hijos que tuvieron los inmigranies tambiën en los últimos años en el Gran Santiago. Tanto el promedio de hijos inmigrantes, como el promedio de hijos nativos, favorecerian la menor proporción de niños inmigrantes en los sectores menos acomodados de la ciudad: la población inmigrante de estos sectores habría llegado sola o soltera, con mayor frecuencia que en los sectores de nivel más elevado $\mathrm{y}$, entre los

Cuadro 55

PORCENTAJES DE INMIGRANTES POR SEXO Y EDAD POR SECTORES DEL GRAN SANTIAGO

\begin{tabular}{lrrrrr}
\hline & \multicolumn{5}{c}{ Sectores } \\
& Oriente & Central & \multicolumn{1}{c}{ Sur } & Noroeste & Total \\
\cline { 2 - 6 } & 32,7 & 35,0 & 28,2 & 27,9 & 31,1 \\
Hombres (total) & 8,6 & 8,3 & 6,3 & 5,3 & 7,0 \\
$0 \cdot 14$ & 39,5 & 39,7 & 39,7 & 34,6 & 38,4 \\
$15 \cdot 39$ & 65,9 & 65,6 & 65,3 & 64,6 & 65,4 \\
40 y más & 42,2 & 41,5 & 32,8 & 29,4 & 36,8 \\
Mujeres (total) & 11,3 & 7,6 & 9,0 & 4,6 & 7,9 \\
$0-14$ & 53,3 & 46,0 & $4,4,0$ & 39,2 & 45,7 \\
$15-39$ & 63,3 & 66,7 & 66,3 & 60,3 & 64,7 \\
40 y más & & & & &
\end{tabular}

a Ordenados según nivel económico-social decreciente. (Véase el capítulo IV para más detalles sobre la formación de los sectores.) 
adultos, con una edad media más baja y por tanto, en general, con menos hijos. Este mismo hecho, unido a su probable mayor fecundidad, determinaria una mayor proporción de nativos entre sus hijos. ${ }^{98}$

\section{Estado CIVIL Y FECUNDIDAD}

Dos hechos importantes se deducen de los datos de la encuesta respecto del estado civil de la población femenina: i) la menor proporción de mujeres casadas (inmigrantes o nativas) que de hombres, y ii) la nupcialidad más tardía de la mujer inmigrante.

Ambas situaciones, en forma independiente de otros factores demográficos y sociales, tienen una evidente influencia sobre el nivel de la tasa de natalidad ${ }^{99}$ y de la fecundidad diferencial de nativas e inmigrantes, respectivamente. La diferencia entre la proporción de casadas y casados es importante entre los inmigrantes (68,8 y 50,8 , respectivamente), en tanto que sólo moderada entre los nativos $(46,0$ y 40,7 por ciento respectivamente), aunque al tipificar por la edad estas proporciones, disminuye considerablemente la diferencia entre hombres y mujeres inmigrantes hasta acercarse a la diferencia encontrada para los nativos. ${ }^{100}$ (Véase el cuadro 56. )

Lo que si puede ser claramente interpretado es la existencia de un porcentaje más elevado de casados que de casadas, sobre todo a partir de una edad cercana a los 30 años, lo cual se debe en parte a la mayor cuota de mujeres viudas y separadas $y$, en parte, a la mayor soltería femenina. Aquella mayor cuota de viudas y separadas se deriva de la mayor longevidad femenina, pero también de la mayor frecuencia con que los hombres se vuelven a unir en segundas, etc., nupcias. Este último hecho, al igual que la mayor soltería, podrían atribuirse parcialmente al

98 Pueden consultarse los capítulos III y I en relación con el tipo de migración y la edad de llegada al Gran Santiago.

99 Como mayor precisión podría decirse, sobre la tasa de fecundidad global, esto es, la relación de nacimientos a población femenina en edad de procrear.

100 Se considera la población de 12 y más años de edad. La tipificación consistió en aplicar las proporciones por estado civil de cada grupo de edad de los inmigrantes, a la población nativa respectiva. Que disminuyera la diferencia entre las proporciones de casados de hombres y mujeres inmigrantes, significa que sus estructuras por edad difieren más que en los nativos. La composición por el estado civil de hombres y mujeres suele estar afectada, aunque en proporción diferente, por mala declaración. La situación más típica sería la mayor tendencia en el hombre a declararse soltero cuando está unido de facto. Por esta circunstancia frecuentemente el número de casadas excede al de los casados (incluyendo uniones de facto). Sin embargo, según el censo de 1960, la relación entre uniones de facto y el total de las uniones era similar para ambos sexos (aproximadamente del 5 por ciento). 
bajo índice de masculinidad de la población del Gran Santiago y éste, a su vez, a la inmigración diferencial por sexo. (Véase la sección 2 del presente capítulo.)

La nupcialidad más tardía de la mujer inmigranie se deduce de las proporciones de solteras entre 20 y 34 años de edad, claramente más altas enire las inmigrantes. Como se comentará inmediatamente, la edad promedio de casamiento de las mujeres inmigrantes y nativas, habría que considerarla como parte de la explicación de la fecundidad diferencial de estos dos grupos.

La fecundidac se estudió en las mujeres casadas, viudas, divorciadas y separadas, excluyéndose por consiguiente a aquellas que declararon ser solteras. El cuadro 57 contiene datos sobre el número promedio de hijos (nacidos vivos) tenicios oor las mujeres de 20 a 4.9 años de edad.

El número promedio de hijos de las mujeres de estas edades resultó ser de 3,3, zanto para las nativas como para las inmigrantes. ${ }^{101}$ Esta igualdad oculta una leve superioridad de la fecundidad de las nativas, debide a que ésías son en promedio más jóvenes que las inmigrantes. Tipificando los resultados se pone de manifiesto ese diferencial: 3,3 contra 3, I. La misma observación se desprende del examen del número promedio de hijos por edad de la mujer, el que es más alto sistemáticamente en las nativas. ${ }^{102}$

Limitando la comparación a mujeres casadas, nuevamente el promedio tipificado de hijos tenidos es mayor entre las nativas de la ciudart: 3,4 contra 3,2 . (Yéase el cuadro 37 .)

Los resuliados que anteceden no abonan, por consiguiente, el supuesto generalmente aceptado çe la más alta fecundidad de las mujeres inmigrantes; y en el caso del Gran Santiago, más bien lo contrario. El hecho de que la mayoría de las inmigrantes lleguen solteras y su relativamente más tarcía edad de casamiento, como se d:jo antes, podrían explicar esa sicuación. Por otro lado, también es probable que parte de las mujeres que ilegan casadas y con hijos no sean representativas de la población femenina de los lugares de origen y, en consecuencia, su fecundidad sea algo menor.

101 Un cálculo similar para mujeres inmigrantes llegadas después de los 14 años de edad, arrojó idéntico recultado.

1012 El número promedio de hijos de mujcres inmigrantes de más de 50 años do edad es superior al de mujeres nativas (véase el cuadro 57). No obstante, el margen de error en las edades superiores es muy alto (pequeños números, mala declaración), aparte de que el promedio no está tipificado por edad. 
Cuadro 56

COMPOSICION PORCENTUAL SEGUN EL ESTADO CIVIL DE MAYORES DE 12 AÑOS, DE INMIGRANTES Y DE NACIDOS

EN EL GRAN SANTIAGO

\begin{tabular}{|c|c|c|c|c|c|c|}
\hline \multirow{2}{*}{$\begin{array}{c}\text { Sexo } \\
\text { y grupos } \\
\text { de } \\
\text { edades }\end{array}$} & \multicolumn{3}{|c|}{ Inmigrantes } & \multicolumn{2}{|c|}{ Nacidos en el Gran } & \multirow{2}{*}{$\begin{array}{c}\text { Santiago } \\
\text { Viudos, } \\
\text { divorcia- } \\
\text { dos y } \\
\text { separados }\end{array}$} \\
\hline & Solteros & Casados $^{\mathrm{a}}$ & $\begin{array}{l}\text { Viudos, } \\
\text { divorcia- } \\
\text { dos y } \\
\text { separados }\end{array}$ & Solteros & Casadosa & \\
\hline \multicolumn{7}{|l|}{ Hombres } \\
\hline $12 \cdot 14$ & 100,0 & - & - & 100,0 & - & - \\
\hline $15-19$ & 96,7 & 3,3 & 一 & 97,5 & 2,5 & 一 \\
\hline $20-24$ & 66,1 & 32,2 & 1,7 & 64,3 & 34,2 & 1,5 \\
\hline $25-29$ & 35,1 & 63,6 & 1,3 & 31,1 & 65,0 & 3,9 \\
\hline $30-34$ & 15,2 & 81,9 & 2,9 & 8,7 & 88,2 & 3,1 \\
\hline $35-39$ & 8,8 & 89,7 & 1,5 & 7,9 & 87,5 & 4,6 \\
\hline $40 \cdot 49$ & 3,1 & 92,7 & 4,2 & 8,2 & 87,7 & 4,1 \\
\hline 50 y más & 5,1 & 81,1 & 13,8 & 3,4 & 84,0 & 12,6 \\
\hline Ignorada & 一 & - & - & - & - & 一 \\
\hline 12 y más & 25,7 & 68,8 & 5,5 & 51,0 & 46,0 & 3,0 \\
\hline $\begin{array}{l}12 \text { y más } \\
\text { ajustadab }\end{array}$ & 51,8 & 45,6 & 2,6 & 51,0 & 46,0 & 3,0 \\
\hline \multicolumn{7}{|l|}{ Mujeres } \\
\hline $12 \cdot 14$ & 100,0 & - & - & 99,7 & 0,3 & - \\
\hline $15-19$ & 89,7 & 9,1 & 1,2 & 88,2 & 11,1 & 0,7 \\
\hline $20-24$ & 58,3 & 38,0 & 3,7 & 51,5 & 46,0 & 2,5 \\
\hline $25 \cdot 29$ & 36,6 & 59,4 & 4,0 & 28,8 & 63,7 & 7,5 \\
\hline $30 \cdot 34$ & 23,4 & 69,3 & 7,3 & 19,6 & 72,7 & 7,7 \\
\hline $35 \cdot 39$ & 15,7 & 75,1 & 9,2 & 19,5 & 71,7 & 8,8 \\
\hline $40-49$ & 13,6 & 70,3 & 16,1 & 13,8 & 68,5 & 17,7 \\
\hline 50 y más & 13,9 & 40,3 & 45,8 & 12,4 & 39,2 & 48,4 \\
\hline Ignoradac & 100,0 & - & - & 一 & - & 100,0 \\
\hline 12 y más & 30,9 & 50,8 & 18,3 & 47,8 & 40,7 & 11,5 \\
\hline $\begin{array}{l}12 \text { y más } \\
\text { ajustada } \mathbf{b}\end{array}$ & 50,2 & 39,1 & 10,7 & 47,8 & 40,7 & 11,5 \\
\hline
\end{tabular}

a Incluye uniones de facto.

b Ajustando la composición por edad de los inmigrantes a la de los nacidos en el Gran Santiago.

c Tres casos. 
CUAdro 57

PROMEDIO DE HIJOS (NACIDOS VIVOS) TENIDOS POR MUJERES NO SOLTERAS MAYORES DE 20 AÑOS, INMIGRANTES Y NACIDAS EN EL GRAN SANTIAGO

\begin{tabular}{|c|c|c|c|c|}
\hline \multirow{2}{*}{$\begin{array}{l}\text { Grupos } \\
\text { de } \\
\text { edades }\end{array}$} & \multicolumn{2}{|c|}{$\begin{array}{c}\text { Casadas, }{ }^{\mathrm{a}} \text { viudas, } \\
\text { divorciadas y separadas }\end{array}$} & \multicolumn{2}{|c|}{ Casadas ${ }^{a}$} \\
\hline & Inmigrantes & $\begin{array}{c}\text { Nacidas } \\
\text { en el } \\
\text { Gran Santiago }\end{array}$ & Inmigrantes & $\begin{array}{c}\text { Nacidas } \\
\text { en el } \\
\text { Gran Santiago }\end{array}$ \\
\hline $20 \cdot 24$ & 1,85 & 2,05 & 1,91 & 2,10 \\
\hline $25-29$ & 2,72 & 2,79 & 2,75 & 2,90 \\
\hline $30-34$ & 3,33 & 3,77 & 3,56 & 3,81 \\
\hline $35-39$ & 3,67 & 4,20 & 3,85 & 4,36 \\
\hline $40-49$ & 3,75 & 3,65 & 3,79 & 3,72 \\
\hline $20 \cdot 49$ & 3,32 & 3,32 & 3,41 & 3,38 \\
\hline $20-49$ ajustada $\mathbf{b}$ & 3,12 & 3,32 & 3,19 & 3,38 \\
\hline 50 y más & 4,25 & 4,10 & 4,46 & 4,26 \\
\hline
\end{tabular}

" Incluye uniones de facto.

b Ajustando la composición por edad de las inmigrantes a la de las nacidas en el Gran Santiago.

\section{EdUCACIóN}

a) El nivel de instrucción se investigó mediante dos preguntas, relativas a la clase de enseñanza (primaria, etc.) y al último curso o año aprobado. Los datos que se analizan aquí corresponden a la población mayor de 15 años, esto es, la que sobrepasó la edad escolar obligatoria.

Para facilitar su estudio y en razón del tamaño de la muestra, el nivel de instrucción se estudia utilizando unas pocas categorías, las que para la masa de la población proporcionan buenas indicaciones, $y$ son las siguientes:

i) Sin instrucción (ningún año aprobado de enseñanza).

ii) Con menos de 4 años de enseñanza elemental o primaria.

iii) Con 4 a 6 años de enseñanza elemental.

iv) Con uno o más años de enseñanza secundaria, o con educación universitaria o superior. 
v) Otras formas de enseñanza no asimilables al nivel secundario ni al superior (escuelas técnicas femeninas, vocacionales, de sordomudos, etcétera).

En el cuadro 58 se presenta la distribución porcentual de la población investigada según esas categorías, por sexo, edad y status migratorio. En el gráfico 4 se representan los porcentajes (acumulados) del cuadro citado, para lo cual se establecieron tres escalones o niveles: algún año de enseñanza (categorías ii], iii], iv] y v]); cuatro años de enseñanza elemental o un nivel superior (categorías iii], iv] y v]); un año o más de enseñanza secundaria, universitaria o superior (categoría iv]).

Previo a la consideración de las diferencias de nivel de educación entre inmigrantes y nativas, conviene anticipar brevemente cuáles son las diferencias más salientes en relación con el sexo y la edad. El nivel de instrucción observado en hombres y mujeres nativas, por su semejanza, permite pensar que las condiciones y facilidades para la educación de niños y jóvenes, de uno y otro sexo, no difieren. Por el contrario, la educación de los inmigrantes es en promedio más elevada que la preparación de las inmigrantes, lo que podria atribuirse a una condición más desfavorable de la mujer en los lugares de origen; por ejemplo, sólo el 68,5 por ciento de las inmigrantes tenía cuatro o más años de enseñanza, frente al 78,8 por ciento encontrado entre los inmigrantes. (Véase el cuadro 58.)

En relación con la edad, el nivel de educación empeora al aumentar aquélla, lo cual se explica porque las facilidades de instrucción han sido mejores para las generaciones más jóvenes. Quiere decir que en la comparación global de los niveles de educación de nativos e inmigrantes, hay que considerar la diferente estructura por edad de ambos grupos. (Véanse el cuadro 59 y el gráfico 4.)

Teniendo en cuenta la edad, en el caso de los hombres el status migratorio no introduce mayores diferencias en el nivel de educación, en particular en la población de 15 a 29 años de edad. En edades más elevadas, la condición de los nativos es ligeramente mejor.

Distinta es la situación que se presenta en la población femenina, ya que las inmigrantes, especialmente las más jóvenes, tenían un nivel promedio significativamente más bajo que las nativas. El nivel es peor en las mujeres que inmigraron en la última década (1952-1962), como se desprende de las siguientes proporciones de mujeres con 4 o más años de enseñanza, del grupo de edad 15-29 años: nativas, 89,7 por ciento; inmigrantes de antes del año $1952,82,6$ por ciento, e inmigrantes del período 1952-1962, 70,6 por ciento. Las diferencias que 
Ct:adro 58

NIVEL DE INSTRUCCION DE LA POBLACION MAYOR DE 15 AÑOS DE EDAD, EN EL GRAN SANTIAGO

(Distribución porcentual)

\begin{tabular}{|c|c|c|c|c|c|c|c|c|}
\hline \multirow{3}{*}{ Nivel de instrucción } & \multicolumn{8}{|c|}{ Sexo y edad } \\
\hline & \multicolumn{4}{|c|}{ Hombres } & \multicolumn{4}{|c|}{ Mujeres } \\
\hline & $\begin{array}{c}\text { Más } \\
\text { de } \\
15\end{array}$ & $\begin{array}{c}15 \\
\mathrm{a} \\
29\end{array}$ & $\begin{array}{c}30 \\
\mathrm{a} \\
4.9\end{array}$ & $\begin{array}{c}\text { Más } \\
\text { de } \\
50\end{array}$ & $\begin{array}{c}\text { Más } \\
\text { de } \\
15\end{array}$ & $\begin{array}{c}15 \\
\mathrm{a} \\
29\end{array}$ & $\begin{array}{c}30 \\
\mathrm{a} \\
49\end{array}$ & $\begin{array}{l}\text { Más } \\
\text { de } \\
50\end{array}$ \\
\hline
\end{tabular}

Inmigrantes (periodo$$
\text { 1952.1962) }
$$

$\begin{array}{llllllll}100 & 100 & 100 & 100 & 100 & 100 & 100 & 100\end{array}$

a) Sin instrucción

$\begin{array}{llllllll}4,7 & 2,6 & 4,8 & 14,3 & 11,0 & 8,0 & 10,7 & 27,5\end{array}$

b) Con menos de 4 años de enseñanza elemental

c) Con 4 a 6 años de $\begin{array}{lllllllll}\text { enseñanza elemental } & 34,9 & 37,8 & 31,1 & 32,7 & 37,0 & 37,6 & 36,5 & 35,0\end{array}$

d) Con I año o más de enseñanza secundaria - con educación universitaria o superior

e) Otras formas de en. señanza a

$$
\begin{array}{llllllll}
47,2 & 47,4 & 46,9 & 45,9 & 31,3 & 30,8 & 38,8 & 17,5
\end{array}
$$

f) Sin información

Inmigrantes (períado anterior a 1952)

$\begin{array}{cccccccc}0,5 & 0,9 & - & - & 1,7 & 2,2 & 1,1 & - \\ - & - & - & - & 0,1 & 0,3 & - & -\end{array}$

a) Sin instrucción

$\begin{array}{llllllll}100 & 100 & 100 & 100 & 100 & 100 & 100 & 100\end{array}$

b) Con menos de 4 años de enseñanza ele-

mental

$\begin{array}{llllllll}7,1 & 4,9 & 5,6 & 9,9 & 11,6 & 4,2 & 9,6 & 17,1\end{array}$

c) Con 4 a 6 años de enseñanza elemental

$\begin{array}{llllllll}14,2 & 7,9 & 12,4 & 19,3 & 18,4 & 12,7 & 16,5 & 23,0\end{array}$

d) Con 1 año o más de enseñanza secundaria o con educación universitaria o superior

e) Otras formas de enseñanza a 
Cuadro 58 (continuación)

\begin{tabular}{|c|c|c|c|c|c|c|c|c|}
\hline \multirow{3}{*}{ Nivel de instrucción } & \multicolumn{8}{|c|}{ Sexo y edad } \\
\hline & \multicolumn{4}{|c|}{ Hombres } & \multicolumn{4}{|c|}{ Mujeres } \\
\hline & $\begin{array}{l}\text { Más } \\
\text { de } \\
15\end{array}$ & $\begin{array}{l}15 \\
\mathrm{a} \\
29\end{array}$ & $\begin{array}{l}30 \\
\mathrm{a} \\
49\end{array}$ & $\begin{array}{l}\text { Más } \\
\text { de } \\
50\end{array}$ & $\begin{array}{l}\text { Más } \\
\text { de } \\
15\end{array}$ & $\begin{array}{c}15 \\
\mathrm{a} \\
29\end{array}$ & $\begin{array}{c}30 \\
\mathrm{a} \\
49\end{array}$ & $\begin{array}{l}\text { Más } \\
\text { de } \\
50\end{array}$ \\
\hline f) Sin información & 0,7 & 一 & 0,2 & 1,6 & 0,4 & 0,5 & 一 & 0,8 \\
\hline Nativos de la ciudad & 100 & 100 & 100 & 100 & 100 & 100 & 100 & \\
\hline a) Sin instrucción & 3,5 & 2,0 & 4,1 & 9,2 & 4,0 & 2,4 & 3,8 & 9,6 \\
\hline $\begin{array}{l}\text { b) Con menos de } 4 \text { años } \\
\text { de enseñanza ele- } \\
\text { mental }\end{array}$ & 9,3 & 8,6 & 9,4 & 12,1 & 9,2 & 7,4 & 9,6 & 13,9 \\
\hline $\begin{array}{l}\text { c) Con } 4 \text { a } 6 \text { años de } \\
\text { enseñanza elemental }\end{array}$ & 32,6 & 30,2 & 35,8 & 35,1 & 35,8 & 33,4 & 38,9 & 37,0 \\
\hline $\begin{array}{l}\text { d) Con } 1 \text { año o más de } \\
\text { enseñanza secundaria } \\
\text { o con educación uni- }\end{array}$ & & & & & & & & \\
\hline versitaria o superior & 53,0 & 57,6 & 49,3 & 41,9 & 48,6 & 53,7 & 45,4 & 39,1 \\
\hline $\begin{array}{l}\text { c) Otras formas de en- } \\
\text { señanza a }\end{array}$ & 0,9 & 1,1 & 0,6 & 0,6 & 2,0 & 2,6 & 2,0 & - \\
\hline f) Sin información & 0,7 & 0,5 & 0,8 & 1,1 & 0,4 & 0,5 & 0,3 & 0,4 \\
\hline
\end{tabular}

a Otras formas de enseñanza no asimilables al nivel secundario o superior (escuelas técnicas femeninas, escuelas vocacionales, de sordomudos, etc.).

se encuentran considerando las mujeres con un año de enseñanza secundaria o más, son todavía más acentuadas. ${ }^{103}$ (Véanse el cuadro 58 y el gráfico 4.)

En conclusión, el grupo que ofrecía condiciones de educación particularmente bajas en relación a los demás examinados, era el de las mujeres inmigrantes, sobre todo las mujeres menores de 30 años llegadas en la última década.

b) La matrícula escolar se investigó en las personas de 5 a 28 años de edad. Aquí sólo se presentan datos de la matrícula, sin referencia a la clase de enseñanza ni al curso o año escolar.

103 La menor instrucción de las inmigrantes de 15 a 29 años de edad, del período 1952-1962, en comparación al mismo grupo del período anterior a 1952, se vincula estrechamente con la edad de llegada. Las del último grupo llegaron en promedio con una edad más baja, y por consiguiente pudieron aprovechar, en edad escolar, las facilidades de la ciudad. 


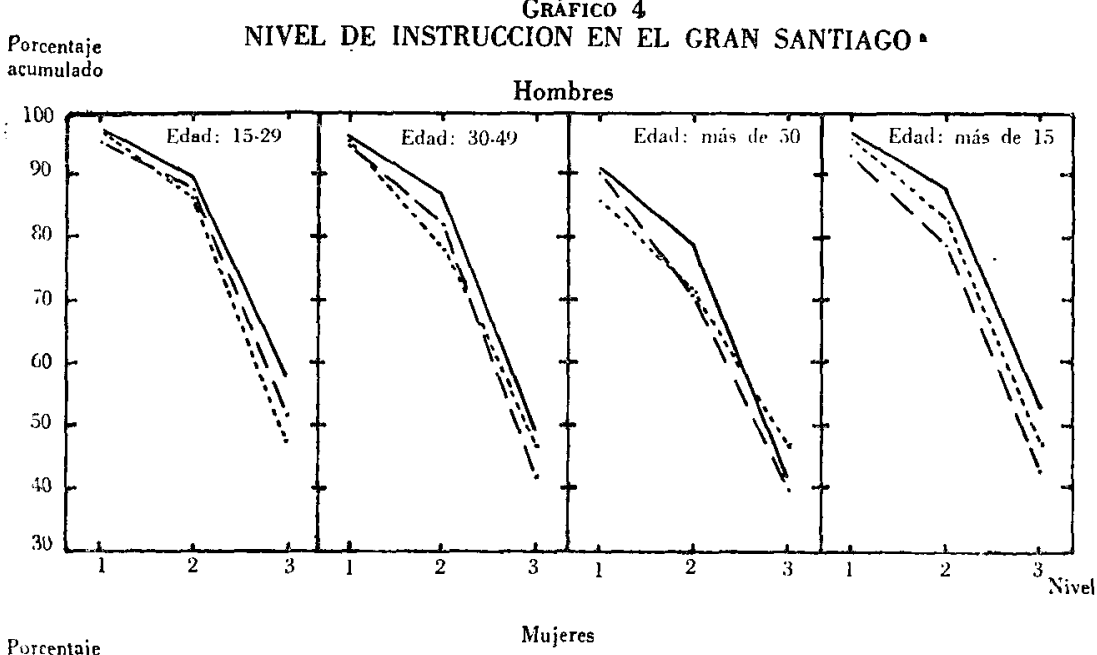

Porcentaj
arumulado

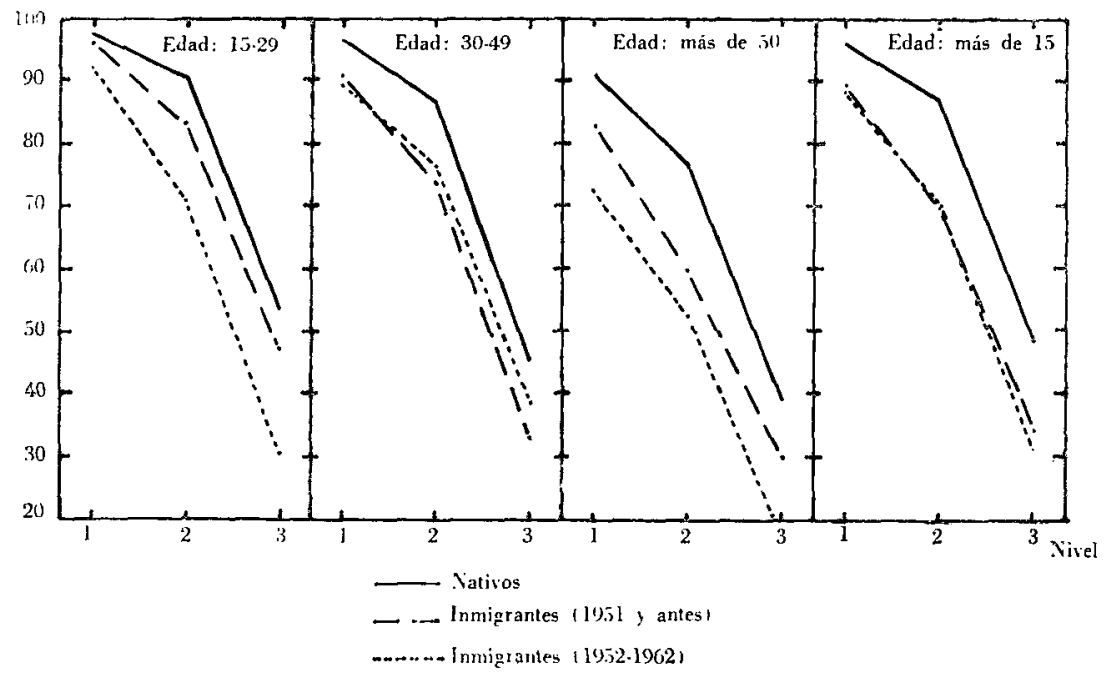

- V'éase el texto. 
CuAdro 59

NIVEL DE INSTRUCCION SEGUN EL SEXO EN EL GRAN SANTIAGO

\begin{tabular}{ccccc}
\hline \multirow{2}{*}{$\begin{array}{c}\text { Sexo y nivel } \\
\text { de instrucción }\end{array}$} & \multicolumn{3}{c}{ Inmigrantes } & $\begin{array}{c}\text { Nativos } \\
\text { de la } \\
\text { ciudad }\end{array}$ \\
\cline { 2 - 4 } cintes & $1952-1962$ & Antes de 1952 & Total & \\
Hombres & \multicolumn{4}{c}{ (Porcentajes) } \\
1 & 95,3 & 92,9 & 93,2 & 96,5 \\
2 & 82,6 & 78,7 & 78,8 & 87,2 \\
3 & 47,7 & 44,1 & 44,1 & 54,6 \\
Mujeres & & & & \\
1 & 89,0 & 88,4 & 88,3 & 96,0 \\
2 & 70,1 & 70,0 & 68,5 & 86,8 \\
3 & 31,3 & 34,1 & 33,2 & 48,6 \\
\hline
\end{tabular}

Cuadro 60

PORCENTAJE DE PERSONAS MATRICULADAS EN EL GRAN SANTIAGO, POR SEXO Y CONDICION DE NATIVAS E INMIGRANTES

\begin{tabular}{|c|c|c|}
\hline \multirow{2}{*}{ Grupos de edades } & \multicolumn{2}{|c|}{ Sexo } \\
\hline & Hombres & Mujeres \\
\hline \multicolumn{3}{|l|}{ Inmigrantes del periodo 1952.1962} \\
\hline 5 a 14 & 92,8 & 83,8 \\
\hline 15 a 28 & 21,3 & 12,6 \\
\hline 5 a 28 & 43,3 & 29,0 \\
\hline \multicolumn{3}{|c|}{ Inmigrantes del periodo anterior a 1952} \\
\hline 5 a 14 & $72,2^{\mathrm{a}}$ & $90,0^{b}$ \\
\hline 15 a 28 & 23,1 & 17,9 \\
\hline 5 a 28 & 28,6 & 26,1 \\
\hline \multicolumn{3}{|l|}{ Inmigrantes (total) } \\
\hline 5 a 14 & 89,6 & 82,5 \\
\hline 15 a 28 & 22,0 & 14,2 \\
\hline 5 a 28 & 38,4 & 28,3 \\
\hline \multicolumn{3}{|l|}{ Nativos de la ciudad } \\
\hline 5 a 14 & 92,1 & 90,2 \\
\hline 15 a 28 & 30,3 & 26,4 \\
\hline 5 a 28 & 63,7 & 47,2 \\
\hline
\end{tabular}

a Sobre 18 casos.

b Sobre 20 casos.

Nota: Salvo indicación en contrario, los porcentajes se han calculado sobre más de 97 (hombres) o de 115 (mujeres) casos. Los de nativos exceden de 780, en cualquier edad $y$ sexo. 
Interesa estudiar el nivel de la matrícula de los inmigrantes, sobre todo en los niños de 5 a 14 años de edad. Estos niños pertenecen, en su gran mayoría, a hogares de padres inmigrantes llegados en los últimos diez años. Por consiguiente, la matrícula de ellos puede, en muchos sentidos, ser equiparada a la de niños nativos, muchos de los cuales son también hijos de inmigrantes, aunque llegados en una época un poco anterior.

Dado que hay diferencias favorables a los hombres, la matrícula se analiza separadamente por sexo. La matrícula de niños nativos de 5 a 14 años, del 92,1 por ciento, no significa necesariamente mayor asistencia escolar que la de los niños inmigrantes de igual edad, del 89,6 por ciento. Esta diferencia en el valor de la matrícula obedece a que todos los niños inmigrantes que vinieron antes del año 1952, tenían más de 10 años, siendo la matrícula de 10 a 14 años más baja, en todos los casos, a las de niños de 5 a 9 años. En efecto, limitando la comparación a los inmigrantes de la última década, la matrícula de los niños de 5 a 14 años sube a 92,8. (Véase el cuadro 60.)

Tratándose de las niñas, sí existe una matrícula superior de las nativas, aun si se la compara con la matrícula de las niñas inmigrantes del período 1952-1962: 90,2 y 83,8 por ciento, respectivamente.

Menos confiables serían Jas conclusiones que podrían sacarse de la población de 15 a 28 años de edad. Aunque hay diferencias notables entre las matrículas de nativos y de inmigrantes, en ambos sexos, este hecho está exagerado por la mayor edad promedio que tienen estos últimos unido a la circunstancia de que la matricula desciende al aumentar la edad. (Véase el cuadro 60.)

\section{Características ECONóMicas}

Los datos obtenidos en la encuesta permiten estudiar aquellas características que se relacionan con la actividad económica de las personas, que generalmente se investigan en los censos de población. El análisis que sigue se divide en las siguientes partes:

a) Tipo de actividad.

b) Nivel del empleo: empleo, desempleo y subempleo.

c) Ocupaciones y clases económico-sociales.

d) Nivel de instrucción de la mano de obra.

De cada uno de estos aspectos se supone que existen diferencias entre la población inmigrante y la nacida en el Gran Santiago. En algunos casos, tales diferencias probablemente existen y son significativas, 
mientras que en otros quizá no haya comportamiento diferencial. Establecer estos hechos contribuye a esclarecer, confirmar o modificar algunas ideas sobre el papel y las condiciones particulares de las personas que emigran a una metrópoli y sus efectos sobre la estructura económico-social.

En la encuesta se investigaron las características económicas de las personas mayores de 14 años de edad. No obstante, para facilitar las comparaciones con otras estadísticas, en este análisis en la mayoría de los casos sólo se consideran las personas mayores de 15 años. Por lo demás, de acuerdo a los resultados de la encuesta, la participación en las actividades económicas en el Gran Santiago de las personas de 14 años, era insignificante.

a) Tipo de actividad. Para establecer el tipo de actividad, se preguntó en el cuestionario sobre el ejercicio habitual de alguna actividad personal lucrativa o algún empleo o trabajo a sueldo, jornal o comisión (o algún trabajo sin remuneración en alguna actividad del jefe de familia o de otro pariente). Se adoptó este procedimiento por estimar que respondía mejor a los objetivos de la encuesta. La finalidad principal no era medir la situación del empleo en un momento dado en la forma más precisa posible y comparable con otras mediciones periódicas y frecuentes, como es el caso en las encuestas de ocupación y desocupación; el interés principal consistía en establecer la situación económico-social de la población en la época de la encuesta, aunque en el cuestionario no se fijó en forma expresa ningún periodo de referencia. Como lógica consecuencia de lo anterior, la ocupación, la categoría y la rama de actividad fueron referidas a la actividad habitual.

El concepto de actividad económica que antecede podría parecer en discordancia con la forma en que se investigaron el grado de empleo (horas de trabajo), el desempleo, las causales del empleo parcial y las del desempleo, y los ingresos. En efecto, todas estas informaciones están referidas a la semana inmediata anterior al momento de la encuesta (en el caso del ingreso puede también ser el último mes), y no necesariamente a la actividad habitual declarada. La razón de este cambio de enfoque fue simple, pero poderosa: obtener una razonable exactitud en la información. Sería correr un riesgo grande, en verdad, el confiar en la memoria de los encuestados (muchas veces su cónyuge, pariente o allegado) respecto de materias tales como el tiempo trabajado y las causales del desempleo y del empleo parcial, referidos a un tiempo relativamente largo.

No deberia exagerarse el temor de la falta de comparatibilidad de los datos. Es razonable esperar que, en la gran mayoría de los casos, el tiempo trabajado, el desempleo y los ingresos se refieren a la actividad habitual declarada. Más aún, en los casos en que no ocurriera así 
podría esperarse que se tratase de una actividad (ocupación, etc.) que generalmente cae en el mismo grupo de la clasificación que se usa para el análisis de los datos (por ejemplo, trabajadores manuales y no manuales). La experiencia muestra que es ilusorio basar el análisis en clasificaciones detalladas, entre otras razones por el pequeño número de casos que interviene. Por otra parte, el nivel del empleo y el ingreso valen por sí solos como elementos de apreciación de las condiciones sociales de la población, sin que necesariamente haya que vincularlos, para muchos propósitos, a las ocupaciones o a los sectores de la eco. nomía.

Los resultados obtenidos señalan un nivel de participación más elevada entre los inmigrantes que entre los nativos en la mayoría de las edades. Las diferencias son relativamente mayores en la población femenina. (Véase el cuadro 61.)

Las diferencias más pronunciadas, en el sentido mencionado, se encontraron respecto de los inmigrantes más jóvenes (15 a 24 años) llegados en los últimos 10 años (1952-1962). La participación de los integrantes llegados antes de 1952 se aproxima mucho a la de los nativos. La tasa de participación ${ }^{104}$ masculina de los inmigrantes de 15 a 24. años del período 1952-1962 fue del 73,5 por ciento, mientras que la correspondiente tasa de los inmigrantes de antes de 1952 fue del 63,6 y la de los nativos, sỏlo del 60,7 por ciento. En la población femenina las cifras respectivas fueron: $57,0,34,7$ y 30,3 por ciento.

Estos resultados sugieren que los inmigrantes llegados en una época reciente se ven impelidos a trabajar más temprano, en promedio, que la restante población. Es probable que este comportamiento diferencial obedezca, al menos en parte, a la falta de apoyo familiar, o simplemenie al hecho de haber emigrado precisamente para trabajar. Los inmigrantes llegados antes de 1952 y que están en el grupo de edad 15 a 24 , llegaron siendo niños y, por lo tanto, a cargo de otras personas. Es razonable esperar que su comportamiento se asemeje al de los nativos, como parece ocurrir.

En el amplio tramo de los 25 a los 59 años de edad, las tasas de participación masculina de poblaciones con distintos niveles de desarrollo varían poco dentro de ese intervalo y se las puede considerar globalmente. Como en dicho grupo de edades suelen encontrarse tasas de actividad similares en distintas clases de poblaciones, con independencia de las condiciones económico-sociales respectivas, llama la atención la divergencia entre las tasas de los inmigrantes llegados antes de 1952 (91,9 por ciento) y las tasas de los inmigrantes de la última década

104 Se entiende por tasa de participación, el porcentaje de personas económicamente activas en la población total del mismo sexo y edad. 
Cuadro 61

TASAS DE PARTICIPACION EN ACTIVIDADES ECONOMICAŞ

\begin{tabular}{|c|c|c|c|c|c|c|}
\hline \multirow{3}{*}{$\begin{array}{c}\text { Sexo } \\
\text { y } \\
\text { grupos } \\
\text { de } \\
\text { edades }\end{array}$} & \multicolumn{4}{|c|}{ Inmigrantes } & & \\
\hline & \multicolumn{2}{|c|}{$\begin{array}{c}\text { Del periodo } \\
1952-1962\end{array}$} & \multicolumn{2}{|c|}{$\begin{array}{c}\text { De antes } \\
\text { de } 1952\end{array}$} & \multicolumn{2}{|c|}{ Nativos } \\
\hline & $\begin{array}{c}\text { Número } \\
\text { de } \\
\text { casos }\end{array}$ & $\begin{array}{c}\text { Tasas } \\
\text { (por } \\
\text { ciento) }\end{array}$ & $\begin{array}{c}\text { Número } \\
\text { de } \\
\text { casos }\end{array}$ & $\begin{array}{c}\text { Tasas } \\
\text { (por } \\
\text { ciento) }\end{array}$ & $\begin{array}{c}\text { Número } \\
\text { de } \\
\text { casos }\end{array}$ & $\begin{array}{c}\text { Tasas } \\
\text { (por } \\
\text { ciento) }\end{array}$ \\
\hline & (1) & (2) & (3) & $(4)$ & (5) & (6) \\
\hline \multicolumn{7}{|l|}{ Hombres } \\
\hline 15 y más & 424 & 83,7 & 978 & 81,1 & 1499 & 77,9 \\
\hline $15-24$ & 155 & 73,5 & 88 & 63,6 & 636 & 60,7 \\
\hline $25 \cdot 59$ & 249 & 94,4 & 703 & 91,9 & 793 & 94,2 \\
\hline 60 y más & 20 & 30,0 & 187 & 48,7 & 70 & 48,6 \\
\hline \multicolumn{7}{|l|}{ Mujeres } \\
\hline 15 y más & $662^{b}$ & 45,5 & 1324 & 32,3 & $1754^{\mathrm{b}}$ & 31,2 \\
\hline $15-24$ & 272 & 57,0 & 95 & 34,7 & 671 & 30,3 \\
\hline $25-59$ & 351 & 39,6 & 987 & 36,5 & 955 & 35,1 \\
\hline 60 y más & 37 & 13,5 & 242 & 14,0 & 127 & 7,1 \\
\hline
\end{tabular}

a Razón entre la población económicamente activa y la población total del mismo sexo y edad.

b Incluye dos personas de edad desconocida.

$(94,4$ por ciento) y de los nativos $(94,2)$. Si bien las diferencias relativas son apenas del orden de 2,7 y 2,5 por ciento, por tratarse de grupos que reúnen un número grande de casos tales diferencias son estadísticamente significativas.

Sin embargo, más que la diferencia misma, llama la atención el bajo nivel de la participación de los inmigrantes llegados antes de 1952. En ese 8 por ciento de personas no económicamente activas tiene un peso importante la presencia de personas jubiladas en aquella población. Esto se explica porque se trata de un grupo relativamente más viejo que los otros dos. (En la población inmigrante llegada antes de 1952, de edad superior a 15 años, el 20 por ciento tenía más de 60 años, mientras que en los nativos esta proporción era de sólo 5 por ciento.)

Las tasas de participación femenina del grupo de edad 25 a 59 años confirman los resultados encontrados en la población de 15 a 24 . 
La tasa de actividad entre las inmigrantes de la última década $(39,6$ por ciento) es más alta que la de las inmigrantes llegadas antes de 1952 $(36,5$ por ciento) y que la de las nativas $(35,1$ por ciento $)$.

De las edades más avanzadas, dado lo pequeño de los números, no se podrían derivar conclusiones relativamente seguras.

Los resultados comentados en esta sección confirman, en cuanto al sentido de las diferencias, los obtenidos en la ya referida encuesta de ocupación y desocupación de junio de 1963. En el cuadro 62 figuran las diferencias entre las tasas de participación de inmigrantes y nativos de ambas encuestas.

b) Nivel de empleo. En esta parte se analizan datos sobre desocupación, tiempo trabajado en la semana anterior al momento de la encuesta, causas del empleo a tiempo parcial e ingresos derivados del trabajo personal.

Las cifras de desocupación comprenden a las personas económicamente activas que no trabajaron en la semana anterior al momento de la encuesta y manifestaron estar buscando trabajo, con exclusión de los que lo hacían por primera vez. Tampoco incluyen a las personas que no trabajaron por causas como vacaciones, enfermedad pasajera, mal tiempo, conflictos patronales, reparaciones del equipo y otras causas análogas, sin tomar en consideración si buscaban o no trabajo. ${ }^{105}$

105 EI concepto de desocupado es, por lo tanto, más limitado que aquel que surge de las definiciones generalmente seguidas en los censos de población y en las encuestas de ocupación y desocupación, en los cuales se incluye a todas las personas que no trabajaron en el período de refcrencia (una semana, etc.) y que buscaban empleo y, además, a aquellas otras que lo habrían hecho si no fuera por causa de enfermedad pasajera, o por haber hecho arreglos para comenzar a trabajar dentro de un cierto plazo, o porque esperaban volver al empleo del que habian sido despedidas por un período de tiempo indefinido.

Las personas económicamente activas que no trabajaron en la semana de referencia por alguna de las causas antes mencionadas, y que no fueron incluidas en este estudio entre las desocupadas, forman una categoría especial dentro del grupo de las personas ocupadas, como se indica en el cuadro 64. Su exclusión de entre los desocupados se podría justificar considerando que constituyen un grupo heterogéneo en cuanto a las causas por las cuales no trabajaron, y que el único criterio para tomar una decisión sería la declaración sobre si buscan o no trabajo.

Respecto a la exclusión de los que buscan trabajo por primera vez también podría justificarse en este estudio. Hay motivos para dudar de la exactitud de csta información. Muchos jóvenes probablemente declaran no buscar trabajo simplemente porque no esperan encontrarlo. El bajo nivel de las tasas de actividad de las personas de 15 a 19 años obtenido en la encuesta, parece confirmar esta suposición. Por otra parte, el número de personas que declararon buscar trabajo por primera vez carece de significación cuantitativa.

Una última observación: la semana a la cual están referidos los datos no es una semana especifica. Como aproximadamente el 90 por ciento de las encuestas 
Cuadro 62

TASAS DE PARTICIPACION EN ACTIVIDADES ECONOMICAS DE INMIGRANTES Y DE NATIVOS DEL GRAN SANTIAGO $Y$ COMPARACION ENTRE LAS TASAS OBTENIDAS EN LA ENCUESTA DE INMIGRACION (1962) Y EN LA ENCUESTA DE OCUPACION Y DESOCUPACION DE $1963^{\mathrm{a}}$

\begin{tabular}{|c|c|c|c|c|}
\hline \multirow{3}{*}{$\begin{array}{l}\text { Sexo } \\
\text { y grupos } \\
\text { de } \\
\text { edades }\end{array}$} & \multicolumn{2}{|c|}{$\begin{array}{l}\text { Diferencias entre las tasas } \\
\text { de inmigrantes y nativos } \\
\text { (inmigrantes - nativos) }\end{array}$} & \multirow{2}{*}{\multicolumn{2}{|c|}{$\begin{array}{l}\text { Diferencias relativas de las tasas } \\
\text { de las dos encuestas, tomando } \\
\text { como base }(=100) \text { la encuesta } \\
\text { de ocupación y desocupación } \\
\text { de junio de } 1963\end{array}$}} \\
\hline & \multirow{2}{*}{$\begin{array}{l}\text { Encuesta } \\
\text { de inmi- } \\
\text { gración }\end{array}$} & \multirow{2}{*}{$\begin{array}{c}\text { Encuesta } \\
\text { de ocupación } \\
\text { y des- } \\
\text { ocupación }\end{array}$} & & \\
\hline & & & $\begin{array}{c}\text { Inmigran- } \\
\text { tes }\end{array}$ & Nativos \\
\hline & (1) & (2) & (3) & (4) \\
\hline \multicolumn{5}{|l|}{ Hombres } \\
\hline 15 y más & $+4,0$ & $+3,1$ & $+3,0$ & $+2,0$ \\
\hline $15-19$ & $+8,3$ & $\begin{array}{l}+2,7 \\
\end{array}$ & $\begin{array}{r}+17,8 \\
\end{array}$ & $\begin{array}{r}5,4 \\
+\quad 5\end{array}$ \\
\hline $20-24$ & $+4,3$ & $+2,7$ & $+8,5$ & $+6,7$ \\
\hline $25-34$ & & $-4,9$ & b & $\mathrm{b}$ \\
\hline $35 \cdot 44$ & $-1,7^{\mathrm{c}}$ & $-3,0$ & $\mathbf{b}$ & b \\
\hline $45 \cdot 64$ & & $-2,0$ & b & b \\
\hline 65 y más & $-1,7^{d}$ & $+3,4$ & b & $\mathrm{b}$ \\
\hline \multicolumn{5}{|l|}{ Mujeres } \\
\hline 15 y más & $+5,5$ & $+7,9$ & $-4,4$ & $+2,3$ \\
\hline $15-19$ & $+27,7$ & $+26,3$ & $+11,4$ & $+19,6$ \\
\hline $20-24$ & $+11,1$ & $\begin{array}{l}+18,7 \\
\end{array}$ & $-13,1$ & $-0,5$ \\
\hline $25-34$ & & $+10,4$ & b & b \\
\hline $35-44$ & $+2,2^{\mathrm{c}}$ & $+4,4$ & b & b \\
\hline $45-64$ & & $+4,2$ & b & b \\
\hline 65 y más & $+6,9 d$ & $+0,1$ & b & b \\
\hline
\end{tabular}

a Encuesta efectuada por el Instituto de Economía de la Universidad de Chile.

b Los grupos de edades no son comparables.

c De 25 a 59 años.

d De 60 y más años.

se realizaron en el lapso de 4 meses (mayo a septiembre), habria que aceptar que las condiciones del empleo prácticamente no variaron en ese intervalo. Las encuestas trimestrales de ocupación y desocupación que se realizan en el Gran Santiago, desde hace varios años no revelan variaciones estacionales apreciables. La tendencia general demuestra que el nivel de desocupación sufrió pocos cambios en los últimos cinco años (5 a 6 por ciento en la población masculina y 3 a 4 por ciento en la femenina). 
Cuadro 63

TASAS DE DESOCUPACION EN EL GRAN SANTIAGOa

\begin{tabular}{|c|c|c|c|c|c|c|}
\hline \multirow{3}{*}{$\begin{array}{c}\text { Sexo } \\
\text { y } \\
\text { grupos } \\
\text { de } \\
\text { edades }\end{array}$} & \multicolumn{4}{|c|}{ Inmigrantes } & & \\
\hline & \multicolumn{2}{|c|}{$\begin{array}{c}\text { Del período } \\
1952-1962\end{array}$} & \multicolumn{2}{|c|}{$\begin{array}{l}\text { De antes } \\
\text { de } 1952\end{array}$} & \multicolumn{2}{|c|}{ Nativos } \\
\hline & $\begin{array}{c}\text { Número } \\
\text { de } \\
\text { casos }^{b}\end{array}$ & $\begin{array}{c}\text { Tasas } \\
\text { de } \\
\text { desocu- } \\
\text { pación }\end{array}$ & $\begin{array}{c}\text { Número } \\
\text { de } \\
\operatorname{casos}^{b}\end{array}$ & $\begin{array}{l}\text { Tasas } \\
\text { de } \\
\text { desocu- } \\
\text { pación }\end{array}$ & $\begin{array}{c}\text { Número } \\
\text { de } \\
\text { casos }^{b}\end{array}$ & $\begin{array}{c}\text { Tasas } \\
\text { de } \\
\text { desocu- } \\
\text { pación }\end{array}$ \\
\hline & (1) & (2) & (3) & (4) & (5) & (6) \\
\hline & \multicolumn{6}{|c|}{ (Porcentajes) } \\
\hline \multicolumn{7}{|l|}{ Hombres } \\
\hline 15 y más & 355 & 5,4 & 793 & 4,5 & 1167 & 6,0 \\
\hline $15-24$ & 114 & 8,8 & 56 & 3,6 & 386 & 6,2 \\
\hline $25-59$ & 235 & 3,8 & 646 & 5,0 & 747 & 6,2 \\
\hline 60 y más & 6 & - & 91 & 2,2 & 34 & $\rightarrow$ \\
\hline Mujeres & 301 & 1,3 & 427 & 1,9 & 547 & 1,6 \\
\hline 15 y más & 155 & 0,6 & 33 & 3,0 & 203 & 2,0 \\
\hline $15-24$ & 139 & 2,2 & 360 & 1,9 & 335 & 1,5 \\
\hline $25-59$ & 5 & - & 34 & - & 9 & - \\
\hline 60 y más & 2 & - & - & & & \\
\hline
\end{tabular}

a Razón entre población desocupada y población económicamente activa.

b Personas económicamente activas.

\section{Desocupación}

Este estudio no pretende medir el nivel de la desocupación, sino tan sólo establecer si existen niveles diferenciales entre inmigrantes y nativos, para lo cual se requiere menor exactitud en la medición del fenómeno.

Primero se analizará la población masculina. Los resultados obtenidos indican que la tasa de desocupación de los nativos $(6,0$ por ciento) es un poco más elevada que la correspondiente tasa de los inmigrantes (4,8 por ciento). A su vez, la tasa de desocupación de los inmigrantes de la última década $(5,4$ por ciento) fue más alta que el valor promedio correspondiente a todos los inmigrantes. ${ }^{106}$ (Véase el cuadro 63.)

106 En la encuesta de ocupación y desocupación realizada por el Instituto 


\section{Subempleo}

Pueden usarse varios datos de la encuesta para obtener indicaciones de la existencia y magnitud del subempleo y, consecuentemente, poder medir el subempleo diferencial entre nativos e inmigrantes.

En verdad no se conoce un método único satisfactorio capaz de medir las variadas formas del subempleo, ni teórica ni prácticamente. Aquí se analizan datos que usualmente se emplean para estimar la exis-

de Economía de la Universidad de Chile en junio de 1963 se encontró una diferencia en el mismo sentido ( 7,2 por ciento en los nativos y 4,6 por ciento en los inmigrantes en conjunto).

Según los resultados de la citada encuesta, las tasas de desocupación decrecen rápidamente al aumentar la edad, así en el caso de los nativos como en el de los inmigrantes. Por ejemplo, las tasas de desocupación de inmigrantes correspondientes a las edades $15-19,25-34$ y $35-44$ son $15,3,5,1$ y 4,0 por ciento, respectivamente; y las tasas de los nativos: $13,5,5,6$ y 3,8 por ciento. Por el contrario, en la encuesta de inmigración no se da un patrón por edades similar, excepto, al parecer, entre los inmigrantes llegados en la última década. En efecto, éstos registraron una tasa del 8,8 por ciento en el grupo de edades $15-24$ y del 4,0 por ciento en el grupo 25 a 59 .

La diferencia más notable de ambas encuestas reside en las tasas de desocupación de los trabajadores jóvenes. La encuesta de ocupación y desocupación da una tasa dos veces más alta que la encuesta de inmigración en el grupo de edades 15-24. En la tasa de desocupación de la primera encuesta se incluyen las personas que buscan trabajo por primera vez, las que fueron excluidas de la segunda encuesta. A partir de los 25 años, las tasas de los inmigrantes son más altas en la encuesta de ocupación y desocupación que en la de inmigración, aunque a escasa distancia.

TASAS DE DESOCUPACION DERIVADAS DE LA ENCUESTA DE OCUPACION Y DESOCUPACION DE JUNIO DE 1963 EN EL GRAN SANTIAGOa

\begin{tabular}{|c|c|c|c|c|}
\hline \multirow{2}{*}{ Grupos de edades } & \multicolumn{2}{|c|}{ Hombres } & \multicolumn{2}{|c|}{ Mujeres } \\
\hline & Inmigrantes & Nativos & Inmigrantes & Nativas \\
\hline & \multicolumn{4}{|c|}{ (Porcentajes) } \\
\hline 15 y más & 4,6 & 7,2 & 3,1 & 4,9 \\
\hline $15-19$ & 15,3 & 13,5 & 5,4 & 14,9 \\
\hline $20-24$ & 7,6 & 10,5 & 2,9 & 6,3 \\
\hline $25 \cdot 34$ & 5,1 & 5,6 & 4,1 & 2,4 \\
\hline $35-44$ & 4,0 & 3,8 & 2,8 & 3,0 \\
\hline $45-64$ & 2,8 & 6,3 & 1,6 & 1,8 \\
\hline 65 y más & 2,9 & 3,3 & - & - \\
\hline
\end{tabular}

a La encuesta, realizada por el Instituto de Economía de la Universidad de Chile, investigó unas 13500 personas de todas las edades y, por lo tanto, es de tamaño comparable al de la encuesta de inmigración (10800 aproximadamente). 
tencia y la magnitud de ciertas formas visibles del desempleo, como son las horas o días trabajados en un intervalo de tiempo, o del desempleo encubierto, como son los ingresos y el hecho de buscar trabajo.

Tiempo trabajado. En el cuadro 64, las personas económicamente activas ocupadas están clasificadas, con referencia a la semana anterior al momento de la encuesta, en las siguientes situaciones: trabajaron 35 o más horas; trabajaron menos de 35 horas, y no trabajaron.

Aquellos que trabajaron menos de 35 horas semanales se dividieron a su vez en dos subgrupos, según la causa de esa jornada reducida. El primer subgrupo se formó con las personas que no trabajaron aquel mínimo porque no encontraron oportunidades de trabajo o de empleo por más tiempo, en forma que, se diría, traduce las condiciones prevalecientes del empleo; este subgrupo constituye lo que aquí se denominará desde ahora "trabajadores a tiempo parcial". El segundo subgrupo quedó formado por los que trabajaron menos de 35 horas semanales por estar de vacaciones, enfermos de modo pasajero o en conflictos patronales, por mal tiempo, por reparación de equipos, etc., hechos todos que revisten carácter ocasional y transitorio. De paso hay que señalar que este segundo subgrupo constituye una fracción pequeña de los que declararon trabajar menos de 35 horas, algo inferior al 10 por ciento.

Las personas que no trabajaron ( $y$ no clasificadas como desocupadas) son asimilables, en ambos casos, a aquellas que trabajaron menos de 35 horas y que están ubicadas en el segundo subgrupo antes mencionado. En efecto, no trabajaron por vacaciones, enfermedades pasajeras, conflictos patronales, mal tiempo, etc. Este último grupo representa en la encuesta el 2 por ciento del total de los económicamente activos ocupados. Es probable que una parte de ellos sean verdaderos desocupados, pero, como se desprende de la cifra anterior, el efecto que produciría este probable error de clasificación sería mínimo.

Los resultados se examinan por sexo, comenzando con los hombres. (Véase el cuadro 64.) La primera impresión es que el empleo de tiempo completo es más elevado de lo que pudo haberse esperado, a saber: el 90 por ciento aproximadamente, tanto en los nativos como en los inmigrantes. Quizá corresponda mejorar dicho porcentaje en uno o dos puntos con una parte de las personas que no trabajaron (y que no son desocupados) y de las que trabajaron menos de 35 horas semanales, de modo que el trabajo a tiempo parcial seria del orden del 6 al 7 por ciento.

A juzgar por estas cifras, el subempleo visible es relativamente pequeño comparado con el obtenido en encuestas de otros países de la América Latina, Asia y Africa. Aunque se trata de una ciudad que es 


\section{Cuadro 64}

NIVEL DEL EMPLEO ${ }^{a}$ EN EL GRAN SANTIAGO ENTRE LOS INMIGRANTES Y LOS NATIVOS

\begin{tabular}{|c|c|c|c|c|c|c|}
\hline $\begin{array}{ll}\text { Sexo } \\
\text { y } \\
\text { grupos } \\
\text { de edades }\end{array}$ & $\begin{array}{c}\text { Trabajadores } \\
\text { ocupados } \\
\text { (total } \\
\text { de casos) } \\
\end{array}$ & $\begin{array}{c}\text { A } \\
\text { tiempo } \\
\text { completo } \\
\end{array}$ & $\begin{array}{c}\text { A } \\
\text { tiempo } \\
\text { parcial } \\
\text { c } \\
\end{array}$ & (A) & (B) & $(\underset{f}{\mathrm{C}})$ \\
\hline & (1) & (2) & (3) & (4) & (5) & (6) \\
\hline \multicolumn{7}{|l|}{ HOMBRES } \\
\hline \multicolumn{7}{|l|}{ Inmigrantes del } \\
\hline período $1952-62$ & 336 & 93,1 & 5,4 & 0,9 & 0,6 & - \\
\hline $15-24$ & 104 & 96,2 & 3,8 & 一 & - & 一 \\
\hline $25 \cdot 59$ & 226 & 92,0 & 5,8 & 1,3 & 0,9 & - \\
\hline 60 y más & 6 & 83,3 & 16,7 & - & - & $\longrightarrow$ \\
\hline \multicolumn{7}{|l|}{ Inmigrantes de } \\
\hline antes de 1952 & 757 & 88,5 & 7,0 & $1, l$ & 3,0 & 0,4 \\
\hline $15-24$ & 54 & 90,7 & 7,4 & - & 1,9 & - \\
\hline $25-59$ & 614 & 90,6 & 5,5 & 1,0 & 2,4 & 0,5 \\
\hline 60 y más & 89 & 73,0 & 16,9 & 2,2 & 7,9 & - \\
\hline Nativos. & 1097 & 90,2 & 7,0 & 0,5 & 2,0 & 0,3 \\
\hline $15 \cdot 24$ & 362 & 89,2 & 8,3 & 0,3 & 1,9 & 0,3 \\
\hline $25 \cdot 59$ & 701 & 90,7 & 6,6 & 0,6 & 1,7 & 0,4 \\
\hline 60 y más & 34 & 88,2 & 2,9 & - & 8,9 & - \\
\hline \multirow{2}{*}{\multicolumn{7}{|c|}{$\begin{array}{c}\text { MuJERES } \\
\text { Inmigrantes del }\end{array}$}} \\
\hline & & & & & & \\
\hline período $1952-62$ & 297 & 92,6 & 6,1 & 0,3 & 1,0 & - \\
\hline $15-24$ & 154 & 95,5 & 3,9 & - & 0,6 & - \\
\hline $25-59$ & 136 & 91,2 & 7,3 & 一 & 1,5 & - \\
\hline 60 y más & 5 & 40,0 & 40,0 & 20,0 & - & - \\
\hline Edad desconocida & 2 & - & - & - & - & - \\
\hline \multicolumn{7}{|l|}{ Inmigrantes de } \\
\hline antes de 1952 & 419 & 81,1 & 14,6 & 0,5 & 3,1 & 0,7 \\
\hline $15-24$ & 32 & 81,3 & 3,1 & - & 12,5 & 3,1 \\
\hline $25-59$ & 353 & 81,9 & 14,7 & 0,3 & 2,5 & 0,6 \\
\hline 60 y más & 34 & 73,5 & 23,5 & 3,0 & - & - \\
\hline Nativas & 538 & 83,3 & 14,5 & 0,4 & 1,5 & 0,3 \\
\hline $15-24$ & 199 & 90,0 & 8,5 & 0,5 & 0,5 & 0,5 \\
\hline $25-59$ & 330 & 79,7 & 17,9 & - & 2,1 & 0,3 \\
\hline 60 y más & 9 & 66,7 & 22,2 & 11,1 & - & - \\
\hline
\end{tabular}

Distribución relativa.

- Empleados a tiempo completo (35 y más horas semanales), incluyendo trabajadores que

cumplen un horario profesional de menos de 35 horas semanales (médicos, profesores, etc.).

Empleados a tiempo parcial (menos de 35 horas semanales), excepto los que trabajaron

menos de 35 horas semanales por vacaciones, enfermedades pasajeras, mal tiempo, conflic-

tos patronales, reparaciones del equipo y causas similares.

a Trabajaron menos de 35 horas en la semana debido a vacaciones, enfermedades pasajeras, mal tiempo, conflictos patronales, reparaciones del equipo y causas similares.

- No trabajaron en la semana de referencia debido a vacaciones, enfermedades pasajeras, mal tiempo, conflictos patronales, reparaciones del equipo y causas similares. Se excluye a los desocupados (cesantes).

s. Sin información. 
centro de las actividades del pais, donde sin duda se ofrecen las mejores oportunidades de empleo, el subempleo visible, visto a través de aquella cifra del 6 al 7 por ciento, se presenta como un problema de poca monta. Juntando esta medida del subempleo con la desocupación encontrada, la conclusión sería que el 85 por ciento aproximadamente de la población trabajadora del Gran Santiago se encontraba ocupada a tiempo completo. Sin embargo, como se dice más adelante, el análisis de los ingresos parece indicar la existencia de un importante subempleo encubierto.

En las edades centrales ( 25 a 59 años), en las cuales las condiciones de ocupación suelen ser más regulares que en los grupos de edades extremas, el nivel de ocupados a tiempo completo varía poco de nativos (90,7 por ciento) a inmigrantes (inmigrantes de antes de 1952, 90,6 por ciento; del período 1952-1962, 92,0 por ciento).

En el grupo de edades 15 a 24 años, los inmigrantes del período 1952-1962 registraban un porcentaje ( 96,2 por ciento) apreciablemente más alto que el de los nativos (89,2 por ciento). Los inmigrantes de antes de 1952 tienen un porcentaje intermedio, pero lo pequeño de los números de este último grupo no da suficiente confianza al resultado. Esto quiere decir que los inmigrantes jóvenes de la última década ocupados, están trabajando en un elevado porcentaje a tiempo completo. Al mismo tiempo, la tasa de desocupación de este mismo grupo es también la más elevada.

Tal situación podría interpretarse de varias maneras: una selección por ocupaciones donde el trabajo a tiempo parcial es menos frecuente, o bien dichos inmigrantes no están en situación de poder escoger empleos a tiempo parcial en la misma medida que lo están los otros sectores, empleos que ofrecen mejores condiciones de trabajo, pero baja remuneración.

El empleo femenino a tiempo completo en el grupo de edades 15 a 24 es comparable al respectivo empleo masculino. Se encontró una diferencia, similar a la anotada para los hombres, entre las nativas (90,0 por ciento) y las inmigrantes del período 1952-1962 (95,5 por ciento). El resultado de las inmigrantes de antes de $1952(81,3)$ hay que tomarlo con reservas porque se apoya tan sólo en 33 casos.

En el grupo más numeroso de 25 a 59 años, el empleo a tiempo completo disminuye con respecto al grupo de edad anterior y, por consiguiente, aumenta el emplec a tiempo parcial. En resumen, en la población femenina de 25 a 59 años el empleo a tiempo parcial es del orden del 15 por ciento, excepto entre las inmigrantes de la última década, entre las cuales es de aproximadamente 7 por ciento, o sea, casi la mitad. 
El empleo a tiempo parcial aumenta en las edades superiores a 60 años en todos los grupos. Sin embargo, hay que advertir que estos resultados se apoyan en números pequeños.

Como conclusión podría decirse que el empleo femenino a tiempo parcial aumenta al avanzar la edad, alcanzando un nivel relativamente moderado, quizá del 20 por ciento, después de los 40 años aproximadamente y que es más bajo el empleo a tiempo parcial en las mujeres que inmigraron en la última década, siendo equiparable al volumen del empleo parcial de los hombres que inmigraron en igual período.

Personas cesantes que buscan trabajo. El hecho de estar buscando trabajo también se ha utilizado como una indicación del subempleo encubierto. ${ }^{107}$

La pregunta sobre si busca o no empleo se formuló en el cuestionario a todas las personas económicamente activas, incluso a las que ya tenían una ocupación o empleo. A los entrevistadores se les instruyó para que distinguieran los casos de aquellos que estaban "efectivamente" buscando otra ocupación o empleo (avisos, trámites personales, etc.) y no incluyeran entre los que buscan empleo a aquellos que "desean o aspiran" a cambiar de ocupación o empleo, pero que no hacían nada en tal sentido.

A fin de profundizar un poco más el significado de las cifras correspondientes a los trabajadores ocupados a tiempo completo (véase el punto anterior), se analiza este grupo según que sus componentes masculinos buscaran empleo o no. En el grupo de 25 a 59 años de edad, el porcentaje de los que buscan empleo varía del 11 al 12, aproximadamente, con pequeñas diferencias entre nativos e inmigrantes de las dos épocas. El porcentaje es más elevado entre los trabajadores de más de 60 años, pero la comparación sería arriesgada debido a lo pequeño de los números. Entre los trabajadores de. 15 a 24 años, los que buscan empleo son un porcentaje más alto que en las otras edades, sobre todo entre los inmigrantes de la última década (18,0 por ciento).

Como la población masculina trabajadora ocupada a tiempo completo representaba cerca del 85 por ciento de la mano de obra masculina, con pequeñas diferencias entre nativos e inmigrantes, si se le resta, por ejemplo, un 12 por ciento, como término medio, correspondiente a los que buscaban trabajo, se llegaría a un 75 por ciento de ocupados a tiempo completo sin subempleo visible o encubierto, si este criterio de medición del subempleo fuera válido.

107 En una encuesta de ocupación y desocupación llevada a cabo en las Filipinas, se consideró subempleo encubierto el trabajo de más de 40 horas semanales y estar buscando trabajo. 
Refiriendo el análisis a los inmigrantes del período 1952-1962 y de 15 a 24, años de edad, alrededor del 77 por ciento de los económicamente activos estaría ocupado a tiempo completo, sin subempleo. En este grupo de personas se encontró el porcentaje más alto de trabajadores a tiempo completo ( 96,2 por ciento), pero también el más alto porcentaje que buscaba trabajo (18,0 por ciento), unido a la más elevada desocupación (8,8 por ciento).

De las trabajadoras a tiempo completo, buscaba trabajo alrededor del 7 por ciento, es decir, algo más de la mitad del respectivo porcentaje masculino. (Véase el cuadro 65.) Deduciendo aquel porcentaje de la cifra de las mujeres ocupadas a tiempo completo y considerando además la tasa de desocupación, se llega a una cifra de 70 a 75 por ciento de trabajadoras a tiempo completo, sin subempleo. Entre las mujeres inmigrantes de la última década, esa proporción se acerca al 75 por ciento $y$, por lo tanto, es similar a la correspondiente a los hombres del mismo grupo (inmigrantes del período 1952-1962).

Ingresos. Las cifras del empleo parcial en función de las horas trabajadas (véase supra) no revelaron un subempleo visible importante. Sin embargo, el subempleo puede estar encubierto por las modalidades locales del empleo asalariado (como la aceptación de bajos salarios con un horario normal por falta de oportunidades de empleo) y por la baja productividad del trabajo en muchas actividades. Estas dos circunstancias deberian reflejarse en el monto de los ingresos.

La información obtenida en la encuesta se limita a los ingresos provenientes de una actividad personal (se excluyen rentas, jubilaciones, intereses) en el último mes. Los ingresos que no estaban referidos a un mes sino a un período menor (semana, etc.), se expresaron en su equivalente mensual. Se puede suponer que en la mayoría de los casos estos ingresos constituyen la parte principal de los recursos económicos de los investigados. Las personas que no recibían ingresos de esta clase, o ninguna clase de ellos, se clasificaron en un grupo separado.

Es difícil determinar cuál es el monto de ingresos que marca el límite del subempleo encubierto. Independientemente de las circunstancias vinculadas a la capacidad profesional de cada trabajador, ${ }^{108}$ un mismo ingreso individual tiene diferente significación sobre el nivel de vida del trabajador (y su familia) según sea el número de personas a cargo y los ingresos que tengan otros miembros de la familia. Por consiguiente, se adoptó, como decisión simple y aproximada, el salario vital legal vigente en 1962.

108 Prescindiendo de la relación entre ingreso y calificación profesional como una forma de subempleo, problema que no podría considerarse aquí. 


\section{Cuadro 65}

TRABAJADORES OCUPADOS A TIEMPO COMPLETO QUE BUSCAN EMPLEO EN EL GRAN SANTIAGO

(Hombres)

\begin{tabular}{|c|c|c|}
\hline Grupos de edades & $\begin{array}{c}\text { Número } \\
\text { de trabajadores } \\
\text { ocupados a tiempo } \\
\text { completo }\end{array}$ & $\begin{array}{c}\text { Porcentaje } \\
\text { de los que } \\
\text { buscan empleo }\end{array}$ \\
\hline Inmigrantes del periodo $1952-1962$ & 313 & 13,4 \\
\hline $15-24$ & 100 & 18,0 \\
\hline $25 \cdot 59$ & 208 & 11,5 \\
\hline 60 y más & 5 & - \\
\hline Inmigrantes de antes de 1952 & 670 & 10,3 \\
\hline $15 \cdot 24$ & 49 & 10,2 \\
\hline $25 \cdot 59$ & 556 & 11,2 \\
\hline 60 y más & 65 & 3,1 \\
\hline Nativos & 989 & 12,8 \\
\hline $15-24$ & 323 & 13,9 \\
\hline $25 \cdot 59$ & 636 & 12,4 \\
\hline 60 y más & 30 & 10,0 \\
\hline
\end{tabular}

a Podría considerarse como indicador del subempleo encubierto.

El salario vital de un empleado particular era de 81,90 escudos mensuales en 1962 y el de un obrero que trabajaba todos los días laborables del mes, de 38,40 escudos. ${ }^{109}$ Sin tomar en cuenta las asignaciones familiares - las que varían con el número de cargas- y deduciendo las imposiciones del seguro, se establecieron dos cifras límites: 70 y 30 escudos, por debajo de las cuales se consideró que había subempleo. Podría pensarse que por debajo de los 70 escudos hay una situación de subempleo y por debajo de los 30 escudos quizá podría hablarse de subempleo agudo. ${ }^{110}$

De acuerdo con el criterio adoptado, más del 40 por ciento de los trabajadores del sexo masculino estaban subempleados -en cualquier grado-; algo más entre los nativos $(44,9$ por ciento) que entre los inmigrantes $(42,1$ por ciento). La diferencia es marcada según se trate

109 Si bien el salario vital de un obrero era de 38,40 escudos, no hay duda de que esa remuneración sólo puede corresponder a un trabajador de baja productividad. Un operario calificado ganaba un salario varias veces más alto.

110. Hacia la mitad de 1962 y a una tasa de cambio que es un promedio de tasa oficial y de la libre, 70 escudos significaban aproximadamente 47 dólares. 
de inmigrantes de la última década o de antes de 1952;49,7 y 38,7 por ciento, respectivamente. En situación de subempleo agudo (menos de 30 escudos) habría alrededor del 6,6 por ciento, cifra que en el caso de los inmigrantes del período $1952-1962$, sube al 8,9 por ciento. (Véase el cuadro 66.)

Limitando la comparación a los trabajadores de 30 a 54 años, o sea, al intervalo de edad dentro del cual se presume que el trabajador alcanza su más alta capacidad de ingresos, el grado de subempleo se reduce, como se esperaba que sucediera, pero las diferencias entre inmigrantes y nativos son de sentido inverso al de antes: nativos con el 30,7 por ciento e inmigrantes con el 34,5 por ciento. Entre los inmigrantes, también la situación es ćesfavorable para los llegados en la última década (37,8 por ciento) con respecto a los llegados antes de 1952 (33,4 por cienio).

La proporción con subempleo agudo (columna 2 del cuadro 66), en el grupo de edad 30 a 54 años es aproximadamente la mitad que el promedio correspondiente a todas las edades. Este subempleo, en cualquier edad, es más alto entre los inmigrantes del periodo 1952-1962 que entre los demás inmigrantes y los naivivos.

Respecto de las mujeres, las trabajadoras nativas con ingresos inferiores a 70 escudos representaban el 63,0 por ciento de dicho grupo, frente al 65,2 por ciento de las inmigrantes de antes de 1952 y al 84,7 por ciento de las de la última década.

Considerando la situación por debajo del límite de los 30 escudos, se encontraron, como es lógico, porcentajes más altos que los correspondientes a los hombres: tenían ingresos inferiores a 30 escudos el 45,3 por ciento de las inmigrantes del periodo 1952-1962; el 27,3 por ciento de las inmigrantes de antes de 1952, y el 20,0 de las nativas. La situación de las inmigrantes de la década 1952-1962 no puede extrañar si se piensa que una gran parte de esa mano de obra trabajaba en servicios domésticos; y aunque es verdad que tales trabajadoras reciben ingresos no monetarios (alojamiento y comida) que también deberían compuiarse, el solo hecho de tener tal ocupación ya es un índice de subempleo.

Comparando estas cifras con las de la mano de obra femenina de 30 a 54 años, la proporción de inmigranies del período 1952-1962 con ingresos inferiores a 30 escudos baja del 45,3 al 29,4, por ciento, lo cual es una indicación de que el trabajo peor remunerado tiene un peso mayor en las mujeres menores de 30 años.

Resumiendo, se puede concluir que en ambos sexos existe subempleo más acentuado entre los inmigrantes de reciente data (1952-1962), que entre los demás inmigrantes y los nativos. Esta particularidad es 
Cuadro 66

POBLACION ECONOMICAMENTE ACTIVA EN EL GRAN SANTIAGO CLASIFICADA SEGUN SUS INGRESOS MENSUALES ${ }^{a}$

\begin{tabular}{|c|c|c|c|c|c|c|}
\hline \multirow{2}{*}{$\begin{array}{l}\text { Sexo y grupos } \\
\text { de edades }\end{array}$} & \multirow{2}{*}{$\begin{array}{l}\text { Número } \\
\text { de tra- } \\
\text { bajadores } \\
\text { (Total) }\end{array}$} & \multicolumn{5}{|c|}{$\begin{array}{l}\text { Trabajadores con el ingreso indicadob } \\
\text { (Distribución porcentual) }\end{array}$} \\
\hline & & $\begin{array}{l}\text { Menos } \\
\text { de } 30\end{array}$ & $30-69$ & $70-99$ & $100-249$ & $\begin{array}{l}250 \\
\text { y más }\end{array}$ \\
\hline & (1) & (2) & (3) & (4) & (5) & (6) \\
\hline $\begin{array}{l}\text { Hombres } \\
\text { De } 14 \text { y más años } \\
\text { Inmigrantes del }\end{array}$ & & & & 189 & 223 & 98 \\
\hline $\begin{array}{l}\text { período 1952-1962 } \\
\text { Inmigrantes de } \\
\text { antes de } 1952\end{array}$ & $\begin{array}{r}737 \\
1073\end{array}$ & $\begin{array}{l}5,6 \\
6,6\end{array}$ & $\begin{array}{l}33,1 \\
38,3\end{array}$ & $\begin{array}{l}19,1 \\
19,0\end{array}$ & $\begin{array}{l}27,1 \\
25,0\end{array}$ & $\begin{array}{l}15,1 \\
11,1\end{array}$ \\
\hline $\begin{array}{l}\text { Nativos } \\
\text { De } 30 \text { a } 54 \text { años } \\
\text { Inmigrantes del } \\
\text { período } 1952-1962\end{array}$ & 1085 & 0,0 & 31,8 & 20,3 & 25,0 & 16.8 \\
\hline $\begin{array}{l}\text { Inmigrantes de } \\
\text { antes de } 1952 \\
\text { Nativos }\end{array}$ & $\begin{array}{l}479 \\
504\end{array}$ & $\begin{array}{l}2,9 \\
2,6\end{array}$ & $\begin{array}{l}30,5 \\
28,2\end{array}$ & $\begin{array}{l}19,2 \\
19,2\end{array}$ & $\begin{array}{l}29,4 \\
31,6\end{array}$ & $\begin{array}{l}18,0 \\
18,4\end{array}$ \\
\hline $\begin{array}{l}\text { Mujeres } \\
\text { De } 14 \text { y más años } \\
\text { Inmigrantes del } \\
\text { periodo 1952-1962 }\end{array}$ & 287 & 45,3 & 39,4 & 7,7 & 6,9 & 0,7 \\
\hline $\begin{array}{l}\text { Inmigrantes de } \\
\text { antes de } 1952 \\
\text { Nativas }\end{array}$ & $\begin{array}{l}396 \\
511\end{array}$ & $\begin{array}{l}27,8 \\
20,0\end{array}$ & $\begin{array}{l}37,4 \\
43,0\end{array}$ & $\begin{array}{l}13,1 \\
15,7\end{array}$ & $\begin{array}{l}17,4 \\
18,6\end{array}$ & $\begin{array}{l}4,3 \\
2,7\end{array}$ \\
\hline $\begin{array}{l}\text { De } 30 \text { a } 54 \text { años } \\
\text { Inmigrantes del } \\
\text { periodo 1952-1962 }\end{array}$ & 68 & 29,4 & 39,7 & 8,8 & 20,6 & 1,5 \\
\hline $\begin{array}{l}\text { Inmigrantes de } \\
\text { antes de } 1952 \\
\text { Nativas }\end{array}$ & $\begin{array}{l}270 \\
213\end{array}$ & $\begin{array}{l}23,7 \\
19,7\end{array}$ & $\begin{array}{l}38,5 \\
37,1\end{array}$ & $\begin{array}{l}13,3 \\
14,1\end{array}$ & $\begin{array}{l}19,6 \\
23,9\end{array}$ & $\begin{array}{l}4,8 \\
5,2\end{array}$ \\
\hline
\end{tabular}

a Ingresos provenientes de actividades personales. Se excluyen los casos con in. gresos desconocidos, o con ingresos de otras fuentes.

b En escudos.

más marcada en las mujeres. Además, el subempleo es más fuerte entre los trabajadores jóvenes que entre los de 30 a 54 años.

c) "Clases" económico-sociales. Las "clases" económico-sociales que se utilizan en este estudio se basan en la profesión y se han formado 
agrupando las categorías principales de la clasificación internacional uniforme de ocupaciones que se usa para la presentación de los datos de los censos de población. ${ }^{111}$

Trabajadores "manuales" y "no manuales" definen las dos "clases" principales. Una primera aproximación al nivel de calificación de la mano de obra estará dada por la importancia relativa de cada uno de estos dos grupos. Si esa calificación es inferior entre los inmigrantes, como podría suponerse, la proporción de trabajadores manuales debe ser más alta que entre los nativos. La duración de la residencia en la ciudad constituye a su vez un elemenio diferenciador entre los inmigrantes; cuanto más corta sea la residencia, menores serán las oportunidades de asimilación y, por consiguiente, también menor la probabilidad de cambiar la condición de manual.

Los trabajadores manuales representaban la fracción más grande de la mano de obra del Gran Santiago, cualesquiera que fuese su status migratorio y sexo. (Véase el cuadro 67.) Tomando globalmente la mano de obra masculina, el porcentaje de trabajadores manuales entre los nativos $(63,0)$ supera a la proporción encontrada entre los inmigrantes de la última década $(61,4)$ y de antes de $1952(58,7)$. Sin embargo, esta situación está afectada por la composición por edad de estos grupos, ya que en los trabajadores de 15 a 24 años, la importancia que ocupa el trabajador manual en la mano de obra inmigrante (aproximadamente el 74 por ciento) es claramente superior a la del trabajador nativo $(60,4$ por ciento). En el grupo de edades 25 a 59 , que es el más numeroso, lógicamente se presenta la situación opuesta. (Véase el cuadro 71.) Estos resultados, unidos al hecho de que la proporción de trabajadores manuales disminuye el aumentar la edad, permiten concluir que efectivamente el trabajador manual representa una propor-

111 "Clases" económico-sociales: (Entre paréntesis se indica el grupo correspondiente de la Clasificación Internacional Uniforme de Ocupaciones):

Trabajadores no manuales

- Profesionales, técnicos y ocupaciones afines (0).

- Gerentes, administradores y funcionarios de categoría directiva (1).

- Empleados de oficina, vendedores y personas en ocupaciones afines ${ }^{a}$ (2) y (3). Trabajadores manuales

- Artesanos y operarios (5), (6), (7) y (8).

- Trabajadores de servicios personales y ocupaciones afines $^{b}(x)$.

- Sirvientes en hogares particulares.

- Obreros y jornalerosa (9).

Agricultores, ganaderos, pescadores, etc. (4).

Otros trabajadores y trabajadores en ocupaciones no identificables o no declara. das $(\mathrm{Y})$.

a Los vendedores ambulantes se incluyeron entre los obreros y jornaleros.

b Los sirvientes en hogares particulares se excluyeron del grupo general de trabajadores de servicios personales, para formar un grupo separado. 
Cuadro 67

"CLASES" ECONOMICO-SOCIALES

(Trabajadores de más de 14 años de edad)

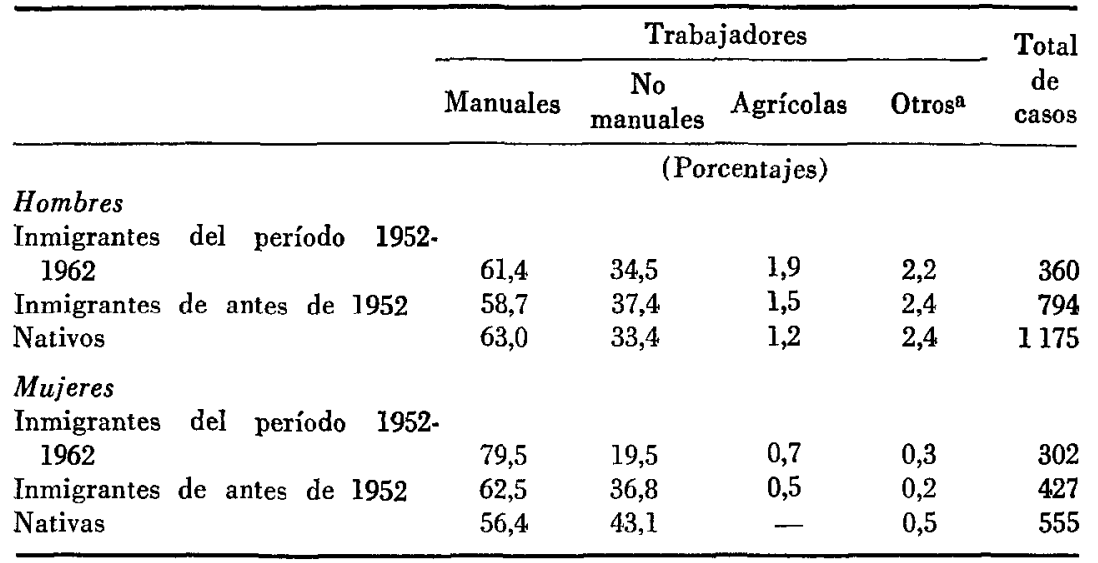

a Principalmente ocupaciones mal definidas o sin información de la ocupación.

ción mayor entre los inmigrantes, en particular entre los inmigrantes de la última década. ${ }^{112}$

La composición de la mano de obra femenina muestra la misma característica observada en los hombres, pero mucho más acentuada. El carácter predominantemente manual de las trabajadoras inmigrantes, con relación a las nativas, apoya al supuesto de su menor calificación. La diferencia es más pronunciada si se consideran las inmigrantes de 15 a 24 años de la década 1952-1962, con una proporción del 90,3 por ciento de trabajadoras manuales, frente a sólo 59,6 por ciento de las nativas. La diferencia persiste entre las trabajadoras de edades más altas, pero en forma menos acusada. (Véanse los cuadros 67 y 71 .)

De las ocupaciones manuales, reviste especial interés el grupo de los "servicios personales", en relación con una probable selectividad de los empleos de baja productividad, según la condición de inmigrante o nativo; lo que se confirmaría en la encuesta, en donde más del 20 por ciento de los trabajadores manuales, entre los inmigrantes (hombres) de la última década, estaban en ocupaciones de aquel grupo, con-

112 La edad promedio de la población nativa es menor que la de los inmigrantes, y entre éstos, la edad promedio más baja corresponde a los inmigrantes llegados en la última década. Lo anterior es válido tanto para los trabajadores de más de 15 años, como para el grupo de 25 a 59 años. 
CUADRO 68

PORCENTAJE DE TRABAJADORES DE LOS SERVICIOS PERSONALES EN EL TOTAL DE TRABAJADORES MANUALES

\begin{tabular}{llccc}
\hline & \multicolumn{3}{c}{ Mujeres } \\
\cline { 4 - 5 } & Hombres & $\begin{array}{c}\text { Todos } \\
\text { los } \\
\text { servicios } \\
\text { personales }\end{array}$ & $\begin{array}{c}\text { En hogares } \\
\text { particulares }\end{array}$ \\
\hline Inmigrantes del período 1952-1962 & & 21,3 & 86,7 & 80,4 \\
Inmigrantes de antes de 1952 & 15,9 & 57,3 & 33,3 \\
Nativos & & 7,7 & 39,0 & 22,0 \\
\hline
\end{tabular}

"Sirvientes domésticas.

tra alrededor del 8 por ciento entre los nativos. También en la mano de obra femenina una parte considerable de las trabajadoras manuales estaba ocupada en "servicios personales", y en mayor proporción entre las inmigrantes recientes (86,7 por ciento) que entre las nativas $(39,0$ por ciento)..$^{113}$ (Véase el cuadro 68.)

Con un criterio y un propósito análogos a los del párrafo anterior, interesa conocer el peso que tienen los "profesionales, técnicos y afines", o sea el grupo más calificado, dentro de los trabajadores no manuales, según sea el status migratorio. Nuevamente se encuentra que el grupo observado tiene mayor importancia relativa entre los inmigrantes, en ambos sexos. (Véase el cuadro 69.) Estos resultados y los del párrafo anterior sugieren que la mano de obra inmigrante, al mismo tiempo que contribuye con una cuota mayor de trabajadores de baja calificación que la población nativa, aporta una mayor a las ocupaciones más calificadas, lo que está acorde con la opinión de algunos investigadores en el sentido de que la emigración opera selectivamente sobre la población que tiene un buen nivel de educación.

Este breve análisis de "clases" económico-sociales se complementa con algunos comentarios sobre la composición de la mano de obra según la "categoría" en la ocupación, o sea la posición en el empleo o en la actividad desempeñada. Con esa finalidad se respetaron las categorías usadas en los censos de población: asalariados, trabajadores por cuenta propia, patrones y trabajadores familiares no remunerados. ${ }^{114}$

113 Una elevada proporción de la mano de obra femenina que trabajaba en "servicios personales", Io hacía en hogares particulares (sirvientes domésticas), proporción que es mayor entre las inmigrantes recientes.

114 Los trabajadores por cuenta propia se distinguen de los patrones en que los primeros no tienen trabajadores asalariados trabajando por su cuenta. 
PORCENTAJE DE PROFESIONALES, TECNICOS Y AFINES EN EL TOTAL DE TRABAJADORES NO MANUALES

\begin{tabular}{lccc} 
& Hombres & & Mujeres \\
\cline { 2 - 3 } Inmigrantes del período 1952-1962 & 21,8 & 45,8 \\
Inmigrantes de antes de 1952 & 21,2 & 31,8 \\
Nativos & 16,8 & \\
\hline
\end{tabular}

Como es bien conocido, con la modernización de la economía, los trabajadores por cuenta propia (agricultores, pequeños comerciantes, artesanos, etc.) son reemplazados por asalariados (operarios de fábricas, vendedores y oficinistas de empresas, etc.). En las grandes ciudades, una fracción considerable de los trabajadores por cuenta propia desarrollan actividades pobremente remuneradas, como consecuencia de la falta de empleos productivos. Si los inmigrantes se enfrentan con mayores dificultades que los nativos en cuanto a la clase de empleo, ello debería reflejarse en una mayor proporción de trabajadores de ese grupo en ocupaciones por cuenta propia.115, 116

Los resultados de la encuesta contradicen esta idea, ya que son precisamente los trabajadores nativos y los inmigrantes que llevan más de diez años de vida en la ciudad los que con mayor frecuencia estaban en la categoría "por cuenta propia" (20 por ciento, aproximadamente), en una relación de dos a uno respecto de los trabajadores que eran inmigrantes recientes ( 10 por ciento). (Véase el cuadro 70.) Si bien estos resultados son aplicables también a la mano de obra femenina, el significado de la importancia relativa de las trabajadoras por cuenta propia está oscurecido por el hecho de que la mayoría de las asalariadas son sirvientes domésticas, lo cual es más notorio entre las inmigrantes recientes. La calificación profesional de ellas es tanto o más baja que la de muchas formas de trabajo por cuenta propia.

d) Nivel de instrucción de la población económicamente activa. La clasificación por ocupaciones utilizada en la sección $6 \mathrm{c}$ ) proporciona una idea aproximada e insuficiente del grado de calificación de la

115 Cierto número de "profesionales, técnicos y afines", cuando no son ni emplean asalariados, caen en la categoría de trabajadores por cuenta propia. Lo mismo puede decirse de algunas otras ocupaciones. De cualquier modo, el peso mayor entre los trabajadores por cuenta propia, cuando éstos constituyen una fracción importante de la mano de obra, depende de actividades poco productivas.

116 Las condiciones de los trabajadores familiares no remunerados son, en muchos aspectos, similares a las de los trabajadores por cuenta propia. No obstante, en las ciudades, la primera categoría carece de peso en la mano de obra. 
Cuadro 70

POBLACION ECONOMICAMENTE ACTIVA, SEGUN CATEGORIAS

DEL EMPLEO

(Personas de más de 15 años)

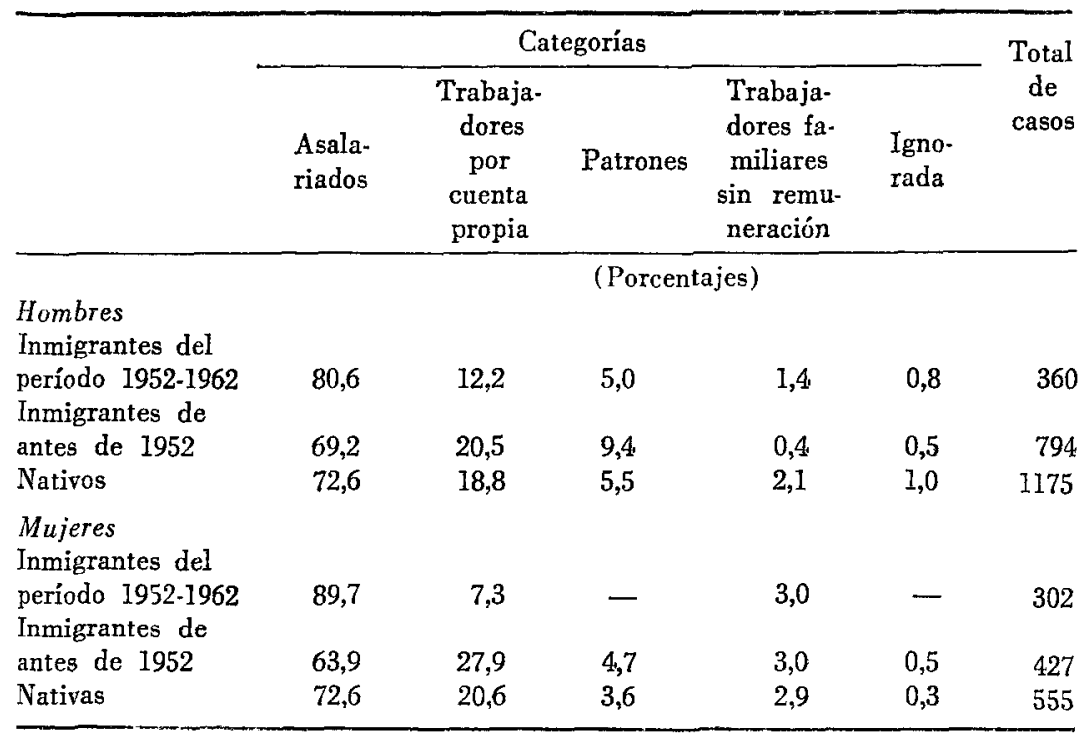

población económicamente activa. Similares ocupaciones, por ejemplo, suelen exigir conocimientos y habilidades profesionales diferentes según el grado de organización de la producción y el estado de la tecnología en los diferentes países $\mathrm{y}$, por consiguiente, son desempeñadas en ellos por trabajadores con diferentes niveles de educación. En consecuencia, si se conoce el nivel de instrucción, se evaluará mejor la capacidad de la mano de obra disponible.

Para estudiar el nivel de educación diferencial de trabajadores inmigrantes y nativos se escogen los mismos escalones o niveles empleados en la sección 5 de este capítulo, esto es: sin instrucción; con meno: de 4 años de enseñanza elemental; con 4 a 6 años de enseñanza elemental, y con un año o más de enseñanza secundaria, o con educación universitaria o superior.

Considéranse primeramente los dos grandes sectores económicosociales ya establecidos: trabajadores manuales y no manuales. Como era de esperar, una mayor proporción de trabajadores no manuales queda situada en niveles de educación relativamente altos, comparativa- 
CUADRO 71

PROPORCION DE TRABAJADORES MANUALES Y NO MANUALES POR GRANDES GRUPOS DE EDADES

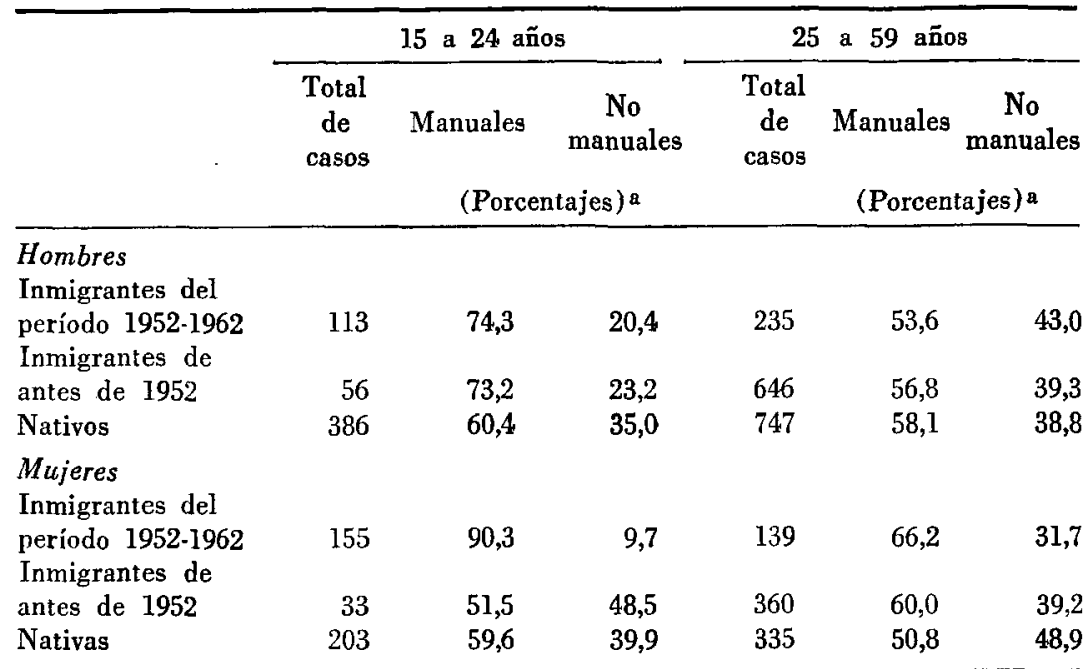

a La suma de los porcentajes no da necesariamente 100. La cantidad que falta corresponde a otras ocupaciones o a casos de ocupaciones no identificadas o no declaradas.

mente con los trabajadores manuales, sean inmigrantes o nativos, hom. bres o mujeres. (Véase el cuadro 72.)

Destácase, al mismo tiempo, que no hay diferencias importantes, dentro del grupo de los trabajadores no manuales, por status migratorio o por sexo. Entre los inmigrantes, el 78 por ciento de los trabajadores no manuales tiene un año o más de enseñanza secundaria; entre los nativos, alrededor del 82 por ciento. Esta similitud revela que en las ocupaciones no manuales se requiere, al menos en una proporción importante de casos, un nivel de educación superior a la enseñanza elemental.

Entre los trabajadores manuales hay diferencias significativas, según se trate de inmigrantes o de nativos: entre los hombres el 31 por ciento de los nativos tenía uno o más años de enseñanza secundaria o superior; de los inmigrantes, sólo el 22 por ciento. En la población femenina esos porcentajes son también más altos entre las nativas: 20 y 12 por ciento respectivamente. Además, cabe decir que las diferencias entre trabajadoras nativas e inmigrantes se observan a partir de un nivel de educación más bajo, de manera que, por ejemplo, el 17 por ciento de las segundas no tenían ningún año de instrucción, frente a 
Cuadro 72

NIVEL DE INSTRUCCION DE LA POBLACION ECONOMICAMENTE ACTIVA, INMIGRANTE Y NATIVA DEL GRAN SANTIAGO EN OCUPACIONES

MANUALES Y NO MANUALES

(Distribución porcentual según el nivel de instrucción)

\begin{tabular}{|c|c|c|c|c|c|}
\hline \multirow{2}{*}{ Sexo y nivel de instrucción } & \multicolumn{2}{|c|}{ Inmigrantes } & \multicolumn{3}{|c|}{ Nativos } \\
\hline & No manuales & Manuales & No & manuales & Manuales \\
\hline Hombres & $\begin{array}{c}100 \\
(421)^{a}\end{array}$ & $\begin{array}{c}100 \\
(684)\end{array}$ & & $\begin{array}{l}100 \\
(389)\end{array}$ & $\begin{array}{c}100 \\
(738)\end{array}$ \\
\hline $\begin{array}{l}\text { Sin instrucción } \\
\text { Con menos de } 4 \text { años de en- } \\
\text { señanza elemental } \\
\text { (primaria) }\end{array}$ & 1 & 21 & & 1 & 15 \\
\hline $\begin{array}{l}\text { Con 4. a } 6 \text { años de ense- } \\
\text { ñanza elemental }\end{array}$ & 17 & 48 & & 14 & 49 \\
\hline $\begin{array}{l}\text { Con un año o más de en- } \\
\text { señanza secundaria, uni- } \\
\text { versitaria o superior }\end{array}$ & 78 & 22 & & 82 & 31 \\
\hline Mujeres & $\begin{array}{c}100 \\
(215)\end{array}$ & $\begin{array}{c}100 \\
(507)\end{array}$ & & $\begin{array}{c}100 \\
(238)\end{array}$ & $\begin{array}{c}100 \\
(312)\end{array}$ \\
\hline $\begin{array}{l}\text { Sin instrucción } \\
\text { Con menos de } 4 \text { años de en- } \\
\text { señanza elemental } \\
\text { (primaria) }\end{array}$ & 1 & 17 & & 0 & 4 \\
\hline $\begin{array}{l}\text { Con } 4 \text { a } 6 \text { años de ense- } \\
\text { ñanza elemental } \\
\text { Con un año o más de en- } \\
\text { señanza secundaria, uni- } \\
\text { versitaria o superior }\end{array}$ & 17 & 43 & & 14 & 60 \\
\hline
\end{tabular}

a Entre paréntesis se indica el número de trabajadores investigados.

un 4 por ciento de las primeras. Estas diferencias indican que en el sector más numeroso de la mano de obra hay una amplia gama de exigencias en materia de educación.

Examinando ahora el nivel de educación diferencial en grupos más específicos de ocupaciones (véase el cuadro 73), se pone de manifiesto que en la mayoría de ellos el nivel de instrucción es más elevado entre los nativos, excepto precisamente aquellas ocupaciones donde el nivel de educación es más alto y donde, por esto mismo, no hay diferencias notables entre inmigrantes y nativos ("profesionales y técnicos" y "gerentes, administradores y funcionarios de categoría directiva"). 
NIVEL DE INSTRUCCION DE LA POBLACION ECONOMICAMENTE ACTIVA, INMIGRANTE Y NATIVA DEL GRAN SANTIAGO, POR OCUPACIONES Y SEXO

\begin{tabular}{|c|c|c|c|c|c|c|c|c|}
\hline \multirow{3}{*}{ Sexo y ocupaciones } & \multicolumn{6}{|c|}{ Porcentajes por arriba del nivel indicado: } & \multirow{2}{*}{\multicolumn{2}{|c|}{$\begin{array}{l}\text { Porcentaje } \\
\text { sin } \\
\text { instrucción }\end{array}$}} \\
\hline & \multicolumn{2}{|c|}{$\begin{array}{l}\text { Un año o } \\
\text { más de } \\
\text { enseñanza } \\
\text { secundaria } \\
\text { o superior }\end{array}$} & \multicolumn{2}{|c|}{$\begin{array}{c}4 \text { a } 6 \text { años } \\
\text { de enseñanza } \\
\text { elemental }\end{array}$} & \multicolumn{2}{|c|}{$\begin{array}{c}\text { Menos de } 4 \\
\text { años de } \\
\text { enseñanza } \\
\text { elemental }\end{array}$} & & \\
\hline & $\begin{array}{l}\text { Inmi- } \\
\text { grantes }\end{array}$ & $\begin{array}{l}\text { Nati- } \\
\text { vos }\end{array}$ & $\begin{array}{l}\text { Inmi- } \\
\text { grantes }\end{array}$ & $\begin{array}{l}\text { Nati- } \\
\text { vos }\end{array}$ & $\begin{array}{l}\text { Inmi- } \\
\text { grantes }\end{array}$ & $\begin{array}{l}\text { Nati- } \\
\text { vos }\end{array}$ & $\begin{array}{l}\text { Inmi- } \\
\text { grantes }\end{array}$ & $\begin{array}{l}\text { Nati- } \\
\text { vos }\end{array}$ \\
\hline \multicolumn{9}{|l|}{ Hombres } \\
\hline $\begin{array}{l}\text { Profesionales y técnicos } \\
\text { Gerentes, administrado- } \\
\text { res y funcionarios de }\end{array}$ & 94 & 97 & 100 & 98 & 100 & 100 & - & - \\
\hline $\begin{array}{l}\text { categoría directiva } \\
\text { Empleados de oficina y }\end{array}$ & 87 & 74 & 97 & 96 & 100 & 100 & - & 一 \\
\hline vendedores ${ }^{\mathbf{a}}$ & 70 & 80 & 92 & 96 & 98 & 99 & 2 & 1 \\
\hline Operarios ${ }^{b}$ & 23 & 34 & 72 & 83 & 92 & 97 & 8 & 3 \\
\hline $\begin{array}{l}\text { Trabajadores de los ser- } \\
\text { vicios personalese }\end{array}$ & 28 & 39 & 81 & 91 & 96 & 93 & 4 & 7 \\
\hline $\begin{array}{l}\text { Obreros y jornaleros } \\
\text { Mujeres }\end{array}$ & 11 & 17 & 51 & 63 & 79 & 88 & 21 & 12 \\
\hline $\begin{array}{l}\text { Profesionales y técnicas } \\
\text { Empleadas de oficina y }\end{array}$ & 92 & 95 & 100 & 100 & 100 & 100 & - & - \\
\hline vendedoras ${ }^{\mathrm{a}}$ & 70 & 79 & 92 & 96 & 99 & 100 & 1 & 0 \\
\hline Operarias $^{b}$ & 23 & 23 & 76 & 90 & 96 & 100 & 4 & 0 \\
\hline $\begin{array}{l}\text { Trabajadoras de los ser- } \\
\text { vicios personales } \\
\text { Sirvientes de hogares }\end{array}$ & 11 & 32 & 45 & 76 & 73 & 88 & 27 & 12 \\
\hline particulares & 7 & 6 & 48 & 59 & 80 & 93 & 20 & 7 \\
\hline
\end{tabular}

a Excluidos los vendedores ambulantes, que figuran entre los obreros y jornaleros.

b Incluyendo conductores de medios de transporte.

c Excluyendo a los sirvientes de hogares particulares.

En algunas de las restantes ocupaciones ("empleados de oficina" y "vendedores", excluidos los vendedores ambulantes) se observa que las diferencias operan a partir de los 7 años de instrucción, mientras que 
en otras ("operarios", incluyendo los conductores de medios de transporte, y "servicios personales" en la mano de obra masculina), las diferencias ya se producen a partir de los 4 años de instrucción. En el caso de las mujeres, las diferencias son aun más acentuadas y adversas a las inmigrantes, a partir de un año de instrucción en los "servicios personales" y en las "sirvientes de hogares particulares".

Finalmente, es de señalar que más del 20 por ciento de los inmigrantes del sexo masculino que trabajan como "obreros y jornaleros", y de las mujeres inmigrantes ocupadas en los "servicios personales" y como "sirvientes de hogares particulares", no registraba ningún año de instrucción. La instrucción de los nativos con estas últimas ocupaciones es relativamente mejor.

Es interesante comparar los niveles de educación por ocupaciones encontrados en el Gran Santiago con los correspondientes a un país industrializado como los Estados Unidos. En el grupo de "profesionales y técnicos" casi no hay diferencias. Estas aparecen en las restantes ocupaciones y son de mayor importancia en las actividades manuales. La comparación se hace tomando los porcentajes de trabajadores con 7 y más años de instrucción para el Gran Santiago, y con 8 y más años para los Estados Unidos. En cualquiera de los dos casos se trata de personas con uno o más años de enseñanza secundaria o superior. (Véase el cuadro 74.)

CuAdro 74

NIVEL DE INSTRUCCION DE LA MANO DE OBRA EN EL GRAN SANTIAGO $Y$ EN LOS ESTADOS UNIDOS (1950)

Porcentajes de trabajadores con el nivel de educación indicado

Gran Santiago Estados Unidos

(7 y más años) (8 y más años)

No manuales

Profesionales y técnicos

Gerentes, administradores y funcionarios

de categoría directiva

Oficinistas y vendedores

Manuales

Operarios

Servicios personales
95

80

75

98

91

93

28

26
71. 


$$
\nabla
$$

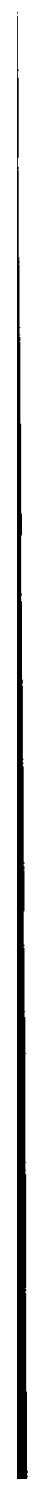




\section{LOS EFECTOS DEMOGRAFICOS}

Parte 2

\section{Estudio de los hogares}

\section{INTRODUCCIÓN}

En las tres secciones de este capítulo se examinan diversas características de los hogares, en relación con el status migratorio del jefe, con la finalidad principal de señalar aquellas diferencias que puedan presentar tales caracteristicas, según que el jefe del hogar sea o no un inmigrante, y en caso afirmativo, según sea la duración de su residencia en el Gran Santiago. Dado que esta duración es un factor importante en el proceso de asimilación, el análisis presta especial atención a los inmigrantes recientes, en este caso los llegados en la década 19521962. Si bien hubiera sido más indicado considerar un período menor, como son cinco años, en vez de diez, el número de casos por examinar habría sido demasiado pequeño $\mathrm{y}$, por consiguiente, los resultados de menor significación estadística.

En particular se estudian: i) condiciones de la vivienda; ii) es. tructura del hogar (composición, tamaño, etc.) y iii) caracteristicas económicas (número de personas económicamente activas, ingresos del jefe, tipo de actividad de la esposa del jefe, etc.).

Para orientar al lector a través de los resultados y conclusiones parciales que se irán exponiendo en las distintas secciones, dada la diversidad de aspectos que intervienen en el análisis y la estrecha relación que existe entre varias de las características examinadas, así como también porque hay resultados que reconocen el mismo factor explicalivo, parece justificado presentar anticipadamente las principales conclusiones que se obtuvieron, en vez de darlas al final del capítulo o de cada sección. Conviene tener en mente una observación general al considerar las diferencias que se encuentran entre los hogares, según 
sea el status migratorio del jefe, cuál es la edad promedio de los mismos. Los jefes nativos tienen la edad media más baja; los inmigrantes de antes de 1952, la más alta, y la de los llegados en la última década ocupa una posición intermedia. ${ }^{117}$ Esto tiene importancia en cuanto a la composición y tamaño del hogar, características que a su vez afectan a otras, tales como densidad de vivienda, personas económicamente activas, promedio de niños menores de 14 años y algunas más como se irá viendo oportunamente.

En los diferenciales que se han estudiado, se destacan las situaciones vinculadas a los inmigrantes recientes (1952-1962), las que se apartan de las de los otros dos grupos formados por nativos e inmigrantes de antes de 1952, los cuales generalmente no acusan diferencias destacadas entre sí. Tienen particular significación la comparación entre hogares de jefes nativos y de jefes inmigrantes recientes, por ser más comparables en razón de la composición por edades de tales jefes; en cambio, los inmigrantes más antiguos están representados por jefes de una edad promedio bastante más elevada, como es lógico que así sea.

Los resultados principales se pueden resumir como sigue:

Los hogares de jefes inmigrantes llegados en la última década poseen condiciones de vivienda más desfavorables que las correspondientes a hogares de jefes con otros status migratorios (nativos e inmigrantes de antes de 1952), lo que se verifica respecto del "tipo" de vivienda (materiales de construcción de la vivienda y clase de convivencia), los servicios (alcantarillado, agua, etc.) y el título de tenencia.

La densidad de personas por pieza habitación es más baja en los hogares con jefes inmigrantes recientes cuando se trata de hogares con relativamente pocos miembros (menos de siete), lo cual se verifica en general y en hogares con ciertas características, como son los hogares con pocas piezas y los hogares donde la densidad es por lo menos de dos personas por pieza. La explicación de esta menor densidad se encuentra, al menos parcialmente, en el menor tamaño promedio de los hogares con jefes inmigrantes recientes, lo que a su vez está relacionado con el tipo "unifamiliar" predominante. No obstante, en hogares con 7 y más miembros, son los que tienen jefes inmigrantes recientes los que acusan mayor densidad; lo cual podría pensarse como una expresión de las condiciones de vivienda de un sector de inmigrantes recientes que viven en grupos familiares numerosos, y que en este caso representan un 15 por ciento del total de los hogares con tales jefes (en hogares con jefes nativos, representan el 22 por ciento).

Entre los hogares con jefes inmigrantes recientes, es más elevada la proporción de hogares "unifamiliares", y también los formados por

117 Entre los jefes nativos se incluyó a los inmigrartes que llegaron antes de cumplir 14 años de edad. 
una pareja sin hijos o con hijos solteros únicamente. En esta característica, quizá por la analogía de edad de los jefes, se asemejan más a los hogares de jefes nativos que a los hogares de inmigrantes antiguos.

Así como los hogares con jefes inmigrantes recientes son de un tamaño promedio más pequeño que los otros, con una alta concentra. ción en los tamaños 3-4-5; también entre aquellos hogares se da la mayor proporción de hogares de una sola persona, y de hogares donde el jefe es una mujer con hijos solteros.

Por último, como es obvio, se encuentra una proporción más alta de personas inmigrantes en hogares con jefes inmigrantes recientes, lo cual se acentúa como diferencial respecto de hogares con jefes con otro status migratorio, al aumentar el número de miembros del hogar. En particular, en estos mismos hogares, en la mayoría de los casos, la mayor parte de los miembros ya habían nacido en la época de la migración y probablemente llegaron con el jefe del hogar.

Un miembro activo por hogar es la característica más frecuente, la que se acentúa en los hogares con jefe inmigrante reciente, lo cual de nuevo aparece vinculado al tipo "unifamiliar" prevaleciente y al menor tamaño promedio de estos hogares. Pero al mismo tiempo, en esta clase de hogares se encontró la más baja proporción de hogares sin miembros activos: la edad promedio más baja de estos jefes inmigrantes, respecto de inmigrantes antiguos, explica el sentido de dicho diferencial.

Los jefes inmigrantes gozaban de ingresos más bajos que los jefes nativos (excluyendo jefes sin ingresos personales), lo cual se advierte en la parłe derecha de la distribución de los jefes (tercer cuartil). Los ingresos de la mujer jefe de hogar también acusan un marcado diferencial desfavorable.

En conjunto, una de cada cinco esposas (jefes presentes) eran económicamente activas; esa proporción era algo menor (15 por ciento) en hogares con jefes inmigrantes recientes. En la mujer inmigrante esposa de jefe de hogar, la participación en actividades aumenta con la edad, de tal modo que en hogares con jefes menores de 30 años sólo participa I de cada 10 esposas. En general no se encontró que el nivel de participación de la esposa estuviera asociado al status migratorio combinado del jefe y su cónyuge.

En los hogares sin hijos, la participación de la esposa en actividades económicas no ofrece diferenciales según status migratorio del jefe del hogar. No obstante, en hogares con 1-2-3 hijos menores de 14 años, la participación es más baja en esposas de jefes inmigrantes recientes.

Por último, podría mencionarse que el promedio de hijos menores de 14, años (excluyendo hogares sin hijos de esta edad), es más bajo para las esposas de jefes inmigrantes recientes, tanto si las mujeres son 
activas o no. En consecuencia, no es claro que el número de hijos menores de 14 años puede tener un efecto desfavorable respecto del nivel de participación en actividad de las esposas con status inmigrante, de lo cual se deduce que tiene que haber otra explicación. No obstante, no se descarta que pueda existir un efecto dado por la edad promedio de los hijos menores de 14 años, ya que la edad tiene en general más importancia que el número de hijos menores, siendo importante la presencia de hijos menores de, por ejemplo, 5 años.

\section{Condiciones DE LA VIVIENDA}

Las condiciones de la vivienda están referidas, en este informe, al "tipo" de vivienda (como se lo define más adelante), los "servicios" de que dispone la misma, el título de "tenencia" del jefe de hogar y, finalmente, la "densidad" por pieza-habitación.

El "tipo" de vivienda responde a una clasificación que se basa tanto en los elementos físicos de la vivienda (principalmente a materiales de los muros), como en la clase de convivencia. (Véase el cuadro 75.) Ciertas formas de convivencia, como los cuartos ocupados por un hogar (en una casa donde vive, además, otro hogar), los conventillos y las pensiones, reflejan problemas de vivienda vinculados, con frecuencia, a los bajos ingresos y también probablemente, a la estabilidad social de los inmigrantes: personas que viven solas, familias que no encuentran vivienda independiente.

Los "servicios" (servicios higiénicos, de agua, de luz) completan el cuadro de las condiciones materiales.

La "tenencia" podría ser considerada como un indicador de estabilidad y de arraigo del inmigrante y en general de la capacidad de los. jefes de hogar para resolver el problema de la vivienda. En cuanto a la "densidad" por pieza, tambiẻn podría considerarse como un buen indicador, en una elevada proporción de casos, de distintas condiciones económico-sociales.

Las condiciones de vivienda son estudiadas en tres categorías de hogares, según el status migratorio del jefe: nativos, inmigrantes llegados antes de 1952 e inmigrantes llegados en el período 1952-1965. ${ }^{118}$ El objetivo principal del análisis que sigue recae sobre los diferenciales, si existen, de estas tres categorías de hogares.

a) Tipo de vivienda. En el cuadro 75 se presenta la distribución de los hogares según el tipo de vivienda. De acuerdo con la clasifica-

118 En las categorias de inmigrantes se incluye a los jefes llegados de 14 y más años de edad; los que lo hicieron antes de esa edad, en cualquier período de tiempo, están incorporados a los jefes nativos. 
LOS EFECTOS DEMOGRÁFICOS

CUADRo 75

TIPO DE VIVIENDA SEGUN EL STATUS MIGRATORIO DEL JEFE DE HOGARa

\begin{tabular}{lcccc}
\hline Tipo de vivienda & Total & Nativos & \multicolumn{2}{c}{ Inmigrantes del período } \\
\hline $\begin{array}{l}\text { Vivienda independiente en } \\
\text { edificio de material só- }\end{array}$ & 64,7 & 65,6 & 68,0 & 53,0 \\
$\begin{array}{l}\text { lidob } \\
\text { Piezas en viviendas multifa- } \\
\text { miliaresc }\end{array}$ & 15,5 & 15,2 & 13,1 & 22,4 \\
$\begin{array}{l}\text { Vivienda de material semi- } \\
\text { sólido y no permanented }\end{array}$ & 18,8 & 18,5 & 17,5 & 23,1 \\
$\begin{array}{l}\text { Otras viviendas y sin infor- } \\
\text { mación }\end{array}$ & 1,0 & 0,7 & 1,4 & 1,5 \\
\cline { 2 - 5 } & 100,0 & 100,0 & 100,0 & 100,0 \\
$\begin{array}{l}\text { Total } \\
\text { (Nómero de hogares) }\end{array}$ & $(2136)$ & $(1210)$ & $(645)$ & $(281)$ \\
\hline
\end{tabular}

a No incluye viviendas colectivas: hoteles, conventos, asilos, cárceles, pensiones con más de 6 pensionistas, etc., etc.

$\checkmark$ Casa de tipo unifamiliar, departamentos en casa de departamentos.

c Conventillos, pensiones, piezas en casas con dos o más hogares.

a "Callampas", chozas, construcciones provisionales, etc.

ción resumida en este cuadro, las condiciones de vivienda son peores para los hogares de inmigrantes recientes: 45 por ciento de estos hogares disponen de vivienda que podría calificarse de no satisfactoria, sea por el tipo de coexistencia (conventillo, piezas en casas que ocupan dos o más hogares, pensiones), sea por el material de construcción o su carácter temporario ("callampas", chozas, etc.), por partes iguales. En los hogares de jefes nativos y de jefes inmigrantes de antes de 1952, la proporción de hogares con vivienda no satisfactoria llegaría solamente a un tercio.

Examinando con mayor detalle el tipo de vivienda, se observa que la diferencia más significativa se registra respecto de viviendas en casas de tipo unifamiliar. Sólo 40 por ciento, aproximadamente, de los hogares de jefes inmigrantes de la última década vivía en esa clase de vivienda. La proporción fue de aproximadamente 50 por ciento en los demás hogares. También es de interés mencionar que mientras 17 por ciento de los hogares de aquellos inmigrantes estaba viviendo en "callampas", chozas y similares, la proporción fue consistentemente 14 por ciento en los grupos restantes de hogares. 
CuADro 76

SERVICIOS DISPONIBLES EN LA VIVIENDA, SEGUN EL STATUS MIGRATORIO DEL JEFE DE HOGARa

\begin{tabular}{lrrrr}
\hline Servicios $^{\mathrm{b}}$ & Total & Nativos & \multicolumn{2}{c}{ Inmigrantes del período } \\
\cline { 3 - 5 } & & \multicolumn{4}{c}{ Antes de 1952 } & 1952-1962 \\
\hline & 71,3 & 71,9 & 73,4 & 64,0 \\
Agua, luz y alcantarillado & 16,9 & 16,7 & 16,4 & 18,9 \\
Agua y luz & 4,3 & 3,9 & 4,0 & 6,8 \\
Luz solamente & 7,5 & 7,5 & 6,2 & 10,3 \\
Sin informaciónd & 100,0 & 100,0 & 100,0 & 100,0 \\
Total & $(2136)$ & $(1210)$ & $(645)$ & $(281)$ \\
(Número de hogares) & $(210)$ &
\end{tabular}

a Véase la nota $a$ del cuadro 75.

b Agua o alcantarillado o ambas cosas en la vivienda, o fuera de la vivienda, pero dentro del edificio.

c Diez por ciento, aproximadamente, de estas cifras con sólo agua.

d En su mayoría viviendas sin servicios o con servicios muy limitados.

b) Servicios. Los servicios disponibles en la vivienda confirman los resultados anteriores. Aproximadamente en un 36 por ciento de las viviendas ocupadas por hogares de jefes inmigrantes recientes, faltan parcial o totalmente los servicios básicos (agua, alcantarillado, luz). (Véase el cuadro 76.) En los hogares de jefes nativos y de jefes inmigrantes de antes de 1952, se encontraba en esas condiciones aproximadamente el 27 por ciento.

Podría considerarse que más del 10 por ciento de las viviendas observadas carecen de los servicios señalados o sólo disponen de uno de ellos (luz o agua). Entre estas viviendas se incluyen aquellas que aparecen en el cuadro 76 sin información respecto de los servicios (algo más del 7 por ciento del total), pero de las cuales se sabe que no menos de $2 / 3$ son "callampas" o chozas. Tomando los hogares que viven en esta situación, nuevamente son los que tienen jefes inmigrantes recientes (17 por ciento), los que están en desventaja respecto a los hogares restantes (11 por ciento).

c) Tenencia. En el 39 por ciento de los hogares observados, el jefe de hogar declaró ser propietario. Probablemente esta cifra sobreestima la realidad, en cuanto que incluye a las viviendas de material no permanente ("callampas", chozas, etc.) cuyos ocupantes en su mayoría es probable que no sean propietarios del suelo. En efecto, en 
Cuadro 77

TENENCIA DE LA VIVIENDA, SEGUN EL STATUS MIGRATORIO DEL JEFE DE HOGAR

\begin{tabular}{lrrrr}
\hline Tenencia de la vivienda & Total & Nativos & \multicolumn{2}{c}{ Inmigrantes del periodo } \\
\cline { 4 - 6 } & & \multicolumn{4}{c}{ (Porcentajes) } \\
\hline & 39,0 & 40,4 & 44,7 & 19,9 \\
Propietarios & 51,1 & 50,1 & 46,0 & 66,6 \\
Arrendatarios & 7,0 & 6,7 & 6,4 & 10,0 \\
Usufructuarios & 2,5 & 2,4 & 2,6 & 2,8 \\
Ocupantes de hecho & 0,4 & 0,4 & 0,3 & 0,7 \\
Otras situaciones y situacio- & 100,0 & 100,0 & 100,0 & 100,0 \\
nes no bien establecidas & $(2136)$ & $(1210)$ & $(645)$ & $(281)$ \\
Totales & &
\end{tabular}

a Incluye subarrendatarios. Los subarrendatarios constituyen, aproximadamente, el 5 por ciento de la cifra consignada.

relación a esie último punto, la proporción de ocupantes de hecho $(2,5$ por ciento) no guarda relación, por ejemplo, con la importancia relativa de las viviendas de material semi-sólido y no permanente (19 por ciento). (Véase el cuadro 77.)

Se observó uua importante diferencia en relación al status migratorio del jefe de hogar. Apenas un quinto de los jefes inmigrantes recientes eran propietarios contra dos quintos de los jefes con otro status. (Véase el cuadro 77.) Estas cifras reflejan de cerca la situación de los jefes de hogares unifamiliares. Por lo contrario, las categorías de arrendatarios y de usufructuarios (probablemente muchos de los últimos eran "ocupantes de hecho"), son más frecuentes entre los jefes inmigrantes recientes (77 por ciento).

d) Densidad por pieza-habitación. La densidad media resultante fue de 1,4 personas por pieza; valor sensiblemente igual al encontrado en hogares de jefes de distinto status migratorio. (Véase el cuadro 78.)

Esta densidad media relativamente baja resulta inadecuada para informar sobre las condiciones que soportan muchos hogares.

La densidad varía, en primer lugar, en relación directa con el número de miembros del hogar. La densidad media corresponde, aproximadamente, a la de hogares con 5 miembros, y a partir de hogares con 7 miembros, la densidad sobrepasa las dos personas por pieza, de modo que en los hogares más numerosos se llega a densidades próximas a cuatro personas por pieza. En el cuadro 78 se proporcionan las densi- 
dades medias según el número de miembros del hogar y según el status migratorio del jefe. De acuerdo con esa información, los hogares de jefes inmigrantes recientes tenían, en hogares con más de 6 miembros, densidades más altas que los hogares de jefes con otro status. En segun. do lugar, la densidad variaba en relación inversa al número de piezas disponibles. En consecuencia, es interesante estudiar qué ocurría en viviendas con una y dos piezas. En los hogares con una pieza, la den. sidad llegó a 4,3 personas en los hogares de jefes nativos y, en el caso más favorable, a 3,2 personas en los hogares de jefes inmigrantes con anterioridad a 1952. Cabe señalar que los hogares con una pieza representaban el 15 por ciento de todos los hogares observados, proporción que varía poco según el status migratorio del jefe.

En los hogares con dos piezas ( 23 por ciento del total, con similar proporción según el status migratorio del jefe), la densidad fue de 2,3 personas, no advirtiéndose diferenciales en hogares de jefes con distinto

Cuapro 78

DENSIDAD POR PIEZA-HABITACION, SEGUN EL TAMAÑO DEL HOGAR Y SEGUN EL STATUS MIGRATORIO DEL JEFE

\begin{tabular}{|c|c|c|c|c|c|c|c|}
\hline \multirow{3}{*}{\multicolumn{2}{|c|}{$\begin{array}{l}\text { Número } \\
\text { de personas } \\
\text { en el hogar }\end{array}$}} & \multicolumn{3}{|c|}{$\begin{array}{l}\text { Promedia de personas } \\
\text { por pieza }\end{array}$} & \multicolumn{3}{|c|}{$\begin{array}{l}\text { Promedio de personas por pieza, } \\
\text { de hogares con menos de } 7 \text { piezas }\end{array}$} \\
\hline & & \multirow{2}{*}{ Nativos } & \multicolumn{2}{|c|}{$\begin{array}{l}\text { Inmigrantes } \\
\text { del período }\end{array}$} & \multirow{2}{*}{ Nativos } & \multicolumn{2}{|c|}{$\begin{array}{l}\text { Inmigrantes } \\
\text { del período }\end{array}$} \\
\hline & & & $\begin{array}{c}\text { Antes } \\
\text { de } 1952 \\
\end{array}$ & $1952-1962$ & & $\begin{array}{r}\text { Antes } \\
\text { de } 1952 \\
\end{array}$ & $1952-1962$ \\
\hline & 1 & 0,4 & 0,7 & 0,4 & 0,4 & 0,4 & 0,7 \\
\hline & 2 & 0,6 & 0,7 & 0,6 & 0,7 & 0,7 & 0,7 \\
\hline & 3 & 1,0 & 0,9 & 1,1 & 1,1 & 1,0 & 1,1 \\
\hline & 4 & 1,2 & 1,1 & 1,2 & 1,3 & 1,2 & 1,1 \\
\hline & 5 & 1,4 & 1,3 & 1,5 & 1,5 & 1,4 & 1,6 \\
\hline & 6 & 1,7 & 1,5 & 1,5 & 1,9 & 1,8 & 1,6 \\
\hline & 7 & 1,9 & 1,9 & 2,5 & 2,1 & 2,0 & 2,9 \\
\hline & 8 & 2,1 & 2,3 & 3,1 & 2,4 & 2,4 & 3,1 \\
\hline & 9 & 2,7 & 2,7 & 4,5 & 2,9 & 2,7 & 4,5 \\
\hline & 10 & 2,8 & 2,6 & 3,6 & 3,0 & 2,9 & 3,6 \\
\hline & 11 & 3,1 & - & 2,8 & 3,3 & - & 2,8 \\
\hline & y más & 3,9 & 3,1 & 4,3 & 4,1 & 3,4 & 4,3 \\
\hline $\operatorname{los}$ & $\begin{array}{l}\text { Гodos } \\
\text { hogares }\end{array}$ & 1,47 & 1,37 & 1,43 & 1,50 & 1,44 & 1,49 \\
\hline
\end{tabular}

a No incluye sirvientes domésticos. 
Cuadro 79

DENSIDAD POR PIEZA-HABITACION, EN HOGARES DE UNA, DOS Y TRES PIEZAS, SEGUN STATUS MIGRATORIO DEL JEFEa

\begin{tabular}{|c|c|c|c|c|c|c|}
\hline \multirow{3}{*}{$\begin{array}{l}\text { Número } \\
\text { de piezas- } \\
\text { habitación } \\
\text { del hogar }\end{array}$} & \multirow{3}{*}{$\begin{array}{r}\text { Promedio de } \\
\text { Nativos }\end{array}$} & \multirow{2}{*}{\multicolumn{2}{|c|}{$\begin{array}{c}\text { personas por hogar } \\
\begin{array}{l}\text { Inmigrantes } \\
\text { del período }\end{array}\end{array}$}} & \multicolumn{3}{|c|}{$\begin{array}{l}\text { Promedio de personas en hogares } \\
\text { con más de } 2 \text { personas por pieza- } \\
\text { habitación }\end{array}$} \\
\hline & & & & \multirow{2}{*}{ Nativos } & \multicolumn{2}{|c|}{$\begin{array}{l}\text { Inmigrantes } \\
\text { del período }\end{array}$} \\
\hline & & $\begin{array}{l}\text { Antes } \\
\text { de } 1952\end{array}$ & $1952-62$ & & $\begin{array}{c}\text { Antes } \\
\text { de } 1952\end{array}$ & $1952-62$ \\
\hline 1 & 4,3 & 3,2 & 3,8 & 5,1 & 4,8 & 4,7 \\
\hline 2 & 4,7 & 4,5 & 4,6 & 6,7 & 6,7 & 6,5 \\
\hline 3 & 5,4 & 5,1 & 4,6 & 8,9 & 8,9 & 7,7 \\
\hline
\end{tabular}

a No incluye sirvientes domésticos.

status migratorio. En resumen, en el 38 por ciento de los hogares investigados - aquellos que tenían una o dos piezas solamente-, la densidad es alta y en sentido favorable para los hogares de jefes inmigrantes. (Véase el cuadro 79.)

Es posible individualizar hogares donde el hacinamiento es todavía mayor: los hogares con 1,2,3 piezas, donde hay dos o más personas por pieza. Tales hogares constituyen el 26 por ciento de todos los observados, repartidos en 10, 11 y 5 por ciento, respectivamente, según tengan 1, 2 ó 3 piezas. Las densidades por pieza eran, aproximadamente, de 5 personas en los hogares con una pieza; de 3,3 en los hogares con dos piezas, y de 2,9 personas en los hogares con tres piezas. La tendencia fue un promedio por pieza levemente más bajo en los hogares de inmigrantes recientes. (Véase el cuadro 79.)

\section{Estructura deL Hogar}

a) Tipo y composición del hogar. Bajo la expresión tipo de hogar se clasifican los hogares según que estén formados por una familia, por dos o más familias o por varias personas (puede ser una sola persona) que no forman familia. La unidad de referencia, es, entonces, la familia. ${ }^{110}$

119 Desde este punto de vista los hogares se clasifican en: unifamiliares, multifamiliares, hogares con familia secundaria exclusivamente, hogares sin familias, y hogares en viviendas colectivas. (Véanse las respectivas definiciones en la nota del cuadro 80.) 
Cuadro 80

TIPO DE HOGAR SEGUN EL STATUS MIGRATORIO DEL JEFE

\begin{tabular}{|c|c|c|c|c|}
\hline \multirow[b]{2}{*}{ Tipo de hogar } & \multirow[b]{2}{*}{ Total } & \multirow[b]{2}{*}{ Nativos } & \multicolumn{2}{|c|}{ Inmigrantes del período } \\
\hline & & & $1952-62$ & $\begin{array}{c}\text { Antes } \\
\text { de } 1952\end{array}$ \\
\hline Hogar unifamiliar & 74,2 & 73,7 & 80,1 & 72,5 \\
\hline Hogar multifamiliar & 10,6 & 11,3 & 6,4 & 11,0 \\
\hline $\begin{array}{l}\text { Hogar con familia secunda. } \\
\text { ria exclusivamente }\end{array}$ & 3,3 & 3,6 & 2,8 & 3,1 \\
\hline Hogar sin familias & 10,1 & 10,1 & 6,8 & 11,5 \\
\hline Hogar en vivienda colectiva & 1,8 & 1,3 & 3,9 & 1,9 \\
\hline Total & $\begin{array}{c}100 \\
(2136)\end{array}$ & $\begin{array}{c}100 \\
(1210)\end{array}$ & $\begin{array}{l}100 \\
(281)\end{array}$ & $\begin{array}{c}100 \\
(645)\end{array}$ \\
\hline
\end{tabular}

a "Unifamiliar": es el hogar donde hay un solo núcleo familiar, que es la familia principal o del jefe del hogar. El jefe forma "familia principal" si vive con su esposa (o compañera) o, en su defecto, con hijos solteros (o menores a cargo).

"Multifamiliar": es el hogar donde, además de la "familia principal", viven una o varias "familias secundarias". La "familia secundaria" está integrada por una pareja (excepto la formada por el jefe del hogar), o por un padre (o madre) con hijos solteros (o menores a cargo).

"Familia secundaria exclusivamente": es el hogar donde hay una o varias "familias secundarias", pero no hay "familia principal".

"Sin familia": es el hogar donde no hay "familia principal" ni "familias secundarias".

"En vivienda colectiva": es el hogar que vive en una "residencial" o "pensión".

A su vez, con el término composición del hogar, los hogares son clasificados, principalmente, por las personas que componen el núcleo familiar del jefe del hogar. ${ }^{120}$

En el 70,8 por ciento de los hogares investigados se encontró una pareja principal sin hijos o con hijos solteros. Una proporción casi equivalente $(74,2$ por ciento) son hogares de tipo unifamiliar. Sin embargo, los hogares con una pareja principal (sin hijos o con hijos solteros) no son todos los hogares unifamiliares aunque sí lo es la gran mayoría (93,4 por ciento). También representan una elevada proporción los hogares unifamiliares en aquellos hogares donde el jefe (sin esposa/o o compañera/o) vive con hijos solteros.

120 Por ejemplo: pareja principal (del jefe) sin hijos; pareja principal con hijos solteros; pareja principal con hijos solteros o casados, o de ambos, etc., etc. Véase la enumeración completa en cuadro 81. 
Por otra parte, como se esperaba que ocurriera, en los hogares donde hay hijos casados del jefe, la proporción de hogares multifamiliares es elevada: casi 90 por ciento en hogares donde hay una pareja principal e hijos casados.

Finalmente, los hogares con familia secundaria exclusivamente y los hogares sin familias, corresponden en su mayoría a hogares donde no hay pareja principal ni jefes con hijos solteros.

Estas pocas cifras sirven para mostrar que existe una buena coherencia en las definiciones de "tipo" y de "composición" del hogar, así como en la información respectiva obtenida.

Como ya se dijo en líneas anteriores, el 74,2 por ciento de los hogares investigados son unifamiliares. Un 20 por ciento adicional se divide en partes iguales entre hogares multifamiliares y hogares sin familias. (Véase el cuadro 80.) Los hogares con jefes inmigrantes de la última década se diferencian de los otros dos grupos por la más alta proporción de hogares unifamiliares (80,1 por ciento). Adicionalmente, también se diferencian por la menor proporción de hogares sin familias.

Considerando ahora la composición del hogar, como también se anticipó, el 70,8 por ciento de ellos tiene una pareja principal, sin hijos o con hijos solteros. Los hogares donde no hay pareja principal ni jefes con hijos (solteros o casados), forman el grupo que sigue en orden de importancia con el 8,1 por ciento. El tercer grupo - 7 por ciento- está integrado por hogares cuyo jefe es una mujer con hijos solteros. El 14, I por ciento restante está distribuido entre las otras clases de la composición del hogar. (Véase el cuadro 81.)

Como aspecto diferencial digno de señalar, se menciona la relativamente baja proporción de hogares con una pareja principal, sin hijos o con hijos solteros, entre los hogares cuyo jefe es un inmigrante llegado antes de 1952 (65,0 por ciento). Ello podría tener una explicación por la edad media más alta de los jefes con este siatus, comparada con la edad media de los jefes nativos y los jefes inmigrantes llegados en el período 1952-1962. En armonía con el resultado señalado, la proporción de hogares con pareja principal e hijos casados es más elevada (7,3 por ciento) en los hogares cuyos jefes inmigraron con anterioridad a 1952. (Véase el cuadro 81.)

También vale la pena señalar que la proporción de hogares con jefe mujer e hijos solteros es más importante en los hogares donde la mujer es inmigrante, en particular si es una inmigrante de la última década, que en los hogares donde la mujer es nativa. (Véase el cuadro 81.)

Otra observación, es que la proporción de hogares con jefe solo, es más alta en los hogares con jefes inmigrantes $(6,0$ a 6,8 por ciento) que en los hogares de jefes nativos ( 4,5 por ciento). 
Cuadro 81

COMPOSICION DEL HOGAR SEGUN EL STATUS MIGRATORIO DEL JEFE

\begin{tabular}{|c|c|c|c|c|}
\hline \multirow[b]{2}{*}{ Composición del hogar } & \multirow[b]{2}{*}{ Total } & \multirow[b]{2}{*}{ Nativos } & \multicolumn{2}{|c|}{ Inmigrantes del período } \\
\hline & & & $1952-62$ & $\begin{array}{c}\text { Antes } \\
\text { de } 1952\end{array}$ \\
\hline $\begin{array}{l}\text { a) Pareja principal a sin hi- } \\
\text { jos o con hijos solteros } \\
\text { en el hogar }\end{array}$ & 70,8 & 73,1 & 74,4 & 65,0 \\
\hline $\begin{array}{l}\text { b) Jefe (sin esposa o com- } \\
\text { pañera) con hijos solte- } \\
\text { ros en el hogar }\end{array}$ & 1,3 & 0,8 & 0,7 & 2,3 \\
\hline $\begin{array}{l}\text { c) Jefe mujer, con hijos } \\
\text { solteros en el hogar }\end{array}$ & 7,0 & 5,7 & 10,0 & 8,2 \\
\hline $\begin{array}{l}\text { d) Pareja principal, con hi- } \\
\text { jos solteros o casados o } \\
\text { ambos en el hogar }\end{array}$ & 5,2 & 4,5 & 3,2 & 7,3 \\
\hline $\begin{array}{l}\text { e) Jefe ( } \sin \text { esposa/o, o } \\
\text { compañera } / o) \text { con hijos } \\
\text { solteros o casados o am- } \\
\text { bos en el hogar }\end{array}$ & & & & \\
\hline $\begin{array}{l}\text { bos en el hogar } \\
\text { f) Jefe (sin esposa/o, o } \\
\text { compañera/o), sin hijos } \\
\text { en el hogar, con otras } \\
\text { personas (parientes o }\end{array}$ & 2,1 & 2,0 & - & 3,2 \\
\hline no) & 8,1 & 9,3 & 5,7 & 7,0 \\
\hline g) Jefe solo & 5,4 & 4,5 & 6,0 & 6,8 \\
\hline $\begin{array}{l}\text { h) Otra composición o com. } \\
\text { posición no bien estable- } \\
\text { cida }\end{array}$ & 0,1 & 0,1 & - & 0,2 \\
\hline Total & $\begin{array}{c}100 \\
(2136)\end{array}$ & $\begin{array}{c}100 \\
(1210)\end{array}$ & $\begin{array}{c}100 \\
(281)\end{array}$ & $\begin{array}{c}100 \\
(645)\end{array}$ \\
\hline
\end{tabular}

a Jefe y esposa (o compañera).

Las observaciones anteriores podrían resumirse como sigue: 1) la estructura (tipo y composición) es más simple en los hogares donde el jefe es un inmigrante de la última década, por el mayor predominio que en los otros grupos, de los hogares unifamiliares y de los hogares compuestos por una pareja principal sin hijos o con hijos solteros en el hogar; 2) la más baja proporción de hogares sin familias en los hogares cuyo jefe tiene el status migratorio antes indicado, conjuntamente con la observación 1), colocaría a los jefes inmigrantes 
recientes en mejor posición desde el punto de vista de la organización familiar; 3) los hogares con jefes inmigrantes de antes de 1952 presentan la más alta proporción de hogares de estructura compleja (véase el cuadro 8l, categorías $d]$ y $f]$ ), seguido por los hogares con jefes nativos; 4) en los hogares con jefe inmigrante se encontró una proporción más alta de hogares compuestos por el jefe solo; 5) la presencia de jefe mujer con hijos solteros es más frecuente en los hogares con jefe inmigrante. ${ }^{121}$

b) Tamaño del hogar. El promedio de personas por hogar fue de 4,9 . Dicho valor alcanza a 5,0 en los hogares de jefes nativos, 4,8 en los de jefes inmigrantes llegados antes de 1952 y sólo a 4,4 en los hogares de jefes inmigrantes de la última década. En estos últimos hogares se advierte una concentración más alta de hogares de tamaño medio, ya que los de 3,4 ó 5 personas representan el 56,2 por ciento del total, en tanto que en los otros dos grupos con jefes de otros status, representan sólo el 46,9 por ciento en cada caso.

La mayor concentración de familias numerosas (6 y más miembros) se encuentra en los hogares de jefes nativos, y la mayor concentración de familias pequeñas (1-2 miembros) en los hogares de jefes inmigrantes de antes de 1952 . Al margen de las diferencias señaladas, los hogares se distribuyen en forma regular y según un modelo semejante para los tres grupos de hogares que se comparan, modelo que podría describirse como una curva asimétrica hacia la izquierda, cuyo valor modal cae cerca de 4 .

La mayor densidad del tamaño 3-4-5, observada en los hogares de jefes inmigrantes recientes, es una característica de los hogares unifamiliares, donde la densidad llega al 61,8 por ciento. (Véanse los cuadros 82 y 84 ).

Si se observa lo que ccurre en otros ïipos de hogares, no se encuentran evidencias que permitan descubrir una distribución diferencial según varie el status migratorio del jefe. Esto es válido para los hogares multifamiliares y para los hogares sin familias, los dos tipos de hogares que siguen en importancia numérica, aunque a considerable dislancia, como se ha visto en la sección anterior, a los hogares unifamiliares. (Véase el cuadro 84.)

No obstante, un análisis, al parecer más adecuado, permite descubrir que habría un tamaño diferencial en los hogares muliifamiliares, en el sentido de que también los hogares de este tipo con jefes inmi-

121 Estas mismas conclusiones y probablemente otras podrían sacarse de la tabulación cruzada del tipo de hogar y de la composición. Sin embargo, en este estudio, el pequeño número de casos de algunos marginales no permite un análisis directo más profundo. 
grantes recientes presentan un tamaño más pequeño que los otros hogares multifamiliares. En el cuadro 83 se presentan valores medianos de hogares de todos los tipos, de hogares unifamiliares y de hogares multifamiliares. En los tres casos, la mediana más pequeña corresponde a hogares de jefes del status mencionado. Tratándose de hogares multifamiliares la mediana de este grupo de jefes es 5,9, mientras que la correspondiente a jefes nativos es 6,7. En los hogares unifamiliares las medianas correspondientes son 3,8 y 4,2 , valores que coinciden prácticamente con las medianas calculadas para todos los hogares en conjunto.

El tamaño del hogar está asociado a su composición. En el cuadro 85 figuran promedios de personas en hogares con diversa composición, según el status migratorio del jefe. Los hogares de tamaño medio más grande corresponden a aquellos donde hay hijos casados que viven con el jefe, especialmente aquellos donde hay una pareja principal (casi 8 personas por hogar) $y$, en segundo lugar, los hogares donde hay una pareja principal sin hijos o con hijos solteros, cuyos promedios están ligeramente sobre los promedios generales. Como característica diferencial debe señalarse el tamaño más pequeño de esta clase de hogar (pareja principal, sin hijos o con hijos solteros) cuando el jefe es un

CUADRo 82

DISTRIBUCION DE LOS HOGARES POR SU TAMAÑO, SEGUN EL STATUS MIGRATORIO, DEL JEFE

\begin{tabular}{ccccc}
\hline \multirow{2}{*}{$\begin{array}{c}\text { Número de personas } \\
\text { en el hogar }\end{array}$} & Total & Nativos & \multicolumn{2}{c}{ Porcentaje de hogares de jefes } \\
\cline { 2 - 5 } & & & $1952-62$ & Antes de 1952 \\
\hline 1 & 5,4 & 4,5 & 6,0 & 6,8 \\
2 & 12,1 & 11,6 & 11,0 & 13,3 \\
3 & 14,7 & 12,7 & 19,2 & 16,6 \\
4 & 16,8 & 18,0 & 18,9 & 13,7 \\
5 & 16,6 & 16,2 & 18,1 & 16,6 \\
6 & 12,5 & 13,3 & 12,1 & 11,3 \\
7 & 7,3 & 7,3 & 7,1 & 7,3 \\
8 & 5,3 & 5,9 & 3,6 & 5,0 \\
9 & 3,6 & 4,7 & 0,7 & 2,6 \\
10 & 2,7 & 3,1 & 1,8 & 2,3 \\
11 & 1,1 & 1,2 & 0,4 & 1,4 \\
12 y más & 1,9 & 1,5 & 1,1 & 3,1 \\
\hline Total & 100 & 100 & 100 & 100 \\
& $(2136)$ & $(1210)$ & $(281)$ & $(645)$ \\
\hline
\end{tabular}


Cuadro 83

NUMERO MEDIANO DE PERSONAS EN EL HOGAR, SEGUN TIPO DE HOGAR Y SEGUN STATUS MIGRATORIO DEL JEFE

\begin{tabular}{|c|c|c|c|c|c|c|}
\hline \multirow{3}{*}{ Tipo de hogar } & \multicolumn{6}{|c|}{ Número mediano de personas en hogares con jefe } \\
\hline & \multirow{2}{*}{ Total } & \multirow{2}{*}{ Nativos } & \multicolumn{4}{|c|}{ Inmigrantes de } \\
\hline & & & $1952-62$ & Antes & $\mathrm{de}$ & 1952 \\
\hline Todos los tipos ${ }^{\mathbf{a}}$ & 4,1 & 4,2 & 3,7 & & 4,0 & \\
\hline Unifamiliar & 4,1 & 4,2 & 3,9 & & 4,0 & \\
\hline Multifamiliar & 6,5 & 6,7 & 5,9 & & 6,5 & \\
\hline
\end{tabular}

a Incluye hogares de tipo no detallado en el cuadro.

inmigrante reciente (lo cual podía anticiparse considerando lo que se dijo para los hogares unifamiliares, los que en su gran mayoría tienen esa composición). También es menor el tamaño medio de los hogares de jefes de inmigrantes recientes que responden a la composición de pareja principal con hijos casados (lo cual tiene su correspondencia con lo observado para los hogares multifamiliares) ; pero el valor 7,3 correspondiente a tales hogares, se apoya sólo en la observación de nueve hogares y por consiguiente no podría asignarse valor a este diferencial.

Las observaciones principales relativas al tamaño del hogar se resumen como sigue: $a$ ) el promedio de personas - que para el conjunto es de cinco- de los hogares de jefes inmigrantes de la última década es, aproximadamente, 10 por ciento más pequeño que el promedio de los hogares de jefes con otro siatus migratorio; $b$ ) ello es el efecto, principalmente, de lo que acontece en los hogares unifamiliares, y también, por consiguiente, de lo que se observa en los hogares compuestos por una pareja principal sin hijos o con hijos solteros; c) la concentración del número de hogares "unifamiliares" en los tamaños 3-4-5, es más alta $(61,8$ por ciento) en los hogares de jefes inmigrantes de la última década.

c) Composición del hogar según el status migratorio. ${ }^{122}$ En tres de cada cuatro hogares hay por lo menos un inmigrante. Esta realidad

122 Las cifras analizadas excluyen a los sirvientes domésticos, los que no han sido considerados para determinar el tamaño del hogar ni, por consiguiente, la proporción de inmigrantes en los mismos. Por otra parte, se incluye como tales a todos los inmigrantes, cualquiera que sea la edad que tenían al tlegar al Gran Santiago. Sin embargo, la definición de jefe inmigrante sólo aleanza a aquellos que llegaron después de cumplir 14 años de edad; los jefes que inmigraron a una edad más temprana están juntos con los jefes nativos. 


\section{Cuadro 84:}

DISTRIBUCION DE HOGARES POR SU TAMAÑO, SEGUN TIPO DE HOGAR Y SEGUN STATUS MIGRATORIO DEL JEFE

\begin{tabular}{|c|c|c|c|c|c|}
\hline & \multirow{3}{*}{$\begin{array}{l}\text { Tipo de hogar y número } \\
\text { de personas en el hogar }\end{array}$} & \multicolumn{4}{|c|}{ Porcentaje de hogares con jefe } \\
\hline & & \multirow[b]{2}{*}{ Total } & \multirow[b]{2}{*}{ Nativos } & \multicolumn{2}{|c|}{ Inmigrantes de } \\
\hline & & & & $1952-62$ & $\begin{array}{c}\text { Antes } \\
\text { de } 1952\end{array}$ \\
\hline 1) & Hogar unifamiliar & 100 & 100 & 100 & 100 \\
\hline & $\begin{array}{l}1-2 \\
3-5 \\
6 \text { y más }\end{array}$ & $\begin{array}{l}11,2 \\
55,3 \\
33,5\end{array}$ & $\begin{array}{l}10,1 \\
54,4 \\
35,5\end{array}$ & $\begin{array}{l}11,6 \\
61,8 \\
26,6\end{array}$ & $\begin{array}{l}13,5 \\
53,6 \\
32,9\end{array}$ \\
\hline 2) & Hogar multifamiliar & 100 & 100 & 100 & 100 \\
\hline & $\begin{array}{l}1 \cdot 2 \\
3 \cdot 5 \\
6 \text { y más }\end{array}$ & $\begin{array}{r}- \\
19,5 \\
80,5\end{array}$ & $\begin{array}{l}\overline{-} \\
17,5 \\
82,5\end{array}$ & $\begin{array}{l}\overline{16,6} \\
83,4\end{array}$ & $\begin{array}{r}- \\
23,9 \\
76,1\end{array}$ \\
\hline 3) & $\begin{array}{l}\text { Hogar con familia secundaria } \\
\text { exclusivamente }\end{array}$ & 100 & 100 & 100 & 103 \\
\hline & $\begin{array}{l}1-2 \\
3-5 \\
6 \text { y más }\end{array}$ & $\begin{array}{r}- \\
77,8 \\
22,2\end{array}$ & $\begin{array}{r}- \\
72,7 \\
27,3\end{array}$ & $\frac{-}{100}$ & $\begin{array}{l}- \\
80,0 \\
20,0\end{array}$ \\
\hline 4) & Hogar sin familias & 100 & 100 & 100 & 100 \\
\hline & $\begin{array}{l}1-2 \\
3-5 \\
6 \text { y más }\end{array}$ & $\begin{array}{r}81,4 \\
17,2 \\
1,4\end{array}$ & $\begin{array}{r}81,8 \\
16,5 \\
1,7\end{array}$ & $\begin{array}{r}79,0 \\
21,0 \\
-\end{array}$ & $\begin{array}{r}81,1 \\
17,6 \\
1,3\end{array}$ \\
\hline & Hogar en vivienda colectiva & 100 & 100 & 100 & 100 \\
\hline & $\begin{array}{l}1 \cdot 2 \\
3 \cdot 5 \\
6 \text { y más }\end{array}$ & $\begin{array}{r}52,6 \\
39,5 \\
7,9\end{array}$ & $\begin{array}{l}40,0 \\
40,0 \\
20,0\end{array}$ & $\begin{array}{r}63,6 \\
36,4 \\
-\end{array}$ & $\begin{array}{r}58,3 \\
41,7 \\
-\end{array}$ \\
\hline & Todos los tipos & 100 & 100 & 100 & 100 \\
\hline & $\begin{array}{l}1-2 \\
3-5 \\
6 \text { y más }\end{array}$ & $\begin{array}{l}17,5 \\
48,1 \\
34,4\end{array}$ & $\begin{array}{l}16,1 \\
46,9 \\
37,0\end{array}$ & $\begin{array}{l}17,0 \\
56,2 \\
26,8\end{array}$ & $\begin{array}{l}20,1 \\
46,9 \\
33,0\end{array}$ \\
\hline
\end{tabular}


Cuadro 85

PROMEDIO DE PERSONAS POR HOGAR, SEGUN COMPOSICION DEL HOGAR Y STATUS MIGRATORIO DEL JEFE

\begin{tabular}{|c|c|c|c|c|}
\hline \multirow{3}{*}{$\begin{array}{l}\text { Composición } \\
\text { del hogar }\end{array}$} & \multicolumn{4}{|c|}{ Promedio de personas en el hogar con jefe } \\
\hline & \multirow[b]{2}{*}{ Total } & \multirow[b]{2}{*}{ Nativos } & \multicolumn{2}{|c|}{ Inmigrantes de } \\
\hline & & & $1952 \cdot 62$ & $\begin{array}{c}\text { Antes } \\
\text { de } 1952\end{array}$ \\
\hline (a) $(1-2)$ & 5,2 & 5,3 & 4,8 & 5,1 \\
\hline (b) $(3)(\mathrm{H})$ & 4,2 & $3,8^{a}$ & $\ldots b$ & 4,3 \\
\hline (c) (3) (H) & 3,9 & 4,1 & 3,6 & 3,7 \\
\hline (d) (4) & 7,8 & 7,7 & $7,3^{\mathrm{c}}$ & 8,0 \\
\hline (c) (5) & 6,8 & 7,0 & - & 6,6 \\
\hline (f) $(6.7)$ & 3,4 & 3,5 & 3,4 & 3,3 \\
\hline$(g)(8)$ & 1,0 & 1,0 & 1,0 & 1,0 \\
\hline (h) $(x)$ & - & $-b$ & - & $\longrightarrow$ \\
\hline Total & 4,9 & 5,0 & 4,4 & 4,8 \\
\hline
\end{tabular}

a Véase el cuadro 81. b 10 hogares. c Menos de 3 hogares. d 9 hogares.

adquiere mucha significación si se considera que por lo menos 9 de cada 10 inmigrantes eran personas mayores de 15 años. Si a esto se agrega la observación de que la mayoría de los hogares son de tipo unifamiliar (básicamente formados por una pareja sin hijos o con hijos solteros), se puede deducir que en una proporción elevada de hogares hay un inmigrante adulto, y que éste es frecuentemente el jefe o su esposa (o compañera)..$^{123}$

En efecto, un indicador de la presencia de un miembro importante del hogar con status de inmigrante, lo es la proporción, 43,3 por ciento, de jefes inmigrantes. $Y$ en los restantes hogares, de jefes nativos, el 59,0 por ciento de ellos tiene por lo menos un inmigrante, y en una parte importante de los mismos la esposa (o compañera) es inmigrante. ${ }^{124}$ En conclusión, aproximadamente en dos de cada tres hogares el jefe o la esposa (compañera) o ambos son inmigrantes.

$A$ fin de precisar qué importancia numérica tienen los inmigrantes respecto del total de personas que forman el hogar, en relación al status

123 Sobre 2136 hogares observados, en 1641 de ellos hay por lo menos un inmigrante.

124 Aproximadamente, son inmigrantes el 25 por ciento de las esposas (comyañeras) de jefes no inmigrantes con cónyuge presente en el hogar. 
Cuadro 86

PORCENTAJE DE MIEMBROS INMIGRANTES,a SEGUN TAMAÑO DEL HOGAR Y STATUS MIGRATORIO DEL JEFE

\begin{tabular}{cccc}
\hline & \multicolumn{3}{c}{ Inmigrantes por 100 personas } \\
\cline { 2 - 4 } Personas & & \multicolumn{2}{c}{ Inmigrantes de $b$} \\
\cline { 2 - 4 } & Nativos & $1952-62$ & Antes de 1952 \\
\cline { 3 - 4 } 1 & 20,4 & 100 & 100 \\
2 & 36,5 & 85,5 & 80,8 \\
3 & 27,9 & 72,2 & 69,2 \\
4 & 23,8 & 77,8 & 53,4 \\
5 & 18,8 & 69,0 & 45,0 \\
6 & 18,9 & 64,7 & 42,2 \\
7 & 16,6 & 65,7 & 35,3 \\
8 & 12,7 & 55,0 & 33,2 \\
9 & 12,3 & 44,4 & 33,3 \\
10 y más & 8,7 & 74,7 & 27,0 \\
Total & 18,4 & 70,3 & 45,2 \\
\hline
\end{tabular}

a Se consideran inmigrantes llegados a cualquier edad.

b Inmigrantes llegados de 14 y más años de edad.

Cuadro 87

DISTRIBUCION DE LOS HOGARES POR EL NUMERO DE INMIGRANTES, a SEGUN EL STATUS MIGRATORIO DEL JEFE

\begin{tabular}{|c|c|c|c|c|}
\hline \multirow{3}{*}{$\begin{array}{c}\text { Número } \\
\text { de inmigrantes } \\
\text { en el hogar }\end{array}$} & \multicolumn{4}{|c|}{ Porcentaje de hogares } \\
\hline & \multirow[b]{2}{*}{ Total } & \multirow[b]{2}{*}{ Nativos } & \multicolumn{2}{|c|}{ Inmigrantes de ${ }^{b}$} \\
\hline & & & $1952-62$ & $\begin{array}{l}\text { Antes } \\
\text { de } 1952\end{array}$ \\
\hline 0 & 23,2 & 41,0 & - & - \\
\hline 1 & 31,7 & 35,1 & 19,6 & 30,7 \\
\hline 2 & 25,7 & 16,9 & 25,3 & 42,2 \\
\hline 3 & 10,1 & 5,0 & 18,9 & 15,8 \\
\hline 4 & 4,8 & 1,6 & 16,0 & 6,0 \\
\hline 5 & 2,2 & 0,2 & 9,9 & 2,5 \\
\hline 6 y más & 2,3 & 0,2 & 10,3 & 2,8 \\
\hline Total & $\begin{array}{l}100 \\
(2136)\end{array}$ & $\begin{array}{c}100 \\
(1210)\end{array}$ & $\begin{array}{l}100 \\
(281)\end{array}$ & $\begin{array}{l}100 \\
(645)\end{array}$ \\
\hline
\end{tabular}

a Se consideran inmigrantes llegados a cualquier edad.

b Inmigrantes llegados de 14 y más años de edad. 
migratorio del jefe, en el cuadro 86 se presentan las proporciones del número de inmigrantes. Dado que esa proporción varía con el tamaño del hogar, disminuyendo cuando este último aumenta, las cifras reflejan esta variable. La proporción global es netamente más alta $(70,3$ por ciento) en los hogares cuyo jefe es un inmigrante de la última década, que en los hogares de jefes inmigrantes de antes de 1952 $(45,2)$, y la proporción observada en estos últimos hogares es, a su vez, más alta que la de hogares de jefes nativos $(18,4$ por ciento).

Al aumentar el tamaño del hogar decrece la proporción de inmigrantes en el mismo, debido, principalmente, a la correlaciön entre tamaño del hogar y número de niños. ${ }^{125}$ No obstante, en los distintos tamaños de hogar se observa que se mantienen los diferenciales, ya señalados en el párrafo anterior, según el status migratorio del jefe.

Otro aspecto de interés es el hogar típico - modal - respecto del número de inmigrantes. EI hogar típico de los hogares de jefe nativo es el hogar sin inmigrantes (41,0 por ciento), seguido de cerca en frecuencia (35,1 por ciento) por el hogar con un inmigrante. (Véase el cuadro 87.)

El hogar típico de los hogares de jefes inmigrantes de antes de 1952, es el hogar de dos inmigrantes (42,2 por ciento). En segundo lugar, están los hogares con un inmigrante (30,7 por ciento).

Por último, de los hogares de jefes inmigrantes de la última década, el hogar típico tiene también dos inmigrantes $(25,3)$, aunque ahora esta característica predomina menos que en el caso de hogares de jefes inmigrantes de antes de 1952, como resulta de comparar las frecuencias relativas de cada uno. En los primeros, el 55,1 por ciento de los hogares se sitúa a la derecha del valor típico, mientras que en los segundos sólo el 27,1 por ciento.

Podría señalarse adicionalmente, como otra nota diferencial de los hogares de jefes inmigrantes que, tratándose de inmigrantes de antes de 1952, cualquiera que sea el tamaño del hogar (excepto obviamente hogares de una persona), el valor típico es dos inmigrantes por hogar, mientras que si son jefes inmigrantes recientes el valor típico se desplaza al mismo tiempo que aumenta el número de personas: 3 en los hogares de 3 personas, 4 en los de 4 personas, 5 en los de 5, etc. Este último comportamiento es explicable debido al poco tiempo transcurrido desde la llegada del jefe inmigrante, de modo que una parte importante de esos hogares está compuesta exclusivamente por inmigrantes. ${ }^{126}$

125 Esto es cierto en el caso de los hogares unifamiliares, los que constituyen una elevada proporción del total de hogares. (Véase el parágrafo a] de esta sección.)

126 Un análisis más detallado que considere la proporción de inmigrantes -los valores típicos-, según el tamaño del hogar, sufriría las limitaciones que 


\section{Características económicas del hogar}

a) Número de personas económicamente activas. En los hogares investigados el número más frecuente de personas económicamente activas era el de una. Esta característica es más marcada en los hogares de jefes inmigrantes recientes $(60,5$ por ciento) y, por lo contrario, menos frecuente en los hogares de jefes inmigrantes de antes de 1952 (43,9 por ciento). Los hogares de jefes nativos ocupan una situación intermedia (51,3 por ciento). (Véase el cuadro 88.)

Si se consideran los hogares con dos o más personas económicamente activas, entonces una proporción más elevada corresponde a los hogares de jefes inmigrantes de antes de 1952. Las diferencias señaladas en relación a la antigüedad de la residencia de los inmigrantes, se deben a la mayor proporción de hogares multifamiliares entre los de larga residencia. Esta última situación tiene una explicación, a su vez, en la edad media más alta de tales inmigrantes. (Véase el cuadro 88.)

Los hogares sin personas económicamente activas revisten un especial interés. Se puede asumir que la mayor parte de ellos son hogares con muy bajos ingresos. Contra lo que podría haberse esperado, entre los hogares de jefes inmigrantes recientes se encontró la menor proporción de hogares sin miembros activos (5,4 por ciento). Una explicación razonable es otra vez la edad media de estos inmigrantes, comparada con la edad de los jefes inmigrantes de más larga residencia. Entre estos últimos debería encontrarse una mayor proporción de inactivos (jubilados, pequeños rentistas, etc.). Sin embargo, esta explicación no parece ser suficientemente completa, como se deduce del examen simultáneo del "tipo" de hogar.

La frecuencia de hogares sin miembros económicamente activos es particularmente alta en los hogares "sin familias" y en los hogares en "vivienda colectiva" (pensiones), sobre todo entre los primeros. Los hogares "sin familias" (constituyen un 10 por ciento de todos los hogares observados), revelaron un 29 por ciento de casos donde no había ningún miembro activo. Tanto en los hogares de jefes nativos como de jefes inmigrantes de antes de 1952, la proporción fue cercana a la mencionada; en los hogares de jefes inmigrantes recientes, de sólo 10 por ciento, si bien esta última cifra se apoya en sólo 19 hogares. (Véase el cuadro 88.) No surge una explicación lógica de por qué en los hogares "sin familias", y en los hogares en pensiones, la proporción de hogares sin miembros activos fue tan importante. Cabe recordar (véase

impone la pequeñez de las cifras, en particular del grupo de hogares de jefes inmigrantes del período 1952-1962. 
Cuadro 88

NUMERO DE PERSONAS ECONOMICAMENTE ACTIVAS EN EL HOGAR, SEGUN "TIPO" DE HOGAR Y SEGUN STATUS MIGRATORIO DEL JEFE

\begin{tabular}{|c|c|c|c|c|c|}
\hline \multirow[b]{2}{*}{$\begin{array}{l}\text { Número de personas } \\
\text { económicamente } \\
\text { activas }^{\mathrm{a}}\end{array}$} & \multicolumn{5}{|c|}{ Tipo de hogar } \\
\hline & $\begin{array}{c}\text { Todos } \\
\text { los } \\
\text { hogares }\end{array}$ & $\begin{array}{c}\text { "Unifami- } \\
\text { liar" }\end{array}$ & $\begin{array}{l}\text { "Multifa- } \\
\text { miliar" }\end{array}$ & $\begin{array}{c}\text { "Sin } \\
\text { familias" } \\
\text { y con } \\
\text { "familias } \\
\text { secundarias" } \\
\text { exclusiva- } \\
\text { mente }\end{array}$ & $\begin{array}{c}\text { En } \\
\text { vivienda } \\
\text { colectiva } \\
\text { (pensión) }\end{array}$ \\
\hline
\end{tabular}

\begin{tabular}{|c|c|c|c|c|c|}
\hline \multirow[b]{2}{*}{0} & \multicolumn{5}{|c|}{$\begin{array}{c}\text { (Porcentaje de hogares) } \\
\text { Jefes nativos }\end{array}$} \\
\hline & 7,9 & 5,5 & 2,2 & 24,9 & 20,0 \\
\hline 1 & 51,3 & 57,1 & 18,2 & 48,5 & 40,0 \\
\hline 2 & 27,7 & 28,2 & 34,3 & 18,2 & 40,0 \\
\hline 3 & 8,4 & 6,3 & 27,8 & 4,2 & - \\
\hline 4 y más & 4,7 & 2,9 & 17,5 & 4,2 & 一 \\
\hline \multirow[t]{2}{*}{$\begin{array}{l}\text { Total } \\
\text { (Número de hogares) }\end{array}$} & $\begin{array}{c}100 \\
(2210)\end{array}$ & $\begin{array}{l}100 \\
(893)\end{array}$ & $\begin{array}{l}100 \\
(137)\end{array}$ & $\begin{array}{l}100 \\
(165)^{b}\end{array}$ & $\begin{array}{l}100 \\
(15)\end{array}$ \\
\hline & \multicolumn{5}{|c|}{ Jefes inmigrantes de antes de 1952} \\
\hline 0 & 10,1 & 8,1 & 2,8 & 24,5 & 16,6 \\
\hline 1 & 43,9 & 49,4 & 9,9 & 42,6 & 41,7 \\
\hline 2 & 27,0 & 26,5 & 36,6 & 20,2 & 41,7 \\
\hline 3 & 13,0 & 11,3 & 32,4 & 8,5 & - \\
\hline 4. y más & 6,0 & 4,7 & 18,3 & 4,2 & - \\
\hline \multirow[t]{2}{*}{$\begin{array}{l}\text { Total } \\
\text { (Número de hogares) }\end{array}$} & $\begin{array}{l}100 \\
(645)\end{array}$ & $\begin{array}{l}100 \\
(468)\end{array}$ & $\begin{array}{l}100 \\
(71)\end{array}$ & $\begin{array}{l}100 \\
(94) \mathrm{e}\end{array}$ & $\begin{array}{l}100 \\
(12)\end{array}$ \\
\hline & \multicolumn{5}{|c|}{ Jefes inmigrantes del periodo $1952-1962$} \\
\hline 0 & 5,4 & 5,3 & - & 7,4 & 9,1 \\
\hline I & 60,5 & 63,5 & 16,7 & 59,3 & 72,7 \\
\hline 2 & 22,4 & 22,7 & 22,2 & 22,2 & 18,2 \\
\hline 3 & 7,8 & 6,7 & 22,2 & 11,1 & - \\
\hline 4 y más & 3,9 & 1,8 & 38,9 & - & - \\
\hline $\begin{array}{l}\text { Total } \\
\text { (Número de hogares) }\end{array}$ & $\begin{array}{l}100 \\
(281)\end{array}$ & $\begin{array}{l}100 \\
(225)\end{array}$ & $\begin{array}{l}100 \\
(18)\end{array}$ & $\begin{array}{l}100 \\
(27)^{d}\end{array}$ & $\begin{array}{l}100 \\
(11)\end{array}$ \\
\hline
\end{tabular}

a No incluye sirvientes domésticos.

b De los cuales, 121 son hogares "sin familias".

c De los cuales, 74 son hogares "sin familias".

d De los cuales, 19 son hogares "sin familias". 
la sección 3 a]) que por lo menos la mitad de los hogares "sin familias" estaban compuestos por una sola persona, y no menos del 80 por ciento por no más de dos miembros.

b) Ingresos del jefe del hogar. En este análisis se excluye a aquellos jefes de hogar no económicamente activos. ${ }^{127} \mathrm{El}$ ingreso se refiere a los derivados de trabajo personal, exclusivamente, y por lo tanto, no incluye jubilaciones, pensiones, intereses ni otras rentas de capital.

A los fines de establecer una mejor comparación, se podrian considerar hogares "unifamiliares" con esposa (compañera) del jefe presente. Esta clase de hogar representó el 71 por ciento de los hogares examinados, variando levemente con el status migratorio del jefe. A continuación se presentan los valores cuartiles de los ingresos mensuales, según el status migratorio del jefe:

INGRESOS MENSUALES DEL JEFE EN HOGARES "UNIFAMILIARES" CON ESPOSA (COMPAÑERA) DEL JEFE PRESEN'TE

(Escudos del año 1962)

\begin{tabular}{|c|c|c|c|}
\hline \multirow{2}{*}{$\begin{array}{c}\text { Valores } \\
\text { cuartiles } \\
\text { del ingreso }\end{array}$} & \multirow[b]{2}{*}{ Nativos } & \multicolumn{2}{|c|}{ Inmigrantes del período } \\
\hline & & $\begin{array}{c}\text { Antes } \\
\text { de } 1952\end{array}$ & $\begin{array}{c}\text { De } 1952 \\
\text { a } 1962\end{array}$ \\
\hline Primero & 66,2 & 62,2 & 62,3 \\
\hline Segundo & 109,2 & 93,9 & 93,5 \\
\hline Tercero & 253,5 & 203,0 & 195,1 \\
\hline
\end{tabular}

En las cifras anteriores no es aparente la existencia de un ingreso diferencial, excepto en el extremo derecho de la distribución. En efecto, una cuarta parte de los jefes nativos recibían ingresos superiores a $E^{o}$ 250, entretanto la misma proporción de jefes inmigrantes sólo recibía aproximadamente $\mathrm{E}^{\mathrm{o}} \mathbf{2 0 0}$. Si, en lugar de hogares "unifamiliares", se tomaran en consideración todos los "tipos" de hogar, pero siempre con esposa (compañera) presente, los resultados apenas diferirían de los anteriores.

El cuadro siguiente incluye hogares cuya situación difiere de la de los hogares ya examinados: son hogares con esposa (compañera) no presente y hogares cuyo jefe es una mujer. Estos hogares representan aproximadamente, el 7 y 12 por ciento, respectivamente, de los hogares

127 Sobre los 2136 hogares observados, en 1815 (85,0 por ciento) de ellos el jefe es económicamente activo y por consiguiente recibe ingresos derivados de una actividad personal. 
analizados en esta sección. Dado que el número de tales hogares es pequeño, sólo se presentan los ingresos medianos:

INGRESOS MENSUALES DEL JEFE EN HOGARES CON ESPOSA (COMPAÑERA) NO PRESENTE Y EN HOGARES CON JEFE MUJER, SEGUN EL STATUS MIGRATORIO DEL JEFE

(Escudos de 1962)

\begin{tabular}{lccc}
\hline \multirow{2}{*}{ Clase de hogar } & Nativos & \multicolumn{2}{c}{ Inmigrantes del período } \\
\cline { 3 - 4 } & & $\begin{array}{c}\text { Antes } \\
\text { de 1952 }\end{array}$ & $\begin{array}{c}\text { De 1952 } \\
\text { a } 1962\end{array}$ \\
\hline Esposa no presente & 109,1 & (Ingreso mediano) & 65,0 \\
Jefe mujer & 84,4 & 85,0 & 49,3 \\
\hline
\end{tabular}

Como se puede ver, en ambas clases de hogares el ingreso mediano de jefes nativos es más elevado, hecho que ya se insinúa, pero con menos intensidad, en los hogares "unifamiliares" con esposa presente. Respecto de la diferencia anotada en el ingreso del jefe de hogares con esposa no presenie, sería arriesgada cualquier explicación, ya que se trata de un número pequeño de observaciones. En cuanto a los hogares cuyo jefe es una mujer, ei sentido del diferencial encontrado confirmaría lo que se observó en general respecto del ingreso de las mujeres nativas o inmigrantes. ${ }^{128}$

c) Actividad económica de la esposa (compañera) del jefe. Una de cada cinco esposas (compañeras) de jefes de hogar eran económicamente activas. ${ }^{129}$

Esta proporción se observa con una notable regularidad independientemente del status migratorio de la mujer y del jefe del hogar. (Véase el cuadro 89.)

La mencionada proporción varía poco en relación con la edad del jefe del hogar. Sin embargo, la proporción se aparta bastante de aquel promedio tratándose de esposas (compañeras) inmigrantes de jefes de menos de 30 años, las cuales eran económicamente activas sólo en la proporción de una a diez. También se aparia, ahora en sentido contrario, respecio de esposas (compañeras) inmigrantes de jefes nativos de 40 a 59 años, donde es de tres por cada diez, aproximadamente. Quiere decir que las esposas (compañeras) inmigrantes jóvenes ofrecían una

$128 \mathrm{Al}$ respecto puede consultarse el capitulo $\mathrm{V}$.

129 Se entiende que se examinan hogares con esposa (compañera) del jefe presente. 
PARTICIPACION EN ACTIVIDADES ECONOMICAS DE LA ESPOSA (COMPANERA) DEL JEFE, SEGUN EL STATUS MIGRATORIO DEL JEFE Y DEL PROPIOa

Porcentaje de esposas (compañeras) económicamente activas

\begin{tabular}{lccccc}
\hline & \multicolumn{4}{c}{ Status migratorio ${ }^{\mathrm{b}}$} \\
\cline { 2 - 3 } Edad del jefe & \multicolumn{2}{c}{ Jefe nativo } & & \multicolumn{2}{c}{ Jefe inmigrante } \\
\cline { 2 - 3 } \cline { 5 - 6 } & $\begin{array}{c}\text { Esposa } \\
\text { nativa }\end{array}$ & $\begin{array}{c}\text { Esposa } \\
\text { inmigrante }\end{array}$ & & $\begin{array}{c}\text { Esposa } \\
\text { nativa }\end{array}$ & $\begin{array}{c}\text { Esposa } \\
\text { inmigrante }\end{array}$ \\
\hline Todas edades & 19,3 & 19,2 & & 19,4 & 18,5 \\
Menos de 30 & 19,9 & 6,7 & & 16,1 & 12,2 \\
$30-39$ & 19,8 & 15,0 & & 20,0 & 17,4 \\
$40-49$ & 25,4 & 29,0 & & 21,6 & 22,7 \\
$50-59$ & 11,0 & 29,0 & & 18,6 & 16,8 \\
60 y más & 9,8 & 19,0 & & 17,9 & 18,7 \\
\hline
\end{tabular}

a Resultados de 1619 hogares (hogares con esposa o compañera del jefe presente). De éstos, 439 son hogares con jefe y esposa inmigrantes; 694, hogares con jefe y esposa nativos; 247 , hogares con jefe inmigrante y esposa nativa, y 239 , hogares con jefe nativo y esposa inmigrante.

b Se consideraron inmigrantes, tanto respecto del jefe como de su esposa (cónyuge), si Ilegaron al Gran Santiago después de cumplir los 14 años de edad. En caso contrario están incluidos entre los nativos.

participación en actividades más baja que el promedio, mientras que las de edad relativamente alta tenían una participación superior al promedio.

Un análisis simultáneo del status migratorio y de la actividad, indicó una virtual independencia de estas variables, lo que es aplicable tanto a los jefes nativos como a los inmigrantes. (Véase el cuadro 90.) Sin embargo, en el caso de los jefes nativos esa aparente independencia oculta asociaciones positivas y negativas existentes en hogares de jefes de distintas edades. En efecto, el índice de asociación es de $-0,552$ para el grupo de jefes menores de 30 años; crece al aumentar la edad, de modo que llega a ser $+0,536$ para el grupo de 50 a 59 años. Vale decir, en las parejas jóvenes de jefes nativos, la actividad de la mujer está negativamente asociada a la calidad de inmigrante $y$, por lo contrario, positivamente asociada en las parejas de jefes nativos de edad relativamente alta. (Véase el cuadro 90.)

Tratándose de jefes inmigrantes, los resultados indican baja asociación entre el status de la esposa (compañera) y su actividad económica.

d) Actividad económica de la esposa (compañera) del jefe del hogar y número de niños menores de 14, años de edad presentes en el 
hogar. Se parte del supuesto de que el nivel de participación de la cónyuge está directamente asociado al número de hijos en edades infantiles. Para verificar este supuesto se analiza la información relativa a hijos presentes menores de 14 años de edad. Es probable que la información sobre hijos menores de 7 años, por ejemplo, podría ser más apropiada para los propósitos perseguidos, por ser estos últimos los que crean más obstáculos al trabajo de la mujer fuera del hogar. Como se dirá más adelante, la existencia de hijos menores de 7 años es un factor adicional al número de hijos menores de 14.

En el cuadro 91 se presentan los porcentajes de esposas (compañeras) económicamente activas, según el número de hijos menores de 14. años, en hogares con esposa (compañera) del jefe presente. De este cuadro merece destacarse que: 1) el porcentaje de económicamente activas en hogares sin hijos menores de 14 años, es del orden de 20 a 25 por ciento, variando poco según el siatus migratorio del jefe; 2) el porcentaje de económicamente activas no disminuye, o disminuye poco hasta hogares con 3 hijos menores de 14, años, excepio en los hogares de jefes inmigrantes de la última década donde se produce un cambio importanie a partir de un hijo, y 3) el porcentaje disminuye mucho en los hogares donde hay numerosos hijos menores de 14 años, como serían los hogares con 4 y más hijos.

Cuadro 90

ASOCIACION ENTRE LA CONDICION DE ECONOMICAMENTE ACTIVA Y LA DE INMIGRANTE DE LA ESPOSA (COMPANERA) DEL JEFE, SEGUN EL STATUS MIGRATORIO DEL JEFEa

\begin{tabular}{|c|c|c|c|}
\hline \multirow{3}{*}{ Edad del jefe } & \multicolumn{3}{|c|}{ Status migratorio del jefe } \\
\hline & Todos los jefes & Nativos & Inmigrantes \\
\hline & $\begin{array}{c}\text { Coeficiente } \\
\text { de asociación } \\
\text { b }\end{array}$ & $\begin{array}{c}\text { Coeficiente } \\
\text { de asociación }\end{array}$ & $\begin{array}{c}\text { Coeficiente } \\
\text { de asociación }\end{array}$ \\
\hline Todas edades & $-0,020$ & $+0,002$ & $-0,032$ \\
\hline Menos de 30 & $-0,397$ & $-0,552$ & $-0,161$ \\
\hline $30-39$ & $-0,116$ & $-0,167$ & $-0,084$ \\
\hline $40-49$ & $+0,016$ & $+0,090$ & $+0,031$ \\
\hline $50-59$ & $+0,229$ & $+0,536$ & $-0,060$ \\
\hline 60 y más & $+0,200$ & $+0,368$ & $+0,024$ \\
\hline
\end{tabular}

¿ Véase la nota b del cuadro 89.

b Este índice varía entre -1 y +1 . El valor 0 indicaria independencia entre las variables. Para más detalle véase Kendall, M. G. "The Advanced Theory of Statistics", vol. I, capítulo I3. 
Cuadro 91

PORCENTAJE DE ESPOSAS (COMPAÑERAS) ECONOMICAMENTE ACTIVAS EN HOGARES CON ESPOSA (COMPANEERA) DEL JEFE

PRESENTE, SEGUN EL NUMERO DE HIJOS MENORES DE 14 AÑOS DE EDAD PRESENTES Y EL STATUS MIGRATORIO DEL JEFE DE HOGAR

\begin{tabular}{|c|c|c|c|}
\hline \multirow{3}{*}{$\begin{array}{l}\text { Número de hijos } \\
\text { menores de } 14 \text { años } \\
\text { de edad presentes } \\
\text { en el hogar }\end{array}$} & \multicolumn{3}{|c|}{ Status migratorio del jefe del hogar } \\
\hline & \multicolumn{3}{|c|}{ Inmigrantes del período } \\
\hline & Nativos & $\begin{array}{c}\text { Antes } \\
\text { de } \\
1952 \\
\end{array}$ & $1952-1962$ \\
\hline & \multicolumn{3}{|c|}{ (Porcentajes) } \\
\hline Ninguno & 21,4 & 25,3 & 23,1 \\
\hline Uno & 24,3 & 21,2 & 14,6 \\
\hline Dos & 20,7 & 19,7 & 15,4 \\
\hline Tres & 19,6 & 20,0 & 12,5 \\
\hline Cuatro y más & 12,6 & 13,1 & 7,5 \\
\hline $\begin{array}{l}\text { Total } \\
\text { (Número de hogares) }\end{array}$ & $\begin{array}{l}19,3 \\
(936)\end{array}$ & $\begin{array}{l}\overrightarrow{20,4} \\
(466)\end{array}$ & $\begin{array}{l}\overline{15,2} \\
(217)\end{array}$ \\
\hline
\end{tabular}

Un segundo método alternativo de análisis de la relación entre la participación de la cónyuge del jefe y el número de hijos menores de 14. años, consiste en calcular el promedio de hijos. En el cuadro 92 se presentan los resultados incluyendo y excluyendo los hogares sin hijos menores de 14, años. Las cifras correspondientes a hogares donde no hay cónyuge presente se dan a título ilustrativo.

Tales resultados indicarían que las cónyuges no económicamente activas tenían, en promedio, un número de hijos menores de 14 años más elevado que las cónyuges económicamente activas. La diferencia, que en conjunto es de aproximadamente 30 por ciento, es más amplia todavia en las esposas (compañeras) de jefes inmigrantes de la última década (49 por ciento).

Si se eliminan aquellos hogares donde no hay hijos menores de 14 años, como es lógico el número promedio de hijos aumenta en aproximadamente 20 por ciento, pero subsistiendo las diferencias anotadas, eso sí, de una magnitud más pequeña.

Un factor adicional que podría influir en la participación en actividades económicas de la cónyuge del jefe, es la presencia de hijos menores de 7 años de edad. Los resultados obtenidos parecen confirmar este supuesto. En los hogares donde la cónyuge es económicamente activa se encontró, en media, 54 hijos menores de 7 años por cada 100 menores de 14; si la cónyuge era no económicamente activa, la relación 
fue de 60 por cada 100. La primera de las proporciones mencionadas varía poco con el status migratorio del jefe ( 51 a 55 por 100). La segunda, por lo contrario, registra variaciones desde 54 (inmigrantes de antes de 1952) a 69 por ciento (inmigrantes de 1952-1962). Esta última cifra es coherente con los resultados del cuadro 91 en el sentido de que la participación en actividades económicas de las esposas (compañeras) de jefes inmigrantes de la última década era particularmente baja. Nuevamente, la edad promedio más baja de este último grupo surge como factor explicativo, por estar asociada con menor edad promedio de los hijos.

e) Asistencia escolar, composición del hogar (cónyuge presente y no presente) y actividad económica de la esposa (compañera) del jefe. En esie análisis está implícito el supuesto de que la asistencia escolar

Cuadro 92

PROMEDIO DE HIJOS MENORES DE I4 AÑOS DE EDAD PRESENTES EN EL HOGAR, SEGUN LA COMPOSICION DEL HOGAR

(CONYUGE PRESENTE Y NO PRESENTE), TIPO DE ACTIVIDAD DE LA ESPOSA (COMPANERA) Y STATUS MIGRATORIO DEL JEFE DEL HOGARa

\begin{tabular}{|c|c|c|c|c|}
\hline \multirow{3}{*}{$\begin{array}{l}\text { Composición } \\
\text { del hogar y tipo } \\
\text { de actividad de } \\
\text { la esposa } \\
\text { (compañera) } \\
\text { del jefe }\end{array}$} & \multirow{3}{*}{ Total } & \multicolumn{3}{|c|}{ Status migratorio del jefe del hogar } \\
\hline & & \multirow[b]{2}{*}{ Nativos } & \multicolumn{2}{|c|}{ Inmigrantes del período } \\
\hline & & & $\begin{array}{l}\text { Antes } \\
\text { de } 1952\end{array}$ & $1952-1962$ \\
\hline $\begin{array}{l}\text { Esposa (compañera) } \\
\text { presente y activa } \\
\text { Esposa (compañera) }\end{array}$ & $\begin{array}{c}1,75 \\
(2,49)\end{array}$ & $\begin{array}{c}1,90 \\
(2,49)\end{array}$ & $\begin{array}{c}1,60 \\
(2,62)\end{array}$ & $\begin{array}{c}1,39 \\
(2,19)\end{array}$ \\
\hline $\begin{array}{l}\text { Esposa (compañera) } \\
\text { presente y no ac- } \\
\text { tiva }\end{array}$ & $\begin{array}{c}2,29 \\
(2,99)\end{array}$ & $\begin{array}{c}2,40 \\
(3,04)\end{array}$ & $\begin{array}{c}2,16 \\
(3,06)\end{array}$ & $\begin{array}{c}2,07 \\
(2,64)\end{array}$ \\
\hline $\begin{array}{l}\text { Cónyuge no presen. } \\
\text { te (jefe mujer) }\end{array}$ & $\begin{array}{c}0,85 \\
(2,03)\end{array}$ & $\begin{array}{c}0,86 \\
(2,18)\end{array}$ & $\begin{array}{c}0,81 \\
(1,94)\end{array}$ & $\begin{array}{c}0,91 \\
(1,79)\end{array}$ \\
\hline $\begin{array}{l}\text { Cónyuge no presente } \\
\text { (jefe hombre) }\end{array}$ & $\begin{array}{c}0,68 \\
(2,4: 2)\end{array}$ & $\begin{array}{c}0,72 \\
(2,50)\end{array}$ & $\begin{array}{c}0,75 \\
(2,41)\end{array}$ & $\begin{array}{c}0,18 \\
(1,50)\end{array}$ \\
\hline Total & $\begin{array}{r}1,85 \\
(2,79)\end{array}$ & $\begin{array}{c}1,97 \\
(2,86)\end{array}$ & $\begin{array}{c}1,70 \\
(2,82)\end{array}$ & $\begin{array}{c}1,68 \\
(2,47)\end{array}$ \\
\hline
\end{tabular}

a Entre paréntesis, promedios en hogares con al menos un hijo menor de 14 años de edad. 


\section{Cuadro 93}

PORCENTAJE DE ASISTENCIA ESCOLAR ENTRE LOS HIJOS DE 7 A 13 ANTOS DE EDAD, SEGUN LA COMPOSICION DEL HOGAR (CONYUGE PRESENTE Y NO PRESENTE), TIPO DE ACTIVIDAD DE LA ESPOSA (COMPAÑERA) DEL JEFE Y STATUS MIGRATORIO DEL JEFE DEL HOGAR

\begin{tabular}{lllcc}
\hline $\begin{array}{l}\text { Composición del hogar } \\
\text { y tipo de actividad } \\
\text { de la esposa }\end{array}$ & Total & Nativos & \multicolumn{2}{c}{ Inmigrantes del periodo } \\
\cline { 4 - 5 } (compañera) del jefe & & & de 1952 & $1952-1962$ \\
\hline $\begin{array}{l}\text { Esposa (compañera) } \\
\text { presente y activa }\end{array}$ & 92,8 & 90,2 & 95,9 & 100,0 \\
$\begin{array}{l}\text { Esposa (compañera) } \\
\text { presente y no activa }\end{array}$ & 93,1 & 92,2 & 95,6 & 90,7 \\
$\begin{array}{l}\text { Cónyuge no presente } \\
\text { (jefe mujer) }\end{array}$ & 88,5 & 92,6 & 87,2 & 75,0 \\
$\begin{array}{l}\text { Cónyuge no presente } \\
\text { (jefe hombre) }\end{array}$ & 89,5 & 93,9 & 81,8 & 100,0 \\
\hline \begin{tabular}{l} 
Total \\
\hline
\end{tabular} & 92,5 & 92,0 & 94,3 & 90,1 \\
\hline
\end{tabular}

de los niños de 7 a 13 años de edad está vinculada, en cierta medida, al tipo de actividad de la esposa (compañera) del jefe y al hecho de no haber cónyuge (presente) del jefe.

En general, el nivel de asistencia fue elevado, como lo indica el promedio de aproximadamente 93 por ciento. Como se deduciría del cuadro 93, no hay una tendencia definida en cuanto al efecto que pudiera tener el tipo de actividad de la esposa (compañera) del jefe, en hogares con cónyuge presente. La excepción parece ser, sin embargo, lo que sucede en hogares de jefes inmigrantes de la última década, donde se da una diferencia significativa. Llama la atención que el nivel más bajo de asistencia (90,7 por ciento) sea precisamente en hogares donde la esposa (compañera) no es económicamente activa, contra lo esperado.

Las diferencias en el nivel de asistencia son, por lo contrario, am. plias si se comparan hogares con esposas (compañeras) presentes con hogares donde no hay cónyuge (presente). Los resultados de estos últimos hogares se comparan con los de hogares con esposas (compañeras) presentes y económicamente activas. Entre los hogares de jefes nativos no hay diferencias que merezcan mayor análisis. Otra cosa ocurre en los hogares con jefes inmigrantes, donde la presencia de la cónyuge del jefe aparece como un factor favorable a la asistencia escolar. (Véase el cuadro 93.) Sin embargo, las cifras correspondientes a los hogares donde no hay cónyuge presente provienen de un número pequeño de casos, sobre todo de hogares cuyo jefe es un hombre. 


\section{APENDICE I 1 \\ DESCRIPCIÓN DE LA MUESTRA Y CÁLCULO DEL ERROR}

\section{ZONA ABARCADA POR LÁ MUESTRA}

La muestra que se utilizó abarca la zona urbanizada denominada Gran Santiago, la que comprende a las 11 comunas siguientes:

\section{Barrancas \\ Conchalí \\ La Cistema \\ Las Condes \\ La Granja \\ Ñuñoa}

Providencia

Quinta Normal

Renca

San Miguel

Santiago

y los distritos 5 y 6 de la comuna de Maipú, ubicados contiguamente a la comuna de Santiago.

La zona así definida, al momento del levanlamiento del último censo de población (29 de noviembre de 1960), tenia un total de 1954.452 habitantes, y de 379000 viviendas (incluyendo las viviendas colectivas).

\section{TAMaño}

A base de ciertas pruebas realizadas con la información censal de que se disponía cuando se planeó la encuesta (repartición del número de inmigrantes en las comunas, por ejemplo) y de los recursos existentes, se decidió realizar entre las viviendas familiares y los hogares establecidos en residenciales y pensiones (se excluyeron otras viviendas colectivas), una encuesta tal que proporcionara un total útil de 2000 hogares encuestados. Aceptando por anticipado una pérdida del 13 por ciento, se optó por una muestra de tamaño inicial de 2309 viviendas. Bocaz.

1 Este apéndice fue preparado por el profesor del CELADE, señor Albino 
Puesto que la población del Gran Santiago a mitad de 1962 se estimó aproximadamente en 2075000 habitantes y al finalizar la encuesta se logró entrevistar 2137 hogares, con un total de 10836 personas, la muestra efectivamente usada fue de $1 / 191$ de la población $(\mathrm{f}=5,22$ por mil $)$.

\section{Diseño}

Se utilizó una muestra de conglomerados (manzanas), con una etapa de submuestreo dentro de los conglomerados mediante la selección de un número fijo de $n=6$ hogares en viviendas familiares por manzana. Los hogares en residenciales y pensiones formaron un estrato separado, del cual se seleccionaron 45 , de modo tal que el número de personas fuera proporcional dentro de la muestra.

El número de $n=6$ unidades secundarias (viviendas) tomadas de cada unidad primaria (manzana) se estableció con el objeto de conseguir una mayor dispersión de la muestra del Gran Santiago, esto es, un mayor número de puntos de corte en el área, a fin de tener mejor sección transversal que si se hubiera concentrado la muestra en un número menor de manzanas, al tomar, por ejemplo, 10 ó más viviendas por manzana.

Por otra parte, un número menor de entrevistas por manzana habría dispersado mucho la muestra. La información básica usada para este tipo de diseño se obtuvo del material disponible en la Oficina del Censo de la Dirección de Estadística y Censos. Esta Oficina proporcionó listas de manzanas de las comunas del Gran Santiago, con los siguientes datos:

1) distrito en el cual está ubicada la manzana y las calles que la delimitan;

2) número de viviendas familiares;

3) número de viviendas colectivas;

4) número de viviendas deshabitadas;

5) población total;

6) población masculina y femenina.

A base de la lista de manzanas anteriormente citada y usando una probabilidad proporcional al número de viviendas familiares (unidades primarias), se determinaron las manzanas de la muestra (383 en total).

Por último, de las listas de direcciones (hojas de control de empadronamiento del censo) se seleccionaron al azar 6 direcciones distintas de cada manzana de la muestra. 
La Oficina del Censo, por otra parte, confeccionó planos de Ios distritos en que se dividen las columnas, con ubicación y limites de las manzanas.

\section{Evaluación de los Resultados de la muestra}

Para obtener un grado de confianza aceptable en los resultados de una muesíra probabilística, para características no disponibles y proveídas únicamente por la muestra, es necesario comparar alguna información básica dada por ella con datos de otras fuentes de calidad aceptable. De esa manera, por ejemplo, se puede cotejar la distribución por sexo y edad proveniente de la muestra con la del censo que le sirvió de marco.

En la evaluación que sigue, se comparan los resultados de la muestra con los del censo de 1960. La concordancia observada permite aceptar que los otros datos provistos por la muestra son representativos de la población del Gran Saniiago. Se hicieron las siguientes comparaciones básicas de la población:

i) distribución relativa en las comunas.

ii) distribución relativa por sexo y edad, de la comuna de Santiago y de las restantes comunas en conjunto.

iii) distribución de la población económicamente activa y de las tasas de actividad, por sexo y edad.

En el cuadro 1 se indica la distribucín relativa de hombres y mujeres encontrados en el censo de población y en la encuesta de inmigración.

Estas distribuciones no difieren significativamente, ${ }^{2}$ lo cual confirma que la muestra de inmigración es representativa de la población del Gran Santiago.

En el cuadro 2 se indica la disiribución relativa por sexo y edad de la comuna de Santiago $(33,5$ por ciento de la población del Gran Santiago) y de las restantes comunas.

La mayor discrepancia que presentan entre sí la estructura censal y la muestral se produce en el grupo de edad $0-4 .^{3}$ Si se comparan las

2 Para determinar si las diferencias entre la muestra y el censo se pueden atribuir al proceso de muestreo, se usó la prueba estadística denominada de Smirnov-Kolmogorcv.

3 Esta diferencia podria atribuirse principalmente a la cilra del censo. La expcriencia general mue tra que los niños de 0-4 años suelen ser sulvenumcrados en los censos. Bajo este supuesio, la subenumeración censal sería del 15 por ciento. 
Cuadro 1

DISTRIBUCION RELATIVA DE HOMBRES Y MUJERES SEGUN EL CENSO DE POBLACION Y SEGUN LA ENCUESTA DE INMIGRACION

\begin{tabular}{lrrrrr}
\hline \multirow{2}{*}{ Comunas } & \multicolumn{2}{c}{ Hombres } & & \multicolumn{2}{c}{ Mujeres } \\
\cline { 2 - 3 } \cline { 6 - 6 } & Censo & Muestra & & Censo & Muestra \\
\hline Barrancas & 4,3 & 4,1 & & 3,8 & 3,4 \\
Conchalí & 8,8 & 9,3 & & 7,9 & 8,7 \\
La Cisterna & 8,4 & 8,5 & & 7,6 & 7,8 \\
Las Condes & 4,2 & 4,0 & & 4,7 & 3,8 \\
La Granja & 3,8 & 4,1 & & 3,3 & 3,4 \\
Nuñoa & 10,3 & 10,8 & & 11,1 & 11,0 \\
Providencia & 3,7 & 3,4 & 4,9 & 4,4 \\
Quinta NormaI & 8,0 & 7,7 & & 7,5 & 7,1 \\
Renca & 2,9 & 2,6 & 2,6 & 2,6 \\
San Miguel & 13,2 & 14,0 & 12,2 & 13,4 \\
Santiago & 32,4 & 31,5 & 34,4 & 34,4 \\
Total & 100,0 & 100,0 & 100,0 & 100,0 \\
\hline
\end{tabular}

Cuadro 2

DISTRIBUCION RELATIVA POR SEXO Y EDAD EN LA COMUNA DE SANTIAGO Y EN LAS RESTANTES COMUNAS

\begin{tabular}{|c|c|c|c|c|c|c|c|c|}
\hline \multirow{3}{*}{$\begin{array}{c}\text { Grupos } \\
\text { de } \\
\text { edades }\end{array}$} & \multicolumn{4}{|c|}{ Hombres } & \multicolumn{4}{|c|}{ Mujeres } \\
\hline & \multicolumn{2}{|c|}{$\begin{array}{c}\text { Comuna } \\
\text { de Santiago }\end{array}$} & \multicolumn{2}{|c|}{$\begin{array}{l}\text { Comunas } \\
\text { restantes }\end{array}$} & \multicolumn{2}{|c|}{$\begin{array}{c}\text { Comuna } \\
\text { de Santiago }\end{array}$} & \multicolumn{2}{|c|}{$\begin{array}{l}\text { Comunas } \\
\text { restantes }\end{array}$} \\
\hline & Censo & Muestra & Censo & Muestra & Censo & Muestra & Censo & Muestra \\
\hline 0.4 & 12,7 & 14,7 & 16,9 & 19,7 & $\overline{10,1}$ & 12,7 & 14,6 & 16,5 \\
\hline $5-9$ & 9,7 & 10,2 & 13,9 & 13,3 & 8,0 & 8,7 & 12,1 & 12,0 \\
\hline $10-14$ & 8,9 & 10,7 & 11,3 & 11,6 & 7,8 & 7,2 & 10,2 & 11,4 \\
\hline $15 \cdot 19$ & 9,3 & 9,3 & 9,3 & 10,1 & 9,5 & 9,2 & 9,9 & 10,2 \\
\hline $20-24$ & 9,3 & 8,4 & 7,6 & 7,7 & 9,4 & 7,5 & 8,8 & 8,2 \\
\hline $25-29$ & 8,6 & 7,5 & 7,2 & 6,2 & 8,8 & 8,2 & 8,1 & 7,1 \\
\hline $30 \cdot 34$ & 8,2 & 7,5 & 7,5 & 6,2 & 8,2 & 7,8 & 7,8 & 7,0 \\
\hline $35-39$ & 6,5 & 6,8 & 5,9 & 5,3 & 6,8 & 7,2 & 6,2 & 6,1 \\
\hline $40-44$ & 5,8 & 5,3 & 5,1 & 5,2 & 6,3 & 5,4 & 5,1 & 4,8 \\
\hline $45-49$ & 5,3 & 4,2 & 4,3 & 4,5 & 5,9 & 6,2 & 4,4 & 4,9 \\
\hline $50-54$ & 4,8 & 3,9 & 3,6 & 3,4 & 5,2 & 5,3 & 3,7 & 3,5 \\
\hline $55-59$ & 3,6 & 3,2 & 2,5 & 2,4 & 3,9 & 5,0 & 2,7 & 2,7 \\
\hline $60-64$ & 2,9 & 3,7 & 2,0 & 1,8 & 3,6 & 4,0 & 2,4 & 2,1 \\
\hline 65 y más & 4,4 & 4,6 & 2,0 & 2,6 & 6,5 & 5,6 & 4,0 & 3,5 \\
\hline
\end{tabular}


Cuadro 3

POBLACION ECONOMICAMENTE ACTIVA (PEA) Y TASAS DE ACTIVIDAD DE LA POBLACION DEL GRAN SANTIAGO

\begin{tabular}{|c|c|c|c|c|c|c|c|c|}
\hline \multirow{3}{*}{$\begin{array}{l}\text { Grupos } \\
\text { de } \\
\text { edades }\end{array}$} & \multicolumn{4}{|c|}{ Hombres } & \multicolumn{4}{|c|}{ Mujeres } \\
\hline & \multicolumn{2}{|c|}{ PEA } & \multicolumn{2}{|c|}{$\begin{array}{c}\text { Tasas } \\
\text { de } \\
\text { actividad }^{a}\end{array}$} & \multicolumn{2}{|c|}{ PEA } & \multicolumn{2}{|c|}{$\begin{array}{c}\text { Tasas } \\
\text { de } \\
\text { actividada }^{a}\end{array}$} \\
\hline & Censo & Muestra & Censo & Muestra & Censo & Muestra & Censo & Muestra \\
\hline $15-24$ & 23,1 & 24,0 & 66,0 & 63,3 & 33,6 & 30,7 & 39,2 & 37,7 \\
\hline $25 \cdot 29$ & 70,9 & 70,3 & 92,7 & 93,3 & 62,0 & 65,5 & 33,5 & 36,4 \\
\hline 60 y más & 6,0 & 5,7 & 52,2 & 47,3 & 4,4 & 3,8 & 12,4 & 11,8 \\
\hline Total & 100,0 & 100,0 & & & 100,0 & 100,0 & & \\
\hline
\end{tabular}

a Pohlación económicamente activa Población $\times 100$.

estructuras excluyendo este grupo de edad, las diferencias no son significativas. Esto indica que las estructuras dadas por el censo y la muestra concuerdan, excepto quizás en el grupo de edad 0-4.4

Por último, en el cuadro 3 se indican la distribución relativa de la población económicamente activa y las tasas de actividad, de la información dada por el censo y la muestra, por sexo y edad.

Realizando las pruebas estadísticas correspondientes ${ }^{5}$ se encontró que la distribución por edad de la población económicamente activa y las tasas de actividad de la muestra no difieren significativamente de los correspondientes resultados del censo. Esta nueva concordancia entre los datos de la muestra y los del censo es otra indicación de que la muestra es representativa de la población del Gran Santiago, si bien el error muestral de las tasas de actividad de algunas edades, es algo elevado.

4 Para medir si el grado de discrepancia entre la estructura del censo y la de la muestra se debe al proceso de muestreo se usó la prueba de SmirnovKolmogorov.

5 Las pruebas estadísticas que se usaron fueron las siguientes:

a) Para determinar si Ias diferencias de las distribuciones relativas de hombres y mujeres del censo y de la muestra difieren únicamente por efecto del muestreo se hizo la prueba de Smirnov-Kolmogorov.

b) Para determinar si las tasas de actividad dadas por el censo y la muestra no difieren significativamente se usó lo prueba de Chi cuadrado, que para los casos indicados en el cuadro 3 , tiene 3 grados de libertad. 


\section{ERror de muestreo de las estimaciones USADAS}

Las estimaciones usadas en la encuesta de inmigración, pueden clasificarse en 4 tipos:

i) estimación de totales.

ii) estimación de promedios.

iii) estimación de proporciones (porcentajes).

iv) estimación de razones.

Por ejemplo, en el primer grupo puede citarse el número de inmigrantes de 30-39 años; en el segundo el número medio de hijos según la edad de la madre; en el tercero, la proporción de personas sin instrucción; y en el cuarto, la proporción de personas sin instrucción entre los inmigrantes.

A fin de facilitar el cálculo de los errores de muestreo de los diversos tipos de estimaciones antes indicados, se recurrió a la técnica de separación de la muestra total, en dos partes, adoptándose, por comodidad, la división de la muestra en 2 submuestras de igual número de viviendas.

La ventaja de la separación en 2 submuestras de igual tamaño reside en el hecho de que en cada unidad primaria, o grupo de ellas, se puede observar la diferencia que presentan las estimaciones calculadas con cada una de las partes. Estas diferencias pueden ser conden. sadas en una medida de variabilidad de la estimación para la muestra total, de tal manera que, si $d_{i}$ representa la diferencia entre los totales dados por las dos submuestras en la i-ésima unidad primaria, o, en un grupo condensado de ellas, el error relativo de un promedio $\overline{\mathrm{X}}$ estará dado por la relación:

$$
C_{x}=\sqrt{\frac{\sum_{i} d^{2}}{x}}
$$

siendo $\mathrm{x}$ igual al total de individuos con la característica considerada. (Una relación de tipo muy semejante se usa cuando se estiman razones.)

Para algunas de las características más importantes se determinaron los coeficientes de variación de las estimaciones muestrales y se calculó la ley de variación de estos errores relativos según el número (n) de casos incluidos en el subgrupo correspondiente.

Mediante estos procedimientos se prepararon 6 tablas de errores de muestreo para las comunas de Santiago, de Ñuñoa y San Miguel y para 
el Gran Santiago, para inmigrantes y no inmigrantes, en la forma que se expresa a continuación:

- error de totales (cuadro 4)

- error de porcentajes (cuadro 5)

- error de porcentajes de económicamenie activos y de no activos (cuadros 6 y 7 ), $y$

- error de porcentajes de ocupados y desocupados (cuadros 8 y 9 ).

Cuadro 4

ERROR ABSOLUTO PARA LA ESTIMACTON DE TOTALES

(Para inmigrantes y no inmigrantes)

\begin{tabular}{|c|c|c|c|c|c|c|c|}
\hline \multicolumn{2}{|c|}{$\begin{array}{c}\text { Gran } \\
\text { Santiago }\end{array}$} & \multicolumn{2}{|c|}{$\begin{array}{l}\text { Comuna } \\
\text { de } \\
\text { Santiago }\end{array}$} & \multicolumn{2}{|c|}{$\begin{array}{c}\text { Comuna } \\
\text { de } \\
\text { Nuñoa }\end{array}$} & \multicolumn{2}{|c|}{$\begin{array}{l}\text { Comuna } \\
\text { de } \\
\text { S. Miguel }\end{array}$} \\
\hline $\begin{array}{c}\text { Total } \\
\text { Estimado }\end{array}$ & $\begin{array}{c}\text { Error } \\
\text { Absoluto }\end{array}$ & $\begin{array}{c}\text { Total } \\
\text { Estimado }\end{array}$ & $\begin{array}{c}\text { Error } \\
\text { Absoluto }\end{array}$ & $\begin{array}{c}\text { Total } \\
\text { Estimado }\end{array}$ & $\begin{array}{c}\text { Error } \\
\text { Absoluto }\end{array}$ & $\begin{array}{c}\text { Total } \\
\text { Estimado }\end{array}$ & $\begin{array}{c}\text { Error } \\
\text { Absoluto }\end{array}$ \\
\hline 10000 & \pm 1237 & 5000 & \pm 835 & 1000 & 218 & 1500 & \pm 489 \\
\hline 20000 & 1822 & 10000 & I 1217 & 2500 & 482 & 2000 & 564 \\
\hline 25000 & 2078 & 15000 & 1538 & 5000 & 928 & 3000 & 690 \\
\hline 30000 & 2304 & 20000 & 1822 & 7500 & 1377 & 4.000 & 796 \\
\hline 40000 & 2772 & 25000 & 2092 & 10000 & 1825 & 5000 & 889 \\
\hline 50000 & 3200 & 40000 & 2856 & 15000 & 2716 & 7000 & 1050 \\
\hline 70000 & 4. 018 & 60000 & 3792 & 25000 & 4508 & 10000 & 1253 \\
\hline 140000 & 6720 & 90000 & 5094 & 30000 & 5400 & 20000 & 1754 \\
\hline 240000 & 10464 & 170000 & 7208 & 60000 & 10764 & 30000 & 2121 \\
\hline 260000 & 11024 & & & & & 40000 & 2432 \\
\hline 570000 & 22059 & & & & & 120000 & 3792 \\
\hline
\end{tabular}

Cuadro 5

ERROR DE LOS PORCENTAJES DE INMIGRANTES Y NO INMIGRANTES

(Gran Santiago)

\begin{tabular}{rrrrrrrrr}
$\mathrm{n} \backslash \mathrm{r}$ & 5 & 10 & 20 & 40 & 60 & 80 & 90 & 95 \\
\hline 50000 & 1,4, & 2,4 & 3,5 & 3,7 & 3,0 & 2,1 & 1,7 & 1,5 \\
100000 & 1,0 & 1,7 & 2,5 & 2,6 & 2,1 & 1,5 & 1,2 & 1,1 \\
150000 & 0,8 & 1,4 & 2,0 & 2,1 & 1,7 & 1,2 & 1,0 & 0,9 \\
200000 & 0,7 & 1,2 & 1,7 & 1,9 & 1,5 & 1,0 & 0,9 & 0,8 \\
250000 & 0,6 & 1,1 & 1,6 & 1,7 & 1,3 & 0,9 & 0,8 & 0,7 \\
850000 & 0,3 & 0,6 & 0,8 & 0,9 & 0,7 & 0,5 & 0,4 & 0,4 \\
\hline
\end{tabular}


Cuadno 6

ERROR DE LOS PORCENTAJES DE ECONOMICAMENTE ACTIVOS Y DE NO ACTIVOS PARA NO INMIGRANTES

(Gran Santiago)

\begin{tabular}{rcccccccc}
\hline n \} $&{5} &{10} &{20} &{40} &{60} &{80} &{90} &{95} \\
{\hline 5000} &{3,4} &{5,8} &{8,4} &{8,8} &{6,9} &{4,8} &{4,0} &{3,8} \\
{10000} &{2,4} &{4,1} &{5,9} &{6,2} &{4,9} &{3,4} &{2,8} &{\mathbf{2 , 5}} \\
{15000} &{2,0} &{3,3} &{4,8} &{5,1} &{4,0} &{2,8} &{2,3} &{2,1} \\
{50000} &{1,1} &{1,8} &{2,6} &{2,8} &{2,2} &{1,5} &{1,3} &{1,1} \\
{100000} &{0,8} &{1,3} &{1,9} &{2,0} &{1,5} &{1,1} &{0,9} &{0,8} \\
{130000} &{0,7} &{1,1} &{1,6} &{1,7} &{1,4} &{1,0} &{0,8} &{0,7} \\
{260000} &{0,5} &{0,8} &{1,2} &{1,2} &{1,0} &{0,7} &{0,5} &{\mathbf{0 , 5}} \\
{\hline}$
\end{tabular}

Cuadro 7

ERROR DE LOS PORCENTAJES DE ECONOMICAMENTE ACTIVOS Y DE NO ACTIVOS, PARA INMIGRANTES

(Gran Santiago)

\begin{tabular}{rcrrrrrrr}
\hline n ${ }^{\mathrm{r}}$ & 5 & 10 & \multicolumn{1}{c}{20} & \multicolumn{1}{c}{40} & 60 & 80 & 90 & $\mathbf{9 5}$ \\
\hline 2500 & 4,0 & 7,0 & 10,5 & 11,9 & 10,2 & 7,7 & 6,5 & 6,0 \\
5000 & 2,8 & 4,9 & 7,4 & 8,4 & 7,2 & 5,4 & 4,6 & 4,2 \\
10000 & 2,0 & 3,5 & 5,3 & 6,0 & 5,1 & 3,8 & 3,2 & 3,0 \\
20000 & 1,4 & 2,5 & 3,7 & 4,2 & 3,6 & 2,7 & 2,3 & 2,1 \\
40000 & 1,0 & 1,7 & 2,6 & 3,0 & 2,5 & 1,9 & 1,6 & 1,5 \\
80000 & 0,7 & 1,2 & 1,9 & 2,1 & 1,8 & 1,4 & 1,1 & 1,0 \\
\hline
\end{tabular}

Cuadro 8

ERROR DE LOS PORCENTAJES DE OCUPADOS Y DESOCUPADOS, PARA INMIGRANTES ACTIVOS LLEGADOS EN EL PERTODO 1952-1962

(Gran Santiago)

\begin{tabular}{rrrrrrrrr}
\hline n $\backslash$ r & 5 & 10 & 20 & 40 & 60 & 80 & 90 & 95 \\
\hline 2500 & 4,9 & 8,4 & 12,5 & 13,7 & 11,3 & 8,3 & 6,9 & 6,2 \\
5000 & 3,5 & 6,0 & 8,8 & 9,7 & 8,0 & 5,8 & 4,9 & 4,4 \\
10000 & 2,5 & 4,2 & 6,3 & 6,9 & 5,6 & 4,1 & 3,4 & 3,1 \\
20000 & 1,7 & 3,0 & 4,4 & 4,9 & 4,0 & 2,9 & 2,4 & 2,2 \\
40000 & 1,2 & 2,1 & 3,1 & 3,4 & 2,8 & 2,1 & 1,7 & 1,5 \\
60000 & 1,0 & 1,7 & 2,6 & 2,8 & 2,3 & 1,7 & 1,4 & 1,3 \\
\hline
\end{tabular}


Cuadro 9

ERROR DE LOS PORCENTAJES DE OCUPADOS Y DESOCUPADOS,

PARA NO INMIGRANTES ACTIVOS LLEGADOS EN EL PERIODO

1952-1962

(Gran Santiago)

\begin{tabular}{rcrrrrrrr}
\hline $\mathbf{n} \backslash \mathbf{r}$ & 5 & 10 & 20 & 40 & 60 & 80 & 90 & 95 \\
\hline 2500 & 5,2 & 8,9 & 13,1 & 14,3 & 11,7 & 8,5 & 7,0 & 6,4 \\
5000 & 3,7 & 6,3 & 9,3 & 10,1 & 8,3 & 6,0 & 5,0 & 4,5 \\
10000 & 2,6 & 4,5 & 6,6 & 7,2 & 5,8 & 4,2 & 3,5 & 3,2 \\
20000 & 1,8 & 3,1 & 4,6 & 5,1 & 4,1 & 3,0 & 2,5 & 2,3 \\
40000 & 1,3 & 2,2 & 3,3 & 3,6 & 2,9 & 2,1 & 1,8 & 1,6 \\
80000 & 0,9 & 1,6 & 2,3 & 2,5 & 2,1 & 1,5 & 1,3 & 1,1 \\
120000 & 0,7 & 1,3 & 1,9 & 2,1 & 1,7 & 1,2 & 1,0 & 0,9 \\
200000 & 0,6 & 1,0 & 1,5 & 1,6 & 1,3 & 1,0 & 0,8 & 0,7 \\
\hline
\end{tabular}

Los cuadros 4 y 9 permiten obtener sin dificultad la magnitud del orden del error de muestreo de la siguiente manera:

\section{Ejemplo 1}

Supóngase que el número estimado de inmigrantes masculinos de 30-39 años de edad es de 51300 .

En el cuadro 4, para un total estimado del orden de 50000 , el error de muestreo es de 3200 . De esa manera, el número estimado de inmigrantes masculinos estará comprendido enire estas dos cantidades:

$$
\begin{aligned}
51300+3200 & =54500 \\
y & \\
51300-3200 & =48100
\end{aligned}
$$

con una seguridad de 68 por ciento (si se quiere una mayor seguridad, por ejemplo de 95 por ciento, se puede emplear 2 veces la cantidad $3200)$.

\section{Ejemplo 2}

Supóngase que del total de hombres de 30 a 39 años de edad en la población del Gran Santiago, el 50 por ciento está constituido por inmigrantes. Este porcentaje esiimado tendrá - basándose en el cuadro 5 - un error de 2,4 por ciento, ya que el número estimado de hombres de aquella edad es de $n=103500$. 


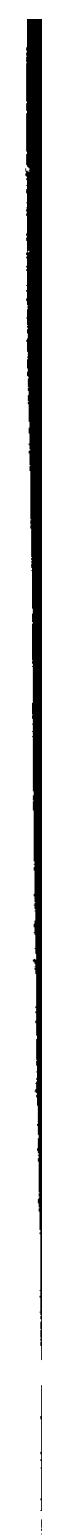




\title{
APENDICE 2
}

\author{
DEFINICIONES, CUESTIONARIOS, ORGANIZACIÓN DEL TRABAJO DE \\ TERRENO Y TARJETA IBM
}

\section{Definiciones}

Los elementos básicos que intervinieron en la encuesta requerían definiciones precisas, pero, al mismo tiempo, fáciles de comprender y aplicar. Aquí se hace referencia solamente a los elementos que constituían unidades de enumeración, esto es: el hogar, jefe del hogar, demás personas que forman parte del hogar y a los inmigrantes.

Dado que el hogar era la unidad secundaria de muestreo, su definición es análoga a la definición de familia censal seguida en el censo de población de 1960, cuyos resultados constituyeron el marco de la muestra. Era de gran importancia definir en forma clara y precisa al hogar, considerando que bajo una misma dirección, en una unidad habitacional (casa, departamento, etc.) destinada normalmente a vivienda de una familia (familia en sentido amplio), pueden vivir dos o más grupos familiares independientes, generalmente no vinculados entre sí.

El hogar familiar se definió como el conjunto de personas (puede ser una sola persona) vinculadas entre sí por matrimonio, consanguinidad, afinidad o adopción, que viven en una vivienda familiar. En muchos casos comprende, además, a simples allegados o huéspedes. Los empleados(as) domésticos(as) eran parte del hogar siempre que dur. mieran habitualmente en la vivienda; en caso contrario, no se consideraban parte del hogar familiar y se excluían de la encuesta.

A su vez, el hogar en residencial o pensiön se definió como un conjunto de personas (puede ser una sola persona) vinculadas entre sí por matrimonio, consanguinidad, afinidad o adopción, que hacen vida común en casa de huéspedes. Como surge de esta definición, los hogares en residenciales o pensiones son núcleos más restringidos que los hogares familiares. Ello se pone más en claro en las instrucciones especiales que se impartieron para censar los hogares existentes en residenciales o pensiones, como paso previo a la selección de hogares en vi- 
viendas de este tipo. Según esas instrucciones, habría tantos hogares de pensionistas como matrimonios (o parejas) y núcleos de un padre (madre o tutor) con hijos o menores a cargo, más las personas excluidas de estos hogares, cada una de las cuales forma un hogar separado. El hogar del dueño o administrador de la residencial o pensión, se definió como un hogar familiar, con exclusión de los huéspedes.

Formaban parte del hogar, de cualquier tipo, y debían incluirse en la encuesta, todas las personas (adultos y niños) que residían efectivamente en la unidad habitacional (vivienda) que ocupaba el hogar considerado. Se estimó que reunían esas condiciones las personas que dormían en la vivienda cuatro días o más de la semana. La definición se completó con varias excepciones a esta última regla, con el fin de incluir a aquellas personas que por la índole de sus ocupaciones o por otros motivos circunstanciales (viajes, vacaciones, etc.), se encontraban temporalmente ausentes del hogar en la época de la encuesta, y de excluir a personas temporalmente presentes (visitantes, etc.). Puede decirse, en consecuencia, que la enumeración se realizó sobre una base "de jure" estricta, tanto en relación a la residencia en el Gran Santiago como a la vivienda.

Para los efectos de la encuesta, se consideró inmigrante a toda persona no nacida en el Gran Santiago. Esta definición, simple y fácil de aplicar, corresponde al concepto usualmente seguido en los censos de población y en otras encuestas especializadas; pero no es completa. Excluye a los nativos del Gran Santiago que, habiendo emigrado, retornan después de un tiempo que puede ser bastante largo. Su consideración presenta algunos problemas que es preferible evitar, sobre todo si se tiene en cuenta que esos casos son de escasa significación numérica en un centro de atracción como el Gran Santiago. En efecto, hay dificultades para calificar a esas personas como inmigrantes en relación al tiempo de ausencia, a las causas de salida y de regreso y a otras circunstancias, como, por ejemplo, si vivió en el exterior o en otra parte del país. Las reglas serían de difícil aplicación por parte de los entrevistadores y quizá podrían constituir una fuente de confusión y, en consecuencia, de errores.

Respecto de las personas nacidas accidentalmente en el Gran Santiago, por asistencia maternal $u$ otras razones, se tomaron precauciones para registrarlas como inmigrantes si en el momento de la encuesta formaban parte de un hogar entrevistado. En forma análoga, no se consideró inmigrantes a las personas nacidas accidentalmente fuera del Gran Santiago.

En las instrucciones a los investigadores se estableció que la información relativa a todos los miembros del hogar debía obtenerse del jefe del hogar. En ausencia de éste, debía entrevistarse a su esposa o com- 
DEFINICIONES, CUESTIONARIOS, ORGANIZACIÓN Y TARJETA IBM 211

pañera, o a la mujer vinculada al jefe que hiciera las veces de ama de casa. Pero mucha más importancia tiene la identificación del jefe de hogar para las estadísticas de hogares, desde el momento que las relaciones de parentesco o vínculos se establecen en el cuestionario con relación al jefe del hogar.

La definición adoptada es simple: jefe del hogar es la persona que los demás miembros del hogar familiar consideran como tal. Hay una sola excepción: si esa persona es una mujer casada cuyo marido forma parte del hogar, el jefe necesariamente es el marido. Sólo en los casos en que los miembros del hogar no podian decir quién era el jefe, se usaban varios criterios de selección que tenían el siguiente orden de aplicación: principal sosićn económico del hogar; mayor autoridad; el arrendatario de la vivienda (o el propietario, en su caso); el hombre adulto de mayor edad; la mujer de mayor edad.

Esta definición de jefe del hogar llevaría, como se comprobó después, a un resultado satisfactorio en un porcentaje elevado de hogares. No se justificaba, entonces, emplear una definición más compleja para cubrir casos muy variados y poco frecuentes, con el consiguiente riesgo de introducir una fuente de errores. Se optó por revisar a posteriori todos los cuestionarios, para reconsiderar aquellos casos en que la selección del jefe no era la más útil para los fines del análisis. En repetidos casos, por ejemplo, la opinión acerca del jefe se basú en el principio de autoridad familiar (padre, madre, hermano mayor, etc.), cuando se trataba de personas de edad avanzada y sin medios propios de sostén. En tales casos, era manifiesto que convenía seleccionar como jefe a un hijo, yerno u otra persona generalmente casada que era el centro de un núcleo familiar interesante.

\section{Cuestioxarios}

Se utilizaron dos cuestionarios. Uno, colectivo, destinado a registrar datos comunes de todos los miembros del hogar; el otro, individual, para realizar entrevistas complementarias, directas y personales, a cada inmigrante revelado por el cuestionario colectivo, siempre que hubiera llegado a vivir al Gran Santiago después de los 14 años de edad.

Los datos del primero de los cuestionarios mencionados, se usarían para el esiudio del nivel y tendencias de la corriente migratoria y de las características demográficas y económicas sociales diferenciales de la población inmigrante, respecto de la población no migrante. A su vez, el estudio de las motivaciones y factores vinculados a los movimientos, la movilidad de los inmigrantes (historia migratoria) y aspectos relacionados con la asimilación de éstos al nuevo medio urbano, dependían de la información del cuestionario individual. 
Para numerosos tópicos del cuestionario colectivo, las respuestas alternativas más frecuentes estaban impresas y pre-codificadas, como son datos de la vivienda, sexo, estado civil, nivel de instrucción, categoría en la ocupación, horas trabajadas y causas de desempleo, entre otras.

Como norma general, se formularon preguntas abiertas para investigar aspectos poco conocidos, respecto de los cuales es casi imposible establecer, por anticipado, las respuestas más frecuentes. Por otra parte, tratándose de consultas sobre motivaciones, opiniones y actitudes, como era el caso del cuestionario individual, se usaron preferentemente preguntas abiertas. No obstante la ventaja de este tipo de pregunta, en el sentido que permite al entrevistado expresarse libremente y con amplitud, también puede ser una fuente de ambigüedades, esto es falta de especificidad de las respuestas. A modo de ejemplo se puede citar la pregunta sobre motivos para emigrar. Como, en una alta proporción, el motivo principal es económico, lo cual se puede anticipar, existe un gran interés en obtener respuestas más específicas, tales como condiciones de trabajo, nivel de salarios o ingresos, desocupación, etc. Otro tanto ocurre con los "motivos familiares", dentro de los cuales caben una variedad de situaciones particulares que interesa conocer.

A continuación se proporciona el contenido resumido de los cuestionarios usados:

\section{Cuestionario colectivo (tópicos)}

Identificación de la vivienda: Hogar N ${ }^{Q}$ - Comuna - Dirección.

Datos de la vivienda: Tipo - Servicio - Número de cuartos - Tenencia.

Datos personales: Nombre - Sexo - Vínculo o relación con el jefe del hogar - Estado conyugal - Número de hijos tenidos nacidos vivos Año de nacimiento - Ultimo año de instrucción aprobado - Asistencia escolar - Tipo de actividad - Ocupación - Rama de actividad - Categoría en la ocupación - Ingreso - Horas trabajadas en la última semana Causas de desempleo y de jornada parcial - Demanda de empleo - Lugar de nacimiento - Año de llegada al Gran Santiago - Lugar de la residencia anterior - Edad al llegar al Gran Santiago - Propósito de la venida al Gran Santiago (sólo para personas llegadas antes de los 14 años).

\section{Cuestionario individual (tópicos)}

Identificación del inmigrante: Hogar № - Persona $\mathrm{N}^{\circ}$ - Nombre Lugar de nacimiento - Edad al llegar al Gran Santiago. 
Historia migratoria (cada movimiento) : Lugar - Fechas de llegada y salida - Ocupación principal - Personas dependientes que lo acompañaron o siguieron.

De la época inmediatamente antes de llegar al Gran Santiago: Motivos de la emigración - Consejos - Ayudas - Actividad económica Bienes raíces dejados en el lugar donde ha vivido - Antecedentes de la familia del inmigrante (edad, ocupación, lugar de residencia, frecuentación).

Después de llegar al Gran Santiago: Primera ocupación - Primera vivienda.

De la vida actual: Ingresos - Previsión social - Participación social (instituciones, etc.) - Opiniones y actitudes generales (17 preguntas).

\section{ORGanización DEL TRabajo EN EL TERRENo}

Con anterioridad a esta encuesta, en el Gran Santiago ya se habian realizado varias investigaciones sociológicas, de salud, de mano de obra y de fecundidad, utilizando métodos análogos. Por otra parte, el nivel medio de instrucción de la población de esta área es suficientemente alto como para asegurar el buen éxito de una encuesta especializada.

Los entrevistadores fueron reclutados, en su mayoría, entre estudiantes de ambos sexos de la Escuela de Sociología de la Universidad de Chile. La elección de este tipo de entrevistador, además de las ventajas de su formación universitaria y de su natural entusiasmo por esta clase de tarea, tuvo a su favor la buena acogida que generalmente tienen los estudiantes en la población de los más diversos niveles sociales. En el momento inicial se comprometió a 76 entrevistadores, pero, por selección y deserción, hacia el final de la encuesta estaban trabajando menos de 30 personas. Como es usual, se proveyó a los entrevistadores de un manual de instrucciones y de los elementos necesarios (listado, croquis, etcétera) para identificar los hogares que debían encuestar.

Las entrevistas comenzaron el 10 de mayo de 1962, habiéndose completado el 76 por ciento de las encuestas a realizar en los primeros 100 días. Este trabajo finalizó hacia el 10 de octubre, cubriendo el 90,5 por ciento de la muestra. Dado que este porcentaje promedio de pérdidas, del 9,5, no era parejo en todas las comunas del Gran Santiago, alli donde fue necesario se completaron nuevas entrevistas. Finalmente quedaron concluidas 2137 encuestas sobre un total de 2309 de la muestra, esto es el 92,6 por ciento. A su vez, se realizaron 2251 entrevistas con el cuestionario individual, sobre un total, dentro de las encuestas concluidas antes citadas, de 2432 entrevistas posibles. 
Además de la revisión crítica de la información recogida, que se hizo en oficina, supervisores controlaron en el terreno aproximadamente el 20 por ciento de las encuestas. Por último, los trabajos de codificación, perforación de tarjetas IBM y tabulados básicos, quedaron terminados a fines de marzo del año 1963.

Esta breve reseña se concluye con un detalle de los campos de la tarjeta IBM y los tópicos que se trasladaron a la misma.

4. Tarjeta ibm para tabulación mecánica

\begin{tabular}{|c|c|}
\hline $\begin{array}{l}\text { Número de columna } \\
\text { de la tarjeta IBM }\end{array}$ & Concepto codificado \\
\hline $1-2-3-4$ & Número de serie del hogar \\
\hline 5 & Comuna donde está situada la vivienda \\
\hline $6-7$ & Número de serie de los miembros del hogar \\
\hline 8 & Sexo \\
\hline 9 & Relación con el jefe del hogar \\
\hline 10 & Estado civil (mayores de 12 años de edad) \\
\hline $11-12$ & $\begin{array}{l}\text { Número de hijos nacidos vivos tenidos (mujeres no } \\
\text { solteras) }\end{array}$ \\
\hline $13-14$ & Año de nacimiento \\
\hline 15 & Status migratorio \\
\hline $16-17$ & $\begin{array}{l}\text { Nivel de educación alcanzado: curso y año (perso- } \\
\text { nas mayores de } 6 \text { años de edad) }\end{array}$ \\
\hline $18-19$ & $\begin{array}{l}\text { Asistencia escolar: curso y año (personas de } 6 \text { a } 28 \\
\text { años de edad) }\end{array}$ \\
\hline 20 & Tipo de actividad \\
\hline $21-22$ & Ocupación \\
\hline 23 & Rama de actividad \\
\hline 24 & Categoría ocupacional \\
\hline $25-26-27$ & Ingreso mensual derivado de actividad personal \\
\hline 28 & $\begin{array}{l}\text { Número de horas trabajadas en la semana anterior } \\
\text { a la entrevista }\end{array}$ \\
\hline 29 & $\begin{array}{l}\text { Motivo por el cual trabajó menos de } 35 \text { horas en la } \\
\text { semana anterior a la entrevista }\end{array}$ \\
\hline 30 & $\begin{array}{l}\text { Motivo por el cual no trabajó en la semana anterior } \\
\text { a la entrevista }\end{array}$ \\
\hline 31 & Si busca o no empleo \\
\hline $32-33$ & Provincia o país de nacimiento \\
\hline
\end{tabular}


(Continuación)

Número de columna de la tarjeta IBM Concepto codificado

Tamaño de la población (en 1952) del lugar de nacimiento

$35-36$

Año de emigración al Gran Santiago

$37-38$

Provincia o país de residencia antes de emigrar al Gran Santiago

39

Tamaño de la población (en 1952) del lugar de residencia anterior

$40-41$

42

Edad al emigrar al Gran Santiago

Propósito de emigración al Gran Santiago de los menores de 14 años que llegaron solos.

\section{Datos de la vivienda}

$43 \quad$ Tipo de vivienda

\section{Servicios de la vivienda}

Número de piezas de la vivienda

Tenencia de la vivienda

Forma de adquisición de la vivienda

Arriendo mensual de la vivienda

\section{Datos del hogara}

50

Tipo de hogar

53-54

55

Composición del hogar

Número de personas que formais el hogar

Número de inmigrantes entre los miembros del hogar

56

Número de niños menores de 14 años en el hogar

Número de niños de 7 a 13 años matriculados en establecimienios die enseñanza

Vúmero de niños de 7 a 13 años no matriculados en establecimientos de enseñanza

* Solamente en la tarjeta del jefe del hogar. La información de las columnas 50 a 65 se codificó mecánicamente. 
(Continuación)

Número de columna de la tarjeta IBM

59

60

61-62

$63-64$

65

66-67

68

69

71

72-73-74-75

76-77

78

80
Concepto codificado

Actividad económica de la esposa (o compañera) del jefe del hogar

Status migratorio del jefe del hogar y de su esposa (o compañera)

Edad de la esposa (o compañera) del jefe del hogar

Nivel de educación de la esposa (o compañera) del jefe del hogar

Número de personas económicamente activas en el hogar

Datos de inmigrantes llegados con más de 14 años de edad

Edad a la cual inició la historia migratoria (a partir de los 14 años de edad)

Número de movimientos migratorios realizados a partir de los 14 años de edad.

Tamaño de la población (en 1962) del lugar de destino del primer movimiento migratorio a partir de los 14 años de edad

Personas dependientes que acompañaron o que siguieron más tarde al inmigrante en el último movimiento al Gran Santiago

Motivo principal para emigrar al Gran Santiago

Tipo de actividad, ocupación y grado de empleo en el lugar desde donde emigró al Gran Santiago

Primera ocupación en el Gran Santiago

Tiempo transcurrido entre la fecha de la emigración y el comienzo de la primera ocupación en el Gran Santiago

Comuna del Gran Santiago donde estaba situada la primera vivienda del inmigrante

Grado de conformidad del inmigrante con la vida en el Gran Santiago 


\section{N D I C E}

PÁG.

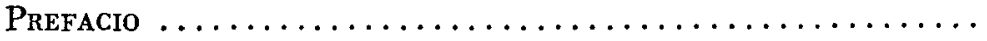

INTRODUCCIÓN

1. El proceso de redistribución de la población en América Latina $. . . \ldots \ldots \ldots \ldots \ldots \ldots \ldots \ldots \ldots . \ldots \ldots$

2. Principales corrientes migratorias $\ldots \ldots \ldots \ldots \ldots \ldots \ldots, 15$

3. Objetivos de la encuesta del Gran Santiago .......... 23

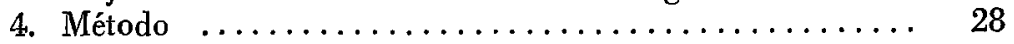

I. La corriente hacia el Gran Santiago. Principales caracte-

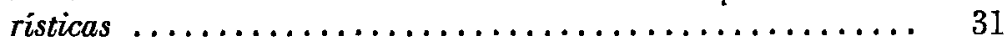

1. Tendencia histórica y composición por sexo ........ 31

2. Estructura por edad de llegada ................ 32

3. Lugar de emigración (última residencia) $\ldots \ldots \ldots \ldots, 40$

4. Lugar de nacimiento y de emigración ............ 49

5. Lugar de origen de los inmigrantes y nivel de instruc-

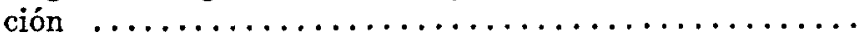

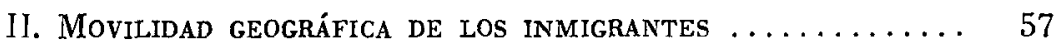

1. Movilidad y edad de llegada ................. 57

2. Movilidad y lugar de emigración $\ldots \ldots \ldots \ldots \ldots \ldots \ldots$. 59

3. Movilidad y lugar de nacimiento $\ldots \ldots \ldots \ldots \ldots \ldots .62$

4. Lugar de nacimiento y lugar de procedencia ........ 64

-5. Movilidad y nivel de instrucción ................ 68

6. Edad inicial de la historia migratoria $\ldots \ldots \ldots \ldots \ldots \ldots, 70$

III. FACTORES ECONÓMICO-SOCIALES VINCULAdOS AL MOVIMIENTO MIgratorio hacia el Gran Santiago $\ldots \ldots \ldots \ldots \ldots \ldots \ldots$

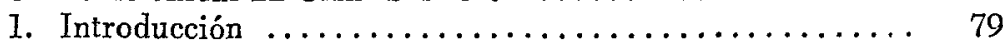

2. La población estudiada y sus principales características .. 80

3. Inmigración individual e inmigración familiar ....... 84 .

:4. Motivo principal del movimiento. Análisis por sexo, edad y zona de emigración $\ldots \ldots \ldots \ldots \ldots \ldots \ldots \ldots$

5. Motivo principal del movimiento. Análisis según el grado de ocupación inmediato anterior al movimiento al Gran Santiago 
6. Motivo principal del movimiento. Análisis por "clases" eco. nómico-sociales ..........................

IV. Algunos aspectos de la asimilación .............. $97^{i}$

1. Ubicación de la vivienda en la ciudad ............ 97

2. Tiempo transcurrido desde la llegada hasta comenzar a trabajar ............................. 101

3. Primera ocupación y nivel de instrucción ......... 106

4. Ocupación y lugar de emigración $\ldots \ldots \ldots \ldots \ldots \ldots \ldots, 110$

5. Movilidad profesional de los inmigrantes ........... \$ll

V. Los effectos demográficos. Parte 1 .............. 129

1. El crecimiento de la población del Gran Santiago ...... 129

2. Estructura por sexo y edad .................. 130

3. Importancia relativa de la población migrante por sectores de la ciudad ........................... 134

4. Estado civil y fecundidad ................... 136

๑5. Educación ........................... 139

- 6. Características económicas ................. 145

VI. Los effectos demográficos. Parte $2 \ldots \ldots \ldots \ldots \ldots \ldots . \ldots \ldots$

Estudio de los hogares ..................... 171

1. Introducción $\ldots \ldots \ldots \ldots \ldots \ldots \ldots \ldots \ldots \ldots \ldots \ldots \ldots \ldots \ldots \ldots$

2. Condiciones de la vivienda ................... 174

3. Estructura del hogar ..................... 179

4. Características económicas del hogar ............ 190

APÉNDICE 1. Descripción de la muestra y cálculo del error ..... 199

APÉNDICE 2. Definiciones, cuestionarios, organización del trabajo de terreno y tarjeta IBM ................. 209

\section{INDICE DE CUADROS Y GRÁFICOS}

\section{Cuadros}

1)1. Urbanización y tasas de crecimiento de la población total y de núcleos de población de distintos tamaños, de países de América Latina, en la década $1950-1960$. . . . . . . . . . . . .

2. Porcentaje de habitantes empadronados en un Estado (provincia) distinto del de nacimiento (ambos sexos) ...........

3. Migración neta inter-regional ocurrida en México en el pe-

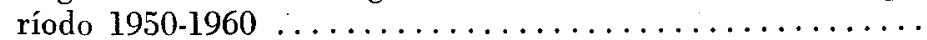

4. Tasas anuales de migración de la zona urbana y del núcleo principal, de varios países de América Latina en periodos re-

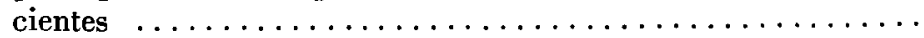

5. Proporción de origen urbano de los inmigrantes y de los emi- 
grantes, hacia y desde la provincia de Concepción (Chile), por regiones de salida y de destino, respectivamente (periodo 1952-

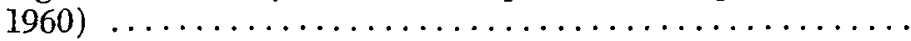

6. Distribución de los inmigrantes por períodos de llegada ....

7. Inmigrantes al Gran Santiago, por edad y por períodos de

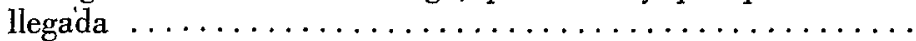

(8. Inmigrantes según la edad de llegada y número de movimientos migratorios, $1942.1962 \ldots \ldots \ldots \ldots \ldots \ldots \ldots \ldots \ldots \ldots$

9. Inmigrantes, por edad de llegada y zona de procedencia, períodos 1952-1962 y 1951 y años anteriores .............

10. Inmigrantes al Gran Santiago por lugar de emigración, ambos

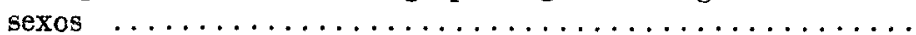

11. Distribución por zonas de procedencia de los inmigrantes

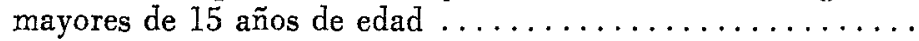

12. Inmigrantes por lugar de emigración, en distintos periodos de Ilegada $\ldots \ldots \ldots \ldots \ldots \ldots \ldots \ldots \ldots \ldots \ldots \ldots \ldots \ldots \ldots \ldots \ldots \ldots \ldots \ldots$

13. Inmigrantes por sexo y edad, según las zonas de emigración,

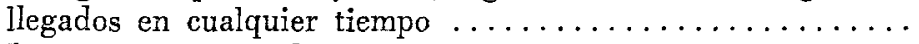

14. Inmigrantes según la región de emigración $\ldots \ldots \ldots \ldots \ldots$

15. Inmigrantes procedentes de la región de nacimiento respectiva

16. Inmigrantes procedentes de su región de nacimiento ......

17. Razón entre el número de inmigrantes clasificados según la zona de nacimiento y el número de inmigrantes procedentes de la respectiva zona, $1952-1962 \ldots \ldots \ldots \ldots \ldots \ldots \ldots$

18. Nivel de instrucción de los inmigrantes, según lugar de na-

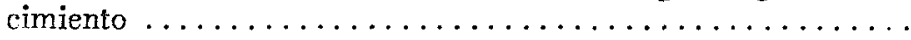

19. Inmigrantes según la edad de llegada al Gran Santiago y según el número de movimientos migratorios realizados después de cumplir I4 años de edad

20. Porcentajes de inmigrantes con un movimiento migratorio (de los movimientos realizados después de cumplir 14 años de edad), según la edad de llegada al Gran Santiago y según el lugar de emigración $\ldots \ldots \ldots \ldots \ldots \ldots \ldots \ldots \ldots \ldots$

21. Movilidad de los inmigrantes llegados al Gran Santiago de I4 a 29 años, según el lugar de emigración ..............

22. Porcentajes de inmigrantes con un movimiento, y proporción

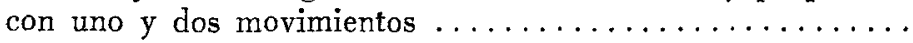

23. Inmigrantes llegados al Gran Santiago de 14, y más años de edad, en un primer movimiento migratorio, del lugar de naci-

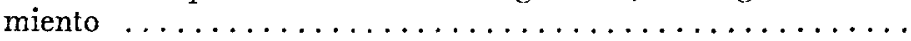

24. Porcentajes de inmigrantes llegados al Gran Santiago de 14 años y más de edad, según lugar de nacimiento y según lugar

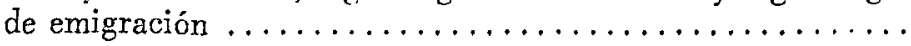


25. Inmigrantes llegados al Gran Santiago de 14 y más años de edad, según lugar de nacimiento y según lugar de emigración

26. Movilidad de los inmigrantes según el nivel de instrucción

27. Inmigrantes llegados al Gran Santiago de 14 y más años de edad, según la edad inicial de la historia migratoria (a partir del nacimiento) y según el número de movimientos ........

28. Porcentaje de inmigrantes llegados al Gran Santiago de 14 y más años de edad, según la edad inicial de la historia migratoria, el lugar de nacimiento y el número de movimientos ..

29. Porcentajes de inmigrantes llegados al Gran Santiago de 14 y más años de edad, según la edad inicial de la historia migratoria después de los 14 años y según el lugar de nacimiento

30. Inmigrantes llegados al Gran Santiago de 14 y más años de edad, según la edad al llegar y el nivel de instrucción en el momento de la encuesta .........................

31. Tasas de participación en actividades económicas de inmigrantes, en el lugar de procedencia y en el Gran Santiago en la época de la encuesta ..........................

32. Inmigrantes según "clases" económico-sociales en el lugar de procedencia, por zonas de procedencia $\ldots \ldots \ldots \ldots \ldots \ldots$.

33. Inmigrantes según el tipo de migración individual y de grupos familiares por zonas de procedencia, periodo 1942-1962 ...

34. Inmigrantes llegados en el período 1942-1962 según el motivo principal para venir al Gran Santiago, y zonas de emigración

35. Inmigrantes llegados en el período 1942-1962, según el motivo principal para venir al Gran Santiago y grado de empleo

36. Inmigrantes llegados en el período 1942-1962, según el motivo principal para venir al Gran Santiago y clases económico-

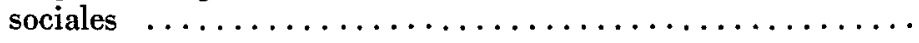

37. Inmigrantes distribuidos según los sectores donde tenían su primera vivienda y su vivienda en la época de la encuesta

38. Distribución de los inmigrantes según el sector en que tenían su vivienda en la época de la encuesta y por lugar de emigra-

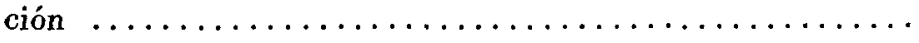

39. Inmigrantes clasificados según el tiempo que necesitaron para comenzar a trabajar en el Gran Santiago, en relación con algunos motivos declarados de la inmigración ..............

40. Inmigrantes clasificados según el tiempo que necesitaron para comenzar a trabajar en el Gran Santiago, y edad al llegar

41. Inmigrantes clasificados según el tiempo que necesitaron para comenzar a trabajar en el Gran Santiago, y lugar de proce-

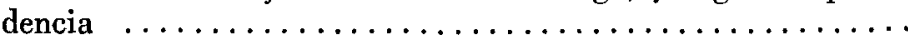


42. Nivel de educación y primera ocupación en el Gran Santiago

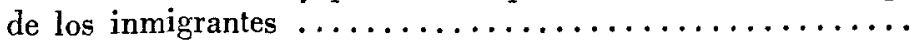

43. Inmigrantes que obtuvieron su primer empleo en el primer año de vida en el Gran Santiago, según la duración en ese empleo

44. Inmigrantes que obtuvieron su primer empleo en el primer año de vida en el Gran Santiago, según la duración en ese empleo y el nivel de educación ..........................

45. Ultimo status económico-social y lugar de emigración ........

46. Movilidad profesional. Composición por ocupaciones ("clases" económico-sociales) de los inmigrantes en tres momentos: antes de emigrar al Gran Santiago, al comenzar a trabajar en el Gran Santiago y en la época de la encuesta ...............

47. Movilidad profesional. Composición por ocupaciones ("clases" económico-sociales) en tres momentos: antes de emigrar al Gran Santiago, al comenzar a trabajar en el Gran Santiago y en la época de la encuesta. (Hombres llegados en el período

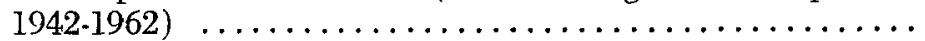

48. Movilidad profesional. Composición por ocupaciones ("clases" económico-sociales), en tres momentos: antes de emigrar al Gran Santiago, al comenzar a trabajar en el Gran Santiago y en la época de la encuesta. (Mujeres llegadas en el período

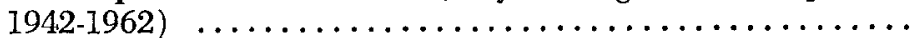

49. Movilidad profesional. Cambio de siatus económico-social: Primera ocupación en el Gran Santiago y ocupación en la época de la encuesta. (Hombres llegados en el período 1942-1962)

50. Movilidad profesional. Cambio de ocupación de trabajadores de algunos grupos de ocupaciones: Primera ocupación en el Gran Santiago y ocupación en la época de la encuesta. (Hom-

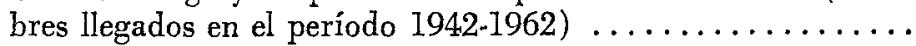

51. Movilidad profesional. Cambio de status económico-social: Primera ocupación en el Gran Santiago y ocupación en la época de la encuesta. (Mujeres llegadas en el período 1942-1962)

52. Porcentajes de inmigrantes al Gran Santiago por sexo y grupos

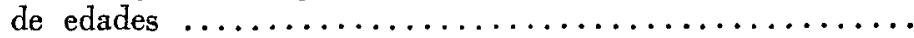

53. Estructuras por edad de las poblaciones inmigrante y nativa del Gran Santiago, por sexo ......................

54. Indices de masculinidad de los inmigrantes y los nativos en el

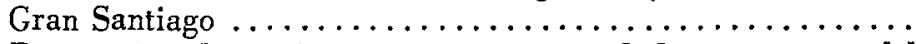

55. Porcentajes de inmigranles por sexo y edad por sectores del

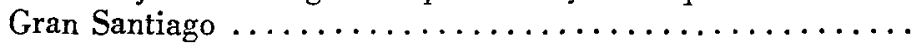

56. Composición porcentual según el estado civil de mayores de 12 años, de inmigrantes y de nacidos en el Gran Santiago ..

57. Promedio de hijos (nacidos vivos) tenidos por mujeres no sol- 
teras mayores de 20 años, inmigrantes y nacidas en el Gran

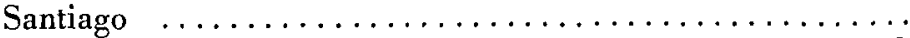

58. Nivel de instrucción de la población mayor de 15 años de edad, en el Gran Santiago ............................ 141

59. Nivel de instrucción según el sexo en el Gran Santiago ....

60. Porcentaje de personas matriculadas en el Gran Santiago, por sexo y condición de nativas e inmigrantes ..............

$\checkmark 61$. Tasas de participación en actividades económicas .........

$\checkmark 62$. Tasas de participación en actividades económicas de inmigrantes y de nativos del Gran Santiago y comparación entre las tasas obtenidas en la encuesta de inmigración (1962) y en la en. cuesta de ocupación y desocupación de $1963 \ldots \ldots \ldots \ldots \ldots$

$\checkmark$ 63. Tasas de desocupación en el Gran Santiago ..............

$\checkmark$ 64. Nivel del empleo en el Gran Santiago entre los inmigrantes y

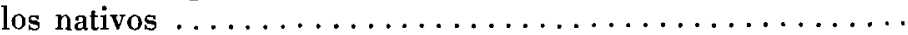

65. Trabajadores ocupados a tiempo completo que buscan empleo en el Gran Santiago ...........................

$\checkmark 66$. Población económicamente activa en el Gran Santiago clasificada según sus ingresos mensuales . . . . . . . . . . . . 160

67. "Clases" económico-sociales ................... 162

68. Porcentaje de trabajadores de los servicios personales en el

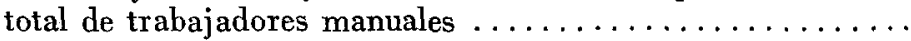

69. Porcentaje de profesionales, técnicos y afines en el total de tra-

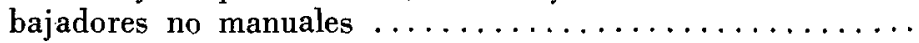

70. Población económicamente activa, según categorías del empleo

71. Proporción de trabajadores manuales y no manuales por gran-

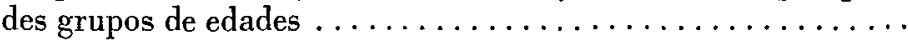

$\imath_{72}$. Nivel de instrucción de la población económicamente activa, inmigrante y nativa del Gran Santiago en ocupaciones manua-

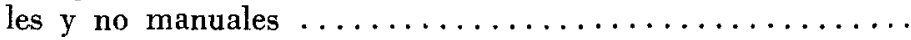

V73. Nivel de instrucción de la población económicamente activa, inmigrante y nativa del Gran Santiago, por ocupaciones y sexo

$V_{74 .}$ Nivel de instrucción de la mano de obra en el Gran Santiago

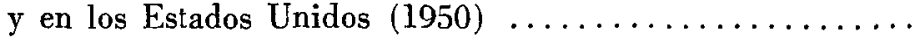

75. Tipo de vivienda según el status migratorio del jefe de hogar

76. Servicios disponibles en la vivienda, según el status migratorio

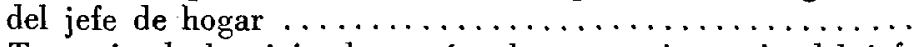

77. Tenencia de la vivienda, según el status migratorio del jefe

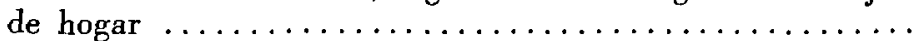

78. Densidad por pieza-habitación, según el tamaño del hogar y según el status migratorio del jefe ................

79. Densidad por pieza-habitación, en hogares de una, dos y tres piezas, según status migratorio del jefe $\ldots \ldots \ldots \ldots \ldots \ldots$ 
80. Tipo de hogar según el status migratorio del jefe $\ldots \ldots \ldots \ldots \quad 180$

81. Composición del hogar según el status migratorio del jefe .... 182

82. Distribución de los hogares por su tamaño, según el status migratorio del jefe ........................ 184

83. Número mediano de personas en el hogar, según tipo de hogar y según status migratorio del jefe $\ldots \ldots \ldots \ldots \ldots \ldots \ldots$

84. Distribución de hogares por su tamaño, según tipo de hogar y según status migratorio del jefe ...............

85. Promedio de personas por hogar, según composición del hogar y status migratorio del jefe $\ldots \ldots \ldots \ldots \ldots \ldots \ldots \ldots$

86. Porcentaje de miembros inmigrantes, según tamaño del hogar y status migratorio del jefe $\ldots \ldots \ldots \ldots \ldots \ldots \ldots \ldots \ldots$

87. Distribución de los hogares por el número de inmigrantes, según el status migratorio del jefe $\ldots \ldots \ldots \ldots \ldots \ldots \ldots \ldots$

88. Número de personas económicamente activas en el hogar, según "tipo" de hogar y según status migratorio del jefe .......

89. Participación en actividades económicas de la esposa (compañera) del jefe, según el status migratorio del jefe y del propio

90. Asociación entre la condición de económicamente activa y la de inmigrante de la esposa (compañera) del jefe, según el status migratorio del jefe $\ldots \ldots \ldots \ldots \ldots \ldots \ldots \ldots \ldots \ldots$

01. Porcentaje de esposas (compañeras) económicamente activas en hogares con esposa (compañera) del jefe presente, según el número de hijos menores de 14 años de edad presentes y el statur migratorio del jefe de hogar $\ldots \ldots \ldots \ldots \ldots \ldots \ldots \ldots$

92. Promedio de hijos menores de 14 años de edad presentes en el hogar, según la composición del hogar (cónyuge presente y no presente), tipo de actividad de la esposa (compañera) y status migratorio del jefe del hogar $\ldots \ldots \ldots \ldots \ldots \ldots \ldots \ldots \ldots$

03. Porcentaje de asistencia escolar entre los hijos de 7 a 13 años de edad, según la composición del hogar (cónyuge presente y no presente), tipo de actividad de la esposa (compañera) del jefe y status migratorio del jefe del hogar ............

\section{GRÁFICOS}

1. Estructura por edad de llegada de los inmigrantes al Gran Santiago. Hombres ......................

2. Estructura por edad de llegada de los inmigrantes al Gran Santiago. Mujeres .................... 37

3. Distribución de los inmigrantes por zonas de emigración . . . 45-46

4. Nivel de instrucción en el Gran Santiago ........... 143 
